\title{
Mortality mitigation of a translocated rare New Zealand frog Leiopelma pakeka
}

\author{
Tanya M KARST
}

A thesis submitted in partial fulfilment of the requirements

for the degree of Master of Science in Conservation Biology

Victoria University of Wellington

2013 
Mortality mitigation of a translocated rare New Zealand frog Leiopelma pakeka. MSc (C)Tanya M Karst 2013

Supervisor: Dr. Ben D Bell

Location: Victoria University of Wellington, Wellington, New Zealand 


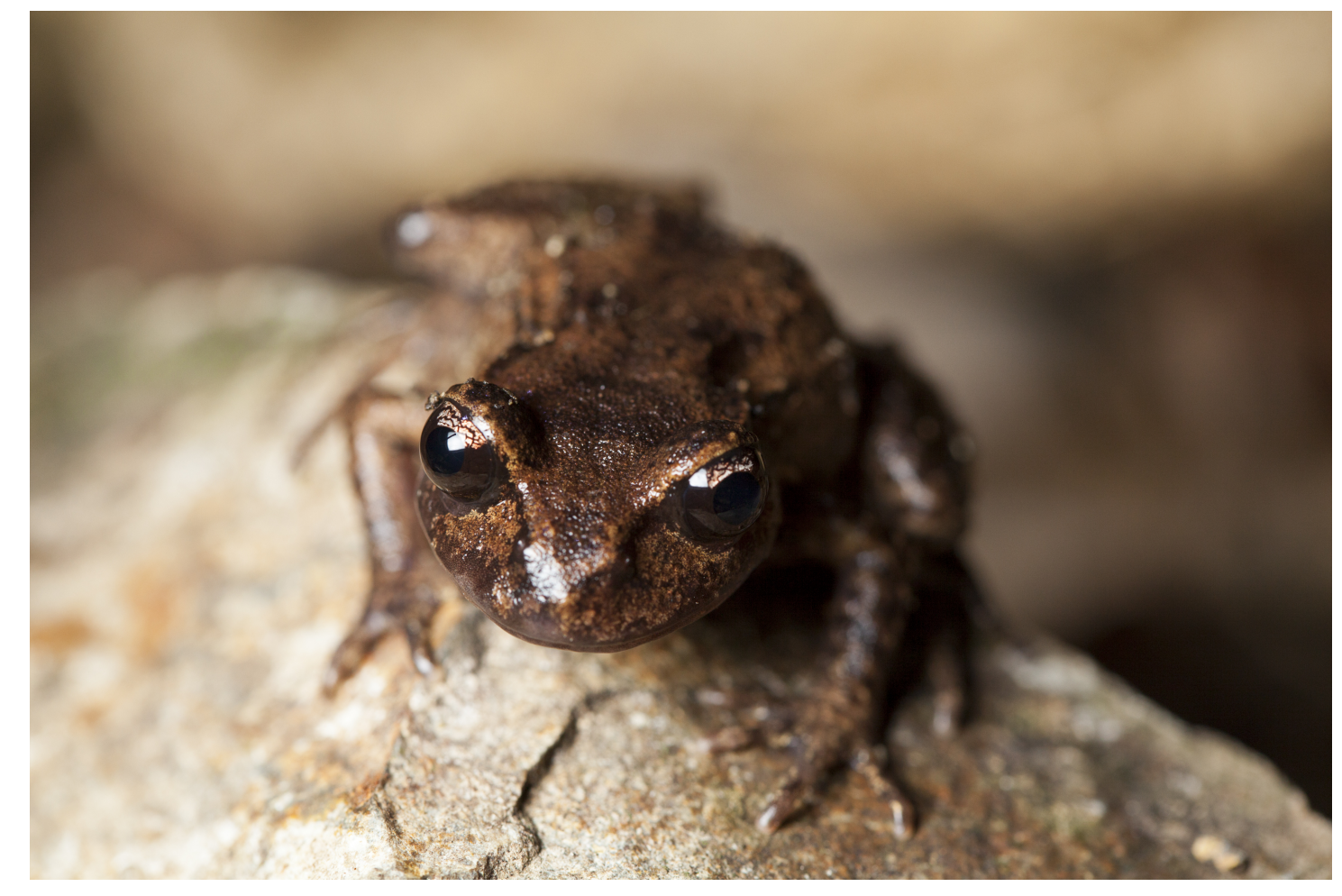

Maud Island frog (Leiopelma pakeka) in the Zealandia wildlife sanctuary.

Photo: João Inacio 



\section{Declaration of Authorship}

I, Tanya M KARsT, declare that this thesis titled, 'Mortality mitigation of a translocated rare New Zealand frog Leiopelma pakeka' and the work presented in it are my own. I confirm that:

- This work was done wholly or mainly while in candidature for a research degree at this University.

- Where any part of this thesis has previously been submitted for a degree or any other qualification at this University or any other institution, this has been clearly stated.

- Where I have consulted the published work of others, this is always clearly attributed.

- Where I have quoted from the work of others, the source is always given. With the exception of such quotations, this thesis is entirely my own work.

- I have acknowledged all main sources of help.

- Where the thesis is based on work done by myself jointly with others, I have made clear exactly what was done by others and what I have contributed myself.

Signed:

Date: 



\section{Abstract}

A small population $(\mathrm{n}=58)$ of Maud Island frogs, Leiopelma pakeka, was translocated to the Zealandia wildlife sanctuary in Wellington, New Zealand in 2006/2007. The 29 frogs that were released into a predator-proof enclosure, along with some of their progeny, are currently spread over three separate predator-proof enclosures. However, their status has not been assessed since 2011. With the aim of establishing a viable, freeranging population, the remaining 29 frogs were released into forested habitat around the original enclosure. In 2010, the translocation of the free-ranging population was assessed as a failure, citing too few founding individuals, inadequate habitat, predation by little spotted kiwi (LSK), Apteryx owenii, and predation by house mice, Mus musculus, as potential factors. This thesis re-addresses the status of L. pakeka in the three enclosures, as well as the potential predation of these threatened endemic frogs by LSK and mice.

Survival of L. pakeka in the three enclosures was estimated by nocturnal emergence over 11 five-night capture periods from October 2012 - August 2013. Identification of individuals was via photography utilizing distinguishable skin patterns and iris vessel (eye venation) patterns. The relocation of six adults after a 2011 census, including one inadvertently missed frog found during this study, left 19 adult frogs in the original enclosure, which continued to survive well, with 18 adults recaptured. In addition, juveniles of varying ages were seen throughout this study. In total, 34 recently metamorphosed froglets were released into a second enclosure over the years of 2008, 2009 and 2011. Night monitoring indicated only 8 individuals had survived, but a full enclosure census on 8 May 2013 revealed 12 of the 34 individuals (35\%) had survived. Three of these frogs were then relocated to the Te Mahanga, publicly viewed enclosure. Emergence during the 11-month period indicated that the six frogs relocated to this enclosure from the original enclosure in October 2011 had survived; however, only two out of the three frogs that were relocated there after the May census had emerged. Additionally, two juveniles of unknown age were also seen in this enclosure.

Potential predation by LSK was assessed by a five-night video analysis (23-28 June 2013) of foraging behavior in the presence of mesh-protected L. pakeka. Out of the 668 videos reviewed, only three videos provided foraging behavior that helped ascertain whether LSK exhibited a potential interest in L. pakeka as a prey item. These videos showed that LSK failed to indicate a strong response to the presence of the frog, suggesting that the LSK in Zealandia do not have a strong predatory interest in L. pakeka. 
To investigate the potential causes of the free-range translocation failure, the habitat was enhanced with more rocks, a kiwi-exclusion fence was erected, and a further 101 L. pakeka were translocated from Maud Island to Zealandia on 2 December 2012. The frogs' survival as well as mouse activity levels (indicated by the presence of mouse prints in tracking tunnels) were monitored over nine five-night capture periods from 17 December 2012 - 2 August 2013. Eighty-six out of the 101 translocated frogs were recaptured. Identification of individuals was via photography utilizing distinguishable skin patterns and iris vessel (eye venation) patterns, or by unique toe-clip combinations. Despite previous assessments, four surviving adults from the 2006/2007 translocation were recaptured as well as 12 of their progeny, resulting in a total of 117 Maud Island frogs for this study. Jolly-Seber analysis indicated high overall survival (0.914, 0.87/0.94, $95 \% \mathrm{CI}$ ), but temporally the population estimates indicated a negative regression starting at the second capture period (slope $=-4.69,-6.70 /-2.68,95 \% \mathrm{CI}$ ). With overall frog emergence, a negative binomial generalized linear model did not show significance in mouse activity levels, precipitation during sampling nor precipitation in the previous 24 hours $(\mathrm{p}>0.05)$. However, temperature did show a positive correlation to overall frog emergence $(p<0.001)$ while relative humidity approached significance $(p=0.0517)$ and indicated a potential positive trend.

This study could not conclusively indicate whether A. owenii or M. musculus prey upon L. pakeka. However, it does suggest that the protected predator-proof enclosures may provide appropriate conditions for the ongoing survival and successful breeding of the endemic anuran. The study also suggests that LSK do not have a strong predatory response to the presence of Maud Island frogs, nor did increased levels of mouse activity have a significant effect on the emergence of the 117 Maud Island frogs. Additionally, the discovery of the four survivors and 12 of their offspring indicates that the original translocation did not entirely fail. This newly acquired knowledge suggests that with the current mammal eradication program, Zealandia may continue with the establishment of a viable, free-ranging population of L. pakeka. Continued monitoring of all Maud Island frogs in the Zealandia sanctuary is recommended as a conservation measure, especially as mice have now established on its original island habitat. 


\section{Acknowledgements}

This thesis was made possible by the help of many people. First, I would like to thank my supervisor, Ben Bell, for giving me an opportunity to work with such an incredible species as well as all the ideas, advice, many edits and generosity of his knowledge. I would also like to thank Zealandia and the Department of Conservation along with Ngati Kuia and Port Nicholson Trust for their approval and support of this thesis. Additionally, I would like to thank Shirley Pledger for the trials and errors in finding a recapture analysis program that worked with my data, as well as Ruud Kleinpaste and MetService for the information you provided.

I relied on a great number of volunteers to accomplish every stage of this study. Thank you to Bernard Smith, Leighton Thomas, Brad Monton and Chris Clark who continuously returned to battle rock collection, uphill relocation of heavy bucket loads of rocks and fence construction. Thank you to Natalie Stewart, Katie Brasell, Mikey Willcox, Tristam Price and Julian Boorman for coming to Maud Island to collect the frogs. Also on this frog collection endeavor, I would like to thank the rangers of Maud Island, Nio Mana and Chris Birmingham for their assistance in frog finding and their great hospitality also to José Grijalva for the VIP ferry crossing.

I would also like the send many, many thanks to Raewyn Empson, Neil Anderson, Rhys Marshall, Paul Savagner, Mary Paul, Linda Beadle, Nicola Robertson, Elliot O'Sullivan, Kerry Charles, Rachel Boschen, Brit Finucci, Nik Long-Rinehart, Cassie Callard, Gustav Kessel, Alan Burman, Anna McPollock, Roz Anderson-Leder, Tylee Reddy and Adrianne Jerrett for becoming frequent froggers and to the many volunteers that came out frogging a handful of times. I'd also like to thank Maurico Navarro, Monica Gruber and Rachael Abbott for all questions relating to R, along with Andrew Digby and Helen Taylor for the kiwi advice. None of this would have been possible without you.

Finally, I would like to give a special thank you to Stephen Cornwell for the vast amount of hours of field assistance, computer assistance and software development. I owe my sanity to his never-ending support and words of encouragement. I am forever grateful.

This thesis was written using the Masters/Doctoral Thesis $\mathrm{AT}_{\mathrm{E}} \mathrm{X}$ template 



\section{Contents}

Declaration of Authorship iv

Abstract vi vi

Acknowledgements $\quad$ viii

List of Figures $\quad$ xiii

List of Tables $\quad$ xvi

1 Conservation Biology in Aotearoa 1

1.1 Introduction . . . . . . . . . . . . . . . . . . . 1

1.1.1 Zealandia's role in conservation . . . . . . . . . . . . . 2

1.1.2 Maōri in conservation . . . . . . . . . . . . . . . . . . . 3

1.2 Maud Island frog, Leiopelma pakeka . . . . . . . . . . . . . . . . . 4

1.2.1 Natural history . . . . . . . . . . . . . . . . . . . . . . 4

1.2.2 Habitat and breeding . . . . . . . . . . . . . 7

1.2 .3 Threats to Leiopelma pakeka . . . . . . . . . . . . . . . . . . . . 8

1.2 .4 Translocation history . . . . . . . . . . . . . . . . . . . 9

1.2.5 Zealandia translocation . . . . . . . . . . . . . . . . . . . 9

1.3 Aims of study . . . . . . . . . . . . . . . . . . . . 11

1.4 Approvals and permits . . . . . . . . . . . . . . . . 13

1.5 Thesis structure . . . . . . . . . . . . . . . . . . 13

2 Emergence and survival of Leiopelma pakeka in predator-proof enclo$\begin{array}{lr}\text { sures in the Zealandia wildlife sanctuary } & 14\end{array}$

2.1 Introduction . . . . . . . . . . . . . . . . . . . . . . . 14

2.2 Methods . . . . . . . . . . . . . . . . . . . . . . 18

2.2 .1 Emergence . . . . . . . . . . . . . . . . . 18

2.2 .2 Identification . . . . . . . . . . . . . . . . . . . . . . 19

2.2 .3 Census of second enclosure . . . . . . . . . . . . . . . . 20

2.2 .4 Data analysis . . . . . . . . . . . . . . . . . 21

2.3 Results. . . . . . . . . . . . . . . . . . . . . 21

2.3 .1 Original enclosure . . . . . . . . . . . . . . . . 21

2.3 .2 Second enclosure . . . . . . . . . . . . . . . . . . . . . . . . . . . . . . . . . .

2.3.3 Te Mahanga enclosure . . . . . . . . . . . . . . . 25 
2.3.4 Eye-Venation questionnaire . . . . . . . . . . . . . . . . . . 25

2.4 Discussion . . . . . . . . . . . . . . . . . . . . 26

2.4 .1 Original enclosure . . . . . . . . . . . . . . 26

2.4 .2 Second enclosure . . . . . . . . . . . . . . . . 27

2.4 .3 Te Mahanga enclosure . . . . . . . . . . . . . . . . . . . . . . . 27

2.4 .4 Identification via eye venation . . . . . . . . . . . . . . . . 27

3 Interest of Apteryx owenii in L. pakeka? $\quad 29$

3.1 Introduction . . . . . . . . . . . . . . . . . . . 29

3.1.1 Is Apteryx owenii interested in Leiopelma pakeka as a food source? 29

3.2 Apteryx owenii prey detection, selection and the possibility of Leiopelma pakeka depredation . . . . . . . . . . . . . . . 31

3.3 Methods . . . . . . . . . . . . . . . . . . . . . 32

3.3 .1 Encounter sites . . . . . . . . . . . . . . . . . 32

3.3 .2 Frog monitoring . . . . . . . . . . . . . . . . . . . . . . . . . . . . . . 34

3.4 Results. . . . . . . . . . . . . . . . . . . 35

3.4.1 Te Mahanga track encounter site . . . . . . . . . . . . . 35

3.4 .2 Swamp track encounter site . . . . . . . . . . . . . . . . . . . 39

3.4.3 Lake Road track encounter site . . . . . . . . . . . . . . . . . . 41

3.4 .4 Frog condition . . . . . . . . . . . . . . . . . . . . . . . . . . . . 43

3.5 Discussion . . . . . . . . . . . . . . . . . 46

4 Leiopelma pakeka survival with sympatric house mice in Zealandia 48

4.1 Introduction . . . . . . . . . . . . . . . . . . . . . 48

4.1 .1 Mice in New Zealand . . . . . . . . . . . . . . . . . . . . 48

4.1.2 Zealandia wildlife sanctuary, mice and frogs . . . . . . . . . . . . . . . . . . . . . . . . . . . . . . . .

4.2 Methods . . . . . . . . . . . . . . . . . . 50

4.2 .1 Study site preparation . . . . . . . . . . . . . . 50

4.2.2 Leiopelma pakeka collection to release . . . . . . . . . . . . . . 52

4.2 .3 Frog monitoring . . . . . . . . . . . . . . . . . 54

4.2 .4 Mus musculus monitoring . . . . . . . . . . . . . . . . . . . . . 55

4.2 .5 Data analysis . . . . . . . . . . . . . . . . . . . . . 56

4.3 Results. . . . . . . . . . . . . . . . . . 58

4.3 .1 Founding population . . . . . . . . . . . . . 58

4.3 .2 Mus musculus monitoring . . . . . . . . . . . . . . . . . . . 59

4.3 .3 Additional frogs found . . . . . . . . . . . . . . . . . . . . 60

4.3 .4 Frog survival . . . . . . . . . . . . . . . . . . . . . . . . . . 61

4.3.5 Mouse activity and weather . . . . . . . . . . . 6 65

4.3 .6 Movements . . . . . . . . . . . . . . . . . 67

4.3 .7 Condition . . . . . . . . . . . . . . . . 69

4.4 Discussion . . . . . . . . . . . . . . . . . . . . . . . . . . . . 72

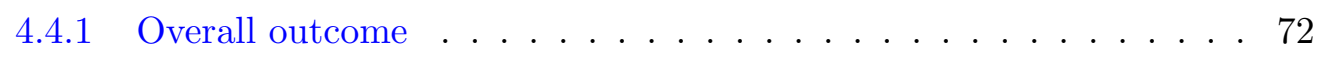

4.4 Mice . . . . . . . . . . . . . . . . . . . . 72

4.4 .3 Survival . . . . . . . . . . . . . . . . . . . . . . . . . . . . . . . . . . . . . .

4.4 .4 Movements . . . . . . . . . . . . . . . . . . 75

4.4 .5 Possibility of escape . . . . . . . . . . . . . . . . . . . . . . . . . . 77

4.4.6 Weather co-variates ... . . . . . . . . . . . 77 
4.4.7 What does this all mean? . . . . . . . . . . . . . . 79

5 Is a free-ranging, viable population of Leiopelma pakeka possible in the Zealandia wildlife sanctuary? $\quad \mathbf{8 0}$

5.1 Summary of results . . . . . . . . . . . . . . . . . . 81

5.2 Study limitations . . . . . . . . . . . . . . . . . . . . . . . . . . 82

5.3 Adaptive Management . . . . . . . . . . . . . . . . . 86

5.4 Moving forward . . . . . . . . . . . . . . . . 87

$\begin{array}{ll}\text { A Maud Island captures (raw data) } & 89\end{array}$

B Leiopelma pakeka enclosure recaptures (raw data) 92

$\begin{array}{ll}\text { C Kiwi-frog encounter (raw data) } & 104\end{array}$

$\begin{array}{ll}\text { D Translocated frog recaptures (raw data) } & 108\end{array}$

E Original translocation survivors and progeny re-captures (raw data) 117

F Trajectories and areas utilized by the 16 most frequently captured frogs

References 


\section{List of Figures}

1.1 Satellite image Zealandia ${ }^{\mathrm{TM}} w$ ildlife sanctuary. Red line depicts fence boundaries. Image: Bing maps . . . . . . . . . . . . . . . 3

1.2 Satellite image of Pelorus Sound, New Zealand. A. Stephen's Island B. Maud Island C. Wellington. Image: Google maps . . . . . . . . . . . . . 5

1.3 Satellite image of Maud Island, Pelorus Sound, New Zealand. Yellow highlighted region is the 16 ha patch of regenerated forest where the main population of L. pakeka survives. Image: Google maps . . . . . . . . . . . 6

1.4 Intra-island translocation from L. pakeka metapopulation in the 16 ha patch of forest (outlined in yellow) to Boat Bay (star). Image: Google maps . . . . . . . . . . . . . . . . . . . 10

1.5 Inter-island translocations from A. Maud Island to B. Motuara Island C. Long Island D. Zealandia, Wellington. Image: Google maps . . . . . . . . 10

2.1 Original predator-proof enclosure for L. pakeka in the Zealandia wildlife sanctuary, Wellington. . . . . . . . . . . . . . . . 15

2.2 Second predator-proof enclosure for juvenile L. pakeka in the Zealandia wildlife sanctuary, Wellington. . . . . . . . . . . . . . . 17

2.3 Te Mahanga track predator-proof enclosure for night tour public viewings of L. pakeka in the Zealandia wildlife sanctuary, Wellington. . . . . . . . . 17

2.4 Example of questionnaire page. Top left: recapture image, right side: four reference choices, bottom left: selected enlarged reference image for comparison. . . . . . . . . . . . . . . . . 20

2.5 Survival and total captures of L. pakeka in the original predator-proof enclosure. Black bar indicates last known to be alive. White star indicates periods captured. Period 1: Oct. 2012, period 11: Jul.-Aug. 2013. . . . . 23

2.6 A. Frog A5 on top of frog B2 (both adult females). B. Juvenile on the back of A5. . . . . . . . . . . . . . . . . 23

2.7 Survival and total captures of L. pakaka in the second predator-proof enclosure. Black bar indicates last known to be alive. White star indicates periods captured. Reloc - relocated to Te Mahanga enclosure. Period 1: Oct. 2012, period 11: Jul.-Aug. 2013. . . . . . . . . . . . . . . . 24

2.8 Survival and total captures of L. pakeka along the Te Mahanga track predator-proof enclosure. Black bar indicates last known to be alive. White star indicates periods captured. Reloc - relocated from the second enclosure. Period 1: Oct. 2012, period 11: Jul.-Aug. 2013. . . . . . . . . . 25

3.1 Apteryx spp. distribution change. Ministry for the Environment (2007). . 30

3.2 Leiopelma spp. distribution of extinct and extant species, used with permission (Bell et al. 1998). . . . . . . . . . . . . . . . . . 30 
3.3 Modified lid of ice-cream container that held an individual L. pakeka which was used for the kiwi-frog encounter study. . . . . . . . . . . 33

3.4 Kiwi-frog encounter site with one place-holder container and two Bushnell TrophyCam cameras. . . . . . . . . . . . . . . . . 34

3.5 Video frames from kiwi-frog encounter captured on 25 June 2013 at 0632 h, camera V2, along the Te Mahanga track. A. Reference image for position of frog container, outlined in red (separate video from LSK images). B-H. LSK probing as it forages in and out of the FOV. Note E, LSK appears to probe immediately adjacent to the frog container. . . . . . . 37

3.6 Video frames from kiwi-frog encounter video captured on 25 June 2013 at $0631 \mathrm{~h}$, camera Z2, along the Te Mahanga track. A. Reference image for position of frog container, outlined in red (separate video from LSK images). B. LSK in FOV foraging in close proximity to the frog container. 38

3.7 Video frames from kiwi-frog encounter video captured on 27 June 2013 at $0112 \mathrm{~h}$, camera V2, along the Te Mahanga track. A. Reference image for position of frog container, outlined in red (separate video from LSK images). B-C. LSK foraging and 'bill flicking' away from the frog container. 38

3.8 Video frames from kiwi-frog encounter video captured on 27 June 2013 at $0112 \mathrm{~h}$, camera Z2, along the Te Mahanga track. A. Reference image for position of frog container, outlined in red (separate video from LSK images). B. LSK exiting the encounter site. Note: LSK is difficult to see and is at the top right edge of the frame. . . . . . . . . . . 39

3.9 Video frames from kiwi-frog encounter video captured on 24 June 2013 at $1753 \mathrm{~h}$, camera V4, along the Swamp track. A. Reference image for position of frog container, outlined in red (separate video from LSK images). B-D. LSK approach, seemingly to probe the frog container (C), and retreat from the encounter site. . . . . . . . . . . . . . 41

3.10 Video frames from kiwi-frog encounter video captured on 27 June 2013 at 1742 h, camera V3, along the Lake Road track. A. Reference image for position of frog container (separate video from LSK images). B-H. LSK foraging around the frog container. Note F, LSK appears to probe into the frog container. Total duration of the frames is $11 \mathrm{~s} . ~ \ldots . . . . .444$

3.11 Weight of each L. pakeka for the duration of the kiwi-frog encounters. . . 45

4.1 Study-site habitat. A. Original habitat at site prior to habitat engineering. B-D. Post-habitat engineering. B. Middle rocky aggregation with walking planks to minimize habitat disturbance. C. Upper rocky aggregation with walking planks and original predator-proof $L$. pakeka enclosure. D. Lower rocky aggregation with the green kiwi-exclusion fence and white PVC overhang. . . . . . . . . . . . . . . . . 5 52

4.2 Study site layout, including $2 \mathrm{~m}$ perimeter buffer zone. Each square represents $1 \mathrm{~m}^{2} \ldots \ldots \ldots \ldots \ldots \ldots \ldots$

4.3 Frog T53 (peg 68), photos taken 14 March 2013 for identification. A. Dorsal. B. Frontal. C. Left lateral. D. Right lateral. . . . . . . . . . . . . 56

4.4 Translocated L. pakeka SVL distribution $(\mathrm{n}=101) \ldots \ldots \ldots \ldots$. . . . 58

4.5 Mouse activity. . . . . . . . . . . . . . . . . . 59

4.6 Increased tunnel activity from left to right. Date set and tracking tunnel number is along the bottom of the tracking card. . . . . . . . . 6 60 
4.7 Survival and total captures of the first 58 L. pakeka (ntot=117). Black bar indicates last known to be alive. White star indicates periods captured. Frogs are listed with increasing SVL . . . . . . . . . . . . . . . 62

4.8 Survival and total captures of the remaining 59 L. pakeka (ntot=117). Black bar indicates last known to be alive. White star indicates periods captured. Frogs are listed with increasing SVL. . . . . . . . . . . . . 63

4.9 Number of captures, minimum number alive (MNA) and population estimate $(\hat{N})$ over successive capture periods. . . . . . . . . . . . . . . 64

4.10 Mean temperature vs. number L. pakeka emerged. Regression line included. 65

4.11 Mean relative humidity vs. number L. pakeka emerged. Regression line included. . . . . . . . . . . . . . . . . 66 66

4.12 Mean body condition index (BCI) ( $\pm 1 \mathrm{SE}$ ) of frogs caught per month. . . 70

4.13 A. Frog T78 with injured rear right foot. B. Frog T13 with lipoma over right pectorals. C. Deceased frog, unknown identity. . . . . . . . . . . 71 


\section{List of Tables}

2.1 The New Zealand threat classification of the four extant species of Leiopelma (Newman et al. 2010, 2013). . . . . . . . . . . . . . . 15

2.2 Number of frogs recaptured and froglets found (yrlng=yearling) during censuses of the original predator-proof enclosure in Zealandia from 20082011. (Zealandia, unpub. data). . . . . . . . . . . . . 16

2.3 Frogs accounted for in the original enclosure $(\star)(n$ tot $=29)$ at the Lukis (2009) study, 2011 census data (Zealandia, unpub. data) and data obtained from this study. $\triangle$ : accounted for and later relocated to the Te Mahanga enclosure. Frogs are listed with increasing SVL. . . . . . . . . 22

2.4 Census of second predator-proof enclosure. . . . . . . . . . . . . . . . . 24

3.1 A quantitative summary of video clips from cameras V2 \& Z2 from the kiwi-frog encounter along the Te Mahanga track with frog B14 recorded throughout the night from 23-27 June 2013. * denotes camera malfunction. 36

3.2 A quantitative summary of video clips from cameras V1 \& V3 from the kiwi-frog encounter along the Swamp track with frog M28 throughout the night from 23-27 June 2013. * denotes camera malfunction. . . . . . . . . 40

3.3 A quantitative summary of video clips from cameras V1 \& V3 from the kiwi-frog encounter along the Lake Road track with frog B12 throughout the night from 23-27 June 2013 . . . . . . . . . . . . . . . . . 42

4.1 Jolly-Seber candidate models selection table with AIC values. (.) indicates constant over time, (t) is time dependent (l) is linear trend. . . . . . 64

4.2 Mean monthly rainfall for the duration of this study. Data obtained by MetSerice (Kelburn) . . . . . . . . . . . . . . . . 67

4.3 Home range estimates by $95 \%$ MCP for the 16 most commonly caught frogs. . . . . . . . . . . . . . . . . 6 68 


\section{Chapter 1}

\section{Conservation Biology in Aotearoa}

\subsection{Introduction}

The science of preserving the Earth's biodiversity and ecosystems is the focus of conservation biology.

New Zealand was one of the last landmasses to be colonized by humans; that, in combination with the isolation from other landmasses, enabled relict and unique biota to evolve and survive until recent times. The colonization of New Zealand by humans, first by Maōri then by Europeans, caused great stress on the ecosystems. Human pressures drastically changed habitats resulting in up to $90 \%$ reduction in various ecosystems (Craig et al. 2000). New Zealand has seen a great loss in its biodiversity due to human expansion, over-harvesting, mass agriculture, introduced plant and animal pests, habitat loss and fragmentation (Craig et al. 2000).

Identifying causes of biodiversity loss and the need to restore and conserve what is left of New Zealand biota led the New Zealand government to establish the Department of Conservation (DOC) in April 1987, thereby honoring the Wildlife Act 1953, the Conservation Act 1987 and the Treaty of Waitangi (Department of Conservation 2013a). The Department of Conservation's management practices result from philosophies and modified practices of European settlers. The practices are viewed as Eurocentric (or Westernized) with a "preservation for conservation" management system (Roberts et al. 1995; Taiepa et al. 1997; Craig et al. 2000). Marine reserves protect about $7.6 \%$ of New Zealand's territorial oceans (U. Rojas Nazar, unpub. data.). In collaboration with regional Iwi, DOC manages 30\% of New Zealand's land (Department of Conservation 2013a; Taiepa et al. 1997; Craig et al. 2000) in the form of national parks, public conservation land and reserves. This effort has given New Zealand the global image of being at the forefront of conservation. 
In an effort to concentrate on New Zealand amphibian conservation, DOC produced the first Native Frog Recovery Plan in 1996 (Newman 1996) which lead to the formation of the Native Frog Recovery Group. The Recovery Group, consisting of DOC staff and various amphibian specialists, meet semi-annually to discuss past, present and future research and advises DOC on how to achieve the goals set out in the Recovery Plan (NZFrog 2006). The Recovery Plan aims to assist with the recovery and conservation of native frogs (Department of Conservation 2013a), as they are a vital component to New Zealand's ecosystems.

\subsubsection{Zealandia's role in conservation}

Zealandia $^{\mathrm{TM}}$ : The Karori Sanctuary Experience (henceforth referred to as Zealandia or the sanctuary) is a 252 ha wildlife sanctuary in Wellington, New Zealand (Fig. 1.1). It is managed by the Karori Sanctuary Trust and has had an integral role in conservation of New Zealand species. Their goal, to return a piece of mainland New Zealand, as much as possible, to a pre-human ecosystem by means of community involvement, education and research (Campbell-Hunt 2002).

Having a wildlife sanctuary in the middle of urban sprawl presents its own challenges. To protect the wildlife in the sanctuary from non-native mammalian predators, as well as to protect free-roaming domestic pets from mammal-targeted pest controls, Zealandia's solution was to build a fence which was specially designed to abate predator invasion. Trials were conducted to test burrowing, jumping and climbing abilities of mammal pests Zealandia wanted to eradicate such as brushtail possums (Trichosurus vulpecula), rats (Rattus spp.), house mice (Mus musculus) and mustelids (Mustela spp.) (CampbellHunt 2002). Short video documentaries of these trials can be viewed at the Visitor Center at the sanctuary (personal observation). After eight months of construction, the sanctuary completed the fence in August 1999. The fence is a pioneering worldfirst predator-proof fence. It is $2.2 \mathrm{~m}$ in height and $8.6 \mathrm{~km}$ in length that encompasses 225 ha of the 252 ha sanctuary. Following fence completion, an extensive trapping and Brodifacoum $^{\mathrm{TM}}$ poisoning eradication program was initiated and Zealandia was declared mammalian pest-free in January 2000 (Zealandia 2012; Campbell-Hunt 2002).

The ecological restoration of the sanctuary in accordance with the sanctuary's Restoration Strategy (2000) is well underway. Over 40 flora and fauna species have been reintroduced into the sanctuary that were either locally or nationally threatened and missing or under represented in the lower North Island. Two functionally extinct trees, matai (Prumnopitys taxifolia) and miro (Prumnopitys ferruginea) and threatened birds such as 


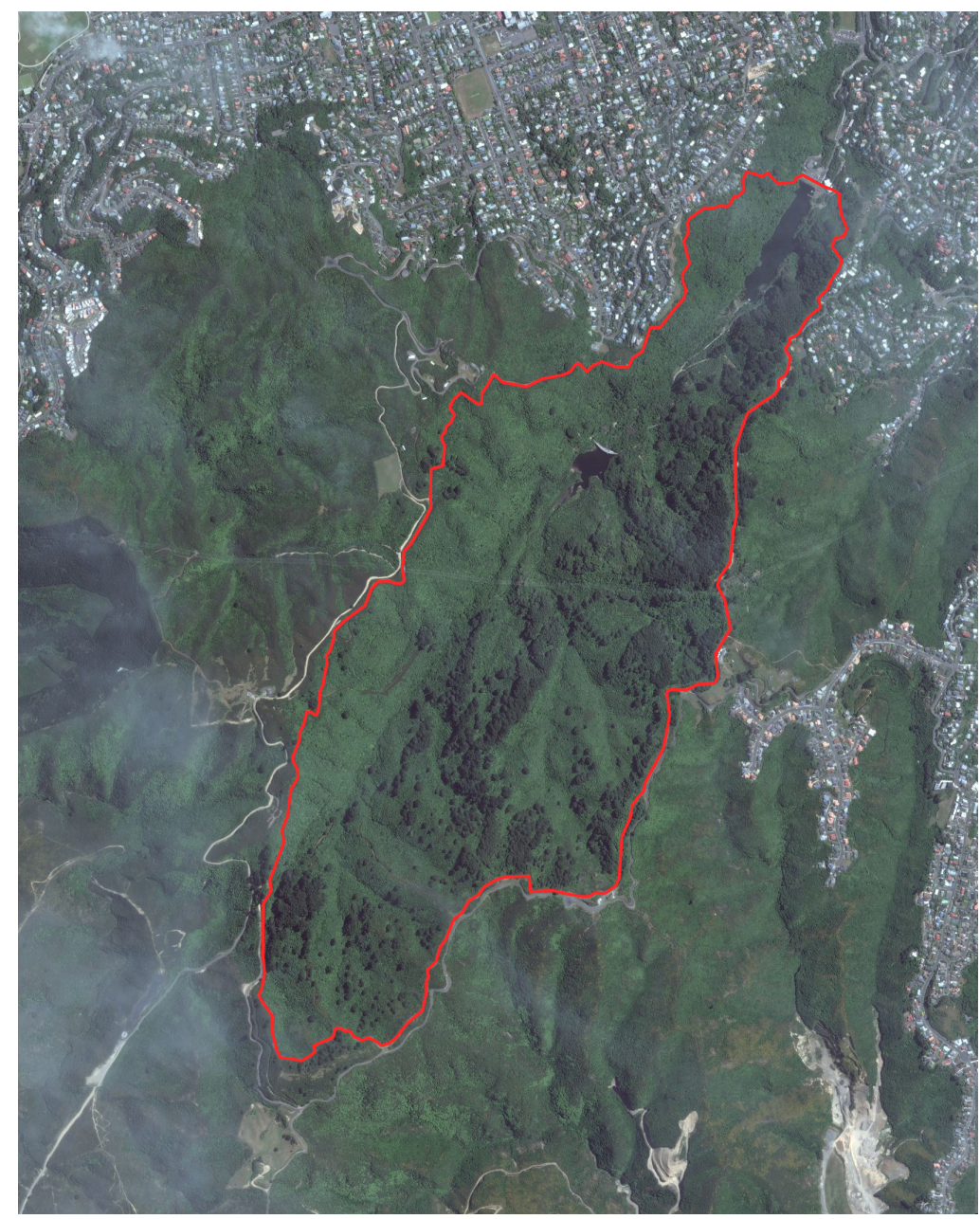

FIgURE 1.1: Satellite image Zealandia ${ }^{\mathrm{TM}}$ wildlife sanctuary. Red line depicts fence boundaries. Image: Bing maps

hihi (Notiomystis cincta), kererū (Hemiphaga novaseelandiae) and kākā (Nestor meridionalis) have been successfully reintroduced to the sanctuary, as well as the endangered Cook Strait giant weta/wētā punga (Deinacrida rugosa) and tuatara (Sphendon punctatus) (Zealandia, unpublished data). All of which increased considerably under the current mouse-control program (R. Empson, per. comm.).

Zealandia's restoration plan has identified native frogs as an integral component of restoring the forest ecosystem typical of pre-human era to the valley (Karori Sanctuary Trust 2000).

\subsubsection{Maōri in conservation}

Aotearoa (New Zealand) was first colonized by Maōri, over one thousand years ago (around $1000 \mathrm{AD}$ ) (Roberts et al. 1995). Maōri culture consider native and indigenous flora and fauna as taonga (treasures). As other indigenous peoples, Maōri culture places 
humans among the Earth's life, as a part of nature, and believes that reciprocity is necessary to ensure future use of the Earth's harvests (Roberts et al. 1995; Taiepa et al. 1997). It is this belief, the use of resources by humans as a natural occurrence, that guides Maōri conservation efforts as a "sustainability for future" use or "reciprocal utilitarianism" management system (Roberts et al. 1995; Taiepa et al. 1997). Although specific iwi management may vary among the different iwi regional councils, it is the core of Maōri conservation philosophy (Berkes et al. 2000; Craig et al. 2000).

Although native frogs were evidently unknown to the local Coromandel iwi (Sharell 1966; Robb 1986) upon the 1852 discovery of what was later to be described as Leiopelma hochstetteri, Hochstetter's frog (Stephenson 1961), all Leiopelma are now considered taonga. The kaitiaki (Maōri environmental caretakers) that look after the Maud Island frog, L. pakeka, in the Nelson and Wellington regions are Ngāti Kuia and Port Nicholson Trust, respectively.

Co-management between Maōri and departments such as DOC and New Zealand universities are underrepresented in current research (Craig et al. 2000; Newman and Moller 2005). The interest and understanding of Maōri knowledge of local social structures and mātauranga (traditional environmental knowledge) has increased among researchers (Berkes et al. 2000) which has enabled iwi to assist in the management of location-specific environmental issues (Taiepa et al. 1997). Co-management and collaborative research in projects such as the traditional Rakiura Titi harvests has seen an improvement (Taiepa et al. 1997; Craig et al. 2000; Newman and Moller 2005), but the amalgamation of the two conservation styles is imperative if conservation is going to be achieved for the remaining unique New Zealand biota.

\subsection{Maud Island frog, Leiopelma pakeka}

\subsubsection{Natural history}

Leiopelma (Anura: Leiopelmatidae) consists of four extant species, Leiopelma archeyi, L. hochstetteri, L. hamiltoni and L. pakeka (ascending size), and five extinct species, $L$. auroraensis, L. markhami, L. waitomoensis, L. miocaenale described by Worthy (1987) and L. acricarina described by Worthy et al. (2013). The genus has plesiomorphic synapomorphies such as nine pre-sacral amphicoelous vertebrae, ventral inscriptional ribs and the retention of tail-wagging (caudalipubioschiotibialis) muscles (Stephenson 1961; Bell 1978, 2008b). They have other characteristics that set them apart from most other anurans such as: round pupils, no tympanum, stapes or vocal sac and the inability to adduct the limbs prior to landing (Bell 1978; Green and Cannatella 1993; Essner 


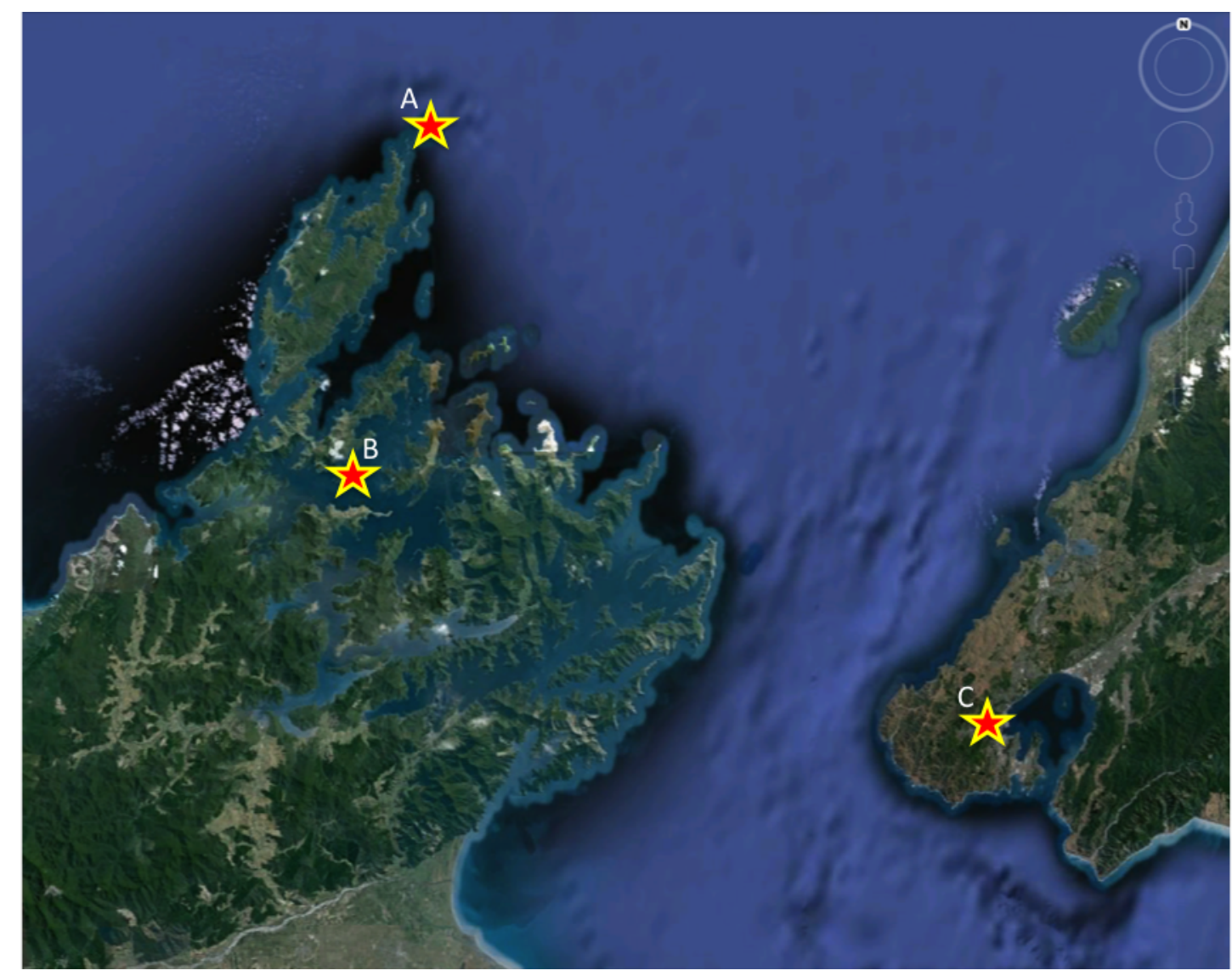

Figure 1.2: Satellite image of Pelorus Sound, New Zealand. A. Stephen's Island B. Maud Island C. Wellington. Image: Google maps

et al. 2010). The leiopelmatids are an archaic lineage that diverged from the extinct Notobatrachus and Vieraella of South America (Green and Cannatella 1993) and their sister taxa, Ascaphus spp. of North America, prior to the tectonic separation of Pangea in the Triassic, 225 mya (Roelants and Bossuyt 2005). They have a slow life history and are K-selected.

The former distribution of Leiopelma is primarily known from sub-fossil remains in karst sites. The L. hamiltoni/pakeka group was once distributed throughout the lower North Island and upper South Island (for distribution, see Worthy 1987). Stephen's Island L. hamiltoni was initially discovered in 1915 by R.G. Smith and formally described by McCulloch (1919). Environmental conditions had led the New Zealand herpetology community to think the species had become extinct until the discovery of frogs on Maud Island in the mid 1930s (Bell et al. 1998), formally reported in 1958, and the re-discovery of a small population on Stephen's Island in 1950 (Stephenson 1961) (Figure 1.2).

Since 1961, the Maud Island frog and Stephens Island frog were regarded as two separate populations of the same species, L. hamiltoni. It was not until 1998 that Ben Bell and colleagues, using allozyme electrophoresis and morphological studies, formally described 
L. pakeka as a separate species. Although the differentiation was challenged (Holyoake et al. 2001), L. pakeka is currently listed as an independent species in the New Zealand Threat Classification System (Newman et al. 2010, 2013) and the IUCN Red List of Threatened Species (IUCN Red List 2012). With the separation of the two species, this means that the only naturally occurring location of L. pakeka is in Pelorus Sound, New Zealand, on the 320 ha Maud Island/Te Hoiere. Maud Island was once cleared for livestock grazing, but the remnant source population (up to 34000 individuals (Le Roux and Bell 2007)) survive in a 16 ha. patch of old-growth forest (Fig. 1.3).

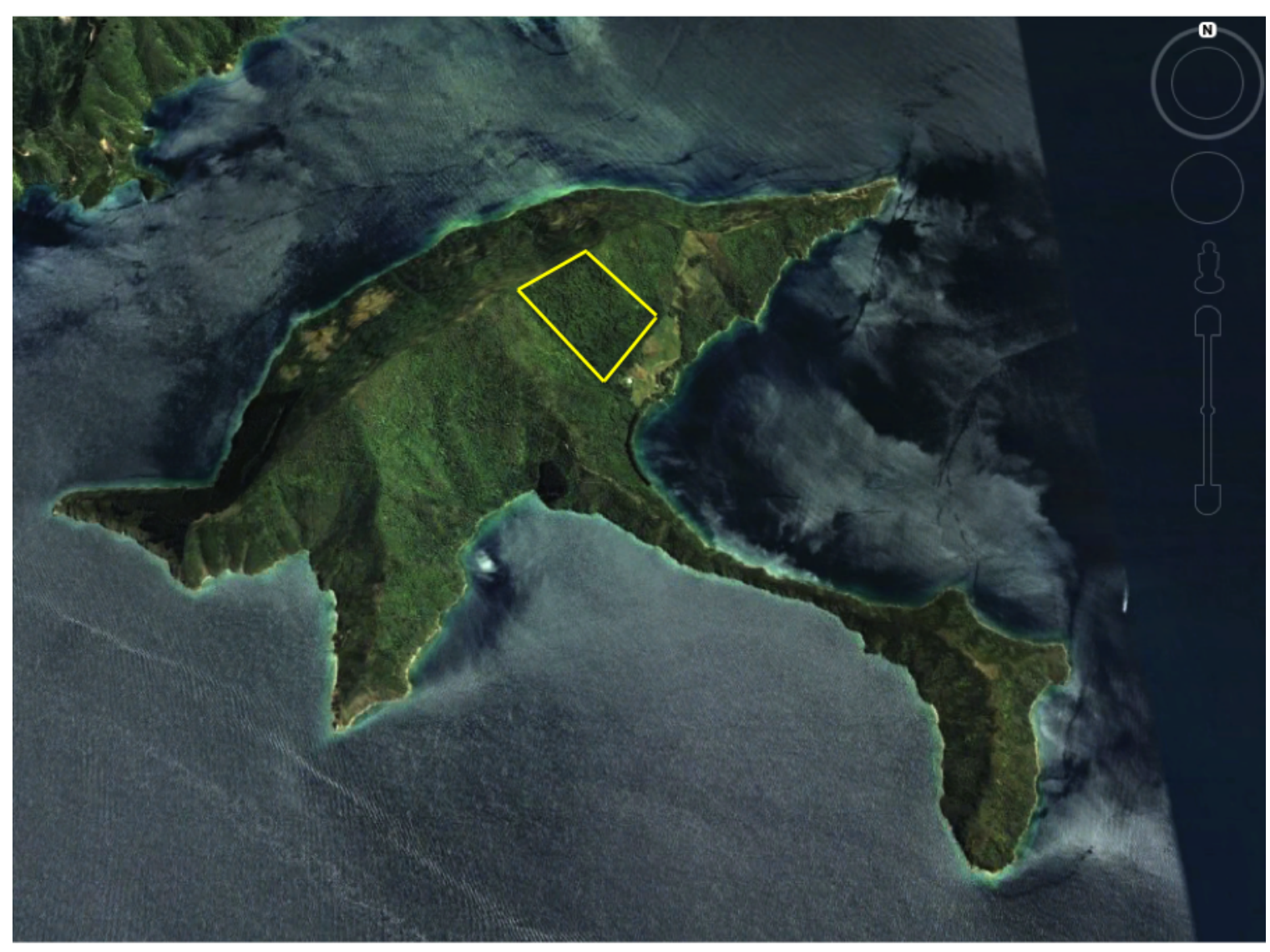

Figure 1.3: Satellite image of Maud Island, Pelorus Sound, New Zealand. Yellow highlighted region is the 16 ha patch of regenerated forest where the main population of L. pakeka survives. Image: Google maps

The holotype, collected in 1960, and various paratypes are held at the Museum of New Zealand Te Papa Tongarewa in Wellington (Bell et al. 1998). They are a cryptic, nocturnal, terrestrial, saxicolous species with no external variation between the sexes other than size with females being the larger (Bell 2008a). Leiopelma have intracapsular (Stephenson 1961), endotrophic development with terrestrial species also being exoviviparous (Bell et al. 2004a; Bell 2008b,a, 2011a; King et al. 2009) and male dorsal brooding (Bell 2008b). Leiopelma pakeka is listed as Vulnerable under the IUCN Red List (IUCN Red List 2012), as Nationally Vulnerable under the New Zealand Threat Classification 
System (Newman et al. 2010, 2013) and ranks number 58 on the top 100 amphibians Evolutionarily Distinct and Globally Endangered list (The Zoological Society of London 2012).

\subsubsection{Habitat and breeding}

The habitat on Maud Island where L. pakeka survive stretches from near sea level to an altitude of 360 meters. The substrate of the forest floor is primarily covered in heavy scree and the precarious slope, most likely rendered the topography too hazardous for grazing animals, awarded a refuge for the remnant frog population. The vegetation is mostly broadleaf with kohekohe (Dysoxylum spectabile) and mahoe (Melicytus ramiflorus) below $200 \mathrm{~m}$ with kamahi (Weinmannia racemosa), hinau (Elaeocarpus dentatus) and miro (Podocarpus ferrugineus) above $200 \mathrm{~m}$. The understorey is comprised of kawakawa (Macropiper excelsum) and kohekohe with a ground layer of young nikau palms (Rhopalostylis sapida) and various ferns (Newman 1990; Bell et al. 2004b; Bell and Pledger 2010).

Due to the lack of vocal sacs Leiopelma do not chorus (Bell 2008b), but alternatively, they communicate via chemo-signals (pheromones) (Lee and Waldman 2002; Waldman and Bishop 2004). To date, neither L. pakeka breeding sites, nor egg clusters have been found on Maud Island (Bell et al. 2010; Bell 2011a). What is known about the breeding cycle has been extrapolated from captive population observations (Bell 1978, 2011a) and hormone analysis (Germano et al. 2012). Leiopelma pakeka have low fecundity and captive observations suggest the breeding season begins in the austral spring/summer and oviposition to occur in November/December (Bell 1978, 1985b, 2011a). In contrast, urinary hormone metabolites and seasonal histological work suggests a winter or early spring breeding season commencement (Germano et al. 2012). Leiopelma pakeka exhibits inguinal amplexus (Bell 1978, 1985b; Waldman 2004) and have been reported in amplexus in trees (Waldman 2004; Germano and Bishop 2007a). It is unknown if the male or female chooses the breeding site, but both sexes, especially males, have been noted to guard the site prior to oviposition (Bell 1978). The eggs are laid in cool, moist depressions under rocks or logs in two strings or clusters of two to 19 eggs (Bell 1985b) which could potentially be shared between two different males (Bell 2008a). Once the oviposition occurs, the male will guard the clutch. Intracapsular development gives way to tailed froglets in seven to 10 weeks time and thereafter the male will dorsally brood the clutch to facilitate the completion of metamorphosis. The entire process from oviposition to metamorphosis completion is from 19 to 21 weeks with maturation taking at least 3-4 years (Bell 1978). 


\subsubsection{Threats to Leiopelma pakeka}

Since the late 1860s (Bell 1982), many amphibian species have been introduced into New Zealand for reasons such as the pet trade, teaching, research and medical purposes (Beebee and Griffiths 2005; King et al. 2009). All have been kept from establishing wild populations with the exception of three Australian bell frogs (Litoria aurea, L. ewingii and L. raniformis) that were intentionally introduced to New Zealand and have since naturalized (Bell 1982). There has been one documented case of L. aurea with the hind legs of an Archey's frog Leiopelma archeyi in its gut (Thurley and Bell 1994), but in general, introduced Australian frogs have different habitat preferences than Leiopelma, therefore do not compete for resources (Thurley and Bell 1994; Bishop 2008).

In New Zealand, the pathogenic chytrid fungus Batrachochytrium dendrobatitdis $(B d)$, which causes the disease chytridiomycosis, was first detected in a Litoria raniformis specimen in 1999 (Waldman et al. 2001; Waldman 2004). Waldman (2004) mentions that the introduced amphibian, $L$. ewingii is known as a carrier of $B d$, but is asymptomatic. The fungus is present in L. archeyi populations in the Coromandel Ranges and in the Whareorino Forest, but not in sympatric L. hochstetteri populations (Bell et al. 2004a). Although the fungus has had detrimental effects on the L. archeyi population (Bell et al. 2004a; Newman et al. 2010), they have been shown to self-cure in a laboratory setting (Shaw et al. 2010) and the peptides secreted by Leiopelma have been shown to be a natural defense against the growth of $B d$ zoospores (Melzer and Bishop 2010). As for $L$. pakeka, the current populations have apparently remained chytrid-free (Bell and Pledger 2010; Lukis 2009; Shaw et al. 2013). Access to islands which hold Maud Island frogs are controlled by DOC and have strict quarantine and biohazard protocols. There is currently no protocol at Zealandia to prevent the fungus from entering and establishing in the sanctuary.

Habitat loss and predation by introduced non-native mammals are the most widely accepted plausible reasons for the decline of all Leiopelma species (Worthy 1987; Bell et al. 2004a, 2010; Melzer and Bishop 2010; Newman et al. 2010). In a review by Toledo et al. (2007), mammals, birds and other frogs, such as the introduced Litoria spp. in New Zealand (Thurley and Bell 1994), were the top three taxa for preying upon post-metamorphic anurans. Native predators of Leiopelma are few, but when predators are encountered, Leiopelma rely on quiescence and crypsis to be inconspicuous (Green 1988; Bell and Pledger 2005; Germano and Bishop 2007b). As anti-predator defenses, L. pakeka are able to give a chirp (singly or in quick succession) and display a headbutting posture which, like many other anuran species (Nosi et al. 2002), exposes the toxin secreting parotoid glands. The secretions are not virulent, but they do appear to be unpalatable to other fauna (Green 1988; Bell 2008b). 
Even with highly toxic secretions, predation is a great risk to many anurans (Toledo et al. 2007), Leiopelma included. Both L. archeyi and L. hochstetteri live sympatrically with mammal predators (Bell et al. 2004a). The primary threat of predation is from rats, Rattus spp., with the discovery of bitten L. archeyi remains in the Whareorino Forest (Thurley and Bell 1994). Egeter et al. (2011), by means of DNA polymerase chain reaction (PCR) analysis of stomach contents, found evidence of rat predation on L. archeyi as well as evidence of predation of L. aurea by pigs (Sus scrofa) and L. raniformis by hedgehogs (Erinaceus europaeus). For Leiopelma pakeka, a mouse incursion had been reported on Maud Island (Ward 2000). The eradication was evidently successful; however, the recent mouse invasion on the island (Department of Conservation 2013b) presents a potential predatory threat to the remnant frog population. A second translocated population survives on Motuara Island which is also mammal predator-free (Tocher and Pledger 2005). Zealandia has a progressive non-native mammal detection and control program which is successful at detecting and eliminating all mammal intruders except the common house mouse, Mus musculus (Zealandia 2012).

\subsubsection{Translocation history}

To increase distribution and mitigate potential deleterious stochastic events, there have been four L. pakeka translocations. The first (1984-85) was an intra-island translocation $(n=100)$ from the source population in the 16 ha patch of forest to a selected regenerating forest in Boat Bay (Fig. 1.4) (Bell et al. 2004b). This population has fared well and continues to increase with new recruitment (Bell et al. 2004b; Tocher and Pledger 2005; Bell et al. 2010). The second, an inter-island translocation, in 1997 to Motuara Island $(\mathrm{n}=300)$, in Queen Charlotte Sound, also resulted in the establishment of a viable population (Tocher and Pledger 2005; Bell et al. 2010). In 2005 there was a translocation to Long Island $(\mathrm{n}=101)$ in Queen Charlotte Sound (Germano 2006) with an additional translocation in 2006/07 to the Zealandia wildlife sanctuary in Wellington $(n=58)$ (Lukis 2009) (Fig. 1.5). Unfortunately, both translocations were considered failures, possibly due to poor habitat and/or predation by little spotted kiwi (LSK), Apteryx owenii (Long Island and Zealandia) and house mice, Mus musculus (Zealandia) (Lukis 2009; Germano and Bishop 2007b; Bell et al. 2010).

\subsubsection{Zealandia translocation}

As documented by Lukis (2009), in an attempt to re-introduce L. pakeka to the lower North Island of New Zealand, a mix of captive ( $n=30$, University of Canterbury) and wild ( $\mathrm{n}=30$, Maud Island) frogs were translocated to Zealandia in February and October 


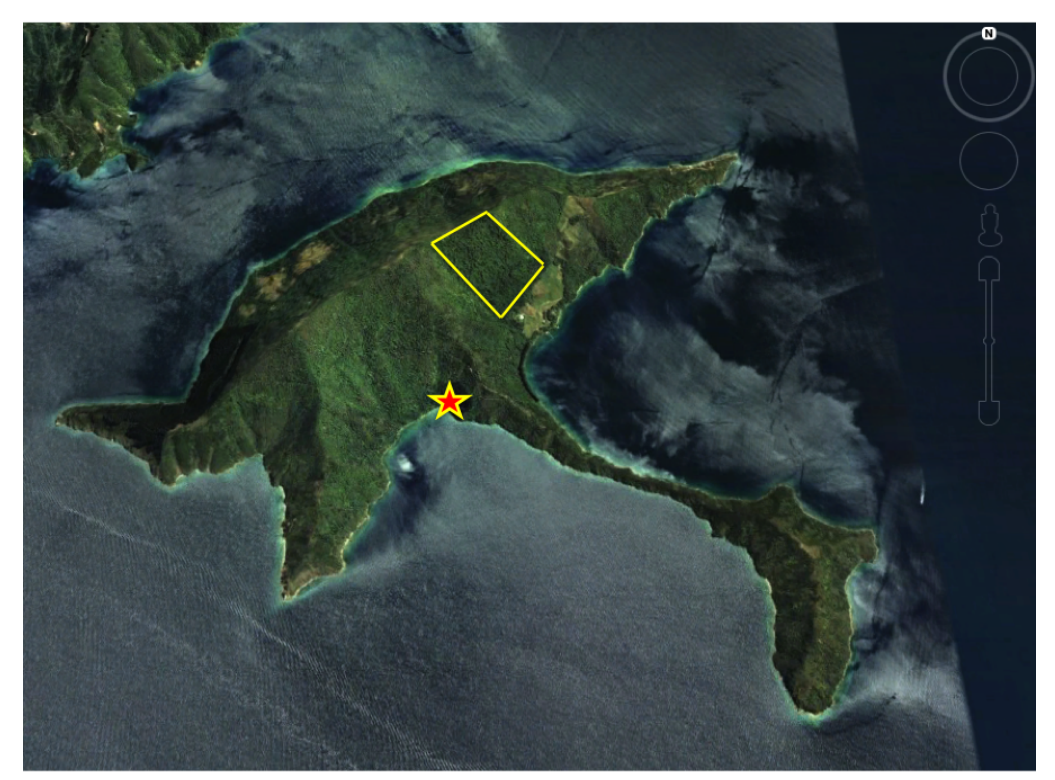

FiguRE 1.4: Intra-island translocation from L. pakeka metapopulation in the 16 ha patch of forest (outlined in yellow) to Boat Bay (star). Image: Google maps

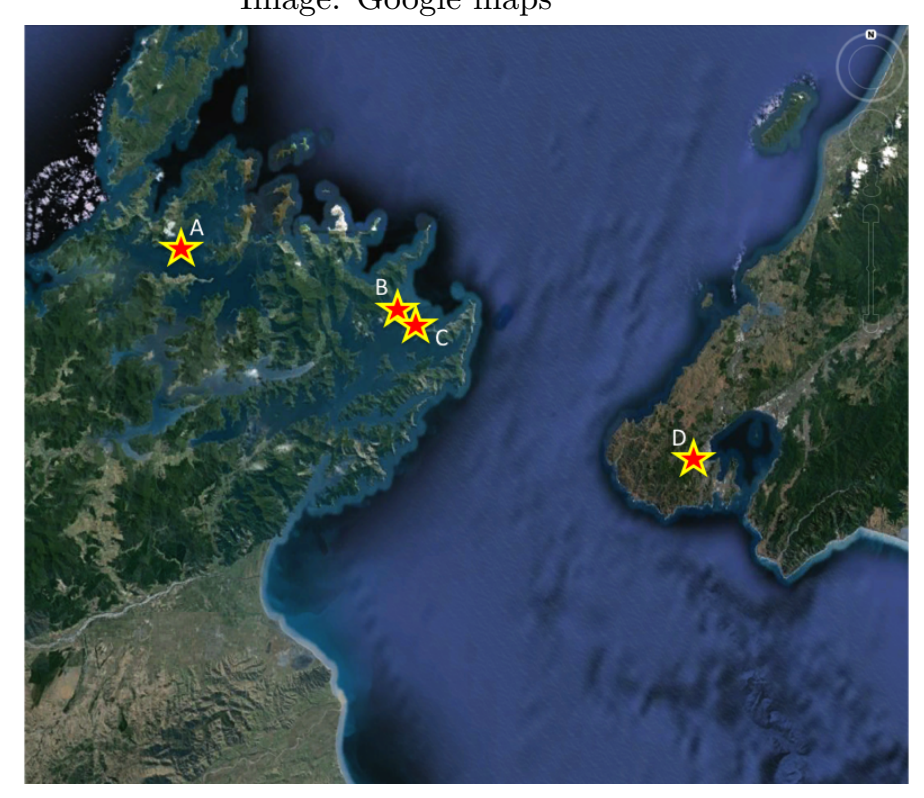

FiguRE 1.5: Inter-island translocations from A. Maud Island to B. Motuara Island C. Long Island D. Zealandia, Wellington. Image: Google maps

2006, respectively. Each group was released into two separate purpose-built predatorproof enclosures to allow for quarantine and habituation. In April 2007, the frogs were split into two groups with a mix of captive and wild individuals. Twenty-nine were kept in the original predator-proof enclosure and the remaining 29 were released into the surrounding forest.

Two months post-release, which coincided with a peak in mouse densities, only 11 out of 
the 29 individuals $(38 \%)$ released into the forest were recaptured during ground searches. One year post-release, only one frog $(3 \%)$ was recaptured. The first census of the original predator-proof enclosure was carried out in 2008. Two egg clutches and a total of eleven froglets were discovered (Bell 2008a), confirming that the habitat inside the enclosure was suitable for breeding. Each subsequent census (2009 \& 2011) confirmed high adult survival and additional progeny (Ben Bell pers. comm. \& Kerri Lukis pers. comm.). Due to likely resource competition in the enclosure, habitat disturbance, as well as to provide a better opportunity for safety and development (Bell 2008a), the progeny found during these censuses were collected and moved to a Victoria University incubator to complete metamorphosis. Once metamorphosis was completed, they were transferred back to Zealandia and put into the second predator-proof enclosure (Ben Bell pers. comm.; Raewyn Empson pers. comm.).

The last free-ranging Maud Island frog was seen in 2008 and post-release movements (dispersal and homing) analyzed by Lukis (2009) could not explain the apparent decline in the population living outside the enclosure. Little spotted kiwi were seen probing rock piles at the Zealandia and Long Island study sites during post-translocation monitoring. This suggests that predation by LSK, as well as predation by mice during peak densities could have been responsible for the disappearance of the free-ranging Maud Island frogs in Zealandia. The low founding number $(n=29)$ may have also exacerbated predation impacts on the founding population.

A third predator-proof enclosure was fabricated along the Te Mahanga track to provide Zealandia night tour patrons with an opportunity to view any emerged frogs and for advocacy of Maud Island frog ecology and conservation. In October 2011, six L. pakeka were removed from the original enclosure and relocated to the Te Mahanga enclosure.

\subsection{Aims of study}

The aims of this study are focused on the Maud Island frogs, L. pakeka, in the Zealandia wildlife sanctuary, Wellington, New Zealand.

\section{The aims of this thesis are conservation biology-focused and address the following questions:}

1. What is the status of the remaining L. pakeka from the original translocation? The first aim of this thesis is to determine how the frogs in the three separate outdoor, predator-proof enclosures have fared since their last human interactions in 2011. The last census of the original enclosure (2011) indicated a high survival. 
The second enclosure which served as a nursery, had not been censused since the last of the froglets were released in 2011. The status of the frogs in the third enclosure had not been assessed since their 2011 relocation.

2. Does Apteryx owenii show an interest in Leiopelma pakeka?

The second aim of this thesis is to investigate potential predation of the Maud Island frog by little spotted kiwi. It is unknown if the LSK in Zealandia could have contributed to the decline of the 2006/2007 translocated frog population. From previous observations of LSK foraging in Maud Island frog habitat, predation is a possibility and warrants investigation.

3. How will a larger population of L. pakeka $(\mathrm{n}=101)$ survive while living sympatrically with M. musculus?

The final aim of this thesis is to investigate possible predation of the Maud Island frog by mice. Peak mouse densities were thought to have had a detrimental impact on the small 2006/2007 translocated cohort of frogs. This investigative study is warranted for the future establishment of Maud Island frogs in Zealandia as well as to provide beneficial information regarding any potential ecological relation between the two species.

This study provides an opportunity for an assessment of the Maud Island frogs in the predator-proof enclosures as well as to ascertain the possible causative agents for the apparent failure of the original translocation completed by Zealandia and documented by Lukis (2009). The possible causatives must be investigated and mitigated if the restoration goals of Zealandia and the Native Frog Recovery Group are to be achieved. With the mouse invasion on Maud Island, this study provides an important opportunity to discern the ecological relationship, if any, between invasive mice and the endemic anuran. With the results of this study, I advise Zealandia whether or not their current mouse control program is suitable for the establishment of a viable free-ranging population of L. pakeka (and potentially L. hochstetteri (Karori Sanctuary Trust 2000)), within the sanctuary and if the population would need protection from kiwi. I also provide adaptive management suggestions for the continuation of gaining greater ecological knowledge of L. pakeka. In addition, the results of this study could serve as a catalyst for future research for a greater understanding of the ecological relationships among mice, kiwi and native frog species. 


\subsection{Approvals and permits}

The research conducted for this thesis was approved and permitted by Ngāti Kuia, Port Nicholson Trust, the Department of Conservation (national permit number 35174-CAP; file number NHS-12-12), Karori Wildlife Sanctuary Trust (research permit number 13) and the Victoria University of Wellington Animal Ethics Committee (approval number 2012R20).

\subsection{Thesis structure}

The chapters of this thesis are structured to address how the remaining individuals from the 2006/2007 translocation have survived in the three predator-proof enclosures and the possible reasons of failure of the original translocation of the free-ranging Leiopelma pakeka in Zealandia. Chapter 2 addresses the survival of the frogs in the three predatorproof enclosures. Chapter 3 addresses the possible interests in L. pakeka by A. owenii. Chapter 4 addresses the survival of 101 additionally translocated L. pakeka while living sympatrically with house mice. Chapter 5 integrates all findings and provides recommendations for adaptive management for a successful establishment of a viable free-ranging population of Maud Island frogs in the Zealandia sanctuary.

Each chapter is written as a separate publication therefore some information is repeated. All references are presented at the end of the thesis. 


\section{Chapter 2}

\section{Emergence and survival of Leiopelma pakeka in predator-proof enclosures in the Zealandia wildlife sanctuary}

\section{$2.1 \quad$ Introduction}

Leiopelma (Anura: Leiopelmatidae) is an endemic New Zealand anuran genus with an archaic lineage that dates back 225 million years (Roelants and Bossuyt 2005). Their evolution on the isolated land mass of New Zealand has allowed them to retain symplesiomorphic characters such as 9 pre-sacral amphicoelous vertebrae, ventral inscriptional ribs and the retention of tail-wagging muscles (caudalipubioschiotibialis) (Stephenson 1961; Bell 1978, 2008b). Habitat loss and predation have most likely caused the recent extinction of the three of the five species (L. auroraensis, L. markhami, L. waitomoensis, L. miocaenale and L. acricarina) (Worthy 1987; Bell et al. 2004a, 2010; Melzer and Bishop 2010; Newman et al. 2010, 2013; Worthy et al. 2013). Additionally, albeit, Leiopelma species have shown low susceptibility to the fungus Batrachochytrium dendrobatidis (Bd) (Bishop et al. 2009; Melzer and Bishop 2010; Ohmer et al. 2013; Shaw et al. 2010) which causes chytridiomycosis, the presence of the fungus in New Zealand puts further pressure on the threatened extant species (Leiopelma archeyi, L. hochstetteri, L. hamiltoni, L. pakeka) (Bell et al. 2004a; Melzer and Bishop 2010; Newman et al. 2010; Shaw et al. 2010, 2013) (threat status, Table 2.1). 


\begin{tabular}{lll} 
Common name & Scientific name & New Zealand threat status \\
\hline \hline Archey's frog & Leiopelma archeyi & Nationally Vulnerable \\
Hochstetter's frog & Leioplema hochstetteri & Declining \\
Hamilton's frog & Leiopelma hamiltoni & Nationally Critical \\
Maud Island frog & Leiopelma pakeka & Nationally Vulnerable \\
\hline \hline
\end{tabular}

TABLE 2.1: The New Zealand threat classification of the four extant species of Leiopelma (Newman et al. 2010, 2013).

Mammal eradication, ecosystem restoration, translocations and captive breeding have been management techniques used to facilitate species survival of New Zealand herpetofauna (Towns et al. 2001; Towns and Ferreira 2001). Protected outdoor husbandry of Leiopelma has previously resulted in successful breeding (Bell 1985a,b, 2008a,b; Gibson and Fraser 2011; Germano et al. 2012). One enclosure that has been undoubtedly successful for L. pakeka breeding is a purpose-built, predator-proof enclosure (one of two) in the Zealandia wildlife sanctuary in Wellington, New Zealand. The original enclosure, which holds the breeding population, and enclosure were built in preparation for a translocation of L. pakeka from the University of Canterbury $(\mathrm{n}=30)$ and from Maud Island $(\mathrm{n}=30)$ in $2006 / 2007$.

As documented by Lukis (2009), after a period of quarantine and habituation, in April 2007, the surviving frogs $(n=58)$ were split into two groups with a mix of male and female, captive and wild individuals. Twenty-nine were kept in the original predatorproof enclosure (Fig. 2.1) and the remaining 29 were released into the surrounding forest.

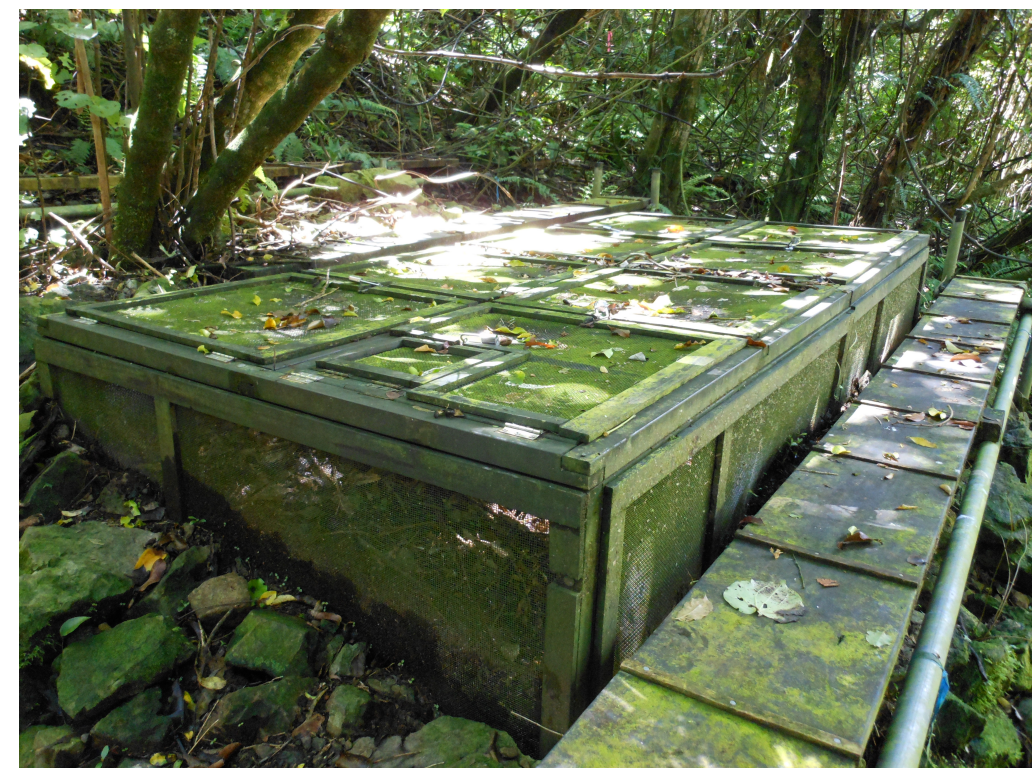

FIGURE 2.1: Original predator-proof enclosure for L. pakeka in the Zealandia wildlife sanctuary, Wellington. 
The first census of the original enclosure was carried out in February 2008. Twentyseven out of the 29 frogs released (93\%) were recaptured. This census also confirmed that the habitat inside that predator-proof enclosure was suitable for breeding with the discovery of two egg clutches and a total of eleven recently hatched tailed froglets (Bell 2008a). Each subsequent census (2009 \& 2011) confirmed high adult survival (Lukis 2009) and additional progeny (Zealandia, unpub. data) (Table 2.2).

Individual identification via distinguishable skin patterns has been shown to be a reliable method for individual amphibian identification (Carafa and Biondi 2004; Bradfield 2004; Webster 2004; Kenyon et al. 2010; Sacchi et al. 2010; Hoque et al. 2011) and was the method used for the Lukis (2009) study. Computer assisted models (CAM) such as ImageJ (Webster 2004; Beukema 2011), Wild-ID (Zaffaroni Caorsi et al. 2012) and ${ }^{3} \mathrm{~S}$ Sacchi et al. (2010) have been shown to be beneficial when large numbers of individuals need identification (e.g. $\mathrm{n}>1000$ ). However, with a small number of individuals of this study, manual photographic identification method (PIM) was more appropriate.

\begin{tabular}{ccc} 
Census year & No. adults recaptured & No. of froglets \\
\hline \hline 2008 & 27 & 11 \\
2009 & 26 & 10 \\
2011 & 24 & $12 / 1$ (yrlng) \\
\hline \hline
\end{tabular}

TABLE 2.2: Number of frogs recaptured and froglets found (yrlng=yearling) during censuses of the original predator-proof enclosure in Zealandia from 2008-2011. (Zealandia, unpub. data).

Due to the confined space and presumed resource competition in the enclosure, as well as safety concerns (possible cannibalism) (Bell 2008a), the progeny found during these censuses $(n=34)$ were collected and moved to a Victoria University incubator to complete metamorphosis (Bell et al. 2010). Once metamorphosis was completed, they were transferred back to Zealandia and put into the second predator-proof enclosure (Fig. 2.2) (Ben Bell pers. comm., Raewyn Empson pers. comm.). The enclosure was partitioned in half to keep cohorts separate. Prior to this thesis, a census involving the removal of all rocks and debris had not been done on this enclosure. 


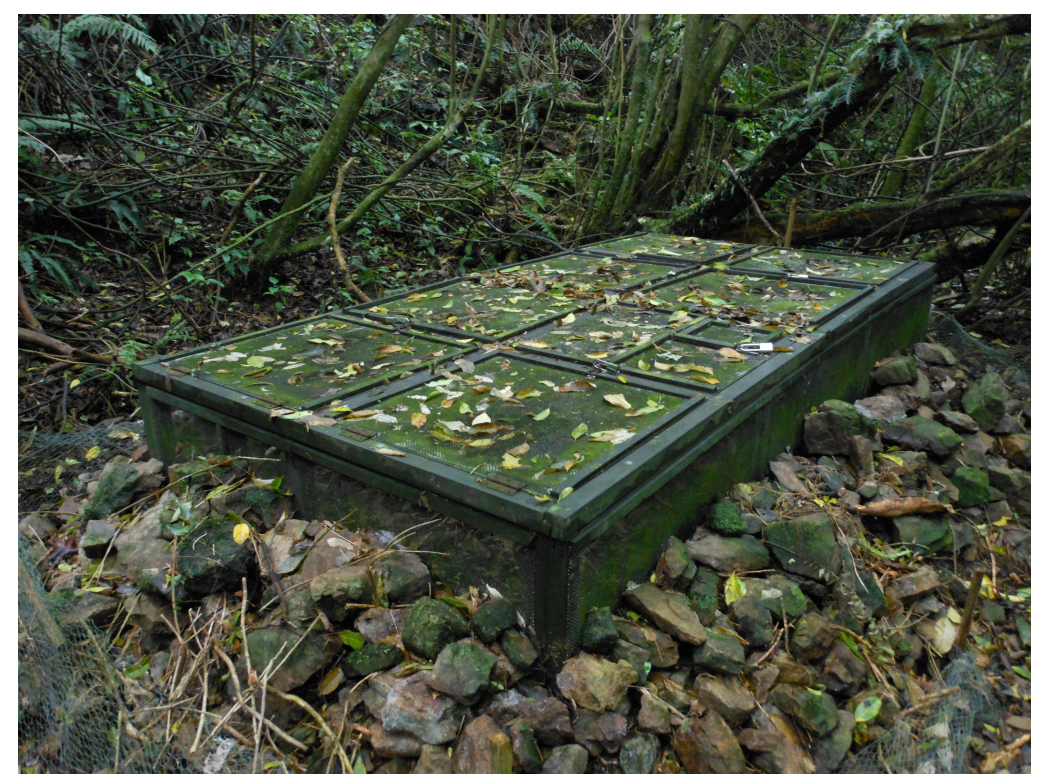

FiguRE 2.2: Second predator-proof enclosure for juvenile L. pakeka in the Zealandia wildlife sanctuary, Wellington.

A third predator-proof enclosure was fabricated along the Te Mahanga track to provide an opportunity for species advocacy as well as to provide Zealandia night tour patrons with an opportunity to view emerged frogs. In October 2011, six adult L. pakeka were removed from the original enclosure and relocated to the Te Mahanga enclosure (Fig. 2.3). Zealandia night-tour guides record if they notice any emerged individuals, but do not identify frogs or quantitatively establish emergence.

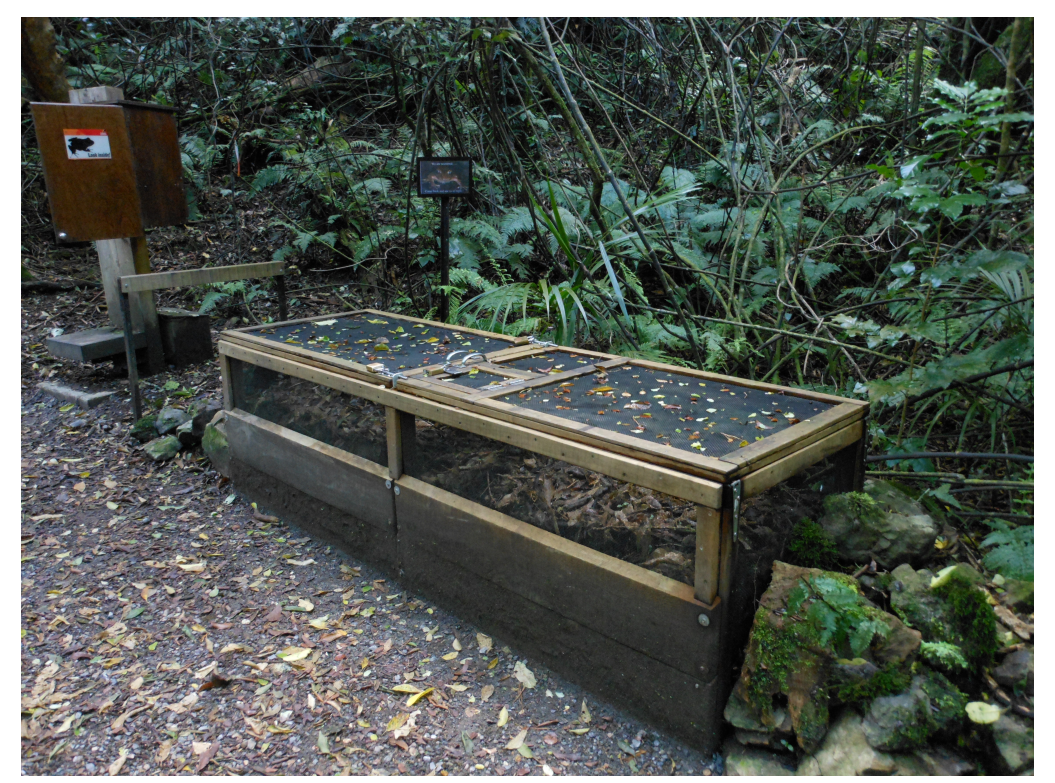

FiguRE 2.3: Te Mahanga track predator-proof enclosure for night tour public viewings of L. pakeka in the Zealandia wildlife sanctuary, Wellington. 
All enclosures have rocks built-up around the outside edges to maintain high moisture and humidity conditions (see Figs. 2.1, $2.2 \& 2.3$ ); they are also topped off with fresh leafy debris and supplemented with invertebrates as needed (Raewyn Empson, pers. comm.).

It is unknown how the individuals in these three enclosures have fared since their last human encounters in 2011. This chapter focuses on the nocturnal emergence and survival of the frogs in each of the three enclosures.

\subsection{Methods}

\subsubsection{Emergence}

Survival and emergence of L. pakeka was established for each of the three predatorproof enclosures in the Zealandia wildlife sanctuary in Wellington, New Zealand. The original and second enclosures measure approximately $1.5 \times 3.1 \times 0.7 \mathrm{~m}$ and are divided into a grid of eight equal sections, each with its own hatch. The Te Mahanga enclosure measures approximately $0.8 \times 2.5 \times 0.7 \mathrm{~m}$ and is divided into two equal hatched sections. Hatches can be seen in Figs. 2.1, 2.2 and 2.3, respectively. As suggested by Cree (1989), all three enclosures were searched the same night to ensure similar climatic conditions.

Searches were made for five consecutive nights approximately every four weeks from 22 October 2012 (period 1) through to 02 August 2013 (period 9). During the months of October and November 2012, the searches started approximately one and one half hours after sunset. After the translocation of L. pakeka in early December 2012 (see Chap. 4 ), the searches started after the completion of the monitoring of the translocated frog study site, which commenced approximately one and one half hours after sunset and varied in duration, anywhere from 60-210 minutes.

The following environmental conditions were noted at the start of each enclosure search: cloud cover (0-clear, 1-partly cloudy, 2-half cloudy, 3-mostly cloudy, 4-overcast), moon phase, wind strength (0-no wind, 1-leaves rustle, 2-leaves/branches in constant motion, 3-branches/trees sway, 4-gales), precipitation (0-none, 1-mist, 2-light/sprinkle, 3medium, 4-heavy/down pour), precipitation in the previous 24 hours (yes/no), substrate condition (0-dry, 1-damp, 2-wet). Wind direction (degrees true north) was obtained from the MetService Kelburn station approximately $7.2 \mathrm{~km}$ northeast of Zealandia. A Hobo data logger (model 8 series 4 ) was used to collect minimum and maximum of both temperature $\left({ }^{\circ} \mathrm{C}\right)$ and relative humidity $(\mathrm{RH})$ in October and November. From 
December 2012 to the completion of the study, minimum and maximum of both temperature $\left({ }^{\circ} \mathrm{C}\right)$ and relative humidity $(\mathrm{RH})$ were recorded by a Digitech hygrometer (model QM7312). The data logger and the hygrometer were placed either on top of the enclosures or immediately adjacent to (second and Te Mahanga enclosures), or at the data station approximately $4 \mathrm{~m}$ away and $1 \mathrm{~m}$ off the ground for the original enclosure (done only if the search of the adult enclosure and search of the translocation site was done simultaneously).

For the original and second enclosures, the search began at the southeast hatch and continued counterclockwise; both hatches were lifted simultaneously for the Te Mahanga enclosure. Dorsal, frontal, right and left lateral photos were taken in situ of emerged individuals with a Nixon Coolpix S6100 with macro setting, with the exception of 18 January 2013 when photographs were taken with a Canon EOS 5D Mark II with Canon EF 100mm f/2.8 USM Macro. The location where each frog was found was marked by Cartesian coordinates. Any frogs seen that were not a translocated adult (e.g. recruits from juvenile to sub-adult) were referred to as juveniles for simplicity and only a total count and locations were recorded.

\subsubsection{Identification}

All L. pakeka in the original and Te Mahanga enclosures were previously photographed for the Lukis (2009) study. These photos were obtained and used for manual PIM. Photographs of the juvenile frogs put into the second/nursery enclosure were taken at the Victoria University of Wellington prior to their return to Zealandia. Due to the small size of the frog, enlarged images became distorted, therefore these were not used to identify emerged individuals. Alternatively, photographs of emerged frogs were taken from the start of the study and compared against each other to determine individual identity.

To assist in identification, particularly with the individuals that were too dark or had indistinguishable markings, eye-vessel patterning (eye venation) was used as suggested by Bell and Pledger (2010) and Bell (2011b). This was done similarly to PIM of skin patterns. Reference photos (taken for the Lukis 2009 study) and recapture photos (taken during this study) were enlarged and the arterial vessels over the iris were carefully compared, taking into consideration vessel dilation and photo quality.

To validate this method, I collaborated with a software developer to produce a tenquestion online questionnaire. Twenty-one individual Maud Island frogs were used for the reference and recapture photo database. The photos used were the same photos used 
to identify the frogs during the study. The images were cropped using Adobe Fireworks CS6 (ver. 12.0.0.236) to reveal only the eyes.

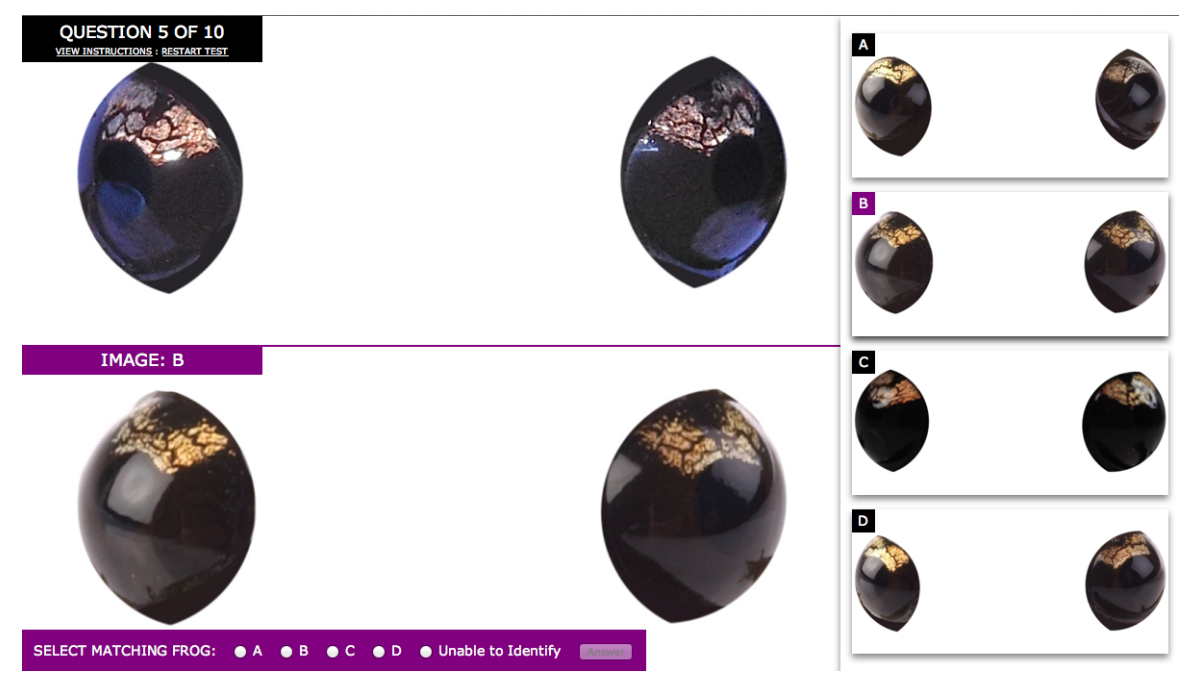

Figure 2.4: Example of questionnaire page. Top left: recapture image, right side: four reference choices, bottom left: selected enlarged reference image for comparison.

Each question image (recapture image) and choices images (reference images) presented were selected at random from the database (for example, see Fig. 2.4). Each question had one correct match. Details obtained were number correct, number incorrect due to mismatch and number incorrect due to non-match. Five demographic questions were asked after the completion of the questionnaire. The questionnaire was distributed via university and social networks.

\subsubsection{Census of second enclosure}

A census of the second predator-proof L. pakeka enclosure was done on 8 May 2013 to establish survivorship of the 34 juveniles released there. Each half of the partition was done separately. All rocks, leaf material and general debris were removed from the enclosure, checked carefully for retreating frogs and placed on a tarpaulin. For each frog found, position and depth in the enclosure, weight, snout-vent length, left tibia length, skin intensity (l-light, m-medium, d-dark, or combination thereof), pattern (p-patterned, m-mottled, u-uniform, or combination thereof) and girth (visual estimation of 1-5, 5 highest girth) were recorded. Dorsal, right and left lateral and frontal photographs were taken for identification, thereafter each frog was placed in separate plastic containers and held in a secured, dark cloth bag. General weather conditions were recorded at the start of the census. 
Once all materials inside the enclosure were removed and all frogs processed, the partition was removed and the rocks were returned to the enclosure. Fresh leafy-debris was used to top-off the rocks and then the frogs were placed back into the enclosure.

\subsubsection{Data analysis}

All statistical analyses were performed with the R statistical package (ver. 3.0.1) using RStudio (ver. 0.98.456) (R Core Team 2013). Shapiro-Wilk was used to test for normality. Non-parametric tests were used where the data was not normally distributed. Mean values are presented with \pm 1 standard error. The data included 54 secondary capture occasions and 11 primary capture periods.

\subsection{Results}

\subsubsection{Original enclosure}

Twenty-nine adult frogs were initially released into the original predator-proof enclosure, and upon the completion of the Lukis (2009) study, 26 (89.7\%) were confirmed alive. Zealandia carried out a census in 2011 confirming the survival of 24 adults (92.3\%). The October 2011 relocation of six adults to the Te Mahanga enclosure, indicated 18 adults remained in the enclosure; however, frog B7, which was inadvertently missed during the 2011 census, was recaptured on 9 May 2013. Throughout this study, I've recaptured 18 of the 19 adults $(94.7 \%)$ that remained in the enclosure (Table 2.3 ).

Out of the 18 recaptured individuals, recaptures varied from one to 28 . Reduced emergence was seen during the colder months with peak periods of emergence during late summer and early autumn (Feb.-Apr.) with 14 frogs emerged during each period (Fig. 2.5). Unexpectedly, peak emergence occurred during the peak drought months of February and March (NIWA 2013).

The majority of the recaptures occurred along the northern and eastern sides of the enclosure. Although some frogs appeared to prefer one side of the enclosure over the other, frogs were often recaptured during the same evening on the opposite side of the enclosure, supporting entire enclosure usage as shown by utilization areas in Lukis (2009). On at least six separate occasions, always in the upper northeastern corner of the mesh, a pair of frogs have been seen one on top of each other. These pairs consisted of only four individuals (A5, B2, B5 and M4). Amplexus is unlikely due to adult females always on top of another adult female or on top of a adult of unknown sex (Fig. 2.6a). On one occasion, a juvenile was on the back of the adult female, A5 (Fig. 2.6b). 


\begin{tabular}{lccc}
\hline & 2009 & 2011 & $2012 / 13$ \\
\hline \hline B12 & $\star$ & $\star$ & $\star$ \\
B3 & $\star$ & $\triangle$ & \\
A3 & $\star$ & $\triangle$ & \\
A2 & $\star$ & $\star$ & $\star$ \\
B14 & $\star$ & $\star$ & $\star$ \\
B11 & & & \\
A5 & $\star$ & $\star$ & $\star$ \\
B2 & $\star$ & $\star$ & $\star$ \\
A4 & $\star$ & $\triangle$ & \\
B4 & $\star$ & $\star$ & \\
A11 & $\star$ & $\star$ & $\star$ \\
11 & & & \\
M28 & $\star$ & $\star$ & $\star$ \\
M27 & $\star$ & $\triangle$ & \\
B10 & & & \\
B7 & $\star$ & & $\star$ \\
M23 & $\star$ & $\star$ & $\star$ \\
M22 & $\star$ & $\triangle$ & \\
M21 & $\star$ & $\star$ & $\star$ \\
M19 & $\star$ & $\star$ & $\star$ \\
M17 & $\star$ & $\triangle$ & \\
B5 & $\star$ & $\star$ & $\star$ \\
M14 & & & \\
M12 & $\star$ & $\star$ & $\star$ \\
M10 & $\star$ & $\star$ & $\star$ \\
M9 & $\star$ & $\star$ & $\star$ \\
M5 & $\star$ & $\star$ & $\star$ \\
M4 & $\star$ & $\star$ & $\star$ \\
M2 & $\star$ & $\star$ & $\star$ \\
\hline \hline & & &
\end{tabular}

TABLE 2.3: Frogs accounted for in the original enclosure $(\star)\left(\mathrm{n}_{\text {tot }}=29\right)$ at the Lukis (2009) study, 2011 census data (Zealandia, unpub. data) and data obtained from this study. $\triangle$ : accounted for and later relocated to the Te Mahanga enclosure. Frogs are listed with increasing SVL.

The number of juveniles (classified in this situation as newly metamorphosed frogs to sub-adult recruits) were counted each night. The juvenile count varied from one up to 15 (6 May 2013) on 44 out of the 54 capture occasions. On five capture occasions (once in period 9 and twice in periods $10 \& 11$ ), juveniles were emerged whereas no adults were emerged. Frogs from most recent breeding cycle emerged in May, June and July 2013. Two young frog that emerged on 6 May measured $11.52 \mathrm{~mm}$ and $12.85 \mathrm{~mm}$. Emergence of juveniles of this size are relatively consistent with the results found by Bell (2011a). The exact number of recruits in this enclosure is unknown. 


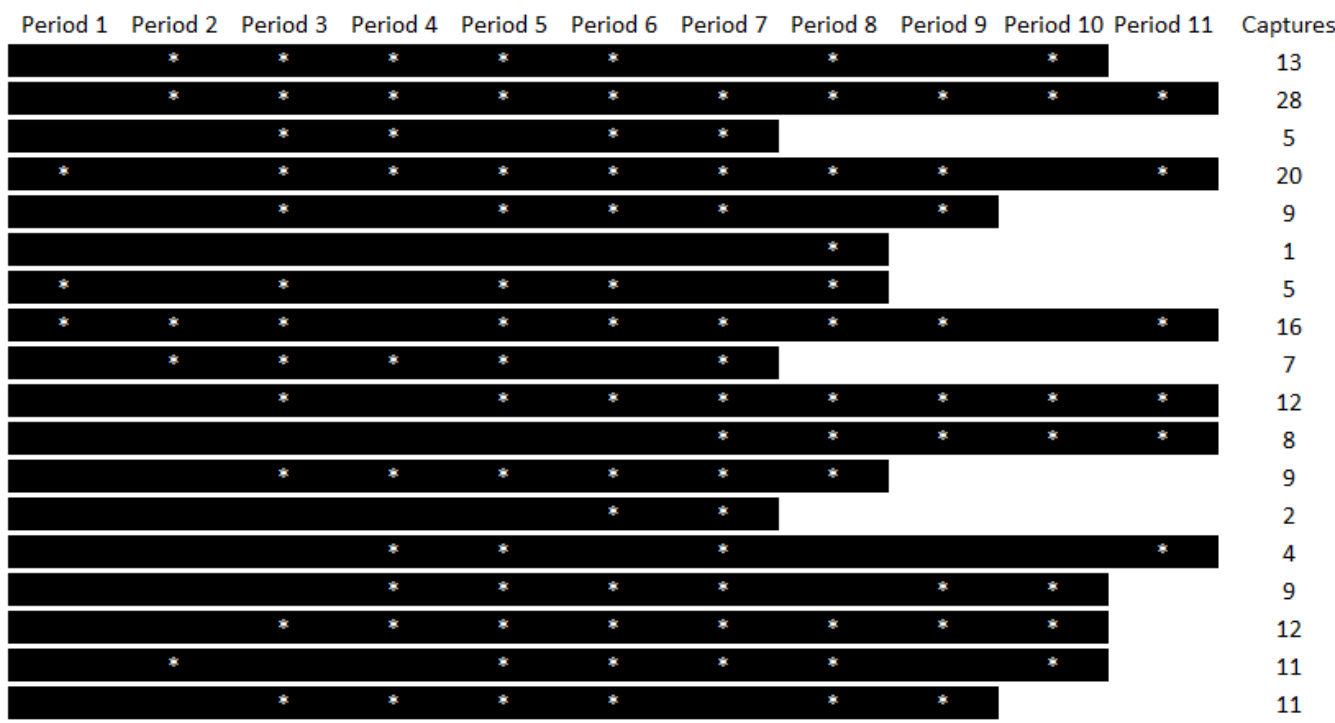

FiguRE 2.5: Survival and total captures of L. pakeka in the original predator-proof enclosure. Black bar indicates last known to be alive. White star indicates periods captured. Period 1: Oct. 2012, period 11: Jul.-Aug. 2013.

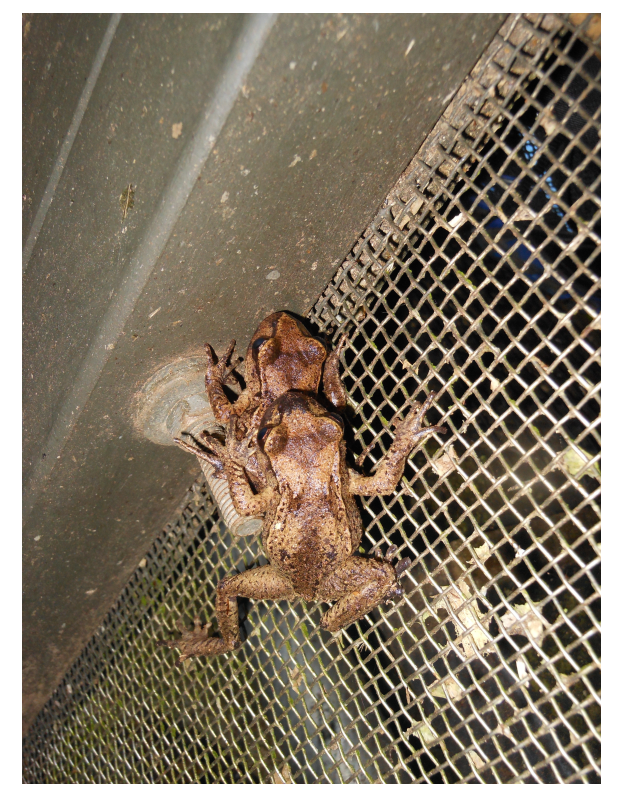

A.

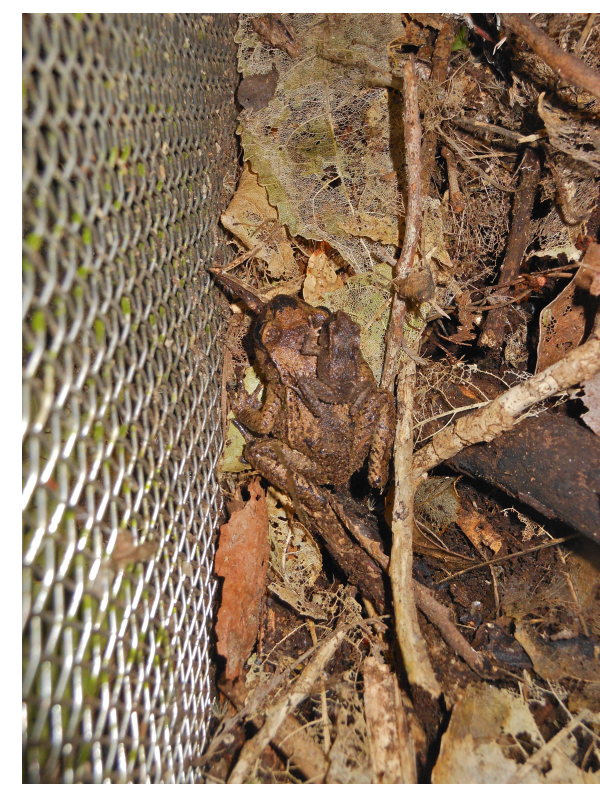

B.

Figure 2.6: A. Frog A5 on top of frog B2 (both adult females). B. Juvenile on the back of A5.

\subsubsection{Second enclosure}

A complete census was conducted on the second predator-proof enclosure in Zealandia on 8 May 2013. Twelve out of the 34 individuals (35\%) that were released into the enclosure survived (Table 2.4). Post ontogenetic pattern change has been previously 
documented in amphibians with PIM identification shown to be successful (Kenyon et al. 2010; Beukema 2011). However, the low resolution of the photographs taken at Victoria University prior to the frogs' release caused the images to become blurred and unclear once enlarged, rendering comparison for identification to the original photographs unsuitable. Photographs obtained during this study were compared to each other for individual frog identification. Frogs N3, N5 and N6 were relocated to the Te Mahanga track enclosure at the completion of the census.

\begin{tabular}{llll}
\hline Frog & SVL & $\begin{array}{l}\text { Weight } \\
(\mathrm{g})\end{array}$ & Side found \\
\hline \hline N1 & 36.56 & 6.2 & south \\
N2 & 36.59 & 5.7 & south \\
N3 & 40.46 & 6.7 & south \\
N4 & 41.28 & 7.4 & north \\
N5 & 33.39 & 3.9 & south \\
N6 & 33.00 & 3.8 & south \\
N7 & 38.15 & 6.3 & south \\
N8 & 37.09 & 5.6 & north \\
N9 & 41.80 & 8.2 & north \\
N10 & 42.18 & 8.8 & north \\
N11 & 38.29 & 7.5 & north \\
N12 & 34.21 & 4.8 & south \\
\hline \hline
\end{tabular}

TABLE 2.4: Census of second predator-proof enclosure.

Only eight out of 12 frogs emerged for the entire duration of the study. Excluding the census, four frogs were recaptured twice, four frogs were recaptured once, whereas 4 frogs were never recaptured. These captures occurred in five out of 11 periods (Fig. 2.7).

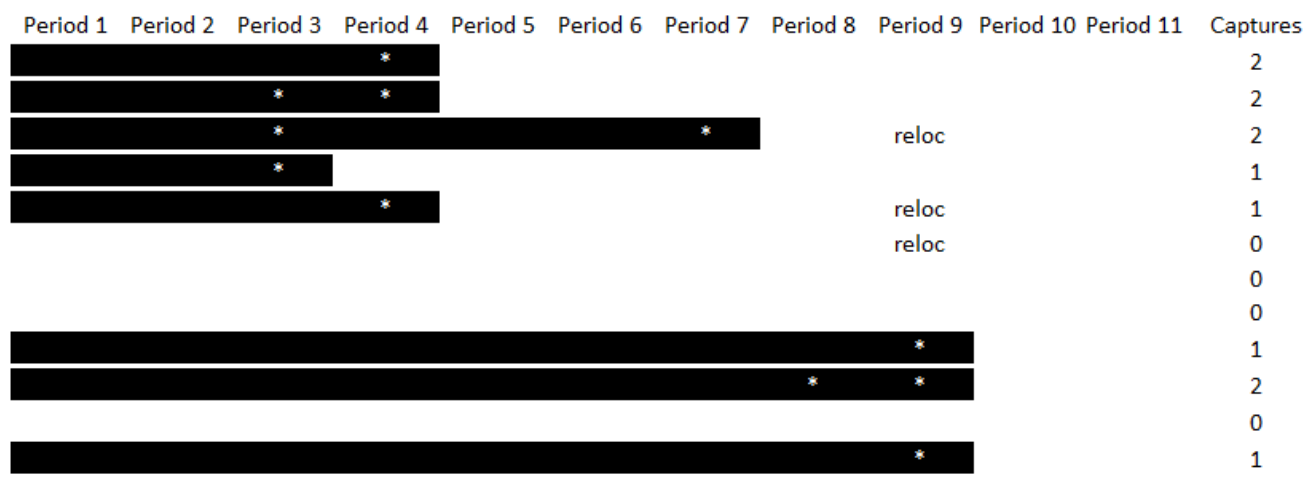

FIGURE 2.7: Survival and total captures of L. pakaka in the second predator-proof enclosure. Black bar indicates last known to be alive. White star indicates periods captured. Reloc - relocated to Te Mahanga enclosure. Period 1: Oct. 2012, period 11: Jul.-Aug. 2013. 


\subsubsection{Te Mahanga enclosure}

The six frogs relocated to this enclosure in October 2011 have all been recaptured during this study. Prior to the relocation of the three frogs from the second enclosure, emergence increased each period with all frogs emerging in period 7 (April). Two of the frogs relocated from the second enclosure emerged only once (Fig. 2.8). New recruits were seen in this enclosure in November, December of 2012, January, April, and June of 2013. The recruits were only counted; one emerged on four occasions and a maximum of two recruits were seen on two separate occasions (Jan. \& Apr.). The exact number of recruits in this enclosure is unknown.

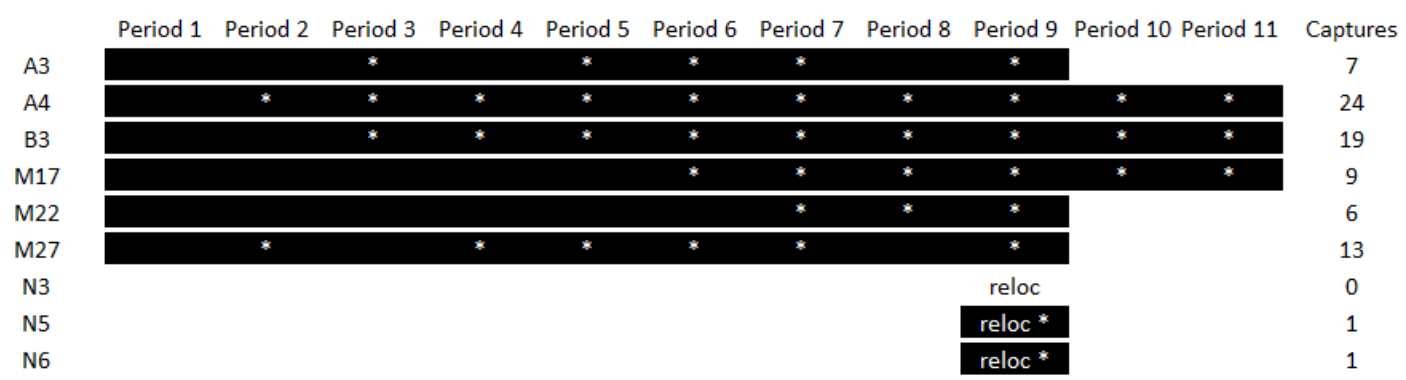

FiguRE 2.8: Survival and total captures of L. pakeka along the Te Mahanga track predator-proof enclosure. Black bar indicates last known to be alive. White star indicates periods captured. Reloc - relocated from the second enclosure. Period 1: Oct. 2012, period 11: Jul.-Aug. 2013.

\subsubsection{Eye-Venation questionnaire}

A total of 549 questionnaires were completed. Out of 10 questions, the mean number of correct answers was $8.05( \pm 0.08)$, mean total incorrect was $1.95( \pm 0.08)$, mean incorrect due to mismatch was $1.35( \pm 0.07)$, mean incorrect due to unable to match was 0.60 $( \pm 0.05)$.

In regard to the questionnaire takers, out of the 549 tests completed, 351 had animal science experience, 164 had pattern recognition experience and 126 were familiar with the Maud Island frog. Mann-Whitney U tests showed significance in the number of correct matches for all three of these categories $(\mathrm{p}<0.05)$. In regard to the number of correct answers: people with animal science experience had a mean of $8.4( \pm 0.08)$ whereas people with no animal science experience had a mean of $7.41( \pm 0.15)$; people with pattern recognition experience had a mean of $8.65( \pm 0.11)$ whereas people without pattern recognition experience had a mean of $7.79( \pm 0.10)$; people familiar with the Maud Island frog had a mean of $8.45( \pm 0.14)$ whereas people unfamiliar with the Maud Island frog had a mean of $7.93( \pm 0.09)$. 
Mann-Whitney U test did not show significance in number correct for gender $(\mathrm{p}>0.05)$, nor did a Kruskal-Wallis test show significance in the number correct per age group $(\mathrm{p}>0.05)$.

\subsection{Discussion}

\subsubsection{Original enclosure}

Albeit, a census of this enclosure was not conducted, the number of individuals recaptured in this study still indicates a relative high survival. The apparent loss of frog B4 with the recapture of the previously missed B7 suggests that either the previous identification was incorrect and this is actually the same individual, or both individuals were still alive but B4 was not recaptured during this study. This is an indication that additional frogs could have been missed during the last census as well as during this study which may still be alive.

Emergence and ecological relationships inside the enclosure are not comparable to freeranging systems due to the confined space and various levels of competition. If all 18 adults recaptured during this study are the only adult survivors, with the addition of at least 15 recruits of varying ages, gives 33 frogs competing for limited resources in a 4.65

$\mathrm{m}^{2}$ enclosure. Adults were found to have transversed the entire enclosure as indicated by Lukis' minimum area utilized, although habitat use appeared to remain on the northern and eastern side of the enclosure, possible due to micro-climate variation. Additionally, at various times throughout this study, adults were seen one on top of another in the north eastern corner. However, it is unknown if Leiopelma pakeka are solitary animals. Leiopelma pakeka been shown to have a home range of only a few square meters on Maud Island (Bell 1994; Bell et al. 2004b; Bell and Pledger 2010) with the centers of activity to shift $1.3 \mathrm{~m}$ per decade (Bell and Moore 2012). It has also been shown that the mean nearest neighbor distance on Maud Island was $0.63 \mathrm{~m}$ away (Bell and Moore 2012). This along with the elevated level of competition in a confined space and the clumping of individuals suggests that this particular enclosure could possibly be overcrowded.

However, the appearance of juveniles of varying ages is an encouraging sign. This study confirms six consecutive successful breeding seasons and it indicates and supports the success of Leiopelma outdoor husbandry (Bell et al. 1985; Gibson and Fraser 2011). Further studies involving the micro-climate conditions and the success of the frogs are suggested. As it stands, it appears that the protective enclosure along with the environmental conditions within the Zealandia sanctuary are conducive to the successful breeding of the Maud Island frog. 


\subsubsection{Second enclosure}

Emergence appeared to be reduced with only eight out of the 12 frogs recaptured on five out of the 11 capture periods. Unlike the original enclosure, the second enclosure (also $4.65 \mathrm{~m}^{2}$ ) has an estimated $62 \%$ fewer frogs to compete for resources. Only seven frogs were competing for resources in the south end of the enclosure, and five competing in the north end. During the census, leafy debris and soil removed were quite damp, particularly on the northern end. The apparent high moisture levels inside the enclosure along with the relatively few individuals could have facilitated the reduced emergence.

\subsubsection{Te Mahanga enclosure}

The six frogs relocated to this enclosure appear to have all survived. The appearance of recruits in this enclosure is encouraging as it is an indication that the process of relocation did not disturb their breeding cycle. Although the juveniles seen in this enclosure were not measured, they did not appear to be frogs from the most recent breeding season. With emergence of the most recent brood emerging for the first time in the late austral summer or early autumn (Bell 2011a), even if breeding occurs slightly earlier as suggested by Germano et al. (2012), the apparent size of the juveniles appear to be too large to have recently dismounted from dorsal brooding. The appearance in November and the apparent size indicate that the frogs were mostly likely from the previous breeding season (summer of 2011/2012). Additional research of these juveniles is warranted. Nonetheless, their presence is encouraging and again, demonstrates that the enclosed environment in Zealandia is conducive to the survival and breeding of these frogs.

\subsubsection{Identification via eye venation}

The overall mean of the number of questions answered correctly suggests that using blood vessel patterns that cover the iris is a successful additional tool for positive identification. Experience in animal science, pattern recognition or familiarity with Maud Island frogs was slightly advantageous to making the correct match. However, the mean of correct answers for people who answered No to the three significant categories was only slightly lower which could indicate that there is room for improvement with practice.

Unfortunately, this method did not help in the identification of juveniles in this study. Enlargement of the juveniles' photos only made one primary vessel apparent, and often that vessel was blurred. Vessel dilation and photo quality made positive matches a 
challenge, but this method helped affirm identification of individuals throughout this study and improvement studies of this method are needed. 


\section{Chapter 3}

\section{Interest of Apteryx owenii in $L$. pakeka?}

\subsection{Introduction}

\subsubsection{Is Apteryx owenii interested in Leiopelma pakeka as a food source?}

Pre-human distribution of the endemic ratite Apteryx spp. (Apterygiformes: Apterygidae) (Fig. 3.1) (Butler and McLennan 1991; Ministry for the Environment 2007) and endemic Leiopelma spp. (Anura: Leiopelmatidae) (Fig. 3.2) (Worthy 1987; Bell et al. 1998) shows both taxa inhabited the lower North Island of New Zealand. When species numbers were plentiful, the potential predation of Leiopelma spp. by Apteryx spp. was unlikely to have had negative consequences for the anuran population. Both taxa have suffered great population losses from various forms of human disturbance (Jolly and Colbourne 1991; McLennan et al. 1996; Sales 2005; Worthy 1987; Bell 2008b) and both have ended up as threatened taxa.

A contributor to New Zealand conservation is the 225-ha Zealandia wildlife sanctuary in Wellington, New Zealand. One of Zealandia's goals is to restore a piece of mainland New Zealand, as much as possible, to a pre-human ecosystem, facilitated by the construction of a predator-proof fence and eradication of all non-native mammals except house mice (Mus musculus) (Campbell-Hunt 2002; Zealandia 2012). 


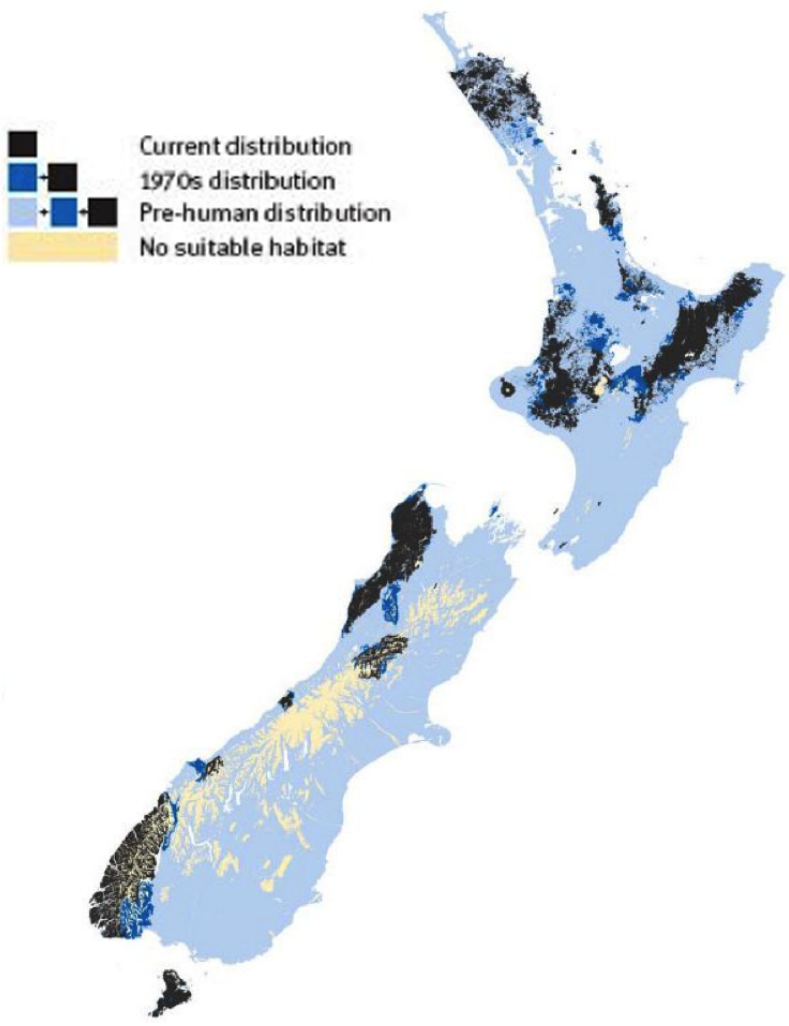

FIGURE 3.1: Apteryx spp. distribution change. Ministry for the Environment (2007).

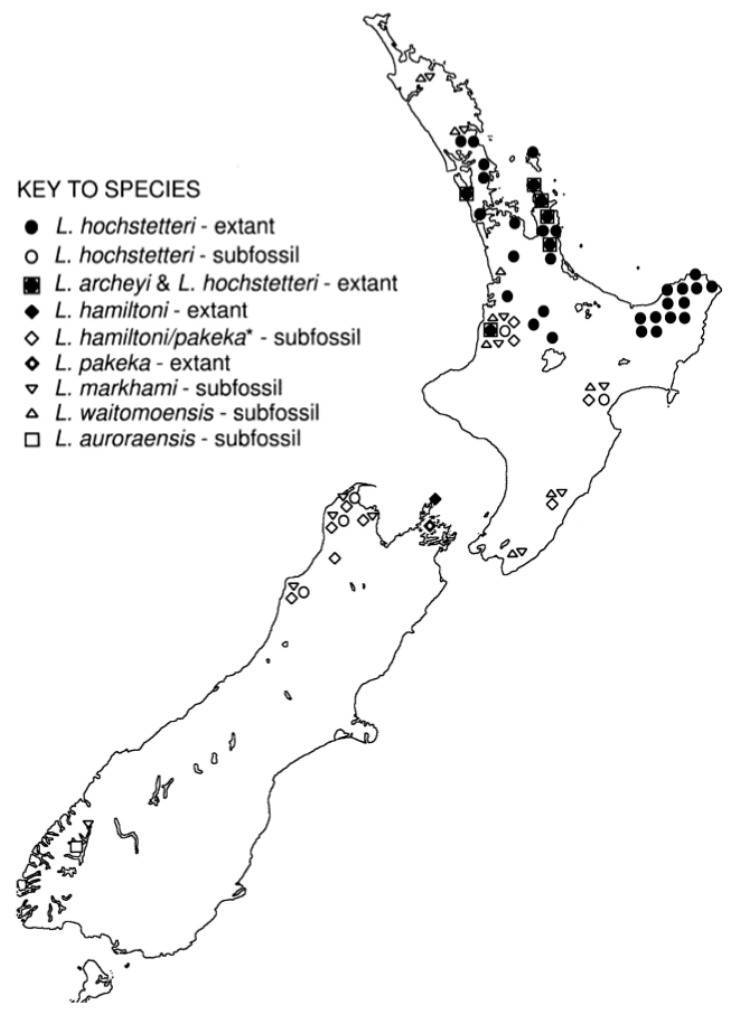

Figure 3.2: Leiopelma spp. distribution of extinct and extant species, used with permission (Bell et al. 1998). 
As a part of Zealandia's ecosystem restoration, both the little spotted kiwi (LSK), Apteryx owenii $(\mathrm{n}=40)$ and the Maud Island frog, Leiopelma pakeka $(\mathrm{n}=58)$ have been reintroduced into the fenced sanctuary. Little spotted kiwi are listed as Near Threatened in the IUCN Red List and as Recovering under the New Zealand Threat Classification, whereas the Maud Island frog is listed as Vulnerable on the IUCN Red List and as Nationally Vulnerable under the New Zealand Threat Classification (Miskelly et al. 2008; Newman et al. 2010, 2013; IUCN Red List 2012). The re-introduction of 40 LSK in 2000/2001 from Kapiti Island (Campbell-Hunt 2002; Zealandia 2012; Digby et al. 2013) has been a success with the last census estimating 120 LSK now living within Zealandia boundaries (Zealandia, unpub. data). In contrast, the 2006/2007 translocation of $29 \mathrm{~L}$. pakeka from Maud Island and the University of Canterbury released into a patch of forest was evaluated as a failure (Bell et al. 2010) after only a single frog was found in 2008 and none thereafter (Lukis 2009). Post-release analysis of dispersal and homing done by Lukis (2009) could not explain the apparent decline in the translocated individuals. It was thought that LSK could have possibly preyed upon the frogs after observations were made of LSK probing rock piles that the frogs inhabited (Lukis 2009). This behavior was also seen during the post-release monitoring of the 2005 L. pakeka translocation to Long Island (Germano 2006).

\subsection{Apteryx owenii prey detection, selection and the pos- sibility of Leiopelma pakeka depredation}

As with all kiwi species, A. owenii have a well developed olfactory bulb (Martin et al. 2007) with nares and pressure-sensitive mechanoreceptors (Cunningham et al. 2007) positioned on the tip of their bill. When kiwi forage for prey they use a combination of arch sniffing (Castro et al. 2010), bill hovering (Cunningham and Castro 2011), rapid tapping, probing (Cunningham et al. 2007), and to a lesser extent, audio (Cunningham et al. 2009; Cunningham and Castro 2011) for detection of soil-dwelling prey. Kiwi may be able to utilize auditory perception, olfaction, direct tactile and vibro-tactile cues selectively or in combination (Cunningham et al. 2009). As for vision, the eyes and optic tectum are reduced; in addition, the end of the bill is out the birds' field of view, negating vision as an effective prey detection sense (Martin et al. 2007).

Analysis of LSK diet revealed that although plant material is consumed (Colbourne et al. 1990; Holzapfel et al. 2008), they are obligate insectivorous selective feeders (Colbourne et al. 1990; Sales 2006). Their diet depends on availability (Kleinpaste 1990; Cunningham and Castro 2011), season (Colbourne et al. 1990), type and age of forest (Moeed and Meads 1987). Little spotted kiwi choose slow-moving invertebrates, such as annelids 
and beetle larvae, from the upper layers of the soil that generally fall within the range of 8-20 mm in length (Colbourne et al. 1990). Although this fits juvenile snout-vent length (SVL), it is unknown if LSK gape size would accommodate the SVL or girth of an adult Maud Island frog. It is also unknown if male and female LSK specialize on different types of prey (Cunningham and Castro 2011).

Although kiwi are not generally known to prey on anurans, there was an observation in Northland, New Zealand of a loose kiwi fecal sample that evidently contained the bones of the Australian introduced hylid, Litoria aurea, along with undigested remains of other food items. It was speculated that the potential toxins secreted by the amphibian resulted in quick expulsion of the gastric contents (Harris-Ching 1990). In addition, invertebrates that secrete defensive chemicals such as millipedes and staphylinid beetles have not been noted in LSK fecal analysis (Colbourne et al. 1990). These observations suggest that toxin secreting fauna like L. pakeka (Green 1988; Melzer and Bishop 2010; Melzer et al. 2011) might be unpalatable (Green 1988; Bell 2008b) and cause discomfort (Harris-Ching 1990) for LSK if consumed.

With a population of LSK well established, Zealandia also plans to continue with the establishment of a free-ranging, viable population of Leiopelma pakeka to help facilitate their mission of returning a portion of mainland New Zealand to a pre-human ecosystem. Their first effort was thought to be unsuccessful, possibly due to interactions with LSK.

This chapter aims to better understand the ecological relationship between the little spotted kiwi and the Maud Island frog within the Zealandia boundaries.

\subsection{Methods}

\subsubsection{Encounter sites}

To ascertain whether A. owenii could have contributed to the L. pakeka translocation failure within the boundaries of the Zealandia wildlife sanctuary, kiwi foraging behavior was digitally recorded during encounters with a mesh-protected Maud Island frog. Encounters were recorded each night from 23 June 2013 - 28 June 2013. Three encounter sites were chosen based on accessibility and the greatest likelihood of being visited by LSK. The sites chosen were along the Te Mahanga track just below the translocation/kiwi-exclusion study site (see chapter 4), on the south side of the Swamp track near the upper dam and Lake Road track in the vicinity of the kiwi feeding tubes.

Three plastic ice-cream containers were fitted with two lids each. One lid was unmodified. The second lid had the center cut out and was fitted with a $1.16 \mathrm{~mm}=17 / 18 \mathrm{awg}$ 
wire mesh (approx. $1.1 \mathrm{~cm}^{2}$ ) to allow for audio, visual and olfactory cues to be received by the kiwi (Fig. 3.3). Small holes were drilled in the bottom of each container for excess water drainage. A second set of three ice-cream containers with unmodified lids were used as place-holders. All equipment was cleaned using Canesten anti-fungal/antibacterial hygiene rinse.

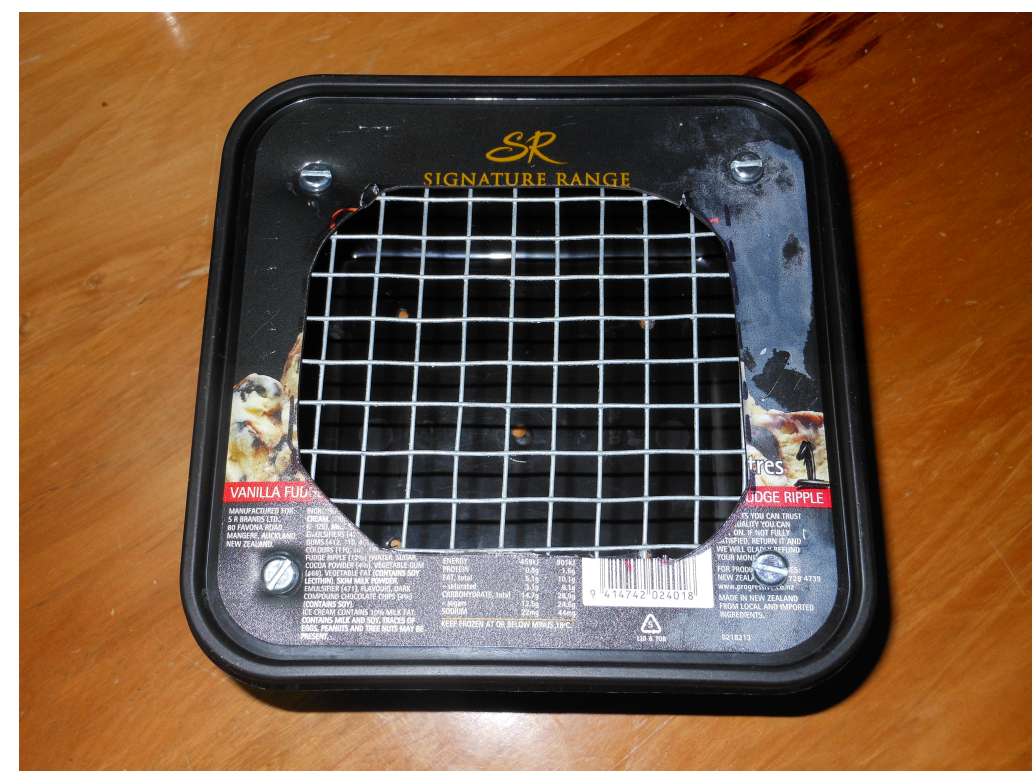

Figure 3.3: Modified lid of ice-cream container that held an individual L. pakeka which was used for the kiwi-frog encounter study.

At each location, a hole was dug and a temporary place-holder container was positioned, flush with the soil surface, to prevent the hole from filling in with debris (Fig. 3.4). Each of the three locations had two Bushnell TrophyCam night-trap cameras (model: $119436 \mathrm{c}$ ) positioned at an approximate $90^{\circ}$ angle in relation to the container. The purpose of this was two-fold; the first was to act as a back-up due to the inconsistent triggering of the cameras and second, to acquire a second angle if the first camera angle was obstructed. The cameras were strapped either to a tree or to wooden stakes. The position of the cameras and correction of field-of-view (FOV) was adjusted using an TEAC Axia monitor (model no. LCD1007). Each camera setting was as follows: video mode, $5 \mathrm{M}$ pixel, $640 \times 480$ video size, $60 \mathrm{~s}$ video duration, $2 \mathrm{~s}$ interval, high sensor level, field scan off, sound on. The distances from the cameras to the frog container were as follows: Te Mahanga track cameras, V2 and Z2 at $0.90 \mathrm{~m}$ and $0.60 \mathrm{~m}$, respectively; Swamp track cameras V4 and Z1 at $0.85 \mathrm{~m}$ and $1.30 \mathrm{~m}$, respectively; Lake Road track cameras V1 and V3 at $1.00 \mathrm{~m}$ and $0.70 \mathrm{~m}$, respectively. 


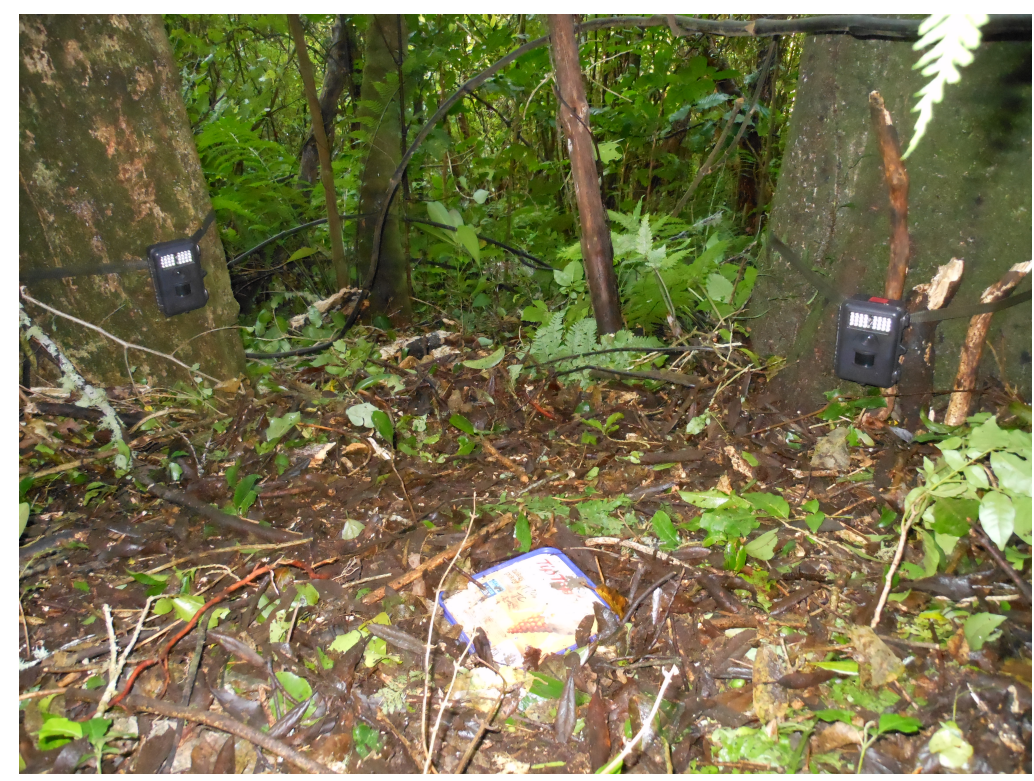

FIGURE 3.4: Kiwi-frog encounter site with one place-holder container and two Bushnell TrophyCam cameras.

Each evening, from 23-27 June 2013 (1530-1735 h), at each site chosen, the place-holder containers were exchanged with the containers containing a frog and the unmodified lid was exchanged with the mesh lid. The containers were placed in the ground with the top of the container flush with the substrate. If necessary, the Secured Digital (SD) cards were loaded back into the cameras and all cameras were turned on and set up.

During each collection from 24-28 June 2013 (0835-0945 h), each SD card in the Bushnell TrophyCam cameras were removed for video download. The wire-mesh lids were exchanged with the unmodified lids. Each container containing a frog was exchanged with a place-holder container. The containers with the frogs were taken back to the original enclosure site and each frog's general health and weight was recorded after which, they were returned to their respective containers and stored in a secured, covered box.

Videos were reviewed and video-frame snapshots were taken with VLC media player on an Apple MacBook Pro OS X (v. 10.7.5).

\subsubsection{Frog monitoring}

On 22 June 2013 at 2030 hours (h), three adult frogs (B14, B12 \& M28) were collected from the original predator-proof enclosure, weight and visual condition were recorded. They were placed in separate, numbered ice-cream containers with an unmodified lid containing damp leafy substrate and kept on site to ensure appropriate climate conditions (Ben Bell, pers. comm.). Each frog stayed in the same container for the duration of the experiment and was allocated to one location only. Frog health was monitored by 
weight and observation of general condition (i.e. activity and injury). Each frog was weighed twice per day prior to, and post kiwi-frog encounters (with the exception of 23 June 2013).

Upon completion of the experiment, the frogs were weighed for a final time, condition was visually assessed and they were returned to the location found in the original enclosure.

\subsection{Results}

Results are discussed per location and camera. There are three types of videos: 1.) those triggered by LSK and have LSK in the video segment; 2.) those triggered by non-kiwi which recorded actions such as Zealandia workers or diurnal bird foraging; 3.) empty videos in which the camera was triggered to start recording, but the source of the trigger was not apparent. The set-up process for the kiwi-frog encounter sites took place prior to the closing of Zealandia daytime visiting hours (1700 h). For dates, times and summaries of videos recorded, see Appendix C.

\subsubsection{Te Mahanga track encounter site}

Frog B14 was allocated to the Te Mahanga kiwi-frog encounter site. The site was located to the east of the L. pakeka translocation site and within the territory of one pair of kiwi (Andrew Digby pers. comm.). The site was set up by $1640 \mathrm{~h}$ each evening and collected by $0945 \mathrm{~h}$ the following morning.

Videos captured overnight from 23-28 June 2013 by camera V2 had two videos that were triggered by LSK, five videos that were triggered by non-kiwi and six videos that were empty, resulting in a total of 13 videos. Videos captured overnight from 23-28 June 2013 by camera Z2 had two videos that were triggered by LSK, one video that was triggered by non-kiwi and two videos that were empty, resulting in a total of five videos. A total of 18 videos were recorded between the two cameras (Table 3.1).

Cameras V2 \& Z2 were triggered by a LSK just after $0630 \mathrm{~h}$ on 25 June 2013. The video from camera V2 (Fig. 3.5) shows a LSK entering the FOV from north (Fig. 3.5.B) traveling south through the encounter site, probing the leaf litter (Fig. 3.5.C-D). As it forages, the kiwi passes its bill in close proximity over the top on the frog container and appears to probe immediately adjacent to the edge of the container (Fig. 3.5.E), leaving the FOV (Fig. 3.5.H) 15 seconds into the video. The LSK re-enters and exits the FOV at $48 \mathrm{~s}$, but well away from the frog container. The corresponding video from camera Z2 (Fig. 3.6) is triggered by the kiwi just as it probes in close proximity to the 
Te Mahanga track - Frog B14

\begin{tabular}{|c|c|c|c|c|c|}
\hline Date set & Camera & $\begin{array}{l}\text { Triggered } \\
\text { by kiwi }\end{array}$ & $\begin{array}{l}\text { Triggered } \\
\text { by non- } \\
\text { kiwi }\end{array}$ & $\begin{array}{l}\text { Empty } \\
\text { clips }\end{array}$ & $\begin{array}{l}\text { Total } \\
\text { videos }\end{array}$ \\
\hline \multirow[t]{2}{*}{23.06 .2013} & V2 & 0 & 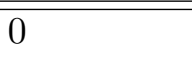 & 0 & 0 \\
\hline & Z2 & 0 & 0 & 0 & 0 \\
\hline \multirow[t]{2}{*}{24.06 .2013} & V2 & 1 & 0 & 1 & 2 \\
\hline & Z2 & 1 & 0 & 0 & 1 \\
\hline \multirow[t]{2}{*}{25.06 .2013} & V2 & 0 & 3 & 2 & 5 \\
\hline & $\mathrm{Z} 2$ & 0 & 0 & 0 & 0 \\
\hline \multirow[t]{2}{*}{26.06 .2013} & V2 & 1 & 2 & 3 & 6 \\
\hline & Z2 & 1 & 0 & 2 & 3 \\
\hline \multirow[t]{2}{*}{27.06 .2013} & $\mathrm{~V} 2$ & 0 & 0 & 0 & $0^{*}$ \\
\hline & $\mathrm{Z} 2$ & 0 & 1 & 0 & 1 \\
\hline Total & & 4 & 6 & 8 & 18 \\
\hline
\end{tabular}

TABLE 3.1: A quantitative summary of video clips from cameras V2 \& Z2 from the kiwi-frog encounter along the Te Mahanga track with frog B14 recorded throughout the night from 23-27 June 2013. * denotes camera malfunction.

frog container (Fig. 3.6.B), quickly passing in and out of the FOV. At $15 \mathrm{~s}$ the kiwi quickly passes in and out of the FOV immediately in front of the camera obstructing the view (approx. $0.5 \mathrm{~m}$ away from the frog container). From 30-43 s, multiple taps can be heard, and appears that the kiwi is investigating the camera, or the immediate surrounds of the camera.

Cameras V2 \& Z2 were triggered by a LSK at $0112 \mathrm{~h}$ on 27 June 2013. The video from camera V2 (Fig. 3.7) shows a LSK traveling from south to north through the encounter site, stopping twice to spend time foraging in one spot. The LSK first stops to forage just inside the bottom left hand corner of the FOV (Fig. 3.7.B, duration approx. 14 s) and moves to the bottom center of the FOV to foraging in one spot (16-30 s), bill flicking (Cunningham and Castro 2011) at $28 \mathrm{~s}$ (Fig. 3.7.C), after by which the LSK continues to forage away from the frog container, eventually moving out of frame at 30 s. The corresponding camera, Z2 (Fig. 3.8), shows a kiwi obstructing the entire frame upon the start of the video and moving out of the FOV at $1 \mathrm{~s}$. The kiwi enters back in the FOV at $43 \mathrm{~s}$, foraging through the leaf litter, away from the frog container, and exiting the encounter site out of the FOV at $55 \mathrm{~s}$ (Fig. 3.8.B). 


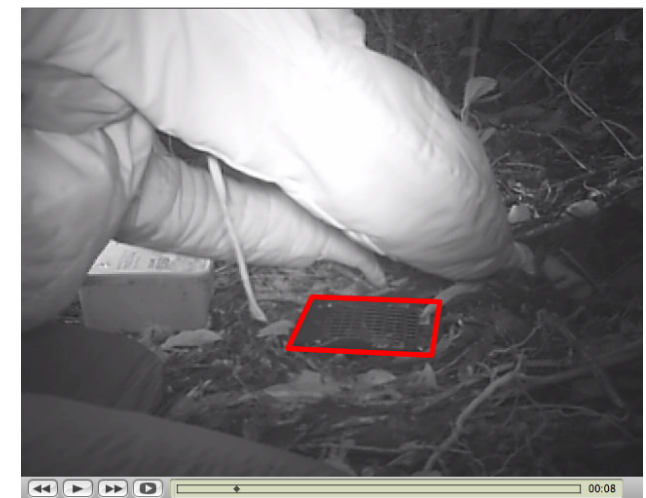

A.

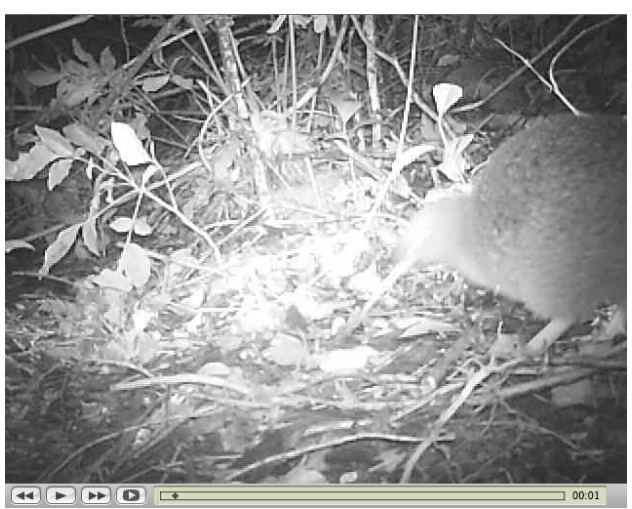

C. $1 \mathrm{~s}$

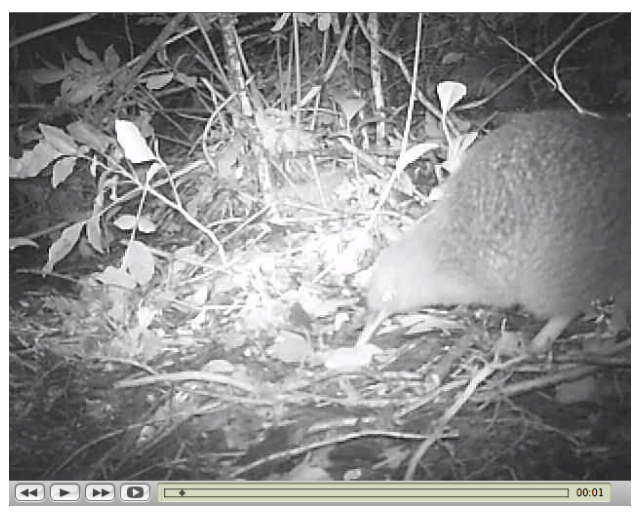

E. $1 \mathrm{~s}$

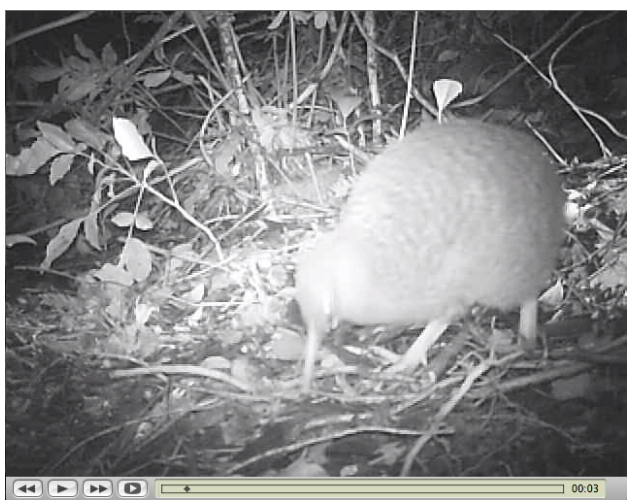

G. $3 \mathrm{~s}$

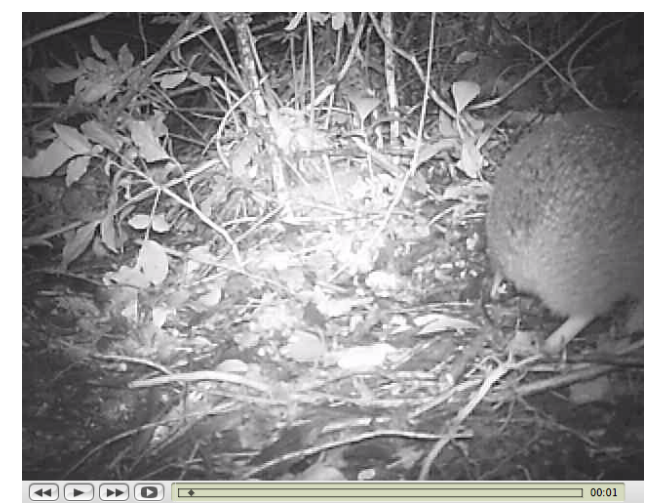

B. $1 \mathrm{~s}$

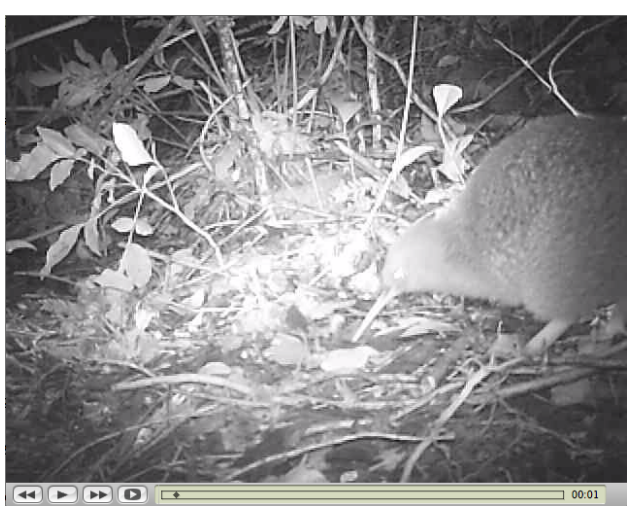

D. $1 \mathrm{~s}$

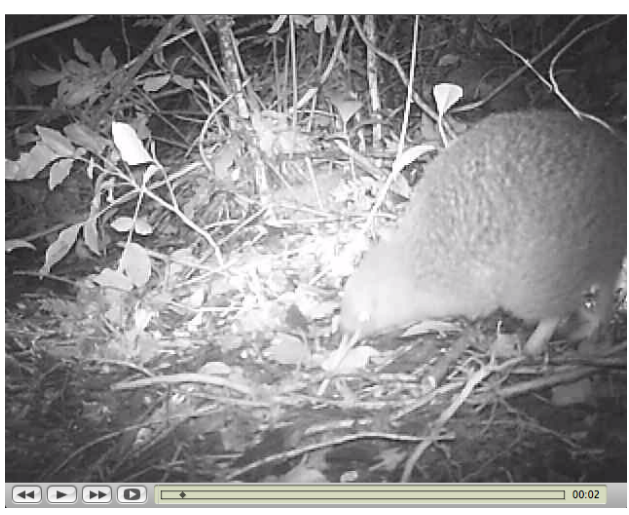

F. $2 \mathrm{~s}$

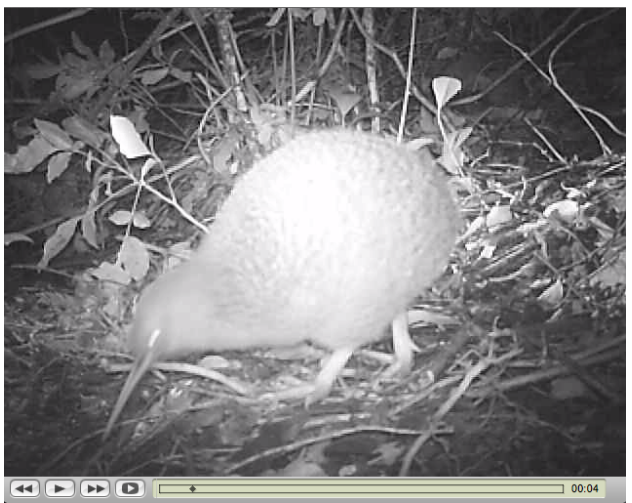

H. $4 \mathrm{~s}$

Figure 3.5: Video frames from kiwi-frog encounter captured on 25 June 2013 at $0632 \mathrm{~h}$, camera V2, along the Te Mahanga track. A. Reference image for position of frog container, outlined in red (separate video from LSK images). B-H. LSK probing as it forages in and out of the FOV. Note E, LSK appears to probe immediately adjacent to the frog container. 


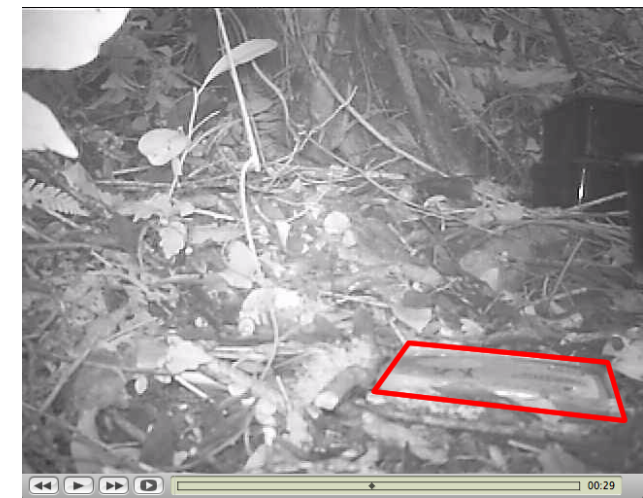

A.

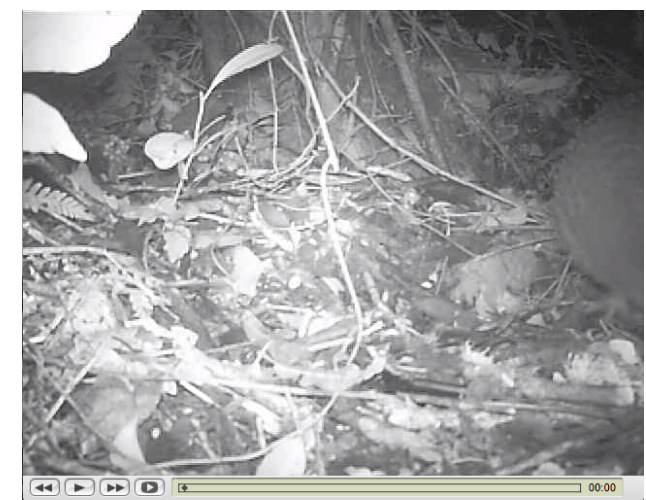

B. 0 s. LSK, right edge of the frame.

FiguRE 3.6: Video frames from kiwi-frog encounter video captured on 25 June 2013 at $0631 \mathrm{~h}$, camera Z2, along the Te Mahanga track. A. Reference image for position of frog container, outlined in red (separate video from LSK images). B. LSK in FOV foraging in close proximity to the frog container.

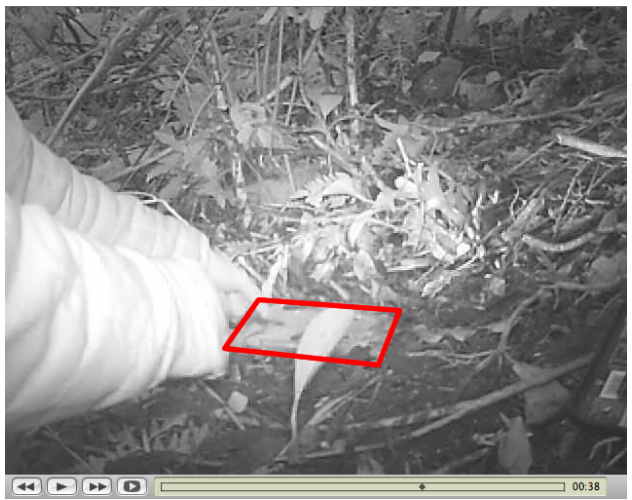

A.

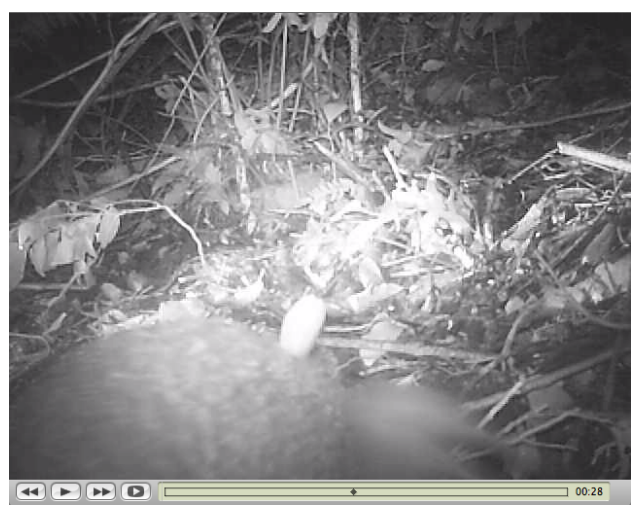

C. $28 \mathrm{~s}$

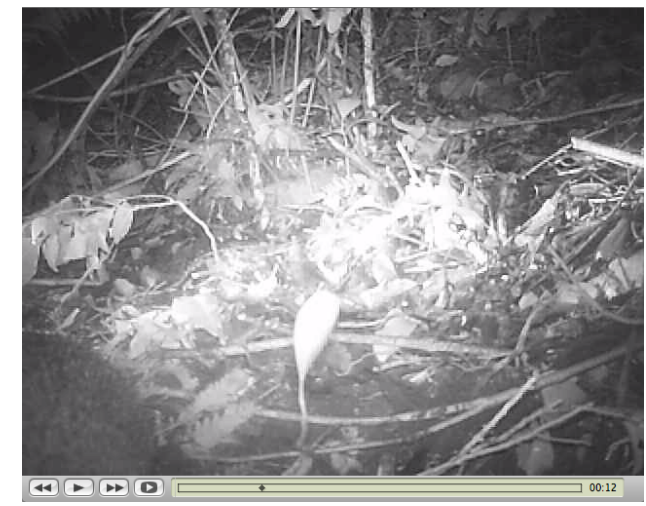

B. $12 \mathrm{~s}$. LSK, left corner of the frame.

FiguRE 3.7: Video frames from kiwi-frog encounter video captured on 27 June 2013 at $0112 \mathrm{~h}$, camera V2, along the Te Mahanga track. A. Reference image for position of frog container, outlined in red (separate video from LSK images). B-C. LSK foraging and 'bill flicking' away from the frog container. 


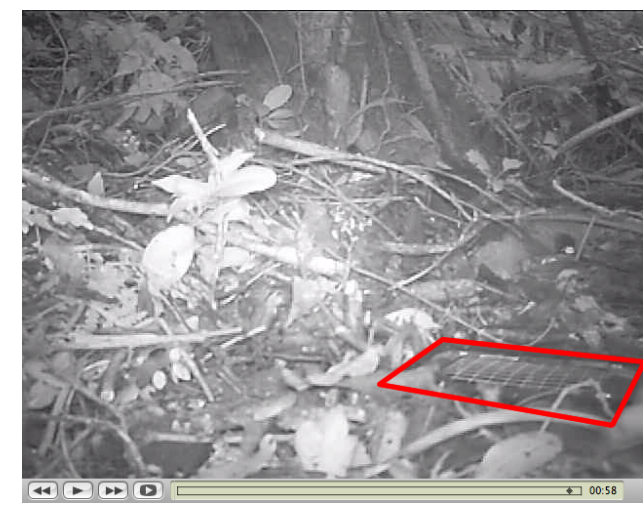

A.

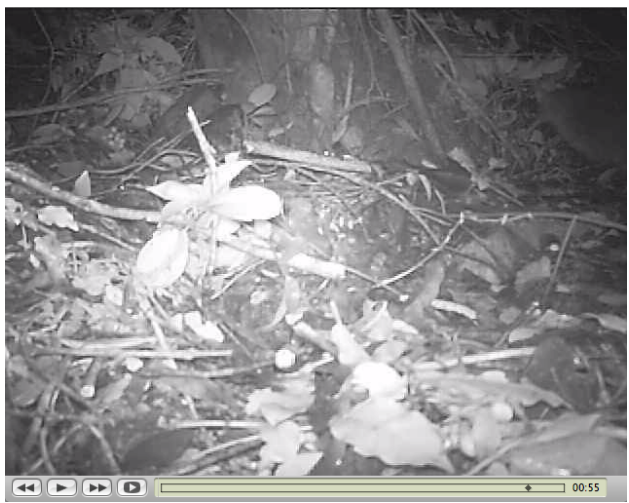

B. $55 \mathrm{~s}$. LSK, top right edge of the frame.

FiguRE 3.8: Video frames from kiwi-frog encounter video captured on 27 June 2013 at $0112 \mathrm{~h}$, camera Z2, along the Te Mahanga track. A. Reference image for position of frog container, outlined in red (separate video from LSK images). B. LSK exiting the encounter site. Note: LSK is difficult to see and is at the top right edge of the frame.

\subsubsection{Swamp track encounter site}

Frog M28 was allocated to the Swamp track kiwi-frog encounter site. The site was located on south side of the Swamp track, in the territory of one pair of kiwi and approximately $10 \mathrm{~m}$ uphill from a frequently used LSK burrow (Andrew Digby pers. comm.). The site was set up for the kiwi-frog encounter by $1735 \mathrm{~h}$ each evening and collected by $0945 \mathrm{~h}$ the following morning.

Videos captured overnight from 23-28 June 2013 from camera V4 had 2 videos that were triggered by LSK, 1 video that was triggered by non-kiwi and 139 videos that were empty, resulting in a total of 142 videos. Camera Z1 malfunctioned during the week of 23-28 June 2013 therefore, no videos were capture. A total of 142 videos were recorded between the two cameras (Table 3.2). 
Swamp track - Frog M28

\begin{tabular}{llllll}
\hline Date set & Camera & $\begin{array}{l}\text { Triggered } \\
\text { by kiwi }\end{array}$ & $\begin{array}{l}\text { Triggered } \\
\text { by non- } \\
\text { kiwi }\end{array}$ & $\begin{array}{l}\text { Total } \\
\text { videos }\end{array}$ & videos \\
\hline \hline 23.06 .2013 & V4 & 0 & 0 & 48 & 48 \\
& Z1 & 0 & 0 & 0 & $0^{*}$ \\
24.06 .2013 & V4 & 2 & 1 & 28 & 31 \\
& Z1 & 0 & 0 & 0 & $0 *$ \\
25.06 .2013 & V4 & 0 & 0 & 54 & 54 \\
& Z1 & 0 & 0 & 0 & $0^{*}$ \\
26.06 .2013 & V4 & 0 & 0 & 7 & 7 \\
& Z1 & 0 & 0 & 0 & 0 \\
27.06 .2013 & V4 & 0 & 0 & 2 & 2 \\
& Z1 & 0 & 0 & 0 & 0 \\
\hline Total & & 2 & 1 & 139 & 142 \\
\hline
\end{tabular}

TABLE 3.2: A quantitative summary of video clips from cameras V1 \& V3 from the kiwi-frog encounter along the Swamp track with frog M28 throughout the night from 23-27 June 2013. * denotes camera malfunction.

On 24 June 2013 at $1753 \mathrm{~h} \& 1754 \mathrm{~h}$ camera V4 was triggered by a single LSK. The video starting at $1753 \mathrm{~h}$ (images not shown) shows a LSK approaching the encounter site from down hill. The LSK turns to the right at 4 seconds and is half in (posterior end)/half out of the FOV, never approaching the frog container. The LSK exits the FOV at $30 \mathrm{~s}$. The video starting at $1754 \mathrm{~h}$ (Fig. 3.9) shows a LSK already in the frame as the camera was triggered to start recording (Fig. 3.9.B). As the LSK foraged and probed the leaf litter, it approached the frog container and appeared either to probe into the container or immediately adjacent to the container (1 s) (Fig 3.9.C). At $2 \mathrm{~s}$, the LSK withdrew its bill and turned to exit the encounter site the way it approached (Fig. 3.9.D), leaving the FOV at $8 \mathrm{~s}$. 


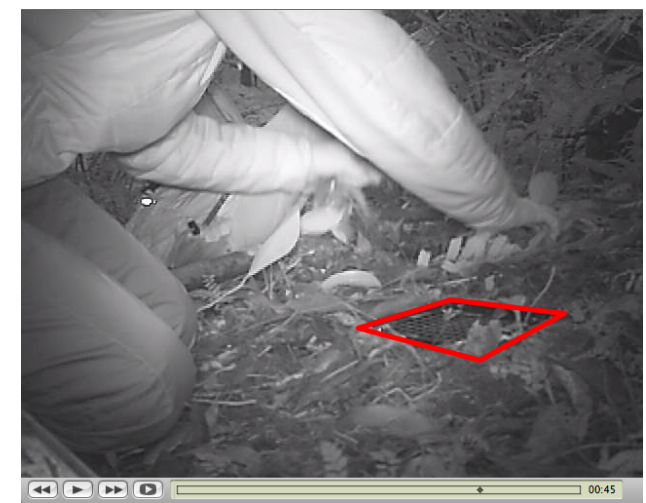

A.

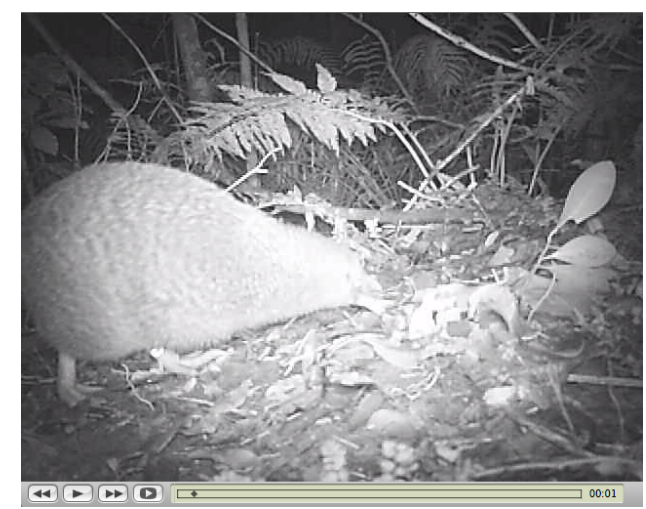

C. $1 \mathrm{~s}$

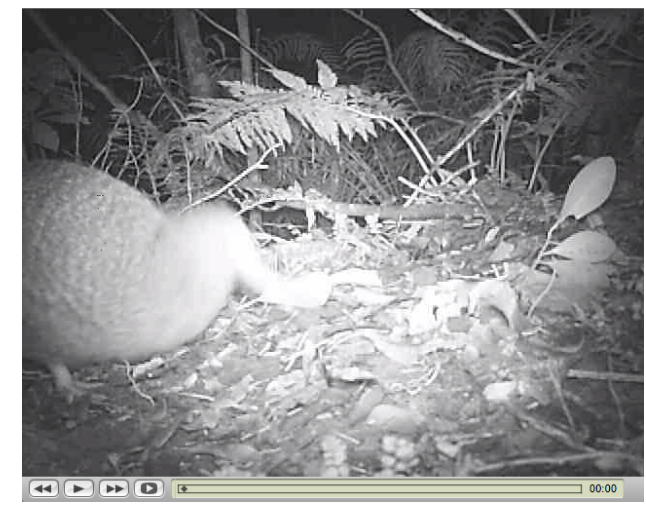

B. $0 \mathrm{~s}$

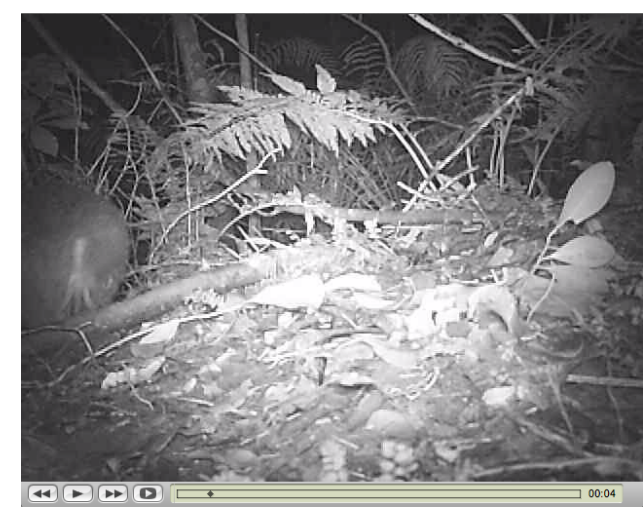

D. $4 \mathrm{~s}$

FiguRE 3.9: Video frames from kiwi-frog encounter video captured on 24 June 2013 at $1753 \mathrm{~h}$, camera V4, along the Swamp track. A. Reference image for position of frog container, outlined in red (separate video from LSK images). B-D. LSK approach, seemingly to probe the frog container (C), and retreat from the encounter site.

On 25 June 2013 at 0350 h, camera V4 was apparently triggered to record by a rodent (image not shown), mostly likely Mus musculus (Bernard Smith pers. comm.). The rodent is only in the FOV for $2 \mathrm{~s}$. The start of the video shows the rodent climbing over a horizontal root that was approximately $12.2 \mathrm{~cm}$ in circumference.

\subsubsection{Lake Road track encounter site}

Frog B12 was allocated to the Lake Road kiwi-frog encounter site. The site was located along side the Lake Road track just to the north of the feeding tubes, at the junction of four kiwi-pair territories (Andrew Digby pers. comm.). The site was set up for the kiwi-frog encounter by $1720 \mathrm{~h}$ each evening and collected by $0920 \mathrm{~h}$ the following morning.

Videos captured overnight from 23-28 June 2013 from camera V1 had 5 videos triggered by LSK, 19 videos that were triggered by non-kiwi and 5 empty videos, resulting in a 
total of 29 videos. Videos captured overnight from 23-28 June 2013 from camera V3 had 9 videos triggered by LSK, 22 videos that were triggered by non-kiwi and 448 empty videos, resulting in a total of 479 videos. A total of 508 videos were recorded between the two cameras (Table 3.3).

Lake Road track - Frog B12

\begin{tabular}{|c|c|c|c|c|c|}
\hline Date set & Camera & $\begin{array}{l}\text { Triggered } \\
\text { by kiwi }\end{array}$ & $\begin{array}{l}\text { Triggered } \\
\text { by non- } \\
\text { kiwi }\end{array}$ & $\begin{array}{l}\text { Empty } \\
\text { videos }\end{array}$ & $\begin{array}{l}\text { Total } \\
\text { videos }\end{array}$ \\
\hline \multirow[t]{2}{*}{23.06 .2013} & $\mathrm{~V} 1$ & 0 & 0 & 2 & 2 \\
\hline & V3 & 1 & 2 & 119 & 122 \\
\hline \multirow[t]{2}{*}{24.06 .2013} & $\mathrm{~V} 1$ & 0 & 7 & 1 & 8 \\
\hline & $\mathrm{V} 3$ & 4 & 2 & 90 & 96 \\
\hline \multirow[t]{2}{*}{25.06 .2013} & $\mathrm{~V} 1$ & 1 & 2 & 0 & 3 \\
\hline & V3 & 0 & 2 & 132 & 134 \\
\hline \multirow[t]{2}{*}{26.06 .2013} & V1 & 1 & 3 & 2 & 6 \\
\hline & $\mathrm{V} 3$ & 0 & 3 & 54 & 57 \\
\hline \multirow[t]{2}{*}{27.06 .2013} & $\mathrm{~V} 1$ & 3 & 7 & 0 & 10 \\
\hline & $\mathrm{V} 3$ & 4 & 13 & 53 & 70 \\
\hline Total & & 14 & 41 & 453 & 508 \\
\hline
\end{tabular}

TABLE 3.3: A quantitative summary of video clips from cameras V1 \& V3 from the kiwi-frog encounter along the Lake Road track with frog B12 throughout the night from 23-27 June 2013

Video clips that were triggered by LSK from 23 June 2013 through to the morning of 24 June 2013 showed LSK foraging in the background of the encounter site (except camera V3 on 23 June 2013 at $2112 \mathrm{~h}$ which shows LSK obstructing the FOV by foraging directly in front of the camera and quickly leave the FOV within $1 \mathrm{~s}$ of the video), with no indication of interest in the frog container (forages within $1 \mathrm{~m}$ of the frog container). This was the same for one video captured by camera V3 (0516 h) on 28 June 2013. Camera V1 on 26 June 2012 at 1812 h showed a LSK either probing or tapping the soil less than $0.5 \mathrm{~m}$ away from the frog container with no indication of interest. No images shown.

On 27 June 2013 at $1740 \mathrm{~h}$ and $1742 \mathrm{~h}$ cameras V1 and V3, respectively, were triggered by a LSK. Camera V1 (1740 h) (no images shown) showed a posterior view of a LSK, which obstructed the view of the frog container. The LSK approached the frog container (at $32 \mathrm{~s}$ ) and with its back facing the camera, foraged adjacent to the container for 20 
$\mathrm{s}$ and then moves to the right of the container and continues out of the FOV. A key point to mention, after the kiwi moves to the right of the container, frog activity in the container is apparent. Camera V3 (1742 h) (Fig. 3.10) showed a LSK in the FOV at the start of the video. The LSK remained foraging in one patch of soil for $13 \mathrm{~s}$ with surface probes (Fig. 3.10.A), bill flicking (Fig. 3.10.B) and deep soil probes (Fig. 3.10.C). At $14 \mathrm{~s}$, the LSK shifts to the right corner for $2 \mathrm{~s}$ to probe the substrate (Fig. 3.10.D) and then quickly moves its bill directly over the frog container (Fig. 3.10.E), and appears to probe into the container (Fig. 3.10.F), after which the LSK withdraws its bill to forage along side the frog container (Fig. 3.10.G \& H) and at $27 \mathrm{~s}$ begins to walk away from the frog container while foraging.

Video captured at $2250 / 2251 \mathrm{~h}$ on cameras V1/V3, respectively, show a small LSK approach the frog container, jump back (at $5 \mathrm{~s}$ ) and make a hasty retreat. The video captured on camera V3 on 28 June 2013 at 0252 h shows a LSK entering the FOV from the left, soil probing. No images shown.

\subsubsection{Frog condition}

Upon collection from the original predator-proof enclosure each frog was active, appeared to be in good condition and weighed $9.2 \mathrm{~g}$ (B14), $11.2 \mathrm{~g}$ (B12) and $7.0 \mathrm{~g}$ (M28). Figure 3.11 shows morning and evening weights per date (omitting weights for 23 June). All three frogs fluctuated in weight, gaining and losing weight during the daylight and overnight hours. During morning monitoring, each frog appeared to exhibit reduced activity, presumably due to low overnight temperatures, with no apparent injuries. The following evening health monitoring, each frog was considerably more active and appeared to maintain good health. 


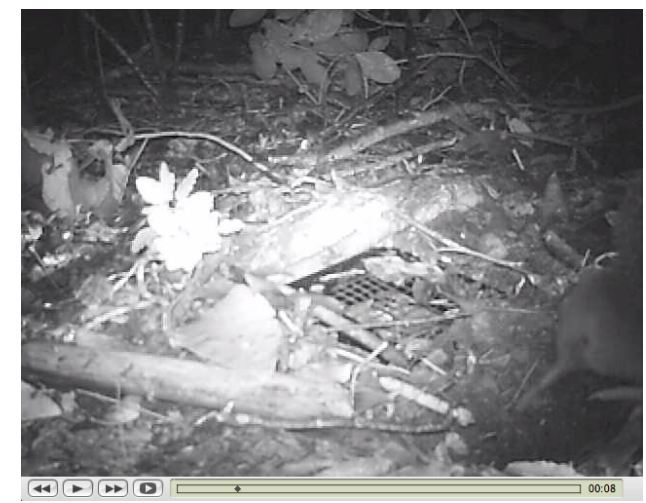

A. $8 \mathrm{~s}$

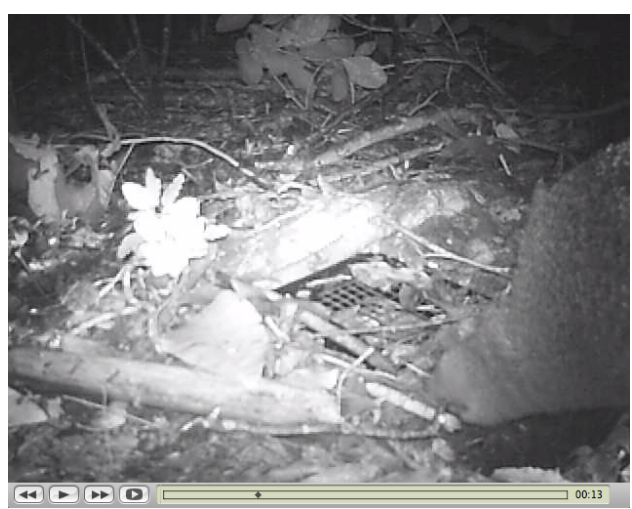

C. $13 \mathrm{~s}$

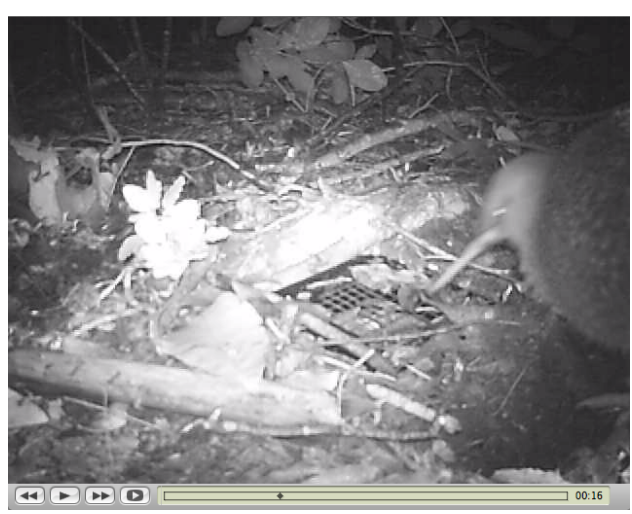

E. $16 \mathrm{~s}$

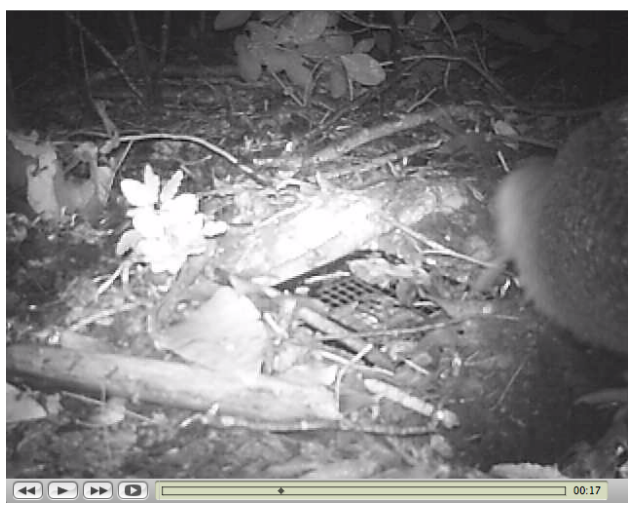

G. $17 \mathrm{~s}$

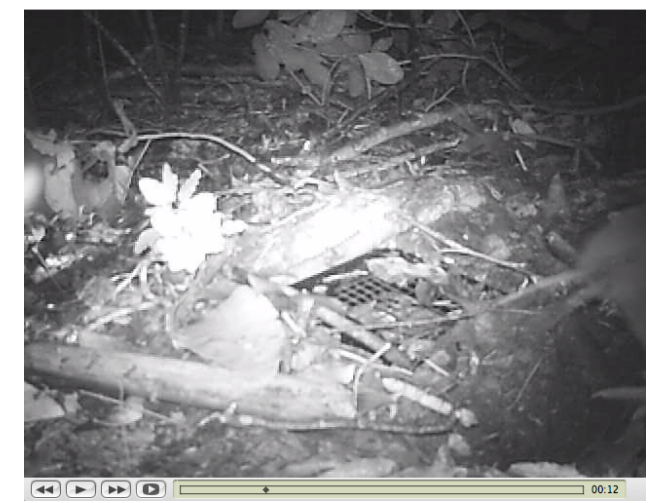

B. $12 \mathrm{~s}$

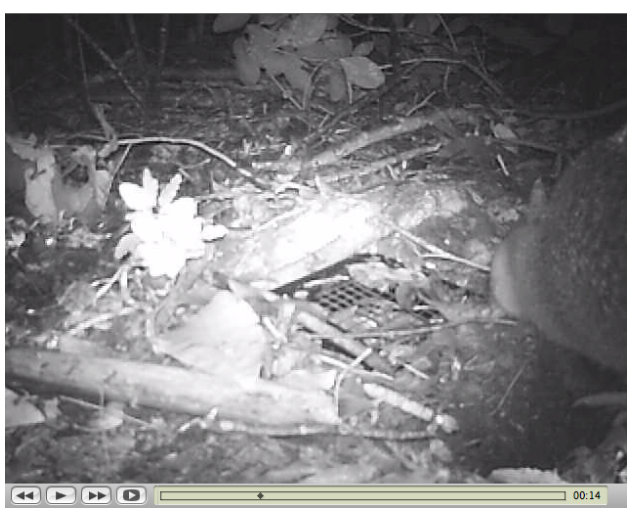

D. $14 \mathrm{~s}$

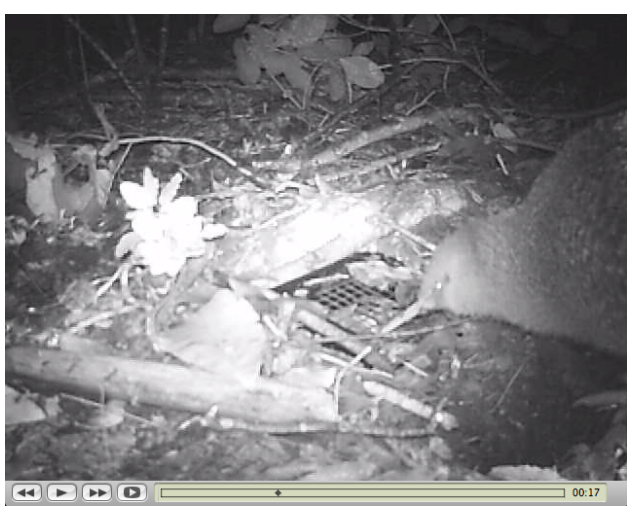

F. $17 \mathrm{~s}$

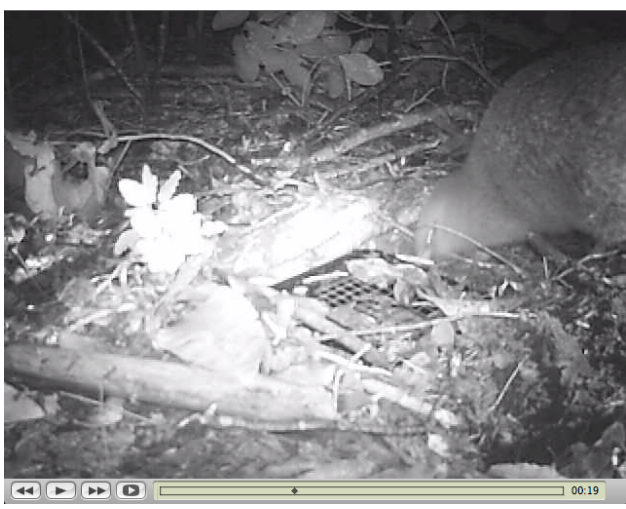

H. $19 \mathrm{~s}$

Figure 3.10: Video frames from kiwi-frog encounter video captured on 27 June 2013 at $1742 \mathrm{~h}$, camera V3, along the Lake Road track. A. Reference image for position of frog container (separate video from LSK images). B-H. LSK foraging around the frog container. Note F, LSK appears to probe into the frog container. Total duration of the frames is $11 \mathrm{~s}$. 
After the final collection on the morning of 28 June 2013 the frogs weighed $8.6 \mathrm{~g}, 10.1 \mathrm{~g}$ and $6.7 \mathrm{~g}$ and lost $0.8,1.1,0.5 \mathrm{~g}$, respectively. Weight fluctuations were not compared to weight fluctuations of frogs from the original enclosure due to this experiment taking place in between emergence monitoring and the request to minimize disturbance in between monthly emergence monitoring of the enclosure.

The substrate in all of the encounter sites remained damp to wet for the duration of the experiment. The total rainfall for the week of 23-28 June was approximately $17 \mathrm{~mm}$ with no rainfall on 23 June and 26 June 2013.

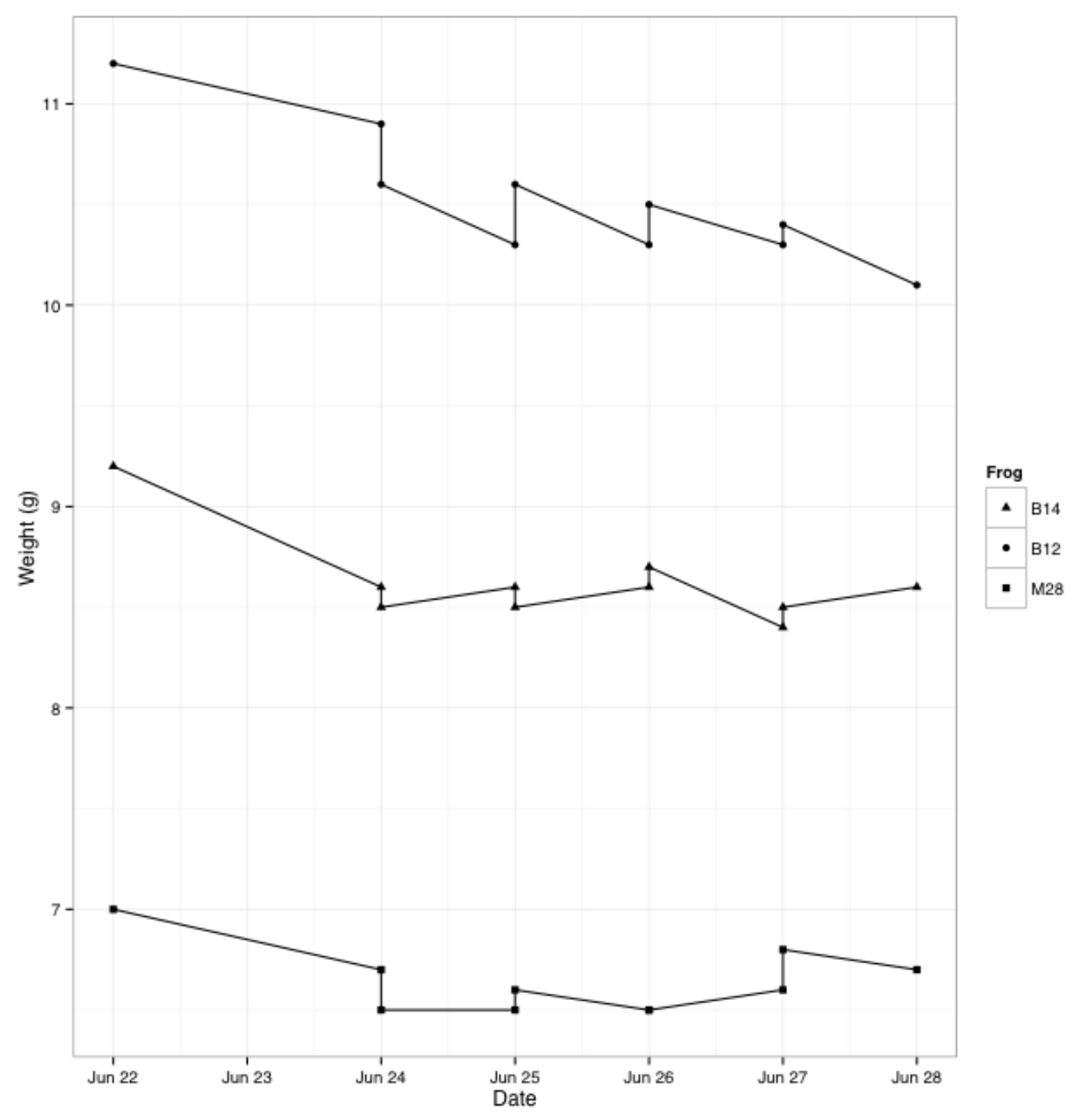

FiguRE 3.11: Weight of each L. pakeka for the duration of the kiwi-frog encounters. 


\subsection{Discussion}

The aim of this study was to investigate the possibility that LSK contributed to the population decline of the 2006/2007 Maud Island frog translocation into the Zealandia wildlife sanctuary. To gain this insight, LSK behavior was recorded while foraging in the presence of a Maud Island frog and the videos were analyzed for any interest and/or predatory behavior toward the frog.

Of the 20 videos that recorded LSK foraging in and around the encounter sites, approximately half showed LSK foraging around the frog containers and only three videos provided foraging behavior that could be used to help determine if LSK have an interest in L. pakeka as a potential prey item. Two videos (recorded on $24 \& 25$ June on the Swamp and Te Mahanga tracks, respectively) show, at minimum, a LSK foraging immediately adjacent to the frog container. This close proximity would possibly allow olfactory cues of the frog to be received by the kiwi. The most compelling video was the 27 June recording along the Lake Road track. The video shows that the LSK clearly detects a prey item in the soil immediately adjacent to the frog container and spends an ample amount of time and effort to exhume the prey. The time spent exhuming the prey compared to the quick passing over, and possibly into the frog container, does not indicate a strong behavioral response by the LSK toward the frog. If the LSK detected the frog as a prey item, I would expect a greater effort by the LSK to obtain the frog. This clear lack of effort leads me to question LSK olfactory sensitivity to L. pakeka chemical cues.

What are the chances that a LSK would encounter L. pakeka and eat it? Kiwi foraging skills and prey detection have evolved to detect their primary prey, soil-dwelling invertebrates. With vision not a reliable method, prey detection is left to auditory, direct/remote (vibro-tactile) touch and olfaction. The rocky habitat, which the frogs prefer, would suggest that it is not conducive to the prey detection sensory system of the kiwi. The frogs are sedentary and although they do transverse across the substrate, vibro-tactile cues propagating through the soil would be limited. Auditory cues would also be minimal due to Leiopelma not being overly vocal. Because of this, a kiwi that would encounter a frog would most likely be by chance via direct touch, while foraging for their normal invertebrate prey. The cryptic, freezing defense mechanism of L. pakeka could possibly lead the kiwi to think the frog is non-organic. Additionally, Maud Island frogs are able to give a defensive chirp which may startle the kiwi causing it to retreat. This could possibly be the explanation for the 27 June recording at the Lake Road track encounter site of a small LSK approaching the frog container, jumping back and quickly retreating. Alternatively, this reaction could have potentially been caused by defensive 
secretions emitted by the frog (Melzer et al. 2011) registering as noxious or offensive to the LSK.

Weight fluctuations of the three frogs used in the experiment could potentially be a representation of normal daily fluctuations as a result of variation in vegetation density and moisture related factors. Variation in vegetation density and proximity to foot-paths could have influenced the relative humidity inside each of the containers. This in turn, could have varied the natural water balance of the amphibians (Cree 1985). As for frog stress, holding frogs in a container, sometime in multiples, is a common practice during collection and transportation. Although capture and handling has been documented to increase the stress hormone corticosterone in amphibians (Narayan et al. 2011), the interactive activity between the frog and LSK during the overnights were limited at each encounter site.

This study is limited by the small sample size. Only three encounter sites were set up within six territories with the potential of catching A. owenii foraging behavior. Within those six territories there was the potential of 11 LSK encountering the frog container (Andrew Digby pers. comm.). Foraging observations therefore need to be interpreted with caution. The foraging behavior recorded does not indicate foraging behavior of all Apteryx species. The LSK in Zealandia do not seem to exhibit neophobia, demonstrated by the inquisitive probing for food around the cameras and frog containers, but this could be due to the LSK becoming accustomed to the consistent alterations in Zealandia.

To my knowledge, putting kiwi and an endemic frog together for observation has not previously been explored. Albeit, it is a limited interaction due to the frog being protected by a container, recording the foraging behavior of $A$. owenii during an encounter with L. pakeka is a novel method to better ascertain the behavioral interactions between the two species. This study could also be used as a baseline for future research in this area. With the assumption that the recorded foraging behavior applies to all the LSK in Zealandia, this study indicates that $A$. owenii living within the Zealandia boundaries do not indicate a predatory interest in L. pakeka.

This exploratory study warrants further research for a more conclusive ascertainment of the ecological interactions between any Apteryx and Leiopelma species via a more direct encounter (i.e. without barriers) between the two species. Animal ethics would have to be carefully considered, but to be able to definitively answer the question, and to be able to provide a great contributing factor to the conservation of both taxa, calculated risks may be necessary. 


\section{Chapter 4}

\section{Leiopelma pakeka survival with sympatric house mice in Zealandia}

\subsection{Introduction}

\subsubsection{Mice in New Zealand}

The house mouse, Mus musculus (Rodentia: Muridae), was first introduced to New Zealand nearly 190 years ago via ship wreck, which landed them on Ruapuke Island off the southern coast of the South Island. Their ability to disperse quickly and adapt to a wide variety of environments enabled them to rapidly spread up through the South Island (Miller and Webb 2001) to the North Island by 1900s (King 1990).

Mice are primarily nocturnal (King 1990), opportunistic omnivores that mainly feed on invertebrates and plant material (Miller and Webb 2001). With their voracious appetites, mice have presented as a predatory threat to a variety of New Zealand fauna such as New Zealand's inanga eggs (Galaxias maculatus) (Baker 2006), McGregor's skink (Cyclodina macregori), and the Cook Straight giant weta (Deinacrida rugosa) (Newman 1994).

The two mainland native frog species, Archey's frog (Leiopelma archeyi) and Hochstetter's frog (L. hochsterreri) (Anura: Leiopelmatidae) manage to survive while under the constant threat of predation (Bell et al. 2004a). However, the survival of the Hamilton's frog (L. hamiltoni) on Stephen's Island and the Maud Island frog (L. pakeka) on 
Maud Island, both in the Marlborough Sounds, have been contributed to the islands' mammal-free status (Stephenson 1961; Towns et al. 2001; Bell 2011a).

The rapid adaptability of mice to exploit various methods of dispersal has allowed mice to invade many New Zealand islands (Miller and Webb 2001; Russell and Clout 2005). A mouse incursion in 2000 added Maud Island to that list (Ward 2000). Eradication was evidently swift, but re-invasion remained a constant threat to the remnant population of the Nationally Vulnerable (Newman et al. 2010) amphibian. The survival of the species is once again threatened by the most recent invasion of mice on Maud Island in November 2013 (Department of Conservation 2013b). Previous evidence has shown predation of the endemic L. archeyi (Thurley and Bell 1994) and the introduced Litoria raniformis by ship rats (Rattus rattus) (Egeter et al. 2011), but to date, there has been no conclusive evidence of mice preying on a Leiopelma species. An assessment of the potential predatory risk of mice is crucial to the survivability of the Maud Island frog and other Leiopelma species.

\subsubsection{Zealandia wildlife sanctuary, mice and frogs}

The Zealandia wildlife sanctuary in Wellington, New Zealand has a 500 year goal of restoring a piece of mainland New Zealand, as close as possible, to a pre-human ecosystem (Campbell-Hunt 2002). To assist with their conservation goals, in 1999, a 2.2 $\mathrm{m}$ high, $8.6 \mathrm{~km}$ predator-proof fence was erected encompassing 225 ha of the sanctuary. Once the fence was complete, an extensive trapping and Brodifacoum ${ }^{\mathrm{TM}}$ mammal eradication program was initialized and Zealandia was declared mammalian pest-free in January 2000 (Zealandia 2012; Campbell-Hunt 2002). Although the fence was designed to abate non-native mammalian predator invasion, there have been biosecurity breaches. Zealandia's active pest monitoring program has detected mustelids (Mustela spp.) in 2004, 2008 and 2012 and ship rats, (Rattus rattus) in 2008 and 2010 (Zealandia, unpub. data). The detection of the breaches was quick and all invaders were successfully eradicated. On the contrary, through fence imperfections and possibly even birds losing their grasp of prey over the sanctuary (R. Empson, pers. comm.), mice were able to re-invade and re-establish in the sanctuary (Zealandia, unpub. data). To monitor and control mouse densities, Zealandia employs the use of approximately 90 trap index lines throughout the sanctuary (Bernard Smith pers. comm.) in conjunction with an annual Brodifacoum $^{\mathrm{TM}}$ bait drop during peak mouse population densities (Lukis 2009).

To date, over 40 native and endemic flora and fauna species have been re-introduced into the valley where Zealandia is located (Zealandia, unpub. data). The re-introduction of native frogs (i.e. Maud Island frog, L. pakeka and potentially Hochstetter's frog, L. 
hochstetteri) has been identified as an integral component of the ecosystem restoration goals (Karori Sanctuary Trust 2000). In 2006/2007, Zealandia re-introduced 29 Maud Island frogs to a selected forested habitat within the sanctuary's boundaries and the population was monitored and documented by Lukis (2009). Two months post-release, only 11 out of the 29 original frogs (38\%) were recaptured. Despite thorough searches, the last free-ranging Maud Island frog was seen in 2008, one year post-release. Dispersal and homing analysis done by Lukis could not explain the drastic decrease in the frog population. With a peak in mouse densities coinciding with the $62 \%$ population loss of the translocated cohort and observations made of mice inhabiting the few rock piles $(n=8)$ available to the frogs, mouse predation was suggested as a possible cause of the loss of the frog population (Lukis 2009). After additional searches of the frog population failed to recapture any individuals, the translocation was assessed as a failure (Bell et al. 2010).

The outcome of the Lukis study presented an opportunity to investigate the population decline of Maud Island frogs in Zealandia and to gain valuable insight to the ecological relationships between mice and Maud Island frogs. To determine if a larger cohort of frogs could survive peak mouse densities and to determine if Zealandia's current mammal eradication program is sufficient at keeping mice densities low enough for the survival of such frogs, an additional translocation was carried out and their survival was monitored. Remedial suggestions of the 2010 IUCN Global Re-introduction Perspectives that were addressed: exclusion of potential avian ground predators by fencing, addition of more secure retreat sites and supplementary release of a larger cohort (Bell et al. 2010).

This chapter therefore focuses on the survival of an additional translocated cohort of L. pakeka ( $\mathrm{n}=101)$ living sympatrically with M. musculus within the boundaries of the Zealandia wildlife sanctuary.

\subsection{Methods}

\subsubsection{Study site preparation}

The site chosen for the kiwi-exclosure/translocation overlaps the Lukis 2009 site, only shifted southeast to utilize as many pre-existing rock piles as possible and to take advantage of pre-existing infrastructure. The site measures $12.5 \times 15 \mathrm{~m}$ and sits on a eastern facing slope. Exact location of the site is unable to be disclosed (see (Lukis 2009)). Over the period of 4 November through to 30 November 2012, habitat engineering took place to prepare the study site of the arrival of the second L. pakeka translocation. 
The perimeter of the study site was laid out and marked with nylon cord and the corners marked by y-posts (waratahs) to allow for fence construction. Y-posts were placed approximately every two meters along the fence line. A trench was dug underneath the perimeter line (approx. $0.5 \mathrm{~m}$ in depth) to allow the base of the fence to buried. Due to the thick growth of vegetation, supplejack vines (Rhipogonum scandens) were selectively pruned back to allow safe passage throughout the site (Fig. 4.1A). To increase the adequacy of rocky habitat, rocks were obtained from approved sites within Zealandia and manually brought to the site. The quantity of rocks around the western and southern sides of the enclosure was increased. Rocks were concentrated around the original predator-proof enclosure, along the western edge and down the slope on the southern edge of the study site (Fig. 4.1B\&C). A separate rock pile, disconnected from the primary rocky substrate, was constructed in the northeastern corner of the study site (Fig. 4.1D). Five rock piles from the Lukis 2009 study, which were located outside the fence perimeter, were carefully dismantled and relocated to add to the rock piles inside the fence line. There were not enough suitable rocks available within the sanctuary boundaries to completely cover the site therefore, only approximately $30 \%$ of the site has rock coverage. Rocks were kept approximately one meter away from the fence. The lower, southeastern corner of the study site is void of rocks and have moderate vegetation cover of various ferns and supplejack vines. The northern edge of the study site was also void of rocks and lacked understorey vegetation, with the exception of the lower rock pile in the northeastern corner. Once the rocks were in place, the kiwi-exclusion fence was constructed (Fig. 4.2).

The kiwi-exclusion fence was constructed with Cyclone ${ }^{\circledR}$ high tensile galvanized hexagonal netting (900 mm x $75 \mathrm{~mm}$ x $1.0 \mathrm{~mm}$ ), 29G heavy duty wire, green shade cloth and Cyclone ${ }^{\circledR} 1.65 \mathrm{~m}$ 7-hole y-posts. The wires along the top and bottom edge were pulled and held taught by fencing ratchet strainers and metal stakes, the bottom wire rested in the bottom of the trench. The shade cloth was pulled taught between the top and bottom wires held with fencing fasteners. The hexagonal fencing was erected on the exterior side of the shade cloth and held together with zip ties. The fencing was cut and stitched around tree roots as necessary to maintain integrity. Once the fence construction was complete, soil and stones were used to fill in the trench. Polyvinyl chloride (PVC) piping ( $80 \mathrm{~mm} \times 3 \mathrm{~m}$ ) was cut in half and placed along the interior of the fence approximately $0.25 \mathrm{~m}$ above the ground to allow mice to jump over and to serve as an overhang to discourage L. pakeka from emigrating out of the study site (Fig. 4.1D). To ensure no gaps existed between the PVC half pipe and the fencing that could be exploited, the half pipe was fastened to pieces of reclaimed wood placed lengthwise along the exterior of the fencing and props were used to close up any remaining gaps 

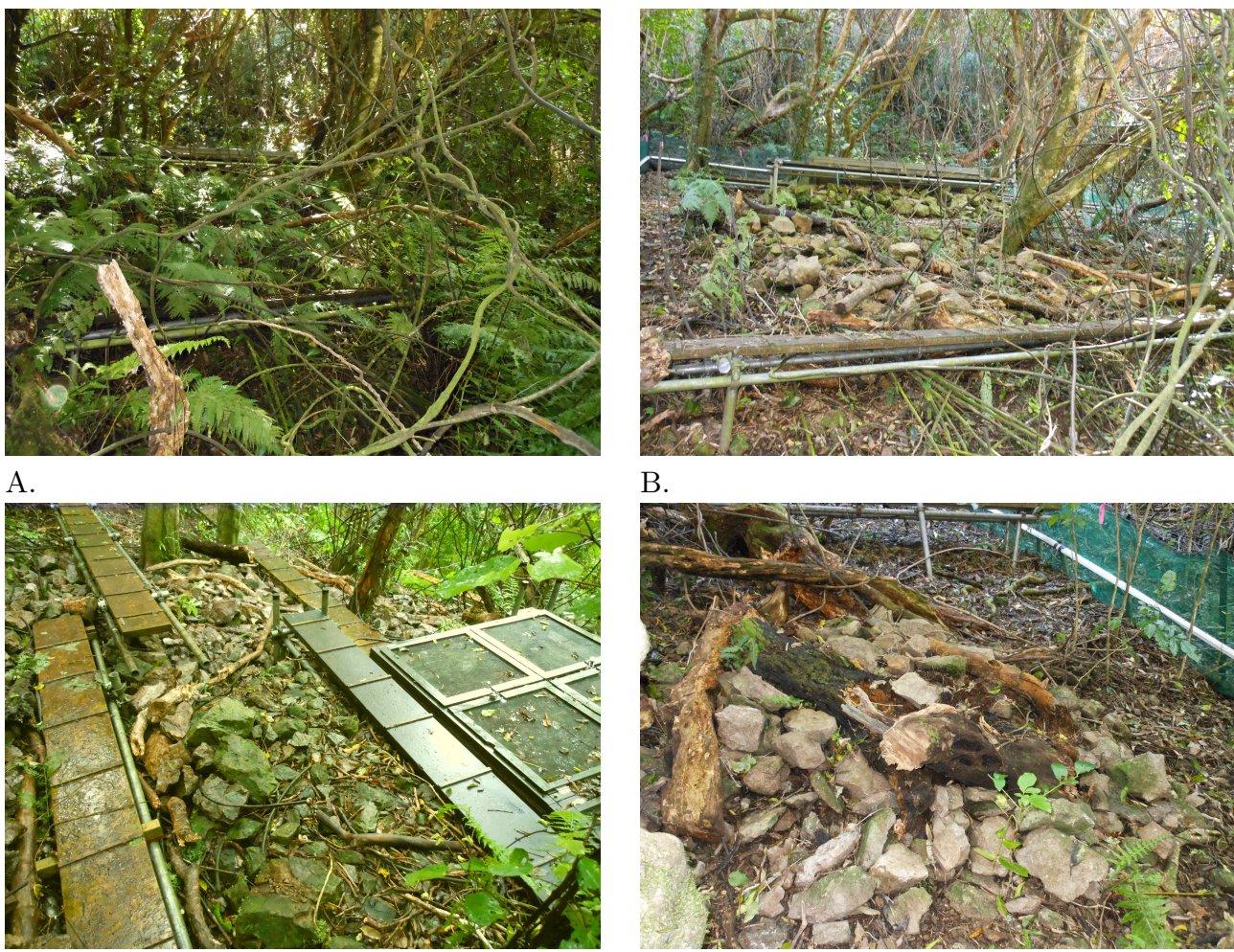

B.

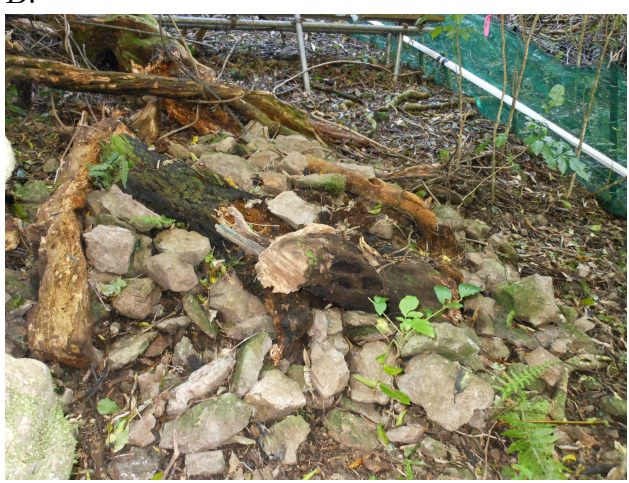

C.

D.

Figure 4.1: Study-site habitat. A. Original habitat at site prior to habitat engineering. B-D. Post-habitat engineering. B. Middle rocky aggregation with walking planks to minimize habitat disturbance. C. Upper rocky aggregation with walking planks and original predator-proof L. pakeka enclosure. D. Lower rocky aggregation with the green kiwi-exclusion fence and white PVC overhang.

from loose fencing. Each length of half-pipe was held together with all-weather duct tape.

All materials were obtained from Bunnings Warehouse, Wellington, New Zealand except: shade cloth, fencing ratchet strainers, metal stakes and reclaimed wood, which were provided by Zealandia.

\subsubsection{Leiopelma pakeka collection to release}

A greater number of founding individuals gives a higher chance of a successful translocation (Tocher and Pledger 2005; Germano and Bishop 2009). Previous amphibian translocations of 100-1000 individuals resulted in an approximate 40\% success rate with the greatest success rate $(67 \%)$ resulting from a translocation of $\geq 1000$ individuals (Germano and Bishop 2009). The effect of removing that large of a quantity of individuals from Maud Island has not been assessed, therefore, guided by the successful translocation to Boat Bay (Bell et al. 2004b), 100 frogs were targeted for translocation. 
Collection of L. pakeka for translocation was carried out 26 November 2012 - 2 December 2012 on Maud Island in the Pelorus Sound, New Zealand. Day and night searches took place in the 16 ha patch of forest where the remnant population survives. The areas searched were split into difference zones and care was taken to not obtain individuals from established long-term study sites. Day searches were carried out by vertically lifting rocks and looking in rotting logs. The night searches were carried out by looking for individuals that had emerged from their diurnal retreat sites. Frogs captured were held in individual plastic bags until processed.

Individuals captured were processed with records taken of zone found, snout-vent length (SVL) (mm), left tibia length (mm), weight (g), girth (scale of 1-5, 5 being largest), skin intensity (l-light, m-medium, d-dark, or a combination thereof), skin pattern (uuniform, p-patterned, m-mottled, or a combination thereof), approximate age (based on SVL) and health (poor, fair, good). Due to the small size of the frogs, delicate nature of their skin and high degree of distinguishable markings, identification was undertaken using photographs of dorsal, left/right lateral and frontal images (Beausoleil et al. 2004; Mellor et al. 2004; Bradfield 2004), or by unique toe-clip combinations (Newman 1990). A maximum of two toes were removed (one toe per foot), taking advantage of any natural toe loss. Measurements and toe-clips were performed by Dr. Ben D Bell and individual clips are stored at the Victoria University of Wellington in $70 \%$ ethanol for potential future genetic analysis.

As each frog was processed, they were then stored in clean plastic containers in groups of up to four frogs per container. Containers contained damp leafy debris and were stored in insulated chilly-bins. Cool, wet towels were draped over the chilly-bins to help control internal climate. Temperature $\left({ }^{\circ} \mathrm{C}\right)$ and relative humidity $(\%)(\mathrm{RH})$ were monitored with a Hobo data logger (model 8 series 4). The chilly-bins were stored out of direct sunlight and in the coolest part of the Comalco Lodge. All equipment was cleaned with Virkon ${ }^{\circledR}$ prior to the departure for Maud Island.

The frogs were transported to the Zealandia wildlife sanctuary in Wellington, New Zealand on 2 December 2012 by maritime and automotive transportation. Once docked in Wellington, the frogs were immediately transported to the sanctuary and released at 1720 hours into the kiwi-exclosure study site. The frogs were divided up and liberated onto three main rock aggregations (30-upper (along the western side), 40-mid (between the frog enclosure and lower plank), 30-lower (on the northeast corner), one-unknown) and were left undisturbed for 15 days (Fig. 4.2). 


\subsubsection{Frog monitoring}

Nocturnal emergence of the translocated cohort was monitored to determine their survival while living sympatrically with mouse population in the Zealandia wildlife sanctuary, Wellington, New Zealand. Searches were conducted for five consecutive nights approximately every four weeks from 17 December 2012 (period 1) through to 2 August 2013 (period 9). Searches commenced approximately one and one half hours after sunset and varied in duration (60-210 $\mathrm{min})$.

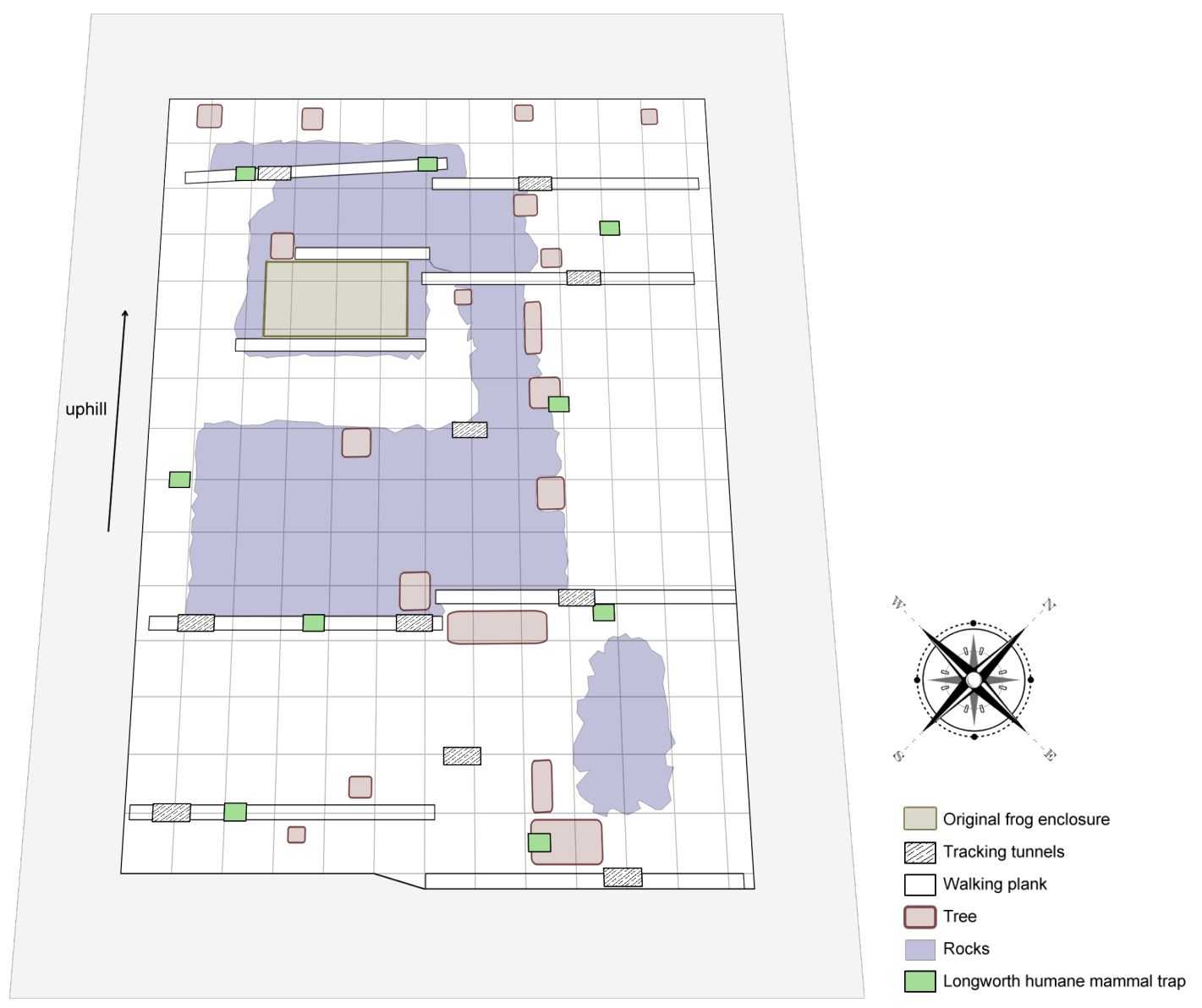

FiguRE 4.2: Study site layout, including $2 \mathrm{~m}$ perimeter buffer zone. Each square represents $1 \mathrm{~m}^{2}$.

The following environmental conditions were noted at the start of each search: cloud cover (0-clear, 1-partly cloudy, 2-half cloudy, 3-mostly cloudy, 4-overcast), moon phase, wind strength (0-no wind, 1-leaves rustle, 2-leaves/branches in constant motion, 3branches/trees sway, 4-gales), precipitation (0-none, 1-mist, 2-light/sprinkle, 3-medium, 4-heavy/down pour), precipitation in the previous 24 hours (yes/no). Wind direction (degrees true north) was obtained from the MetService Kelburn (AWS) (World Meteorological Organisation synoptic number 93437 (Digby et al. 2013)) approximately 7.2 
$\mathrm{km}$ northeast of Zealandia. Minimum and maximum of both temperature $\left({ }^{\circ} \mathrm{C}\right)$ and relative humidity (\%) (RH) were recorded by a Digitech hygrometer (model QM7312). The hygrometer was placed at the data station, on the south end of the site. In addition to searching within the kiwi-exclusion fence, a $2 \mathrm{~m}$ buffer zone around the exterior perimeter of the fence was searched at the start of each session.

Systematic searches were conducted in one-meter transects while traveling uphill to facilitate recaptures. The frogs were held in separate, numbered plastic bags. Each frog was processed separately for identification (photograph and/or toe-clip combination), weight $(\mathrm{g})$, SVL (mm), girth (scale of 1-5, 5 being largest), skin intensity (l-light, mmedium, d-dark, or a combination thereof), skin pattern (u-uniform, p-patterned, mmottled, or a combination thereof) and health (poor, fair, good). All frogs were and returned to their locations found once all processing was complete. The locations were marked by Cartesian coordinates. The study plot measured $12.5 \times 15 \mathrm{~m}(16.5 \times 19 \mathrm{~m}$ including $2 \mathrm{~m}$ perimeter buffer zone). Fifty-six frogs were swabbed for Batrachochytrium dendrobatidis $(B d)$. The swabs are stored at $4^{\circ} \mathrm{C}$ and held at the Victoria University of Wellington for PCR testing when funding is available. Clean nitrile gloves were used to handle the frogs and all equipment was cleaned using Trigene ${ }^{\circledR}$ disinfectant.

Identification was later done via photographic comparison (Fig. 4.3) and/or by toe-clip combination. Comparison of eye vessel patterns (eye venation) was also used to assist in positive identification (see chapter 2).

\subsubsection{Mus musculus monitoring}

To obtain mouse activity levels, 10 tracking tunnels, provided by Zealandia, were placed within the translocation study site in locations that would be mostly likely traveled by mice (e.g. under planks) (Fig. 4.2). Each tracking tunnel, made from wood and corflute, was inserted with a plastic tray with a center section holding a sponge with diluted red food coloring (Hansells ${ }^{\mathrm{TM}}$ ) and with brown paper cut-to-size on either end. Every two weeks starting 3 January 2013 and ending 1 August, the tracking paper was collected and replaced with clean, un-used brown paper. Each piece of paper, or card, was examined for tracks. Invertebrate/weta tracks, mouse tracks (Hasler et al. 2004; Deng et al. 2004) or frog tracks were noted.

During the week of 11 March 2013, nine Longworth humane live mammal traps were placed (locked open) throughout the translocation site for preconditioning. From 16-20 May 2013, the traps were set with relative equal distribution throughout the site in paths most likely frequented by mice (Fig. 4.2). The traps, insulated with dry leaves, were set in accordance with the Longworth recommendations (Bradley 2006) and set by 

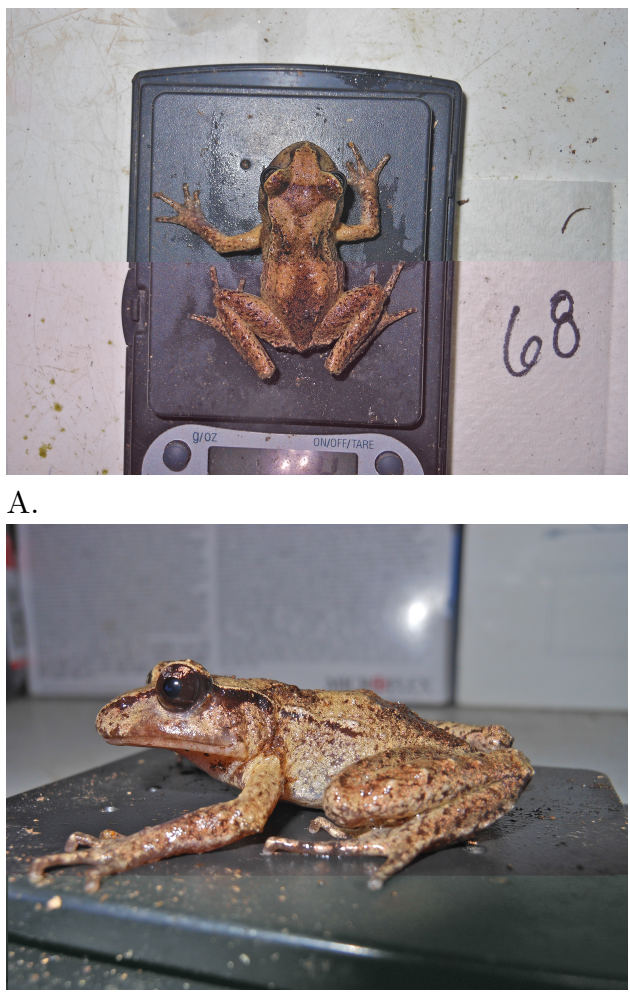

C.

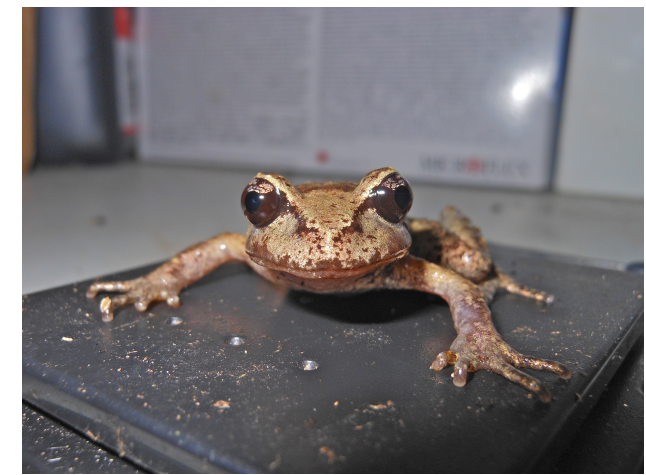

B.

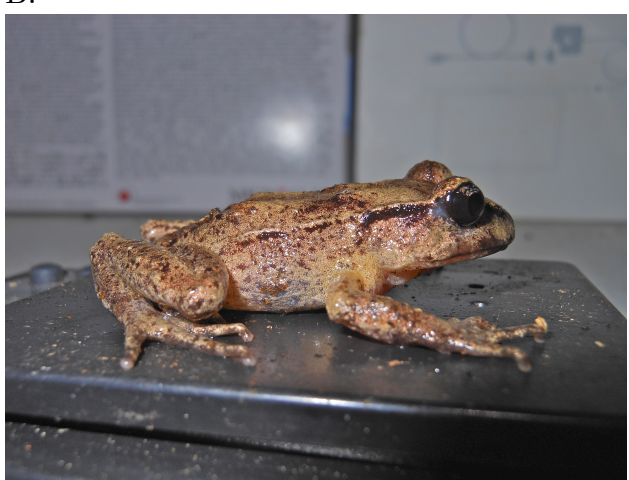

D.

Figure 4.3: Frog T53 (peg 68), photos taken 14 March 2013 for identification. A. Dorsal. B. Frontal. C. Left lateral. D. Right lateral.

$1715 \mathrm{~h}$ each night. The traps were checked by $0830 \mathrm{~h}$ the following morning. The traps remained in the same locations during the day with the trap doors secured in the closed position to deny entry to diurnal animals.

\subsubsection{Data analysis}

An unpublished package (Shirley Pledger, unpub. data) utilizing $\mathrm{R}$ statistical software (ver. 3.0.1) (R Core Team 2013) for an open population was used for recapture analysis. The Jolly-Seber model with maximum likelihood with the lowest Akaike's Information Criterion (AIC) was chosen (Pledger et al. 2010). The model provided survival $(\phi)$ and capture probabilities $(p)$ as well as population estimates $(\hat{N})$ for each period. The data included 44 secondary capture occasions and nine primary capture periods.

Parameters for Jolly-Seber model:

- $n_{j}=$ number of individuals captured at time $j$

- $\hat{N}_{j}=$ population size at time $j$, including individuals underground, at period $K$

- $\phi_{j}=$ survival rate from trip $j$ to trip $j+1(j=1,2, \ldots, K-1)$ 
- $p_{j}=$ probability of capture at time $j$

Population estimates were calculated by: $\hat{N}_{j}=n_{j} / p_{j}$

All statistical analyses were performed with the $\mathrm{R}$ statistical software (ver. 3.0.1) using RStudio (ver. 0.98.484) (R Core Team 2013). The Shapiro-Wilk test was used to test for normality. Non-parametric tests were used where the data were not normally distributed. Mean values are presented with \pm 1 standard error. The negative binomial generalized linear model was used to determine correlation of covariates and total number of frogs emerged. The significance level was set at $\mathrm{p}=0.05$ with $95 \%$ confidence interval (CI). The $\mathrm{R}$ graphical package ggplot2 (Wickham 2009) was used to generate all graphs. Microsoft ${ }^{\circledR}$ Excel $^{\circledR}$ for Mac 2011 (ver. 14.3.7) and Adobe Fireworks CS6 (ver. 12.0.0.236) were used to create images. Trajectory images were created by a collaboration with a software developer using a specifically designed web application and are presented in appendix F.

$\mathrm{R}$ packages adehabitatHR and adehabitatLT (Calenge 2006) were used to analyze home range estimations. The area transversed per individual was estimated with a $95 \%$ minimum convex polygon (MCP), as well as a $95 \%$ least-squares cross validation (LSCV) kernel density estimation. Only frogs captured eight times or greater were included in this analysis $(n=16)$. Results need to be interpreted with the caveat that capture numbers are under the recommendation for home range analysis (Seaman et al. 1999).

Body condition index (BCI) is a measure of relative fitness and is calculated by log weight / log length (Bell et al. 2004b; Lukis 2009). The short duration of the study did not warrant continuous monitoring of individual SVL. This, along with the need to decrease handling time and undue stress of the frogs (Ben Bell pers. comm.), SVL obtained during the collection on Maud Island was used for BCI calculations. Mean weights per period were used to calculate individual BCI per period. The Kruskal-Wallis test was used to compare the change in BCI per period.

Minimum number alive (MNA) was calculated by the summation of the number of individuals caught at time $t$ and the number of individuals present, but not caught at time $t$, that were recaptured at a later stage (Krebs 1966). 


\subsection{Results}

\subsubsection{Founding population}

A total of 105 frogs were captured on Maud Island. Three of the individuals were already marked via toe-clip combination therefore not selected for the translocation and were returned to the sites where they were found. In addition, one frog sustained a lower jaw injury and did not survive. In total, 101 individuals (one extra being inadvertent) were translocated from Maud Island to the Zealandia wildlife sanctuary in Wellington, New Zealand on 2 December 2013. Sixty-eight of the frogs were identified by photograph and 33 were identified by an unique toe-clip combinations (Newman 1990). Using the age classes established for L. hamiltoni by Tocher et al. (2006), the translocated cohort consisted of two juveniles, nine sub-adults unknown sex, 23 adults of unknown sex and 67 adult females. The mean SVL was $40.3( \pm 0.63) \mathrm{mm}$ with a female biased, non-normal distribution $(\mathrm{p}<0.001)$ (Fig. 4.4). Out of the 101 frogs translocated from Maud Island, 86 were recaptured during this study.

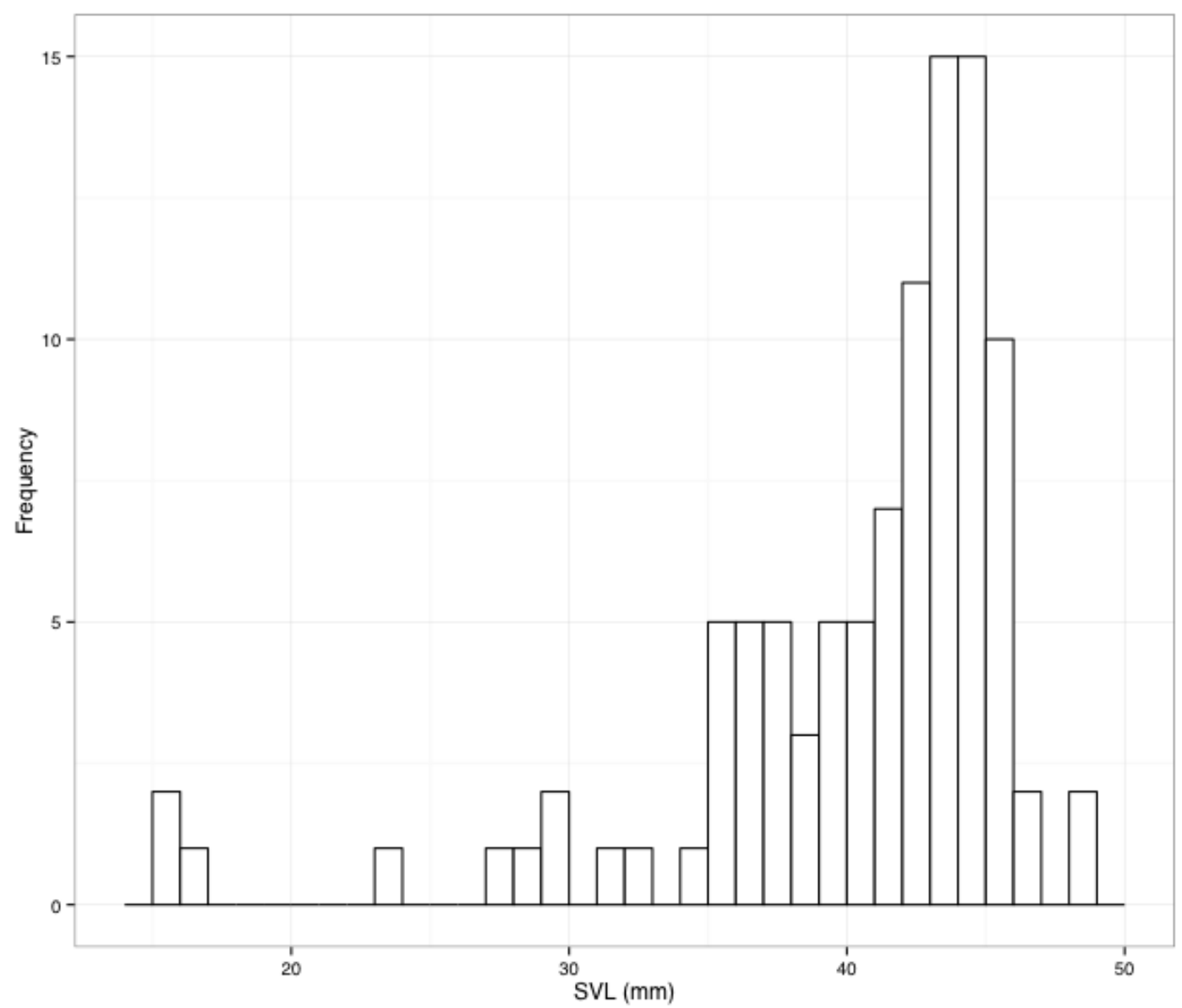

FIGURE 4.4: Translocated L. pakeka SVL distribution $(\mathrm{n}=101)$. 


\subsubsection{Mus musculus monitoring}

The tracking tunnels did not show mouse activity until four weeks after the start of the monitoring, on 31 January 2013. As the weeks continued, the mouse activity in the study site increased as the mouse population reached its peak density (May-June) (Fig. 4.5). Not only were there more tunnels detecting mouse activity, but the numbers of prints on the tracking cards also dramatically increased to the point of not being able to count the number of sets of tracks (Fig. 4.6). The highest level of activity was from 9 May 2013 through to 6 June 2013 with nine out of 10 tracking tunnels showing high activity levels. A drastic reduction in activity was detected beginning 6 June 2013 with only two tracking tunnels showing activity during the 2 -week monitoring. Thereafter, no mouse activity was detected by the tracking tunnels for the remainder of the study. This reduction in mouse activity followed Zealandia's rodent-targeted annual deployment of Brodifacoum $^{\mathrm{TM}}$ that took place the week of 19 May 2013.

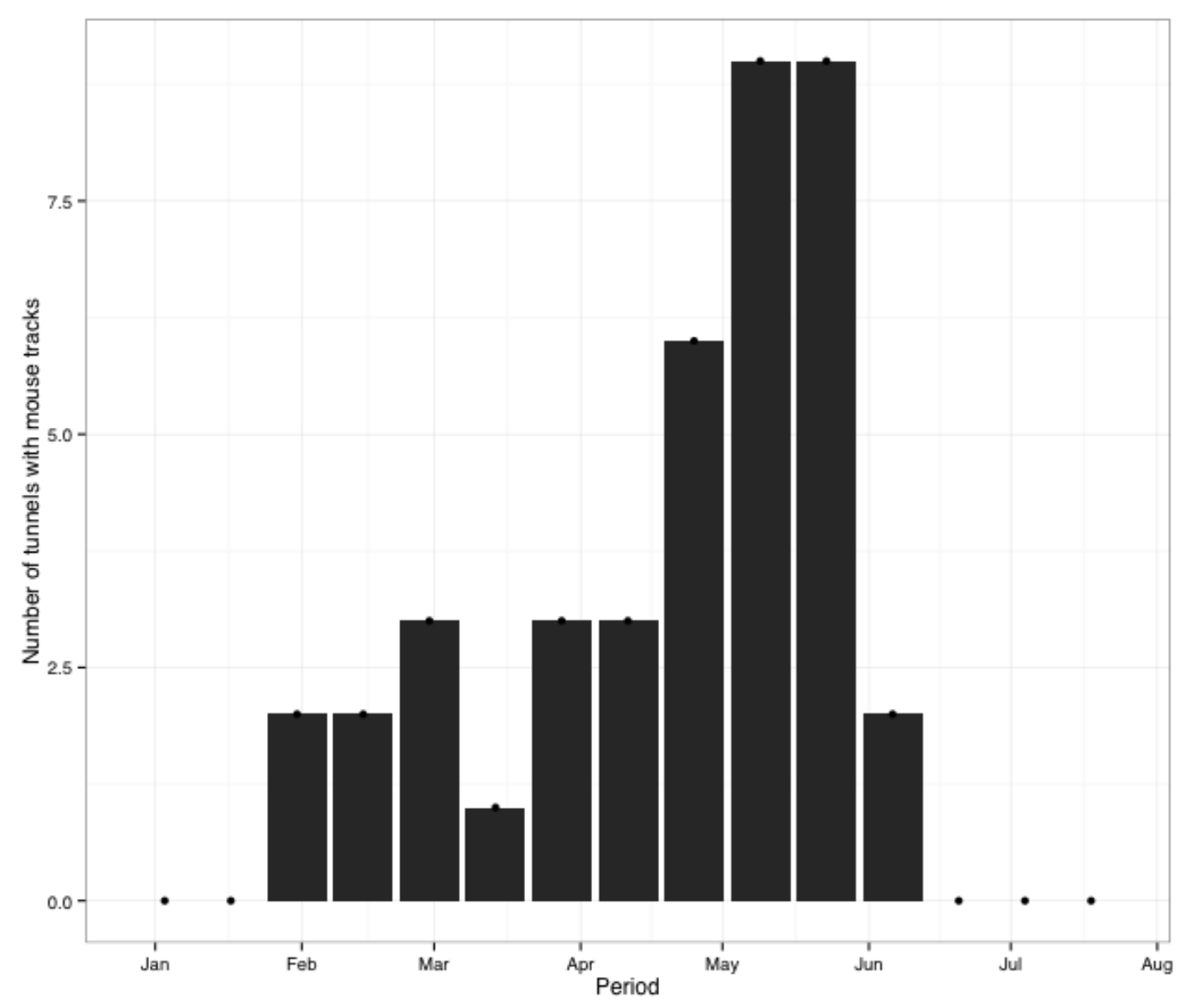

Figure 4.5: Mouse activity.

Despite the Longworth humane live mammals traps being set up during peak mouse activity levels and prior to the deployment of the Brodifacoum ${ }^{\mathrm{TM}}$ bait, not one mouse 

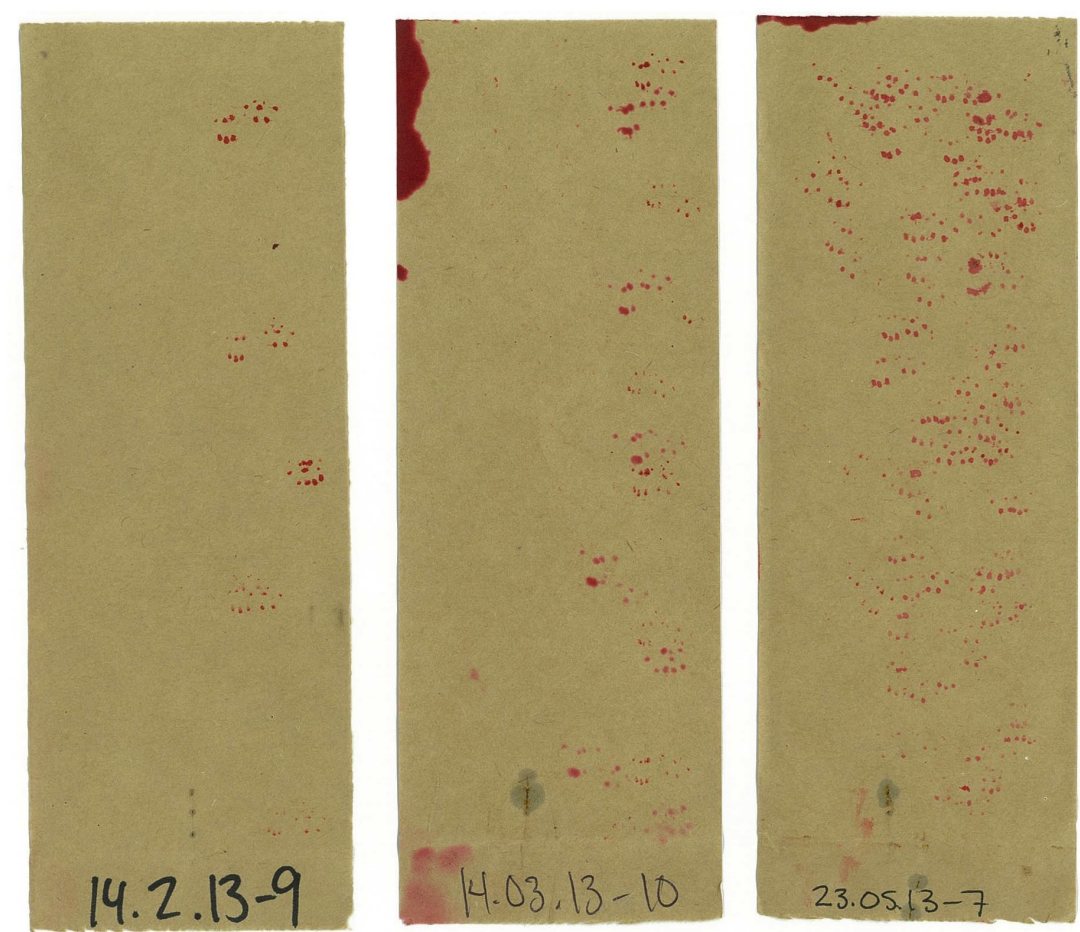

FiguRE 4.6: Increased tunnel activity from left to right. Date set and tracking tunnel number is along the bottom of the tracking card.

was captured. Therefore, a more substantial population density could not be estimated.

\subsubsection{Additional frogs found}

During the length of this study, I found surviving Maud Island frogs from the original 2006/2007 translocation. The first frog found was during the habitat engineering phase (13 November 2012) prior to the second cohort translocation. The frog was located in one of the original rock piles constructed by K. Lukis that, due to the pile lying on the kiwi-exclusion fence boundary, was relocated inside the fence. This particular frog could have either been a new recruit from the surviving adults, or it could have been an escapee from the 2011 census of the original predator-proof enclosure. The frog was measured (27.8 mm SVL, $2.3 \mathrm{~g}$ ), photographed and relocated to a rock pile on the west side of the original predator-proof enclosure. Due to the poor quality of the photographs taken upon initial find, I was not able to positively identify any individual as this frog therefore, this frog was omitted from later analysis.

During the post-release monitoring, I found four surviving adults from the original translocation (B1, B8, B15 \& M15) and 12 additional frogs that I was not able to identify as one of the first or second cohort translocated individuals. For the four adult survivors (13.8\% of the original 29 released), frog M15 was the last one seen 4 November 2007. The last sightings for B15 was 26 May 2007 and for B8 was 13 May 2007. Frog 
B1 had not been recaptured after its initial release on 7 February 2006, until this study on 17 December 2012 (previous capture data was obtained from Lukis (2009)).

I used the same age classes as Lukis (2009) that were established for L. hamiltoni by Tocher et al. (2006), $\mathrm{n}<16 \mathrm{~mm}=$ juvenile $(\mathrm{J}) ; 16 \geq \mathrm{n} \leq 35 \mathrm{~mm}=$ subadults unknown sex (SU); $35<\mathrm{n}<40 \mathrm{~mm}=$ adults unknown sex (AU); $\geq 40 \mathrm{~mm}=$ adult female only (AF). Eleven out of the 12 unidentifiable frogs found were SU, the other was AF. All, except three unidentifiable frogs, were found inside the exclusion fence. Of those three found outside the fence, one was on the south side and the other two were on the north side of the study site amongst the rocky and vine covered substrate.

\subsubsection{Frog survival}

The primary aim of this study was to determine the survival of the frogs living sympatrically with mice. For this reason, survival estimates were done using all frogs found $\left(\mathrm{n}_{\text {tot }}=117\right)$. For the 101 translocated frogs, totals were: one frog was recaptured 13 times, no frogs were recaptured 12 times, one frog was recaptured 11 times, two frogs were recaptured 10 times, four frogs were recaptured nine times, seven frogs were recaptured eight times, three frogs were recaptured seven times, four frogs were recaptured six times, seven frogs were recaptured five times, 11 frogs were recaptured four times, eighteen frogs were recaptured three times, fourteen frogs were recaptured twice, fourteen frogs were recaptured once and fifteen frogs were never recaptured. For the 16 frogs that were discovered already on site, totals were: one frog was recaptured 10 times; three frogs were recaptured three times; four frogs were recaptured twice; and four frogs were only captured once. For capture histories, see Figs. $4.7 \& 4.8$.

The JS model with the lowest AIC was with survival $(\phi)$ held constant over time, time dependent probability of capture $(p)$ and population estimation $\left(\hat{N}_{j}\right)$ with a linear trend beginning at the second period $\left(\phi() p.(t) N_{j}(1)\right.$ from per=2) (Table 4.1). Overall $\phi$ was high $(0.914,0.87 / 0.94 \mathrm{CI})$, which is greater than the one-year post-release survival estimates $(64.2 \%)$ after release of the Boat Bay translocation (Bell et al. 2004b). $\hat{N}_{j}$ showed a negative regression (slope $=-4.69,-6.70 /-2.68 \mathrm{CI}$ ), which follows the initial trend in population estimates from the Boat Bay and Motuara Island translocations (Bell et al. 2004b; Tocher and Pledger 2005). The MNA indicated a decline in population estimates (Fig. 4.9). This conservative method is the worst case scenario and the estimate of the last period of capture (Jul-Aug 2013) represents unique individuals recaptured during that period only.

Note: Probability of recapture $\left(p_{j}\right)$ is needed to accurately estimate the population estimate $\left(\hat{N}_{j}\right)$ therefore $\left(\hat{N}_{1}\right)$ could not accurately be calculated. Additionally, with 


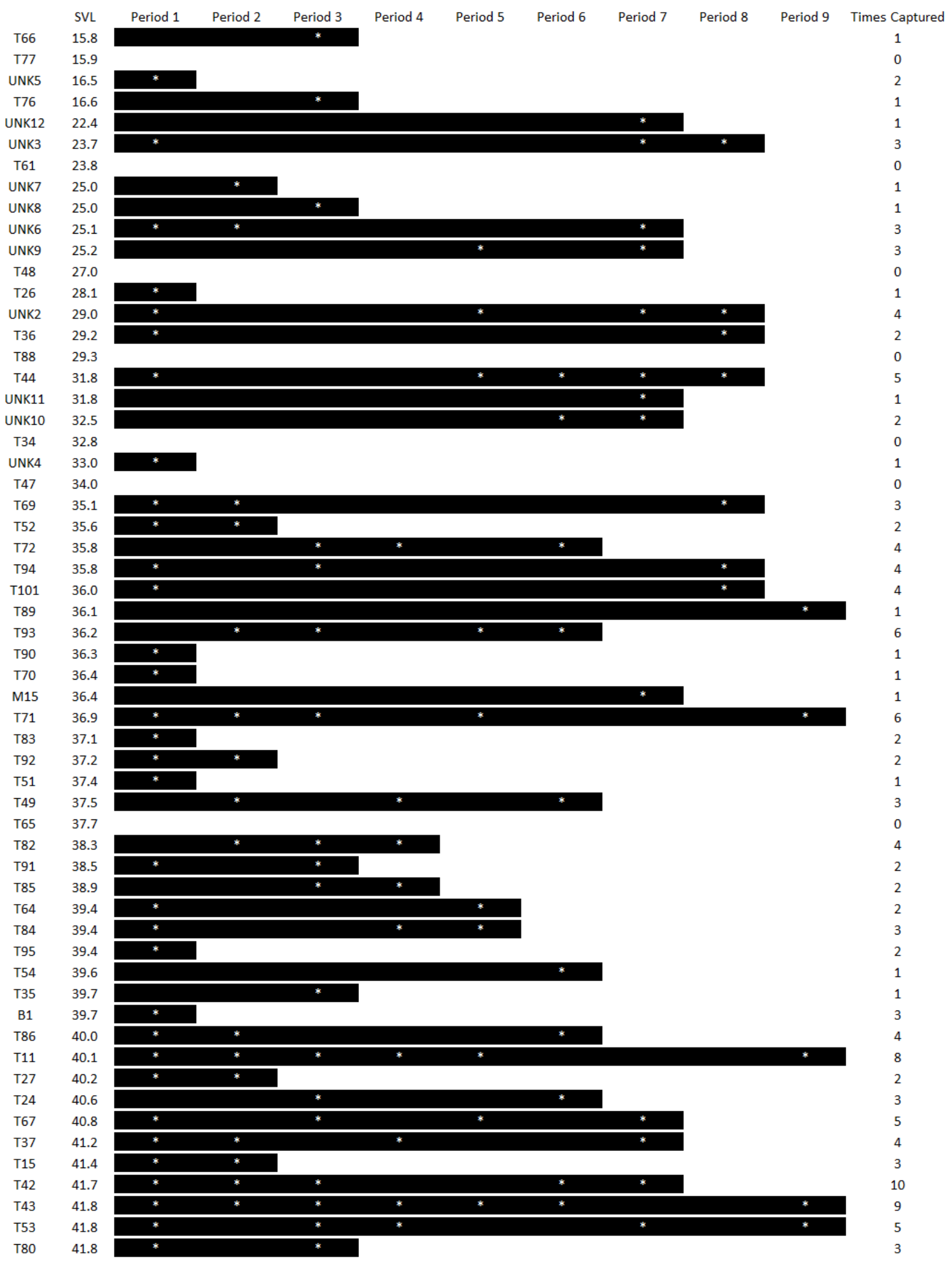

FIGURE 4.7: Survival and total captures of the first 58 L. pakeka $\left(\mathrm{n}_{\text {tot }}=117\right)$. Black bar indicates last known to be alive. White star indicates periods captured. Frogs are listed with increasing SVL. 


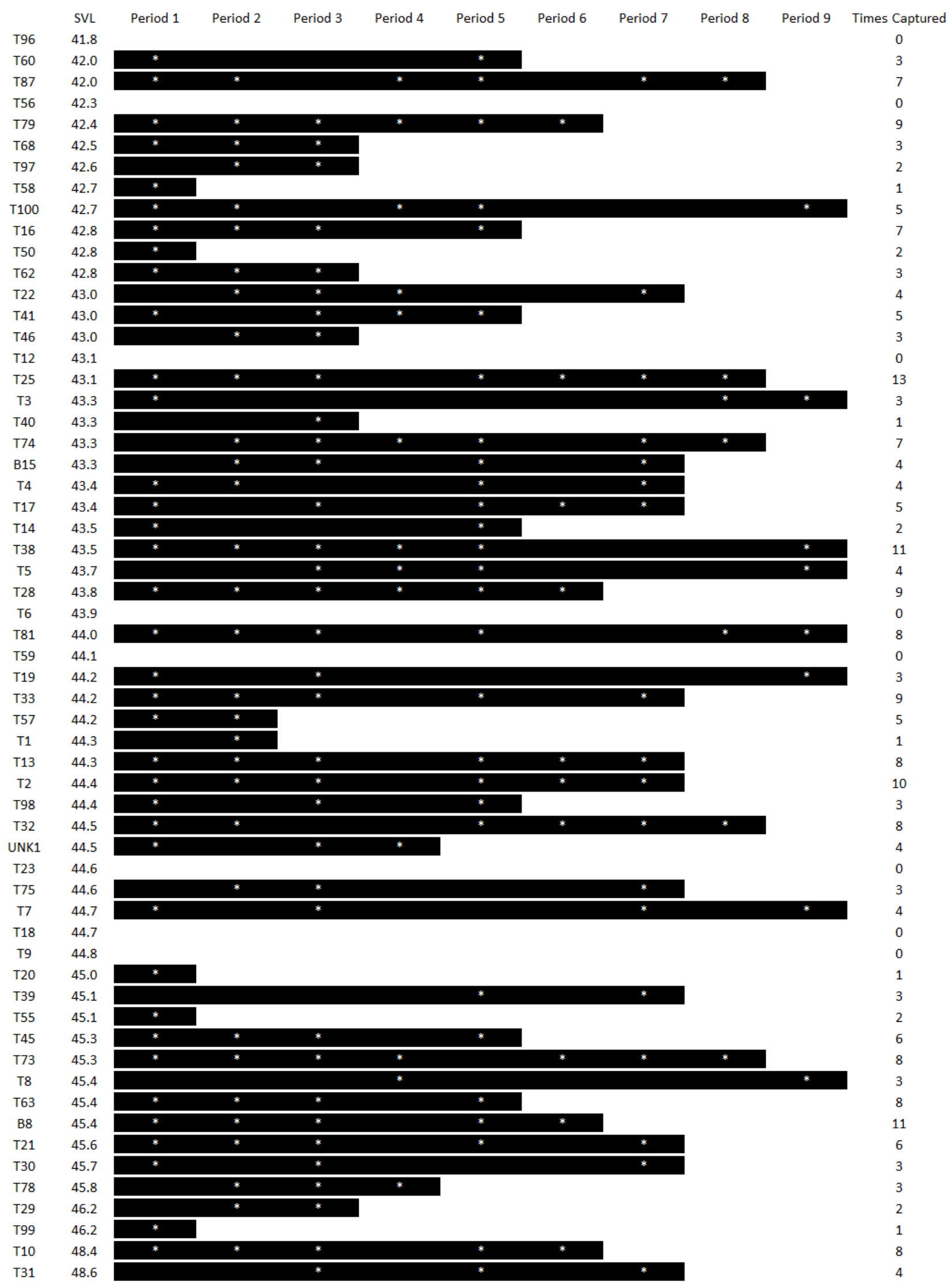

FigURE 4.8: Survival and total captures of the remaining 59 L. pakeka $\left(\mathrm{n}_{t o t}=117\right)$. Black bar indicates last known to be alive. White star indicates periods captured. Frogs are listed with increasing SVL. 
no successive captures after period 9 (Jul-Aug 2013), MNA for period 9 could not be calculated.

\begin{tabular}{llll}
\hline Model & AIC & $\Delta$ AIC & $\mathrm{N}_{p}$ \\
\hline \hline$\phi() p.(\mathrm{t}) \hat{N}_{j}(\mathrm{l})$ from per=2 & 380.85 & 0 & 13 \\
$\phi() p.(\mathrm{t})$ & 389.32 & 8.47 & 18 \\
$\phi() p.(\mathrm{t}) \hat{N}_{j}($.$) from per=2$ & 390.79 & 9.74 & 12 \\
$\phi(\mathrm{t}) p(\mathrm{t})$ & 396.98 & 16.13 & 24 \\
$\phi() p.(\mathrm{t}) \hat{N}_{j}()$. & 407.63 & 26.78 & 11 \\
$\phi(\mathrm{t}) p()$. & 428.68 & 47.83 & 18 \\
$\phi() p.()$. & 433.37 & 52.52 & 11 \\
\hline
\end{tabular}

TABLE 4.1: Jolly-Seber candidate models selection table with AIC values. (.) indicates constant over time, $(\mathrm{t})$ is time dependent (l) is linear trend.

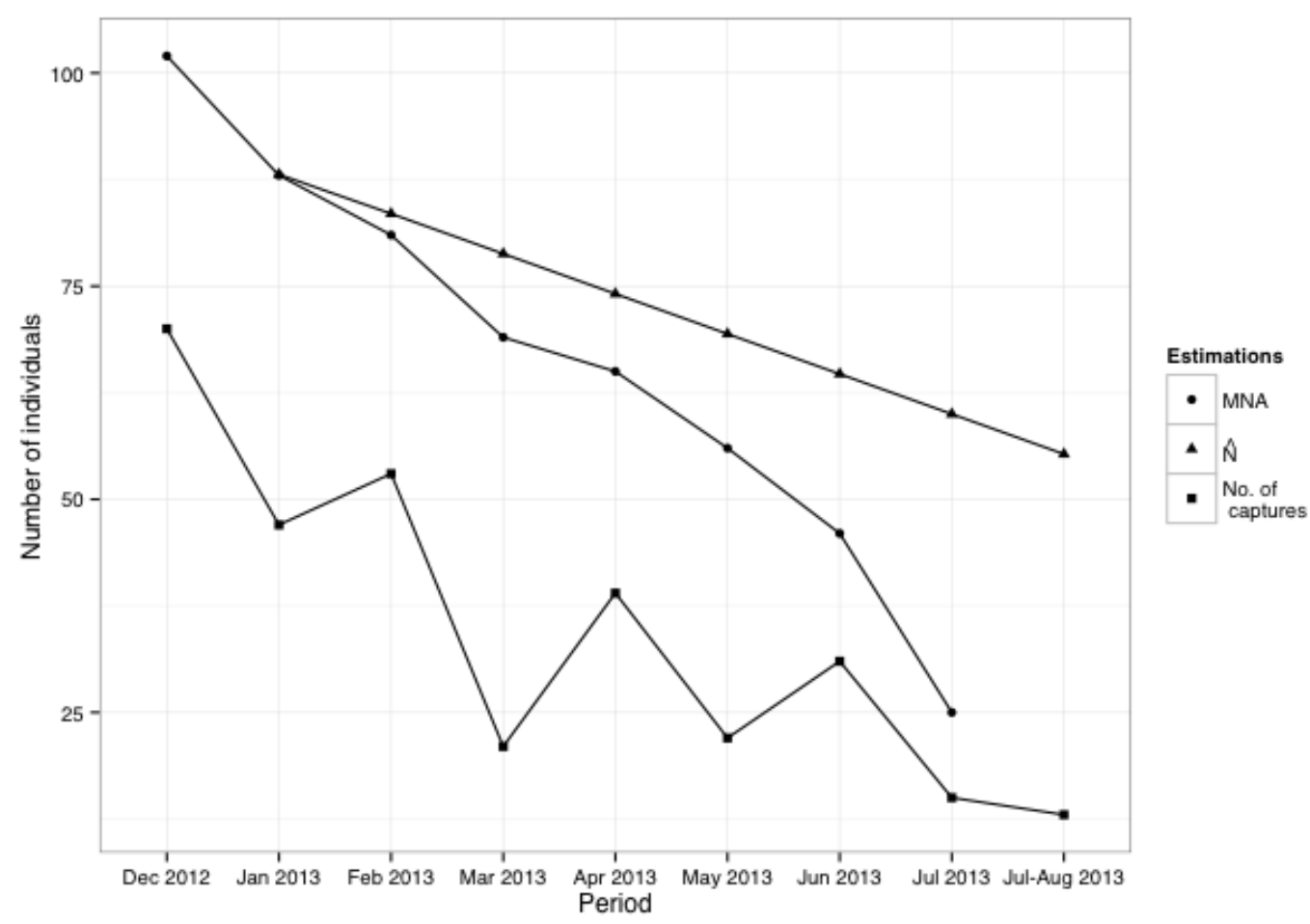

Figure 4.9: Number of captures, minimum number alive (MNA) and population estimate $(\hat{N})$ over successive capture periods. 


\subsubsection{Mouse activity and weather}

The full model included all covariates recorded. The model with the lowest AIC included the number of tunnels with mouse activity, precipitation in the previous 24 hours, precipitation during the monitoring, mean temperature and mean RH. The variables of number of tunnels with mouse activity, precipitation in the previous 24 hours and precipitation during the monitoring did not show significance $(\mathrm{p}>0.05)$. Mean temperature showed a positive correlation $(\mathrm{p}<0.001)$ with overall frog emergence (Fig. 4.10). Mean $\mathrm{RH}$ approached significance $(\mathrm{p}=0.0517)$ showing a potential positive trend with overall emergence (Fig. 4.11).

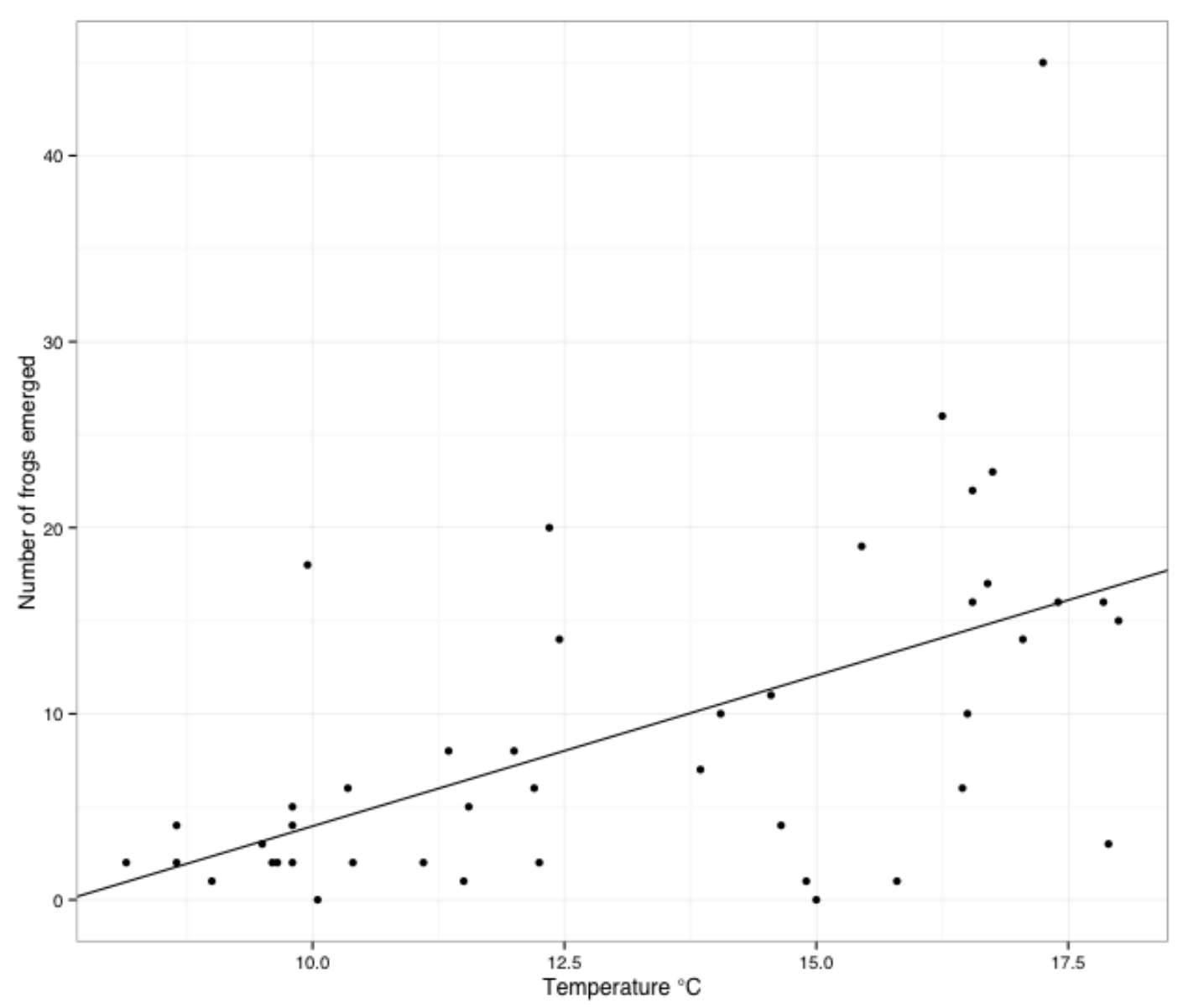

FiguRE 4.10: Mean temperature vs. number L. pakeka emerged. Regression line included. 


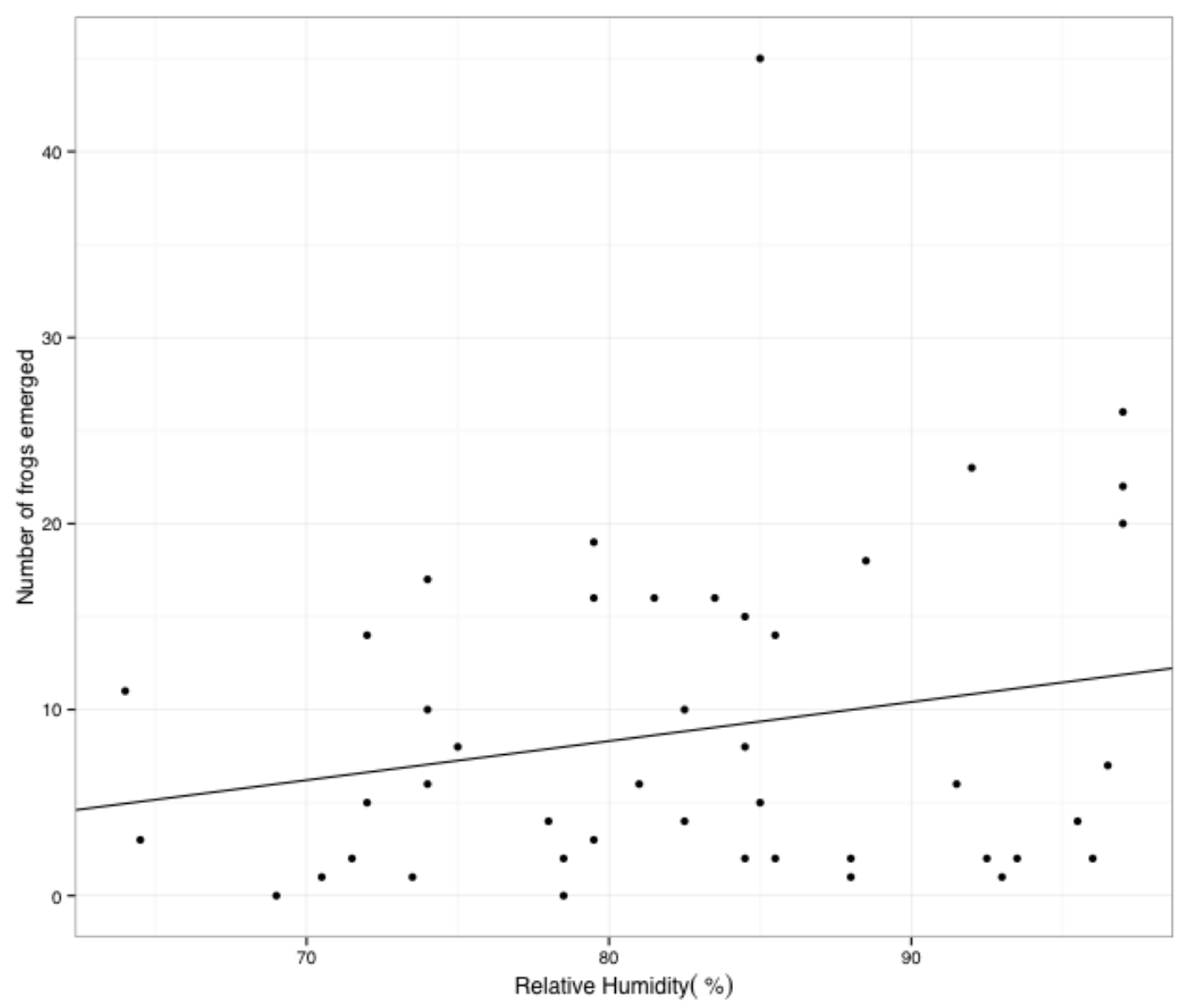

FiguRE 4.11: Mean relative humidity vs. number L. pakeka emerged. Regression line included.

The National Institute of Water and Atmospheric Research (NIWA) reported a decrease in rainfall prior to the start of this study in October 2013. By February and March 2013 (third and fourth capture periods), the drought was at its peak, resulting in a declared drought for the North Island of New Zealand on 15 March 2013 (NIWA 2013). This lack of rainfall was substantiated by the MetService (Kelburn) report of monthly total rainfall (Table 4.2). 


\begin{tabular}{lll}
\hline Month & Rainfall $(\mathrm{mm})$ & $\pm \mathrm{SE}$ \\
\hline \hline Dec 2012 & 2.26 & 0.708 \\
Jan 2013 & 2.85 & 1.251 \\
Feb 2013 & 2.36 & 1.782 \\
Mar 2013 & 2.92 & 1.968 \\
Apr 2013 & 2.89 & 1.093 \\
May 2013 & 4.57 & 1.971 \\
Jun 2013 & 8.41 & 3.239 \\
Jul 2013 & 3.26 & 1.288 \\
\hline
\end{tabular}

TABle 4.2: Mean monthly rainfall for the duration of this study. Data obtained by MetSerice (Kelburn).

\subsubsection{Movements}

There was a significant difference between the number of frogs that moved uphill versus those that moved downhill $\left(\chi^{2}=11.36, \mathrm{df}=1, \mathrm{p}<0.05\right)$. After the initial liberation, 61 of the translocated frogs were recaptured during the first capture period in December 2012. Of those, 18 were released in the upper rock pile, 26 were released in the middle rock pile and 17 were released in the lower rock pile. From the liberation points to the first capture, 40 frogs (65\%) moved uphill, eight which were released in the upper rock pile, 22 which were released in the middle rock pile and 10 which were released in the lower rock pile. Twenty-five percent moved downhill, nine from the upper rock pile, one from the middle and five from the lower rock pile. Only $10 \%$ had lateral movement, one from the upper rock pile, three from the middle and two from the lower rock pile. Few frogs (approx. 16) appeared to have stayed in relative close proximity to their liberation points. For the 61 frogs that were recaptured in the first period, the distance traveled from liberation point to the first point of capture varied from $0.10-15.58 \mathrm{~m}$ with the mean distance of $5.16 \pm 0.45 \mathrm{~m}$. Recaptures were focused around rocky aggregations however, many frogs were recaptured (some repeatedly) on bare soil.

Due to the relatively low number of recaptures for many of those 61 frogs, home ranges were calculated for the 15 frogs that were recaptured eight times or more with the addition of a surviving frog from the 2006/2007 translocation that was captured 11 times, bringing the total to 16 frogs (Table 4.3). The mean minimum convex polygon (MCP) area at $95 \%$ was $12.36 \pm 4.57 \mathrm{~m}^{2}$. Results from the $95 \%$ LSCV kernel density estimation were $30 \%$ greater than MCP estimations for some individuals and inconsistent with home range estimates from Maud Island (Bell and Moore 2012) (data not shown) and therefore were not used for home range estimates. 


\begin{tabular}{lll}
\hline Frog & MCP $\left(\mathrm{m}^{2}\right)$ & Captures \\
\hline \hline T73 & 1.179 & 8 \\
T79 & 2.204 & 9 \\
T32 & 4.057 & 8 \\
T10 & 4.172 & 8 \\
T43 & 4.918 & 9 \\
T11 & 6.392 & 8 \\
B8 & 7.390 & 11 \\
T63 & 7.474 & 8 \\
T42 & 7.747 & 10 \\
T25 & 7.773 & 13 \\
T13 & 8.237 & 8 \\
T81 & 11.700 & 8 \\
T2 & 11.786 & 10 \\
T33 & 13.260 & 9 \\
T38 & 20.835 & 11 \\
T28 & 78.593 & 9 \\
\hline
\end{tabular}

TABLE 4.3: Home range estimates by $95 \% \mathrm{MCP}$ for the 16 most commonly caught frogs.

The trajectories for the 16 frogs most frequently recaptured, nine (56\%) were generally uphill (T81, T63, T73, T33, T32, T25, T13, T11 and T10). The most direct movement was from frog T25, which was released in the lower northeastern end of the study site in lower rock pile. All its recaptures thereafter were uphill, in the northwestern corner. Frog T33, which was released in the middle rock pile, also moved to the same corner of the study site as T25. Frogs T10 (released in the upper rock pile) and B8 (survivor from original translocation) also had their recaptures in the northwestern corner of the study site. This particular end of the site had drier substrate and was free of rocks. Frog T73 (released in the middle rock piles) had the smallest MCP (Table 4.3). All recaptures for T73 were amongst the rocks on the eastern edge of the original frog enclosure. Trajectories and area utilized are shown in Appendix F.

Two of the sixteen frogs (13\%) (T38 and T2) were released in the upper rock piles and had downhill trajectories. Frog T38 stayed to the south side of the site, moving downhill. T2 was last recaptured along the very bottom northeastern edge of the study side, against the fence. Four frogs out of the 16 (25\%) either had slight lateral movement (T42, T43), or were confined to a small MCP (T79, all recaptures within approx. $4 \mathrm{~m}^{2}$ ). Frog B8 was consistently recaptured along the upper northwestern edge of the study 
site. Only one out of the 16 frogs (6\%) (T28) traversed uphill and downhill across the entire $15 \mathrm{~m}$ study site. Frog T28 was released in the upper rock piles and appeared to stay on the southern edge of the study site.

Four frogs in total were found outside the kiwi-exclusion fence. One frog (T83) was found outside the fence on 17 December 2012, approximately $6 \mathrm{~m}$ uphill from a hole in the fence. The hole (approx. 2.5-3.5 cm in diameter) was at ground level and appeared to be made by a LSK pushing its bill through the fence. The hole was repaired and the frog was returned to the center of the study site after all recapture processing was completed. Frog T83 was recaptured for a second time during the same capture period but was not recaptured thereafter. Three additional frogs, all approximately $25 \mathrm{~mm}$ SVL, were found outside the kiwi-exclusion fence and could not be identified as frogs from the 2006/2007 nor to the 2012 translocated cohorts. Therefore, they are most likely progeny from surviving members of the original translocation. One frog was found in the southwestern end of the buffer zone among some small stones and the other two frogs were found in the northwestern end of the buffer zone amongst slightly larger rocks that were covered with supplejack vines. Not knowing the identity of the frogs at the time of capture, all were placed in the center of the study site.

\subsubsection{Condition}

The changes in mean BCI over the duration of the study was found to be significant $(\mathrm{p}<0.001)$. The mean BCI on Maud Island $(0.472 \pm 0.016)$, where just over half $(\mathrm{n}=53)$ were adult females, is comparable to the amalgamation of the release BCI of frogs with SVL $\geq 35 \mathrm{~mm}$ found by Lukis (2009). There was a substantial increase in BCI from the initial capture on Maud Island to January 2013. Thereafter, the BCI per month dropped and fluctuated slightly (Fig. 4.12). 


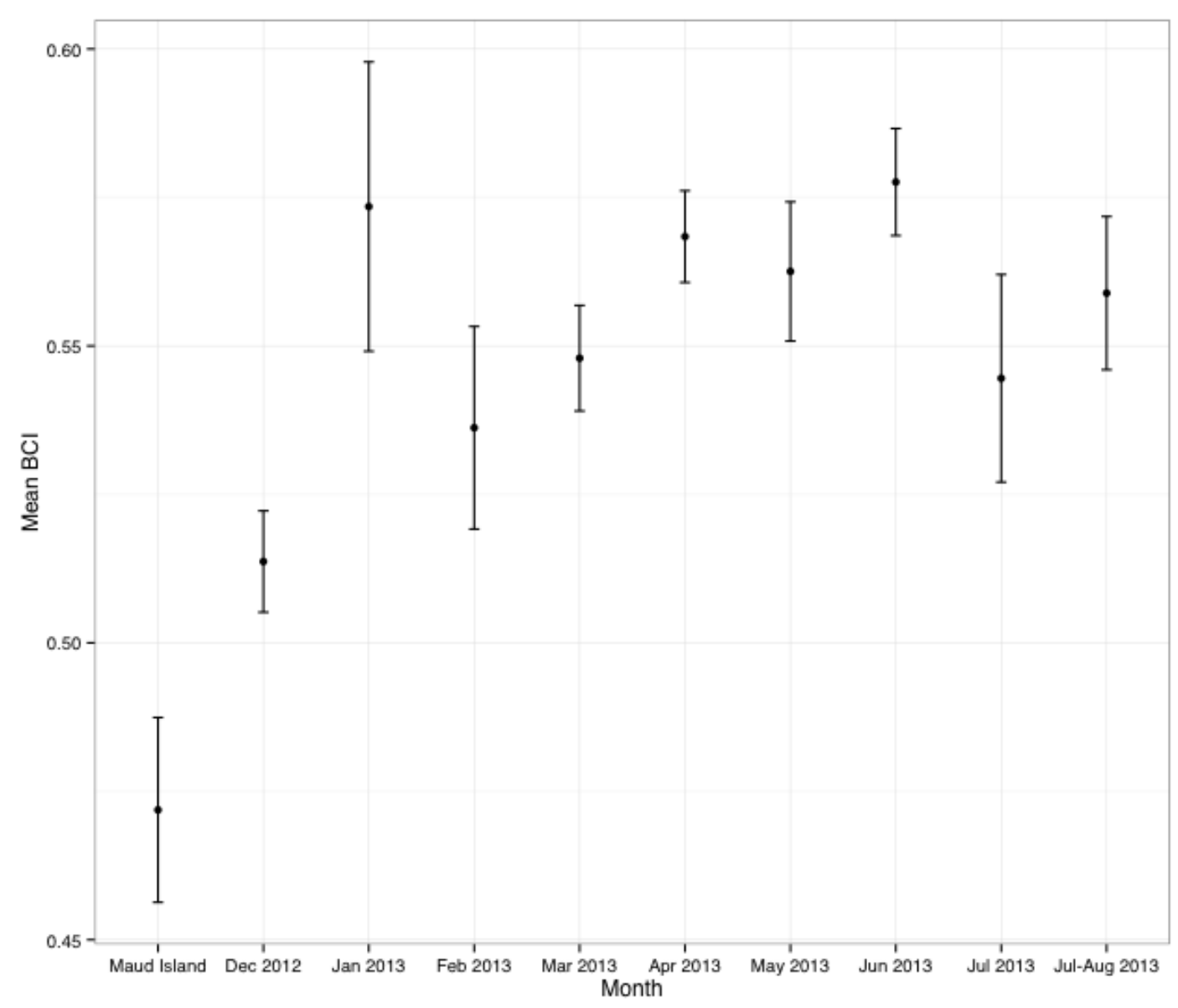

Figure 4.12: Mean body condition index (BCI) ( \pm 1SE) of frogs caught per month.

Frog T78 was recaptured for the third and final time on 14 March 2013. The frog had an injured rear right foot that was noted on the two previous recaptures (Fig. 4.12A). The injury appears to have been obtained on Maud Island prior to its translocation. The frog was active and appeared to be in good health for all three recaptures.

On 10 April 2013, frog T13 was recaptured for the fifth time with a yellow, subcutaneous mass noticeable over the right pectoralis (Fig. 4.12B). The frog was active and the mass did not seem to restrict the normal range of motion of the limb. Although difficult to obtain an accurate measurement due to limb motion changing the shape of the mass, the mass measured approximately $5.2 \mathrm{~mm}$ in diameter. T13 was recaptured on 6 May 2013 and held until 8 May 2013 on site in a clean plastic container with damp leafy debris. On 8 May 2013, T13 was taken to Dr. Danielle Sijbranda, DVM at the Wellington Zoo. Upon arrival at the veterinary office at Wellington Zoo, T13 was active and appeared to be in good condition. A fine needle aspirate was performed and T13 was diagnosed with a lipoma. Dr. Sijbranda recommended monitoring the lipoma with recaptures and cleared the frog to be returned to the study site. T13 was returned to the study site the 


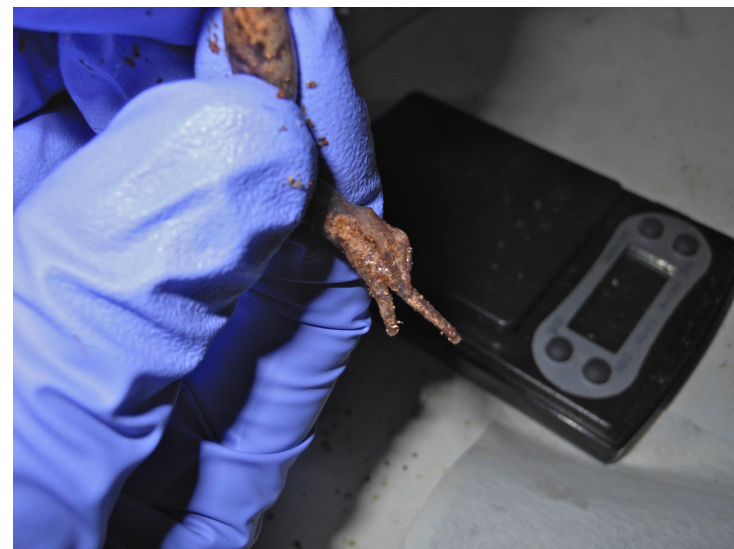

A.

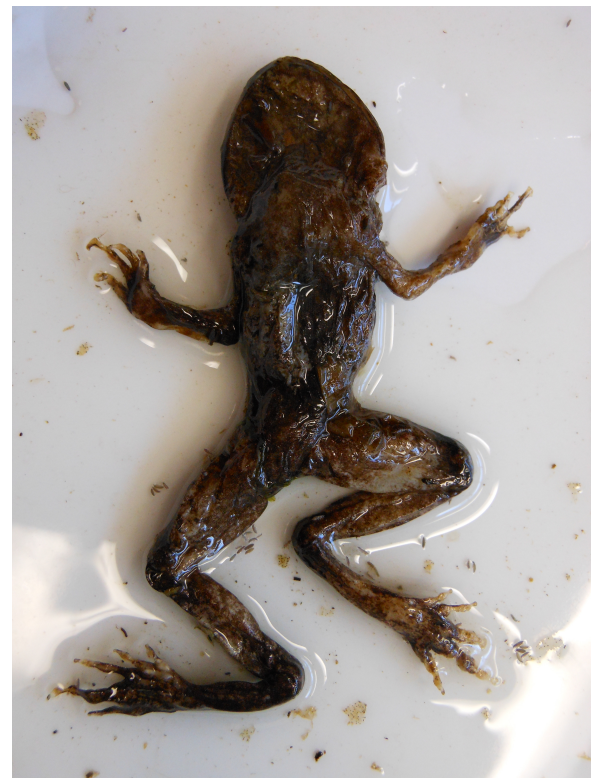

C.

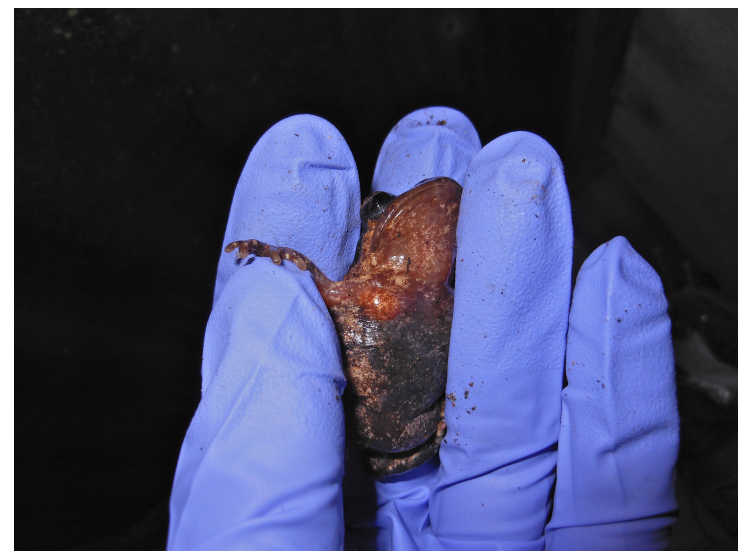

B.

Figure 4.13: A. Frog T78 with injured rear right foot. B. Frog T13 with lipoma over right pectorals. C. Deceased frog, unknown identity.

same day at $1240 \mathrm{~h}$. T13 was recaptured for the ninth and final time on 3 June 2013 with the lipoma still apparent (approx. $5.09 \mathrm{~mm}$ in diameter).

On 7 May 2013, a deceased frog was found in the northeast quadrant of the study site. Upon initial discovery, the frog appeared to be in an intermediate state of decomposition with what appeared to be small white larvae covering the body. A post-mortem examination by Dr. Ben D Bell (Fig. 4.12C) revealed that the frog had been deceased for approximately 3-4 days prior to its discovery and did not appear to have any damage (i.e. bite marks or signs of being crushed). The frog was not toe-clipped and the stage of decay made it impossible to identify by skin markings; therefore, the identity of the frog is unknown. Also on this day, frog T22 was recaptured for the fourth and final time with an inflamed mandibular joint. There were no additional obvious injuries, the frog was active and appeared to be in good condition. 


\subsection{Discussion}

\subsubsection{Overall outcome}

The primary aim of this study was to assess the short-term impact of the mouse population on Maud Island frogs in the Zealandia wildlife sanctuary. This was done by monitoring the survival of an additional, larger cohort of Maud Island frogs $\left(\mathrm{n}_{t o t}=117\right.$ in comparison to $n=29$ ) living sympatrically with house mice. The results suggest that mouse activity did not have significant deleterious effects on these frogs and that their reduced emergence correlates more with temperature and possibly relative humidity rather than a decline in population. Caution needs to be taken when interpreting the results of mouse activity correlation. Demographics of the mouse population were not able to be estimated prior to the Brodifacoum ${ }^{\mathrm{TM}}$ bait deployment. However, results are interpreted with the assumption that an increase in mouse activity is positively correlated with an increase in mouse density.

With a larger founding population and an increase in substantial habitat, the results suggest that Zealandia's mammal eradication program may be adequate for an establishment of a free-ranging, viable Maud Island frog population. This study is of short duration with no mice observed. The data do not provide conclusive evidence regarding mouse predation of L. pakeka and warrant further research and extended monitoring to better determine any long-term trends. In particular, monitoring during summer months of late 2013/early 2014 should be undertaken to investigate whether a recovery occurs in the measured decline.

\subsubsection{Mice}

Introduced mammals, more specifically, rodents, have been thought to be the primary cause of extinction for the three Leiopelma species (Worthy 1987; Towns and Daugherty 1994). The absence of these pests on Maud and Stephen's Islands have been used to explain the survival of the two largest extant species, L. pakeka and L. hamiltoni, respectively (Stephenson 1961; Towns et al. 2001; Bell 2011a). The predation possibility of L. pakeka by mice in Zealandia and now on Maud Island where the only natural population occurs, is of considerable concern. The results of this study and the fate of the frogs in Zealandia over a longer term will be indicative of what might occur on Maud Island. 
The hypothesis of mice predating on L. pakeka in Zealandia was partially derived by Lukis (2009) observing mice in the rock piles which the frog inhabited, as well as recapturing only smaller frogs in the latter stages of her study. This conclusion was not supported by the results of this study. Mice were never observed by myself nor by the many volunteers by which I relied. Additionally, two out of the 13 frogs recaptured during the last period of this study were just over $36 \mathrm{~mm}$ with the remaining frogs being over $40 \mathrm{~mm}$, indicating survival of the larger individuals. Lukis (2009) gave the possible reason for potential predation on larger frogs being that they were unable to find retreat sites that mice could not invade. Although emergence was reduced, larger frogs $\geq 40 \mathrm{~mm}$ were found throughout this study, suggesting that the increased amount of rocky substrate provided substantially more retreat sites that were adequate enough to mitigate mouse invasion, which in-turn, facilitated the frogs' survival. However, if mice presented even slightly as a threat, the enclosed site would have created a formidable obstacle for the frogs to disperse to safety.

Mice seemingly not preying on the frog population is substantiated by the discovery of the unbitten deceased frog and the absence of anuran skeletal remains. Egeter et al. (2011) found that under laboratory conditions, mice ingested only the soft tissue of Litoria raniformis, leaving the skeleton. Additionally, the carcass found had been exposed to potential predators for three to four days suggesting that mice in Zealandia at least do not have an interest in frog carrion. This lack of interest might be due to an abundance of food resources for mice in Zealandia, leaving mice no need to scavenge. However, mice are capable to predating herpetofauna larger than L. pakeka. Newman (1994) found mice predated McGregors skinks on Mana Island with SVLs ranging from 55-115 mm. Therefore, more direct studies of mouse-L. pakeka predation are clearly necessary.

Resource abundance is corroborated by the significant increase in BCI found in this study which suggest no apparent food resource competition between the mice and frogs (as seen and concluded in Lukis (2009)). Resource competition abatement, inter or intraspecific, could be the result of the release of competition generated by a habitat that was possibly at its carrying capacity (Bell and Pledger 2010). Caution does need to be taken when interpreting BCI. Snout-vent length upon initial capture was used for all calculations. This is particularly important for BCI of juveniles and sub-adults captured on Maud Island (approx. 25\%) where their SVL is most likely to have increased. Further, water-balance would also affect the frogs' BCI (Bell et al. 2004b). This said, the fluctuation of BCI from period 4 in February until the end of the study compares to the mean BCI of the founding population at Boat Bay 20 years post translocation (Bell et al. 2004b). This gives encouragement for potential survival of the Zealandia population. 


\subsubsection{Survival}

Six years had passed prior to the discovery of surviving L. pakeka in Zealandia. With a 3-4 year maturation (Bell 1978), at least one generation of progeny could have reached adulthood. The 12 unidentifiable frogs found during this study suggests the four adult survivors and possibly more, had successfully bred. The progeny were of at least two separate age classes (one adult female, 11 sub-adults) indicating more than one successful breeding season. These findings suggest the original translocation was a success as it fits the criteria set forth by Germano and Bishop (2009).

Despite the expected declines in population estimates and number of frogs captured as seen in Bell et al. (2004b); Tocher and Pledger (2005); Lukis (2009), with the addition of the survivors, the survival estimates of this study were high (0.91) and are approaching the successful Boat Bay (0.97) and Motuara Island (0.99) translocations survival estimates (Bell et al. 2004b; Tocher and Pledger 2005). High survival in conjunction with the reduction in population estimates, MNA and number of captures suggests more frogs could be alive than emergence data indicates. This is supported by the actual number of frogs captured being lower than the most conservative population estimation method of MNA. High captures in the beginning of the study could potentially be due to the frogs being unfamiliar with their new habitat and therefore may not have established retreat sites, resulting in higher nocturnal activity. Once they became more familiar with their environment and established retreat sites, the need to emerge may have decreased. Capture-shyness has previously been found for newly marked individuals (Bell and Pledger 2005, 2010). However, the Jolly-Seber model chosen with the probability of capture held constant over time indicates no capture-shyness.

Frogs unaccounted for could be explained by three scenarios: 1. The frogs could be dead. Death of some is expected, but with only one frog found deceased, this can not be contributed as the sole reason. 2. Frogs could be alive but missed by field assistants. I relied heavily on volunteers to help me with this study. People that volunteered through the entire length of this study became quite proficient at searching for and finding emerged frogs. Those that volunteered less often did not appear to be as likely to find frogs. 3. The frogs are alive, but did not emerge from their diurnal retreat sites during the sampling periods or could have dispersed out of the study site. One translocated frog was found outside the exclusion fence. This leads to the possibility that additional frogs could have exploited the various fence imperfections prior to fence repair. Ultimately, all of these factors could have influenced the reduced number of frogs found in the later stages of the study. 
However, these results need to be interpreted with caution. The reduced population estimates, MNA and number of captures are of short duration and do not indicate an accurate representation of survival of the population over time. Alternatively, the results indicate seasonal variation of emergence which is in contrast to what was found in $L$. archeyi by Cree (1989). These contrasting results are likely due to the differences in moisture conditions such as rainfall and relative humidity between the two studies. As long as the "conditions are favorable", Cree (1989) did not find significant differences in number of $L$. archeyi emerged on wet summer and wet winter nights. However, the drought conditions exacerbated by the decrease in temperature could have confounded the effect of reduced emergence of $L$. pakeka in Zealandia.

Proximate and ultimate causes for the population decline of the original translation need further investigation. Multiple successive years of monitoring will give a more accurate indication of potential seasonal affects as well as more accurate survival and population estimates.

\subsubsection{Movements}

Movements of the frogs in this study need to be interpreted with caution as they were confined to a fenced $12.5 \times 15 \mathrm{~m}$ plot; therefore, measurements of their movements do not necessarily reflect their normal behavior in the wild - e.g. regarding measure of home ranges, homing or dispersal.

Movements and home range estimates were calculated for the 16 frogs that were captured eight times or more. Seaman et al. (1999) state that the minimum recommended capture number for kernel density estimations $n \geq 30$, preferably $n \geq 50$. Results from the $95 \%$ LSCV kernel density estimation were $30 \%$ greater than MCP estimations for some individuals and inconsistent with home range estimates from Maud Island (Bell and Moore 2012). This effect has also been reported by Seaman et al. (1999); Row and Blouin-Demers (2006); Laver and Kelly (2008).

These differences in estimations could be the result of autocorrelation caused by small utilization distributions (such as high site fidelity as seen in L. pakeka (Bell and Moore 2012)), which can increase the range of the optimal smoothing parameter (bandwidth) and can lead to an over-estimation of home range (Row and Blouin-Demers 2006). With sufficient number of captures and appropriate choice of bandwidth, MCP and LSCV kernel estimations have been shown to give similar results (Row and Blouin-Demers 2006; Bell and Moore 2012). For these reasons, home ranges incorporating LCSV kernel density estimations are better suited to longitudinal home range analysis such as Bell and Moore (2012), and are not warranted for this short-term study. Therefore, rather 
than using an incorrect smoothing parameter giving inaccurate home range estimates, the more conservative MCP method was used for home range estimations as suggested by Row and Blouin-Demers (2006).

Once L. pakeka establish a home range, they exhibit high site fidelity shifting centers of activity approximately $1.3 \mathrm{~m}$ per decade (Bell and Moore 2012). This high site fidelity only appears to be exhibited in five frogs during this study. However, it is unknown how long it takes an individual to establish its home range. This is likely to vary between individuals through operation of various environmental and conspecific factors (e.g. retreat site availability and dominance). The rocky habitat of the study site was increased since the original 2006/2007 translocation, but only approximately $30 \%$ of the site was covered with rocks. This limited rocky habitat might still be inadequate, providing limited retreat sites for the 117 frogs in the study. The mean MCP estimate of this study is less than half of the mean MCP established by Bell and Moore (2012). Frogs with smaller habitat utilization estimates suggests quick home range establishment. Alternatively, it could be argued that individuals with larger utilization estimates failed to establish a home range within the short duration of this study, resulting in the frog continuing to transverse the site in search of a territory of its own.

Although Lukis (2009) did not find homing to explain the population reduction of the 2006/2007 cohort, Germano (2006) found that L. pakeka have the ability to home over short distances, especially during the breeding season. The timing of the breeding season as suggested by Bell (1978, 1985b, 2011a) and (Germano et al. 2012) could have possibly had a homing effect on the initial movements (those captured in December) of the translocated frogs, $65 \%$ which were in the northwest direction of Maud Island. Of the 16 most frequently recaptured frogs, the centers of activity for $56 \%$ of the frogs appeared to be uphill from their release points. Although the sample size is small, this corroborates the the potential for homing and the uphill movements found by Germano (2006). However, Germano (2006) stated that the approximate $25 \mathrm{~km}$ distance between Long Island (where her translocation study occurred) and Maud Island (source of the studied population) suggested it unlikely "that such a strong and immediate homing instinct would be elicited in these frogs". Maud Island is approximately $78 \mathrm{~km}$ northwest of Zealandia, which incidentally, is in the uphill direction at the study site. Although there is no empirical support, the distance between the Zealandia sanctuary and Maud Island is most likely great enough to discourage homing. Germano (2006) also suggested that the frogs translocated to Long Island could have possibly moved uphill toward more appealing rocky habitat. Additional rocky habitat is located uphill from the site of this Zealandia study, but visual recognition of this rocky habitat was probably obstructed by the shade cloth fencing. Leiopelma pakeka are capable climbers and have been found in trees during this study and previous studies (Waldman and Bishop 2004; Germano and 
Bishop 2007a). Therefore, it is unknown if the uphill movements are a result of homing or from an innate sense of these anurans to climb.

The reduced MCP, as well as the ambiguity in dispersal and homing estimates recorded are to be expected given the confined habitat the frogs inhabit. The removal of the fence would allow for non-restricted movement analysis. Continued monitoring, should the fence be removed, would provide more accurate home range, dispersal and homing estimations and increasing the search area, particularly to the north and west of the study site, could reveal additional survivors.

\subsubsection{Possibility of escape}

Though out this study I have found various imperfections in the fence. Two holes were found 17 December 2012 on the north side of the fence along ground level. The shade cloth appeared to be pushed through from the exterior of the fence and the diameter of the holes (approx. 2.5-3.5 cm) seemingly fit the bill of a LSK. There were no other kiwi-made holes, perhaps due to the occupied pair learning the fence was an impenetrable obstacle. Other imperfections were the result of rainfall eroding the soil out from underneath the fence or fallen trees that uplifted roots and caused additional possible routes of escape. Each hole found was repaired, but the lapsed time in between site monitoring could have allowed for frogs to take advantage of the passage.

\subsubsection{Weather co-variates}

It is difficult to determine the ultimate cause for the reduction in emergence. Temperature, and to a lesser extent $\mathrm{RH}$, could have been proximate causes for reduced emergence as it did show to have a significant effect.

Moisture related variables, specifically precipitation and relative humidity, were expected to have had more significance on emergence. A study on the smaller L. archeyi (Cree 1989) and a study on the similar sized L. hamiltoni on Stephen's Island and L. pakeka on Maud Island (Newman 1990) found moisture related factors (i.e. precipitation and $\mathrm{RH}$ ) to have a significant effect on emergence. As these variables were not found to be significant in this study, the drought experienced during this study could have influenced this outcome. Peak months for the drought in Wellington were February and March (NIWA 2013) with only mean monthly rainfall of $2.36( \pm 1.78) \mathrm{mm}$ and $2.92( \pm 1.97) \mathrm{mm}$, respectively. There were only 21 unique recaptures during March (the smallest being $35.8 \mathrm{~mm}$ ), flanked by 53 in February and 39 in April. It is possible that rainfall could have had more of a significant effect on emergence, but with rainfall only occurring five 
out of 44 capture occasions, perhaps there were too few rainy nights to show a statistical significance. The frogs captured during the drought were active and did not show any signs of desiccation. Even through the drought, the mean BCI was still higher than the mean BCI on Maud Island, indicating a good overall condition. To substantiate the robustness of the frogs recapture during the drought, the collection of individuals on Maud Island took place during a rainless week. This suggests that the frogs captured for translocation (predominately large females), particularly those that emerged at night, are more robust to drier climate conditions and therefore more apt to survive.

In regard to $\mathrm{RH}$, drought conditions would have also affected $\mathrm{RH}$ levels. Cree (1989) found no nocturnal emergence of $L$. archeyi after rainless days and when $\mathrm{RH}$ was $\leq 87 \%$ whereas Newman (1990) found five Stephen's Island frogs in one night with a measurement of $59 \% \mathrm{RH}$ (albeit, this night occurred after three days of diurnal rain showers). The lowest RH recorded during this study was $51 \%$, with three adults females emerged. This was also the night of the coldest temperature recorded during study $\left(5^{\circ} \mathrm{C}\right)$, which was preceded by only $2.6 \mathrm{~mm}$ of rain during the previous week.

This study supports the findings from Newman (1990) where emergence of L. pakeka adults on Maud Island was significantly correlated with temperature. Newman credited the dense Maud Island vegetation as protection against drought conditions whereas on Stephen's Island, the "frog bank" then lacked forest protection, leaving it more exposed to the elements. The Maud Island understory vegetation has grown since the Newman study, but Zealandia has similar forest protection.

The frogs' habitat is climatically well protected by the forest. The effects of wind are mitigated by the dense canopy and the moisture levels are maintained by a variety of factors. 1. The frogs' habitat sits in a valley on an eastern facing slope with the opposite slope providing shelter from the early morning sun. When sunlight does come in contact with frogs' habitat, the dense forest canopy not only mitigates evaporation, but it also lessens the effects of the wind and the direction by which it originates (personal observation). 2. Although there is not much of the vitally important understory, the surface area with rocks covered approximately $30 \%$ of the $187.5 \mathrm{~m}^{2}$ study site. The larger surface area covered by rocks in comparison to the rock coverage in the Lukis (2009) study, could also help maintain soil moisture. These factors along with the quick rehydration rates of the frogs (Cree 1985) suggests possible variables for dehydration mitigation. 


\subsubsection{What does this all mean?}

The indication of mouse activity not having an effect on frog emergence numbers is not only valuable information to the Zealandia wildlife sanctuary, but also to the survival of the remnant population on Maud Island. The latest mouse invasion on Maud Island has set the Native Frog Recovery Group and DOC into action. The Department of Conservation plans to initiate the eradication program in the autumn/winter season when natural food items would be reduced resulting in a greater likelihood of mice taking the bait (Department of Conservation 2013b). However, this postponement of the program will allow mouse densities to increase on the island where the lack of food could cause the mice to switch prey to less favorable, unpalatable food items, such as Maud Island frogs. Additionally, albeit second generation anticoagulant poisons such as the commonly used Brodifacoum $^{\mathrm{TM}}$ has no insecticidal properties, the poison does not appear to present as a secondary poisoning risk to L. pakeka (Eason and Spurr 1995; Booth et al. 2001; Hoare and Hare 2006). However, avian secondary poisoning has been a consequence of using this poison (Eason and Spurr 1995; Hoare and Hare 2006) and research is further warranted for the safety of L. pakeka on Maud Island. Therefore, monitoring the Maud Island frog population through to the end of the eradication program is highly recommended so a contingency plan could be initiated if necessary.

As previously stated, this study does not present conclusive evidence that mice do not prey on Maud Island frogs. However, this research does suggest that the seasonal reduction of temperature and potentially low moisture levels, not mouse activity levels, have an effect on L. pakeka emergence. Additionally, even with limited rocky habitat, over the six years in between the original translocation and the time of this study, through peaks and troughs of the mouse population, some frogs have survived and have bred successfully. These results serve as a segue to future studies for understanding this critically important ecological relationship between the invasive mice and nationally treasured amphibians. The discernment of this relationship will have vital importance to the continued existence for the rest of the Leiopelma genus. 


\section{Chapter 5}

\section{Is a free-ranging, viable population of Leiopelma pakeka possible in the Zealandia wildlife sanctuary?}

This study focused on the Maud Island frogs in the Zealandia wildlife sanctuary where they now inhabit three predator-proof enclosures and a small patch of forest. Previous efforts to establish a free-ranging, viable population in the sanctuary were thought to have failed, but this study found that the first translocation was after all, to a degree, successful.

This thesis was a sequel to the previous Lukis (2009) study to assess the enclosed frog populations in Zealandia and to investigate what might have happened to the original translocation of free-ranging frogs. I focused on three questions: 1. How have the frogs in the three separate predator-proof enclosures fared since their last human contact in 2011? 2. Do the LSK living in Zealandia show an interest in Maud Island frogs while foraging? 3. With more available habitat, how would a larger translocated population of Maud Island frogs survive with the current mouse population?

The following provides a summary and adaptive management recommendations to maintain or increase the current frog populations in Zealandia. 


\subsection{Summary of results}

1. Frogs in the original enclosure still exhibit high survival and successful recruitment. Although 18 out of the remaining 19 frogs were recaptured, there could still be individuals that have survived but were not recaptured. This is supported by multiple periods in between recaptures, such as frog M12 where three capture periods passed inbetween recaptures and frog B7 not being recaptured until the eighth capture period. This is also strongly supported by frog B7 being completely missed in the 2011 census, but was recaptured during this study. This demonstrates how even in an enclosed environment, these cryptic, sedentary animals can be difficult to see even if they are emerged. Even with a possible reduction in numbers, this enclosure provides the right conditions for survival and breeding with evidence of the sixth consecutive successful breeding season provided by sightings of young frogs.

The second enclosure originally served as a nursery enclosure with the addition of 34 newly metamorphosed frogs. This study has shown that 12 have survived, three sub-adults and nine adults. Given the size of the enclosure and the relatively small number of individuals which inhabit it, the few occasions on which these frogs were seen was probably due to little to no competition for resources. The reduced competition would not force the frogs to emerge at night for food. Nonetheless, the second enclosure adds to the success of Leiopelma survival in protected outdoor enclosures and gives a crude estimate of newly metamorphosed juvenile survival rate $(35 \%)$.

The publicly viewed enclosure along the Te Mahanga track housed six individuals for the majority of this study which all have been recaptured. Sightings of juveniles from November through to June indicate that the relocation of the adults did not disturb adult breeding or brooding. This is the first evidence of successful breeding in this enclosure. Three frogs from the second enclosure were relocated to this enclosure in May 2013. Two were recaptured post-relocation. It is too early to determine if all three continue to survive.

The number of recaptures in each enclosure, along with juveniles in the original and Te Mahanga enclosures, indicates that the relatively controlled environment inside the outdoor enclosures provides a conducive environment to the survival and successful breeding of L. pakeka within the Zealandia boundaries.

2. The little spotted kiwi (LSK) recorded on video while foraging in the presence of a Maud Island frog (in a protective container) failed to show a strong response to the presence of the frog. Three videos in three separate LSK territories showed LSK 
foraging immediately adjacent to, and potentially probing into the frog containers, without an apparent pursuit of the frogs. Care was taken during analysis to not confuse neophobia of the newly placed containers with non-interest in the frogs. Behavior of the LSK foraging adjacent to the container, as well as actively probing around the cameras (indicated by sound) indicated no neophobia. The video analysis revealed that when a LSK detects a prey item, it spends a considerable amount of time and effort to extract the prey for consumption. Each occasion on which a LSK foraged in the vicinity of, immediate adjacent to, or passing its bill immediately above the frogs container, did not even warrant a pause of investigation by the LSK. I have come to the tentative conclusion that if a LSK did happen to consume a frog, it would be by chance of stumbling across the frog during normal foraging behavior and that LSK do not seek out the relatively large frogs for prey as they do for smaller invertebrates.

3. With the addition of preferred rocky habitat, along with a larger founding number $(\mathrm{n}=101)$, a population of L. pakeka appears able to survive through peak mouse densities in the Zealandia boundaries. Although emergence numbers declined, Jolly-Seber overall survival estimation was high (91.4\%) and the correlation of emergence and mouse activity levels was not significant $(\mathrm{p}>0.05)$. Reduced emergence is correlated with reduced temperature $(\mathrm{p}<0.001)$ and potentially low relative humidity $(\mathrm{p}=0.0517)$. Although relative humidity is correlated with precipitation, drought conditions limited rainfall and therefore limited rainy nights failed to show a significance in emergence $(\mathrm{p}>0.05)$. The habitat where the frogs are located is well protected by the position in the valley, by the slope of the hillside, forest/canopy protection and the amount of surface area covered by rocky substrate. This protection could have lead to the discovery of the four surviving adults, along with 12 new recruits. Albeit the number is low, this discovery indicates that the 2006/2007 translation was to a degree, a success.

\subsection{Study limitations}

\section{Predator-proof enclosures}

The survival of L. pakeka in the original predator-proof enclosure along with an accurate count of new recruits is only estimated as a complete census was not conducted.

Low emergence in the second enclosure would have led to a considerable underestimation of the number of surviving individuals. This would have been a limitation if the full census had not been carried out. 
Although all six relocated frogs were recaptured in the Te Mahanga enclosure, Zealandia night tours were the first to visit each night and it is unknown if this disturbance caused the frogs to retreat prior to my emergence checks. The Zealandia night tour guides only document if they happened to notice emerged frogs. They do not thoroughly check the enclosure, nor do they take any steps to identify individuals.

As noted by Cree (1989), the quick passing of a beam of light did not appear to disturb the frogs, but prolonged light exposure did cause the frogs to retreat. As each enclosure was checked for emergence section by section, it is possible that frogs emerged in sections yet to be checked picked up on the vibrations and/or illumination caused by the observer, causing them to retreat under the substrate. Additionally, leaf litter was not disturbed therefore a frog that had emerged but just under the first layer or two of leaves may not have been noticed. The inconspicuous nature of these frogs make them easily missed.

Proposed recommendations: The sixth consecutive successful breeding season provides evidence that the habitat inside the original enclosure is conducive to successful husbandry and breeding of L. pakeka. However, the growing population is confined to a small habitat and resource competition and inbreeding depression could present future complications. Some individuals from this enclosure should be relocated to the second enclosure to reduce these pressures. Caution is warranted because the individuals already inhabiting the second enclosure are progeny of the individuals in the original enclosure. An alternative option, the Wellington Zoo has expressed interest in the establishment of a frog population to advocate New Zealand's unique amphibians to its visitors. Working with the guidelines of outdoor amphibian husbandry of Auckland Zoo and with Zealandia, Wellington Zoo could alleviate the potential pressures in the original enclosure by relocating individuals to their facility. Prior to the frogs' relocation, it is recommended that each frog be quarantined and tested for chytrid fungus (Batrachochytrium dendrobatidis).

Emergence in the second enclosure could have been inhibited by the frogs not needing to emerge to acquire resources. The census did provide vital information on their survival, but their survival by checking emergence also could have been improved with a study of longer duration and during more favorable weather conditions (i.e. not during a drought).

Emergence of the frogs inhabiting the Te Mahanga public enclosure could have been affected by the Zealandia night tour participants. Red lights are used by the visitors and frogs do not emerge every night, but it is not known how nightly disturbance affects the frogs. Advocacy of the species is important to the conservation efforts of the species and 
Maud Island frogs are just one of the highlights of the night tours. With this enclosure being relative small, an annual census during the early autumn season should be considered and new progeny removed to prevent over crowding.

$\underline{\text { Kiwi-frog encounters }}$

Results of the kiwi-frog encounters should be interpreted with caution. The LSK in Zealandia are free-range and as close to wild as they can be. However, they could potentially be accustomed to the captive environmental smells, noises, volume of daily visitors and Zealandia daily operations. It is not known if these disturbances have altered LSK behavior in the sanctuary.

The small sample size of only three videos does not necessarily represent the level of interest in frogs of all LSK in Zealandia, nor any other Apteryx species toward Maud Island frogs. The LSK captured on video did not appear to be neophobic toward the equipment used in this study, but this is only conjecture.

Proposed recommendation: A scent test, as done by Cunningham et al. (2009), could be modified to further understand LSK interests in Maud Island frogs. This could be duplicated with other kiwi and frog species as a risk assessment analysis for future translocations.

\section{Founding population}

The founding population ( $\mathrm{n}=101)$ was biased toward adults, particularly adult females. Although this is similar to the translocated populations of the Boat Bay (Bell et al. 2004b) and Motuara Island translocations (Tocher and Pledger 2005), it is not representative of the bi-modal distribution of the Maud Island population (Lukis 2009). In addition, the collection of individuals on Maud Island took place during a rainless week. The frogs emerged during this week could have been more robust to drier weather conditions. This could have influenced (potentially beneficial) the survival of the translocated cohort during peak drought conditions. Conversely, they may have been in greater need of food resources and therefore had emerged due to necessity.

Although a founding population of 100 and 300 individuals resulted in the successful translocations to Boat Bay (Bell et al. 2004b) and Motuara Island (Tocher and Pledger 2005), these relatively low founding numbers are only estimated at a $40 \%$ chance of translocation success (Germano and Bishop 2009).

Proposed recommendation: Future translocations of L. pakeka should be selected to better represent the natural bi-modal population on Maud Island and should be no fewer than 100 individuals. To supplement the Zealandia population, additional translocations may be carried out to offset any population loss. As it takes 3-4 years for the frogs to 
mature, and now that there is a mouse invasion on Maud Island, possibilities for future translocations should be reassessed after the mice are eradicated from Maud Island and there is ample evidence that the frog population has survived in good numbers and are breeding successfully. Thereafter, dates and the quantity of frogs could be addressed.

$\underline{\text { Experimental design }}$

The kiwi-exclusion fence was not only to keep potential predatory kiwi out, but to also mitigate potential dispersal; therefore, the study was restricted to a discrete search area. However, soil erosion and potential kiwi probing caused various imperfections in fence integrity. This allowed one of the translocated frogs to breach the fence, which introduces the possibility that others could have taken advantage of fence imperfections prior to fence mending. If those frogs dispersed beyond the $2 \mathrm{~m}$ buffer zone, they would not have been found. In addition, at least one frog was known to have died during the study. Without evidence of other translocated frogs found outside the fence or of additional deaths, it is not known what could have caused negative trend in the population estimates.

Proposed recommendation: If ultimate dispersal abatement is required, an impenetrable skirt starting below the soil and extending up to the halved PVC pipe should be installed. Care would need to be taken around tree roots to ensure fence integrity.

$\underline{\text { Habitat engineering }}$

The amount of rocky habitat was substantially increased. Newman et al. (1978) and Newman (1990) cite the importance of deep, continuous, connected rocky habitat for the survival of terrestrial Leiopelma. The amount of rocky surface area was increased from the eight disconnected rock piles of the Lukis (2009) study. However, only approximately $30 \%$ of the site was covered with rocks. This is less than the $0.5-1.0 \mathrm{ha}^{2}$ habitat coverage recommended to support a L. pakeka population (Newman 1990). There were not enough available rocks within the Zealandia boundaries that were able to be relocated to provide greater depth.

Understory vegetation may also be an important factor in maintaining moisture levels. Many ferns were unintentionally destroyed by the addition of rocks. Supplejack vines (Rhipogonum scandens) also needed to be pruned back to allow safe passage through the site. This reduction in vegetation is likely to have affected moisture factors at the site and would have reduced opportunities for elevated emergence sites.

Proposed recommendation: Additional rocky substrate should be incorporated with care into the site, particularly on bare earth areas. For biosecurity precautions, the primary choice of rocks would be from inside the Zealandia boundaries. If no additional 
rocks could be obtained from within the sanctuary, rocks should be quarried from outside Zealandia. Artificial cover objects as presented by Wakelin et al. (2003) may also be implemented to provide additional diurnal retreat sites. Additionally, vegetation should be specifically planted to increase the understorey and to help maintain moisture levels. Care would need to be taken to not shift any rocks already on site.

Fence removal could potentially allow those frogs with a large MCP to disperse and acquire a territory. Caution needs to be given, the rocks on site lay upon top soil. Erosion of the soil may allow the rocky substrate to slide down hill over time. A blockade may be required to keep the rocks in their current positions. Additionally, although this research suggests LSK show little interest in L. pakeka removal of the fence could potentially put the frogs at risk.

$\underline{\text { Search methodology }}$

Leiopelma pakeka are inconspicuous, cryptic, relatively sedentary and often do not vocalize (Bell 2008a). Their emergence can be variable (Cree 1989) and although searches were systematic, the frogs are easily overlooked by observer non-familiarity.

Proposed recommendation: Observers should be familiarized with the cryptic nature of the frogs and should go through pictorial practice runs prior to actually field work. In addition, the same observers should be used for the entire duration of the study to reduce the chances of overlooking emerged frogs.

\subsection{Adaptive Management}

The adaptive management suggestions outlined by Lukis (2009) of an increased founding population, exclusion of potential predators (i.e. LSK via exclusion fence) and an increase in rocky habitat were addressed to carry out this study. The results presented in this thesis have given suggestions to what might have caused reduced emergence. However, there is still some ambiguity involving the ultimate cause for population decline in the 2006/2007 translocation as well as whether reduced emergence of this study is solely from seasonal affects.

These ambiguities need to be addressed in the pursuit of L. pakeka establishment in Zealandia. The knowledge gained by these adaptive management questions can be used to develop strategies which can be applied not only to the population within Zealandia, but also to the population on Maud Island and any other potentially translocated populations. 
1. What is the carrying capacity of the three predator-proof enclosures? Would new recruits need to be continuously removed and relocated to ensure minimal intraspecific competition? Would the fabrication of a larger predator-proof enclosure be better suited for a growing population of L. pakeka in the Zealandia sanctuary? What additional locations would be appropriate to receive L. pakeka within Zealandia, or outside facilities such as the Wellington Zoo and/or Pukaha Mt. Bruce Wildlife Centre?

2. Are L. pakeka palatable to LSK? Does the scent of L. pakeka register as a prey item to LSK? Given a no barrier approach, would LSK still appear to be uninterested in L. pakeka?

3. Are L. pakeka palatable to mice? What are the demographic trends of the mouse population in the frogs' habitat in Zealandia? At what mouse density would $L$. pakeka be considered to be at risk of predation? A more conclusive inquiry of mouse-frog interaction is warranted, especially since the latest mouse invasion has potentially jeopardized the species.

4. Although studies have shown that the Leiopelma species have shown low susceptibility to Bd (Bishop et al. 2009; Melzer and Bishop 2010; Ohmer et al. 2013; Shaw et al. 2010), chytridiomycosis infection should not be eliminated as a risk to any of the Leiopelma populations. The swabs taken from the second cohort translocation should be tested for $B d$ prior to any future Leiopelma translocation. To date, Zealandia operates with the assumption that the fungus has not established in the sanctuary, yet there is no preventative measure to ensure such an event does not take place. To prevent the fungus from establishing in the sanctuary, a mandatory boot and pram/wheelchair wheel wash of Trigene at the entrance gate is highly recommended to keep the current frog population safe, and especially prior to any future Leiopelma establishment in the Zealandia wildlife sanctuary.

\subsection{Moving forward}

Until additional predator-free islands are deemed suitable for a Leiopelma population, mainland sanctuaries such as Zealandia are of vital importance to the ongoing survival of the species. This study suggests that neither LSK, nor the peak in mouse activity caused the apparent population decline of the original translocated cohort of L. pakeka and that the more likely factor was low founding number and insufficient rocky habitat. With this information, along with the continued mammal eradication program and the implementation of these adaptive management suggestions, the Zealandia wildlife sanctuary 
does harbor the appropriate conditions to support a free-ranging, viable population of Maud Island frogs.

I recommend an additional survey of the frog population to take place in the beginning of 2014. Although this study did not indicate a significance of precipitation in regard to frog emergence, the survey should take place during optimal weather conditions to maximize frog emergence. Annual searches, at minimum for the next 4 years, will provide important information for the determination of success of the December 2012 translocation. The Society for Conservation Biology (SCB) Victoria University chapter, has expressed interest in involvement and continuation of the frog monitoring in Zealandia. The society's involvement would further support the important relationship between the beneficial sanctuary and the academic research community. In addition to the SCB participation, I recommend local iwi involvement which is underrepresented in any endemic anuran study. Iwi involvement would give an opportunity to develop a greater understanding of the ecology of their taonga and would assist in future Leiopelma co-management opportunities and aid in the conservation of the species.

Another important aspect to Leiopelma conservation is public awareness and experience with the species. Zealandia provides this very opportunity to the participants of the Zealandia night tours by guiding the group past the Te Mahanga enclosure to potentially catch a glimpse of the Nationally Vulnerable Maud Island frog. However, this advocacy opportunity is unavailable to the far greater numbers of daytime visitors of the sanctuary, especially to the younger generation who will eventually be the future caretakers of the species. I have witnessed daytime visitors pass the Te Mahanga enclosure and walk away disinterested once they learn they have to return at night to see the frogs. This missed opportunity creates a disconnect, failing to spark an interest in the species. To provide the opportunity for species advocacy to Zealandia's daytime visitors, I recommend an investment in a night-house viewing room, such as the one for Archey's frogs at the Auckland Zoo. This will allow a greater number of people to view, experience and learn more about the endemic frog. The simple action of seeing a Maud Island frog up close will hopefully create a connectedness, particularly with the younger generation, and elicit an interest in the conservation of the species. 


\section{Appendix A}

\section{Maud Island captures (raw data)}

\begin{tabular}{|c|c|c|c|c|c|c|c|c|c|c|}
\hline Frog ID & Date & $\mathrm{TC}^{1}$ & Girth $^{2}$ & $\begin{array}{l}\mathrm{SVL}^{3} \\
(\mathrm{~mm})\end{array}$ & $\begin{array}{l}\mathrm{Wgt}^{4} \\
(\mathrm{~g})\end{array}$ & $\mathrm{BCI}^{5}$ & $\operatorname{Int}^{6}$ & $\mathrm{Pat}^{7}$ & $\begin{array}{l}\text { Age } \\
\text { class }^{8}\end{array}$ & $\begin{array}{l}\text { Rock } \\
\text { pile }^{9}\end{array}$ \\
\hline $\mathrm{T} 1$ & 26.11 .2012 & & 4 & 44.3 & 9.7 & 0.599 & $\mathrm{~m}$ & $\mathrm{pm}$ & $\mathrm{AF}$ & up \\
\hline $\mathrm{T} 2$ & 26.11 .2012 & 3300 & 2 & 44.4 & 7.6 & 0.535 & $\mathrm{~m}$ & $\mathrm{~m}$ & $\mathrm{AF}$ & up \\
\hline $\mathrm{T} 3$ & 26.11 .2012 & 3400 & 3 & 43.3 & 7.2 & 0.524 & $\mathrm{~m}$ & $\mathrm{~m}$ & $\mathrm{AF}$ & up \\
\hline $\mathrm{T} 4$ & 26.11 .2012 & 3030 & 4 & 43.4 & 7.4 & 0.531 & $\mathrm{~m}$ & $\mathrm{mp}$ & $\mathrm{AF}$ & up \\
\hline $\mathrm{T} 5$ & 26.11.2012 & & 3 & 43.7 & 7.1 & 0.519 & $\mathrm{~m}$ & $\mathrm{mp}$ & $\mathrm{AF}$ & up \\
\hline T6 & 26.11.2012 & & 3 & 43.9 & 6.5 & 0.495 & $\mathrm{~m}$ & $\mathrm{mp}$ & $\mathrm{AF}$ & up \\
\hline $\mathrm{T} 7$ & 26.11 .2012 & 3040 & 3 & 44.7 & 7.5 & 0.530 & $\mathrm{~m}$ & $\mathrm{~m}$ & $\mathrm{AF}$ & up \\
\hline $\mathrm{T} 8$ & 26.11 .2012 & 2000 & 3 & 45.4 & 7.9 & 0.542 & $\operatorname{lm}$ & $\mathrm{p}$ & $\mathrm{AF}$ & up \\
\hline Т9 & 26.11 .2012 & & 4 & 44.8 & 7.3 & 0.523 & $\mathrm{~m}$ & $\mathrm{p}$ & $\mathrm{AF}$ & low \\
\hline T10 & 26.11 .2012 & 3050 & 4 & 48.4 & 9.9 & 0.591 & $\mathrm{~m}$ & $\mathrm{~m}$ & $\mathrm{AF}$ & up \\
\hline $\mathrm{T} 11$ & 26.11.2012 & 3003 & 3 & 40.1 & 6.1 & 0.490 & $\mathrm{~d}$ & $\mathrm{u}$ & $\mathrm{AF}$ & up \\
\hline $\mathrm{T} 12$ & 26.11 .2012 & & 3 & 43.1 & 7.1 & 0.521 & $\mathrm{u}$ & $\mathrm{ml}$ & $\mathrm{AF}$ & mid \\
\hline $\mathrm{T} 13$ & 26.11 .2012 & & 3 & 44.3 & 7.4 & 0.528 & $\mathrm{ml}$ & $\mathrm{p}$ & $\mathrm{AF}$ & mid \\
\hline $\mathrm{T} 14$ & 26.11 .2012 & 0004 & 3 & 43.5 & 6.8 & 0.508 & $\mathrm{~m}$ & $\mathrm{~m}$ & $\mathrm{AF}$ & up \\
\hline $\mathrm{T} 15$ & 26.11 .2012 & & 3 & 41.4 & 6.6 & 0.507 & $\operatorname{lm}$ & $\mathrm{p}$ & $\mathrm{AF}$ & up \\
\hline $\mathrm{T} 16$ & 26.11.2012 & 3004 & 3 & 42.8 & 7.4 & 0.533 & d & $\mathrm{u}$ & $\mathrm{AF}$ & up \\
\hline $\mathrm{T} 17$ & 26.11.2012 & & 3 & 43.4 & 7.1 & 0.520 & md & $\mathrm{p}$ & $\mathrm{AF}$ & mid \\
\hline $\mathrm{T} 18$ & 26.11 .2012 & 3005 & 3 & 44.7 & 8.7 & 0.569 & $\mathrm{~m}$ & $\mathrm{~m}$ & $\mathrm{AF}$ & up \\
\hline T19 & 26.11 .2012 & & 3 & 44.2 & 8.1 & 0.552 & $\mathrm{~m}$ & $\mathrm{mp}$ & $\mathrm{AF}$ & up \\
\hline $\mathrm{T} 20$ & 26.11 .2012 & 4300 & 3 & 45.0 & 6.9 & 0.507 & $\mathrm{~m}$ & $\mathrm{~m}$ & $\mathrm{AF}$ & up \\
\hline $\mathrm{T} 21$ & 26.11 .2012 & 4400 & 3 & 45.6 & 8.9 & 0.572 & $\mathrm{~m}$ & $\mathrm{pm}$ & $\mathrm{AF}$ & low \\
\hline $\mathrm{T} 22$ & 26.11.2012 & & 3 & 43.0 & 7.4 & 0.532 & $\mathrm{~m}$ & $\mathrm{mp}$ & $\mathrm{AF}$ & low \\
\hline $\mathrm{T} 23$ & 26.11 .2012 & 4030 & 3 & 44.6 & 7.7 & 0.537 & $\mathrm{~m}$ & $\mathrm{~m}$ & $\mathrm{AF}$ & low \\
\hline $\mathrm{T} 24$ & 26.11 .2012 & 4040 & 3 & 40.6 & 5.8 & 0.475 & $\mathrm{~d}$ & $\mathrm{u}$ & $\mathrm{AF}$ & up \\
\hline $\mathrm{T} 25$ & 27.11 .2012 & & 4 & 43.1 & 7.6 & 0.539 & $\mathrm{dm}$ & $\mathrm{p}$ & $\mathrm{AF}$ & low \\
\hline $\mathrm{T} 26$ & 27.11.2012 & 3000 & 4 & 28.1 & 2.6 & 0.286 & $\mathrm{dm}$ & $\mathrm{m}$ & $\mathrm{SU}$ & low \\
\hline $\mathrm{T} 27$ & 27.11 .2012 & & 4 & 40.2 & 8.9 & 0.592 & $\mathrm{~m}$ & $\mathrm{~m}$ & $\mathrm{AF}$ & low \\
\hline $\mathrm{T} 28$ & 27.11.2012 & & 4 & 43.8 & 8.4 & 0.563 & $\mathrm{~m}$ & $\mathrm{mp}$ & $\mathrm{AF}$ & up \\
\hline T29 & 27.11 .2012 & & 3 & 46.2 & 8.2 & 0.549 & $\mathrm{~m}$ & $\mathrm{p}$ & $\mathrm{AF}$ & up \\
\hline T30 & 27.11 .2012 & & 4 & 45.7 & 9.3 & 0.583 & md & $\mathrm{p}$ & $\mathrm{AF}$ & mid \\
\hline
\end{tabular}




\begin{tabular}{|c|c|c|c|c|c|c|c|c|c|c|}
\hline T31 & 27.11.2012 & & 4 & 48.6 & 8.3 & 0.545 & md & $\mathrm{mp}$ & $\mathrm{AF}$ & mid \\
\hline T32 & 27.11 .2012 & & 4 & 44.5 & 8.2 & 0.554 & $\mathrm{dm}$ & $\mathrm{m}$ & $\mathrm{AF}$ & low \\
\hline T33 & 27.11.2012 & & 3 & 44.2 & 7.5 & 0.532 & $\mathrm{ml}$ & $\mathrm{p}$ & $\mathrm{AF}$ & mid \\
\hline T34 & 29.11.2012 & 4004 & 4 & 32.8 & 4.1 & 0.404 & $\mathrm{dm}$ & $\mathrm{p}$ & $\mathrm{SU}$ & up \\
\hline T35 & 29.11.2012 & & 3 & 39.7 & 6.5 & 0.508 & md & $\mathrm{p}$ & $\mathrm{AU}$ & mid \\
\hline T36 & 29.11.2012 & 4000 & 4 & 29.2 & 4.4 & 0.439 & md & $\mathrm{m}$ & $\mathrm{SU}$ & mid \\
\hline T37 & 29.11.2012 & & 3 & 41.2 & 4.1 & 0.379 & md & $\mathrm{p}$ & $\mathrm{AF}$ & low \\
\hline T38 & 29.11.2012 & & 2 & 43.5 & 6.1 & 0.479 & $\mathrm{~m}$ & $\mathrm{p}$ & $\mathrm{AF}$ & up \\
\hline T39 & 29.11.2012 & 0400 & & 45.1 & 6.0 & 0.470 & $\mathrm{~m}$ & $\mathrm{~m}$ & $\mathrm{AF}$ & up \\
\hline $\mathrm{T} 40$ & 29.11.2012 & & 4 & 43.3 & 7.2 & 0.524 & $\mathrm{~m}$ & $\mathrm{p}$ & $\mathrm{AF}$ & low \\
\hline $\mathrm{T} 41$ & 29.11.2012 & 4050 & 4 & 43.0 & 7.5 & 0.536 & $\mathrm{~m}$ & $\mathrm{~m}$ & $\mathrm{AF}$ & mid \\
\hline $\mathrm{T} 42$ & 29.11.2012 & & 3 & 41.7 & 6.9 & 0.518 & $\mathrm{~m}$ & $\mathrm{pm}$ & $\mathrm{AF}$ & low \\
\hline $\mathrm{T} 43$ & 29.11.2012 & 4005 & 4 & 41.8 & 6.6 & 0.506 & $\mathrm{dm}$ & $\mathrm{m}$ & $\mathrm{AF}$ & mid \\
\hline $\mathrm{T} 44$ & 29.11.2012 & & 3 & 31.8 & 2.7 & 0.287 & md & $\mathrm{p}$ & $\mathrm{SU}$ & low \\
\hline $\mathrm{T} 45$ & 29.11.2012 & & 3 & 45.3 & 7.6 & 0.532 & $\mathrm{ml}$ & $\mathrm{p}$ & $\mathrm{AF}$ & low \\
\hline $\mathrm{T} 46$ & 29.11.2012 & & 4 & 43.0 & 7.1 & 0.521 & $\mathrm{~m}$ & $\mathrm{mp}$ & $\mathrm{AF}$ & up \\
\hline $\mathrm{T} 47$ & 29.11.2012 & & 4 & 34.0 & 4.3 & 0.414 & $\mathrm{ml}$ & $\mathrm{mu}$ & $\mathrm{SU}$ & low \\
\hline $\mathrm{T} 48$ & 29.11.2012 & 0005 & 3 & 27.0 & 2.6 & 0.290 & $\mathrm{dm}$ & $\mathrm{mp}$ & $\mathrm{SU}$ & low \\
\hline T49 & 29.11.2012 & 0050 & 2 & 37.5 & 5.3 & 0.460 & $\mathrm{dm}$ & $\mathrm{u}$ & $\mathrm{AU}$ & low \\
\hline $\mathrm{T} 50$ & 29.11.2012 & & 4 & 42.8 & 8.1 & 0.557 & $\mathrm{dm}$ & $\mathrm{pm}$ & $\mathrm{AF}$ & low \\
\hline $\mathrm{T} 51$ & 29.11.2012 & & 3 & 37.4 & 5.4 & 0.466 & $\mathrm{~m}$ & $\mathrm{mp}$ & $\mathrm{AU}$ & mid \\
\hline T52 & 29.11.2012 & & 3 & 35.6 & 4.6 & 0.427 & $\mathrm{~m}$ & $\mathrm{~m}$ & $\mathrm{AU}$ & mid \\
\hline T53 & 30.11 .2012 & & 3 & 41.8 & 6.8 & 0.514 & $\mathrm{ml}$ & $\mathrm{pm}$ & $\mathrm{AF}$ & mid \\
\hline T54 & 30.11 .2012 & & 4 & 39.6 & 6.5 & 0.509 & 1 & $\mathrm{p}$ & $\mathrm{AU}$ & mid \\
\hline $\mathrm{T} 55$ & 30.11 .2012 & & 3 & 45.1 & 6.9 & 0.507 & $\mathrm{ml}$ & $\mathrm{p}$ & $\mathrm{AF}$ & mid \\
\hline T56 & 30.11 .2012 & & 4 & 42.3 & 9.4 & 0.598 & $\mathrm{~m}$ & $\mathrm{p}$ & $\mathrm{AF}$ & mid \\
\hline T57 & 30.11 .2012 & & 3 & 44.2 & 7.3 & 0.525 & $\mathrm{~m}$ & $\mathrm{p}$ & $\mathrm{AF}$ & mid \\
\hline T58 & 30.11 .2012 & & 3 & 42.7 & 7.0 & 0.518 & $\mathrm{~m}$ & $\mathrm{~m}$ & $\mathrm{AF}$ & mid \\
\hline T59 & 30.11 .2012 & & 3 & 44.1 & 6.4 & 0.490 & $\mathrm{~m}$ & $\mathrm{pu}$ & $\mathrm{AF}$ & mid \\
\hline T60 & 30.11 .2012 & 0330 & 3 & 42.0 & 7.2 & 0.528 & $\mathrm{~m}$ & $\mathrm{~m}$ & $\mathrm{AF}$ & up \\
\hline T61 & 30.11 .2012 & & 4 & 23.8 & 1.5 & 0.128 & $\mathrm{~m}$ & $\mathrm{mp}$ & $\mathrm{SU}$ & mid \\
\hline T62 & 30.11 .2012 & 0340 & 3 & 42.8 & 7.9 & 0.550 & $\mathrm{~m}$ & $\mathrm{~m}$ & $\mathrm{AF}$ & mid \\
\hline T63 & 30.11 .2012 & 0305 & 4 & 45.4 & 7.7 & 0.535 & $\mathrm{~m}$ & $\mathrm{~m}$ & $\mathrm{AF}$ & mid \\
\hline T64 & 30.11 .2012 & & 4 & 39.4 & 6.3 & 0.501 & $\mathrm{ml}$ & $\mathrm{p}$ & $\mathrm{AU}$ & mid \\
\hline T65 & 30.11 .2012 & & 4 & 37.7 & 5.6 & 0.475 & $\mathrm{~m}$ & $\mathrm{mp}$ & $\mathrm{AU}$ & mid \\
\hline T66 & 30.11 .2012 & & 3 & 15.8 & 0.4 & -0.332 & $\mathrm{~m}$ & $\mathrm{~m}$ & $\mathrm{~J}$ & mid \\
\hline T67 & 30.11 .2012 & 0350 & 2 & 40.8 & 5.2 & 0.445 & d & $\mathrm{u}$ & $\mathrm{AF}$ & mid \\
\hline T68 & 30.11 .2012 & 0303 & 3 & 42.5 & 7.7 & 0.544 & $\mathrm{~m}$ & $\mathrm{mu}$ & $\mathrm{AF}$ & mid \\
\hline T69 & 30.11 .2012 & & 4 & 35.1 & 4.6 & 0.429 & $\operatorname{lm}$ & $\mathrm{p}$ & $\mathrm{AU}$ & mid \\
\hline $\mathrm{T} 70$ & 30.11 .2012 & & 3 & 36.4 & 5.3 & 0.464 & md & $\mathrm{p}$ & $\mathrm{AU}$ & mid \\
\hline $\mathrm{T} 71$ & 30.11 .2012 & & 3 & 36.9 & 4.8 & 0.435 & $\mathrm{dm}$ & $\mathrm{pm}$ & $\mathrm{AU}$ & mid \\
\hline $\mathrm{T} 72$ & 30.11 .2012 & & 3 & 35.8 & 4.8 & 0.438 & md & $\mathrm{p}$ & $\mathrm{AU}$ & mid \\
\hline $\mathrm{T} 73$ & 30.11 .2012 & 0304 & 3 & 45.3 & 7.6 & 0.532 & md & $\mathrm{m}$ & $\mathrm{AF}$ & mid \\
\hline $\mathrm{T} 74$ & 30.11 .2012 & & 3 & 43.3 & 7.2 & 0.524 & $\mathrm{dm}$ & $\mathrm{m}$ & $\mathrm{AF}$ & mid \\
\hline T75 & 30.11 .2012 & & 3 & 44.6 & 7.6 & 0.534 & $\mathrm{dm}$ & $\mathrm{mp}$ & $\mathrm{AF}$ & mid \\
\hline T76 & 12.1 .2012 & & 4 & 16.6 & 0.5 & -0.247 & $\mathrm{~m}$ & $\mathrm{p}$ & SU & mid \\
\hline $\mathrm{T} 77$ & 12.1 .2012 & & 4 & 15.9 & 0.4 & -0.331 & $\mathrm{~m}$ & $\mathrm{~m}$ & $\mathrm{~J}$ & mid \\
\hline $\mathrm{T} 78$ & 12.1 .2012 & & 4 & 45.8 & 8.8 & 0.569 & $\mathrm{~m}$ & $\mathrm{p}$ & $\mathrm{AF}$ & low \\
\hline
\end{tabular}




\begin{tabular}{|c|c|c|c|c|c|c|c|c|c|}
\hline $\mathrm{T} 79$ & 12.1 .2012 & & 4 & 42.4 & 8.0 & 0.555 & md & $\mathrm{p}$ & $\mathrm{AF}$ \\
\hline T80 & 12.1 .2012 & & 4 & 41.8 & 7.3 & 0.533 & $\mathrm{~m}$ & $\mathrm{p}$ & $\mathrm{AF}$ \\
\hline T81 & 12.1 .2012 & 0430 & 3 & 44.0 & 6.8 & 0.507 & $\mathrm{~d}$ & $\mathrm{~m}$ & $\mathrm{AF}$ \\
\hline T82 & 12.1 .2012 & 0440 & 3 & 38.3 & 6.1 & 0.496 & md & $\mathrm{m}$ & $\mathrm{AU}$ \\
\hline $\mathrm{T} 83$ & 12.1 .2012 & & 3 & 37.1 & 5.4 & 0.467 & $\mathrm{~m}$ & $\mathrm{mp}$ & $\mathrm{AU}$ \\
\hline T84 & 12.1 .2012 & & 3 & 39.4 & 5.6 & 0.469 & $\mathrm{~m}$ & $\mathrm{mp}$ & $\mathrm{AU}$ \\
\hline T85 & 12.1 .2012 & & 3 & 38.9 & 5.6 & 0.471 & $\mathrm{~m}$ & $\mathrm{mp}$ & $\mathrm{AU}$ \\
\hline $\mathrm{T} 86$ & 12.1 .2012 & & 3 & 40.0 & 5.8 & 0.477 & $\mathrm{~m}$ & $\mathrm{~m}$ & $\mathrm{AF}$ \\
\hline $\mathrm{T} 87$ & 12.1 .2012 & 0450 & 3 & 42.0 & 6.2 & 0.488 & $\mathrm{dm}$ & $\mathrm{m}$ & $\mathrm{AF}$ \\
\hline $\mathrm{T} 88$ & 12.1 .2012 & & 4 & 29.3 & 2.4 & 0.259 & md & $\mathrm{p}$ & $\mathrm{SU}$ \\
\hline T89 & 12.1 .2012 & & 4 & 36.1 & 5.2 & 0.460 & $\mathrm{md}$ & $\mathrm{mp}$ & $\mathrm{AU}$ \\
\hline T90 & 12.1 .2012 & & 3 & 36.3 & 5.0 & 0.448 & $\mathrm{~m}$ & $\mathrm{pm}$ & $\mathrm{AU}$ \\
\hline T91 & 12.1 .2012 & & 3 & 38.5 & 5.1 & 0.446 & $\mathrm{~m}$ & $\mathrm{p}$ & $\mathrm{AU}$ \\
\hline T92 & 12.1 .2012 & & 3 & 37.2 & 5.0 & 0.445 & $\mathrm{~m}$ & $\mathrm{pm}$ & $\mathrm{AU}$ \\
\hline T93 & 12.1 .2012 & & 3 & 36.2 & 5.9 & 0.495 & $\mathrm{~m}$ & um & $\mathrm{AU}$ \\
\hline Т94 & 12.1 .2012 & & 2 & 35.8 & 4.6 & 0.427 & md & $\mathrm{mp}$ & $\mathrm{AU}$ \\
\hline T95 & 12.1 .2012 & & 3 & 39.4 & 6.1 & 0.492 & $\mathrm{~m}$ & $\mathrm{p}$ & $\mathrm{AU}$ \\
\hline T96 & 12.1 .2012 & & 3 & 41.8 & 5.9 & 0.475 & $\mathrm{~m}$ & $\mathrm{~m}$ & $\mathrm{AF}$ \\
\hline T97 & 12.1 .2012 & 0403 & 3 & 42.6 & 7.2 & 0.526 & $\mathrm{~m}$ & $\mathrm{mp}$ & $\mathrm{AF}$ \\
\hline T98 & 12.1 .2012 & & 3 & 44.4 & 7.0 & 0.513 & $\mathrm{~m}$ & $\mathrm{p}$ & $\mathrm{AF}$ \\
\hline T99 & 12.1 .2012 & & 3 & 46.2 & 9.7 & 0.593 & $\mathrm{~m}$ & $\mathrm{~m}$ & $\mathrm{AF}$ \\
\hline T100 & 12.1 .2012 & & 3 & 42.7 & 8.3 & 0.564 & $\mathrm{~m}$ & $\mathrm{mp}$ & $\mathrm{AF}$ \\
\hline $\mathrm{T} 101^{*}$ & & 0044 & 3 & 36.0 & 3.7 & 0.365 & $\mathrm{~d}$ & $\mathrm{p}$ & $\mathrm{AU}$ \\
\hline
\end{tabular}

1. Toe-clip combination

2. Scale of fatness: 1(skinny)-5(fat)

3. Snout-vent lenth

4. Weight

5. Body Condition Index $\log ($ weight $) / \log (S V L)$

6. Intensity

1- light; m- medium; d- dark

\section{Pattern}

p- patterned; m- mottled; u- uniform

8. J- juvenile; SU- subadult, unknown sex; AU- adult, unknown sex; AF- adult female

9. Rockpile

up- upper rock pile; mid- middle rock pile; low- lower rock pile

*Inadvertently translocated (measurements are from first capture in Zealandia) 


\section{Appendix B}

\section{Leiopelma pakeka enclosure recaptures (raw data)}

\begin{tabular}{|c|c|c|c|c|c|c|}
\hline Frog ID & Date & $\begin{array}{l}\text { Start time } \\
\text { (h) }\end{array}$ & $\begin{array}{l}\text { Stop time } \\
\text { (h) }\end{array}$ & $\mathrm{X}^{1}$ & $\mathrm{Y}^{1}$ & Enclosure \\
\hline $\mathrm{A} 2$ & 19.11 .2012 & $21: 53$ & $22: 32$ & 0.69 & 0.13 & Original \\
\hline $\mathrm{A} 2$ & 20.11.2012 & $21: 43$ & $22: 02$ & 0.86 & 1.47 & Original \\
\hline $\mathrm{A} 2$ & 21.11.2012 & $22: 21$ & $22: 44$ & 1.45 & 0.04 & Original \\
\hline $\mathrm{A} 2$ & 22.11 .2012 & $21: 54$ & $22: 25$ & 0.36 & 0.03 & Original \\
\hline $\mathrm{A} 2$ & 19.12 .2012 & 23:09 & $23: 30$ & 0.03 & 0.40 & Original \\
\hline $\mathrm{A} 2$ & 20.12.2012 & $22: 53$ & $23: 22$ & 1.28 & 0.16 & Original \\
\hline $\mathrm{A} 2$ & 21.12 .2012 & 00:11 & $00: 26$ & 0.51 & 0.04 & Original \\
\hline $\mathrm{A} 2$ & 14.01 .2013 & 00:00 & 00:30 & 1.21 & 0.47 & Original \\
\hline $\mathrm{A} 2$ & 13.02 .2013 & $23: 07$ & $23: 30$ & 0.44 & 0.08 & Original \\
\hline $\mathrm{A} 2$ & 14.03 .2013 & $22: 40$ & $22: 59$ & 1.15 & 0.04 & Original \\
\hline A2 & 06.05 .2013 & $19: 20$ & $19: 58$ & 0.79 & 0.36 & Original \\
\hline $\mathrm{A} 2$ & 09.05 .2013 & $20: 13$ & $20: 35$ & 0.03 & 0.59 & Original \\
\hline $\mathrm{A} 2$ & 04.07 .2013 & $18: 53$ & $19: 13$ & 0.03 & 0.64 & Original \\
\hline A5 & 19.11.2012 & $21: 53$ & $22: 32$ & 3.06 & 0.02 & Original \\
\hline A 5 & 20.11 .2012 & $21: 43$ & $22: 02$ & 3.05 & 0.03 & Original \\
\hline A5 & 21.11.2012 & $22: 21$ & $22: 44$ & 3.07 & 0.03 & Original \\
\hline A 5 & 22.11 .2012 & $21: 54$ & $22: 25$ & 3.01 & 0.02 & Original \\
\hline A5 & 18.12.2012 & 00:13 & $00: 35$ & 3.06 & 0.03 & Original \\
\hline A5 & 19.12 .2012 & 23:09 & $23: 30$ & 3.06 & 0.02 & Original \\
\hline A 5 & 20.12 .2012 & $22: 53$ & $23: 22$ & 2.35 & 0.04 & Original \\
\hline A5 & 15.01 .2013 & $23: 53$ & $00: 13$ & 1.99 & 0.70 & Original \\
\hline A5 & 16.01 .2013 & 00:02 & $00: 23$ & 2.29 & 0.03 & Original \\
\hline A 5 & 11.02.2013 & $23: 21$ & $23: 47$ & 3.06 & 0.03 & Original \\
\hline A 5 & 12.02 .2013 & $23: 18$ & $23: 48$ & 2.72 & 0.03 & Original \\
\hline A5 & 13.02 .2013 & $23: 07$ & $23: 30$ & 2.74 & 0.02 & Original \\
\hline A 5 & 14.02.2013 & $22: 43$ & 23:06 & 3.08 & 0.03 & Original \\
\hline A5 & 15.02 .2013 & $23: 11$ & $23: 29$ & 3.08 & 0.03 & Original \\
\hline
\end{tabular}




\begin{tabular}{|c|c|c|c|c|c|c|}
\hline A 5 & 11.03 .2013 & $21: 50$ & $22: 16$ & 2.62 & 0.03 & Original \\
\hline A 5 & 12.03 .2013 & $21: 30$ & $21: 47$ & 2.88 & 0.03 & Original \\
\hline A5 & 13.03 .2013 & $21: 37$ & $21: 58$ & 2.99 & 0.03 & Original \\
\hline A5 & 14.03 .2013 & $22: 40$ & $22: 59$ & 2.53 & 0.03 & Original \\
\hline A 5 & 08.04 .2013 & $20: 57$ & $21: 17$ & 3.07 & 0.90 & Original \\
\hline A 5 & 09.04 .2013 & $20: 21$ & $20: 45$ & 3.07 & 0.03 & Original \\
\hline A5 & 11.04 .2013 & $20: 42$ & $20: 56$ & 2.99 & 0.04 & Original \\
\hline A 5 & 12.04 .2013 & $19: 43$ & $20: 11$ & 3.07 & 0.11 & Original \\
\hline A 5 & 06.05 .2013 & $19: 20$ & $19: 58$ & 2.71 & 0.04 & Original \\
\hline A5 & 09.05 .2013 & $20: 13$ & $20: 35$ & 3.06 & 0.03 & Original \\
\hline A 5 & 04.06 .2013 & $20: 19$ & $20: 41$ & 3.05 & 0.75 & Original \\
\hline A5 & 06.06 .2013 & $18: 45$ & 19:06 & 3.05 & 0.03 & Original \\
\hline A 5 & 01.07 .2013 & $19: 10$ & $19: 35$ & 3.07 & 0.03 & Original \\
\hline A5 & 29.07.2013 & $19: 51$ & $20: 22$ & 3.01 & 0.02 & Original \\
\hline A11 & 20.12 .2012 & $22: 53$ & $23: 22$ & 0.05 & 0.40 & Original \\
\hline A11 & 16.01 .2013 & 00:02 & $00: 23$ & 1.48 & 0.03 & Original \\
\hline A11 & 12.03 .2013 & $21: 30$ & $21: 47$ & 2.06 & 0.94 & Original \\
\hline A11 & 09.04 .2013 & $20: 21$ & $20: 45$ & 1.20 & 0.73 & Original \\
\hline A11 & 12.04 .2013 & $19: 43$ & $20: 11$ & 0.77 & 0.12 & Original \\
\hline B2 & 22.10 .2012 & $21: 15$ & $21: 38$ & 1.14 & 0.10 & Original \\
\hline B2 & 17.12 .2012 & $01: 58$ & $02: 17$ & 3.01 & 0.18 & Original \\
\hline B2 & 19.12 .2012 & 23:09 & $23: 30$ & 0.98 & 1.13 & Original \\
\hline B2 & 20.12 .2012 & $22: 53$ & $23: 22$ & 3.08 & 0.02 & Original \\
\hline B2 & 14.01 .2013 & 00:00 & $00: 30$ & 3.04 & 0.03 & Original \\
\hline B2 & 15.01 .2013 & $23: 53$ & $00: 13$ & 1.17 & 0.72 & Original \\
\hline B2 & 16.01 .2013 & 00:02 & $00: 23$ & 3.04 & 0.25 & Original \\
\hline B2 & 11.02 .2013 & $23: 21$ & $23: 47$ & 3.07 & 0.04 & Original \\
\hline B2 & 12.02 .2013 & $23: 18$ & $23: 48$ & 3.06 & 0.02 & Original \\
\hline B2 & 13.02 .2013 & $23: 07$ & $23: 30$ & 3.08 & 0.02 & Original \\
\hline B2 & 14.03 .2013 & $22: 40$ & $22: 59$ & 3.07 & 0.03 & Original \\
\hline B2 & 15.03 .2013 & $21: 48$ & $22: 12$ & 2.96 & 0.04 & Original \\
\hline B2 & 08.04 .2013 & $20: 57$ & $21: 17$ & 3.07 & 0.04 & Original \\
\hline B2 & 09.04 .2013 & $20: 21$ & $20: 45$ & 2.12 & 0.90 & Original \\
\hline B2 & 06.05 .2013 & $19: 20$ & $19: 58$ & 1.64 & 0.25 & Original \\
\hline B2 & 09.05 .2013 & $20: 13$ & $20: 35$ & 3.07 & 0.04 & Original \\
\hline B2 & 03.06 .2013 & $18: 57$ & $19: 20$ & 2.53 & 1.25 & Original \\
\hline B2 & 04.06 .2013 & $20: 19$ & $20: 41$ & 3.02 & 0.03 & Original \\
\hline B2 & 06.06 .2013 & $18: 45$ & 19:06 & 3.05 & 0.03 & Original \\
\hline B2 & 29.07 .2013 & $19: 51$ & $20: 22$ & 0.36 & 1.45 & Original \\
\hline B5 & 17.12 .2012 & $01: 58$ & $02: 17$ & 3.07 & 0.03 & Original \\
\hline B5 & 19.12 .2012 & 23:09 & $23: 30$ & 0.11 & 0.76 & Original \\
\hline B5 & 21.12 .2012 & 00:11 & $00: 26$ & 0.37 & 1.13 & Original \\
\hline B5 & 11.02 .2013 & $23: 21$ & $23: 47$ & 0.36 & 0.15 & Original \\
\hline B5 & 14.02 .2013 & $22: 43$ & $23: 06$ & 0.78 & 1.47 & Original \\
\hline B5 & 11.03 .2013 & $21: 50$ & $22: 16$ & 0.42 & 0.03 & Original \\
\hline B5 & 13.03 .2013 & $21: 37$ & $21: 58$ & 0.91 & 0.11 & Original \\
\hline B5 & 12.04 .2013 & $19: 43$ & $20: 11$ & 0.51 & 0.75 & Original \\
\hline B7 & 09.05 .2013 & $20: 13$ & $20: 35$ & 1.04 & 1.45 & Original \\
\hline
\end{tabular}




\begin{tabular}{|c|c|c|c|c|c|c|}
\hline B12 & 25.10 .2012 & $21: 53$ & $22: 22$ & 0.03 & 0.90 & Original \\
\hline B12 & 18.12.2012 & $00: 13$ & $00: 35$ & 0.04 & 0.03 & Original \\
\hline B12 & 11.02 .2013 & $23: 21$ & $23: 47$ & 0.60 & 0.05 & Original \\
\hline B12 & 14.03 .2013 & $22: 40$ & $22: 59$ & 1.30 & 0.03 & Original \\
\hline B12 & 06.05 .2013 & $19: 20$ & $19: 58$ & 0.76 & 0.72 & Original \\
\hline B14 & 24.10 .2012 & $21: 16$ & $21: 53$ & 0.91 & 0.12 & Original \\
\hline B14 & 18.11.2012 & $21: 53$ & $22: 37$ & 1.40 & 0.07 & Original \\
\hline B14 & 22.11 .2012 & $21: 54$ & $22: 25$ & 0.13 & 0.04 & Original \\
\hline B14 & 20.12.2012 & $22: 53$ & $23: 22$ & 0.17 & 0.03 & Original \\
\hline B14 & 11.02 .2013 & $23: 21$ & $23: 47$ & 0.77 & 0.08 & Original \\
\hline B14 & 13.03 .2013 & $21: 37$ & $21: 58$ & 0.30 & 0.03 & Original \\
\hline B14 & 14.03 .2013 & $22: 40$ & $22: 59$ & 0.36 & 0.03 & Original \\
\hline B14 & 15.03 .2013 & $21: 48$ & $22: 12$ & 0.52 & 0.03 & Original \\
\hline B14 & 09.04 .2013 & $20: 21$ & $20: 45$ & 0.12 & 1.46 & Original \\
\hline B14 & 11.04 .2013 & $20: 42$ & $20: 56$ & 0.19 & 0.52 & Original \\
\hline B14 & 09.05 .2013 & $20: 13$ & $20: 35$ & 0.68 & 0.70 & Original \\
\hline B14 & 10.05 .2013 & $19: 24$ & $19: 44$ & 0.43 & 0.04 & Original \\
\hline B14 & 03.06.2013 & $18: 57$ & $19: 20$ & 0.08 & 0.58 & Original \\
\hline B14 & 04.06 .2013 & $20: 19$ & $20: 41$ & 0.80 & 0.08 & Original \\
\hline B14 & 01.07 .2013 & $19: 10$ & $19: 35$ & 0.70 & 0.05 & Original \\
\hline B14 & 02.08 .2013 & 19:14 & $19: 35$ & 0.02 & 0.14 & Original \\
\hline M2 & 22.11 .2012 & $21: 54$ & $22: 25$ & 3.07 & 0.12 & Original \\
\hline M2 & 20.12.2012 & $22: 53$ & $23: 22$ & 2.38 & 0.05 & Original \\
\hline M2 & 14.01 .2013 & 00:00 & 00:30 & 1.50 & 0.04 & Original \\
\hline M2 & 15.01 .2013 & $23: 53$ & $00: 13$ & 1.53 & 1.47 & Original \\
\hline M2 & 11.02 .2013 & $23: 21$ & $23: 47$ & 1.53 & 1.47 & Original \\
\hline M2 & 12.02 .2013 & $23: 18$ & $23: 48$ & 2.39 & 0.08 & Original \\
\hline M2 & 12.04 .2013 & $19: 43$ & $20: 11$ & 3.07 & 1.47 & Original \\
\hline M4 & 20.12.2012 & $22: 53$ & $23: 22$ & 3.05 & 0.04 & Original \\
\hline M4 & 21.12 .2012 & $00: 11$ & $00: 26$ & 2.35 & 0.10 & Original \\
\hline M4 & 12.02 .2013 & $23: 18$ & $23: 48$ & 3.08 & 0.03 & Original \\
\hline M4 & 11.03 .2013 & $21: 50$ & $22: 16$ & 3.06 & 0.03 & Original \\
\hline M4 & 15.03 .2013 & $21: 48$ & $22: 12$ & 2.22 & 0.05 & Original \\
\hline M4 & 08.04 .2013 & $20: 57$ & $21: 17$ & 3.05 & 0.03 & Original \\
\hline M4 & 09.04 .2013 & $20: 21$ & $20: 45$ & 3.07 & 0.38 & Original \\
\hline M4 & 06.05 .2013 & $19: 20$ & $19: 58$ & 3.07 & 0.41 & Original \\
\hline M4 & 09.05 .2013 & $20: 13$ & $20: 35$ & 2.29 & 0.12 & Original \\
\hline M4 & 03.06 .2013 & $18: 57$ & $19: 20$ & 2.22 & 0.05 & Original \\
\hline M4 & 01.07 .2013 & $19: 10$ & $19: 35$ & 2.34 & 0.05 & Original \\
\hline M4 & 29.07.2013 & $19: 51$ & $20: 22$ & 3.07 & 0.03 & Original \\
\hline M5 & 08.04 .2013 & $20: 57$ & $21: 17$ & 0.97 & 1.47 & Original \\
\hline M5 & 09.04 .2013 & $20: 21$ & $20: 45$ & 0.48 & 0.78 & Original \\
\hline M5 & 12.04 .2013 & $19: 43$ & $20: 11$ & 0.03 & 1.17 & Original \\
\hline M5 & 09.05 .2013 & $20: 13$ & $20: 35$ & 0.05 & 1.30 & Original \\
\hline M5 & 10.05 .2013 & $19: 24$ & $19: 44$ & 0.80 & 1.22 & Original \\
\hline M5 & 03.06 .2013 & $18: 57$ & $19: 20$ & 1.57 & 0.62 & Original \\
\hline M5 & 04.06 .2013 & $20: 19$ & $20: 41$ & 0.91 & 0.11 & Original \\
\hline M5 & 02.07.2013 & $19: 23$ & $19: 45$ & 0.51 & 0.15 & Original \\
\hline
\end{tabular}




\begin{tabular}{|c|c|c|c|c|c|c|}
\hline M5 & 29.07.2013 & $19: 51$ & $20: 22$ & 0.71 & 0.67 & Original \\
\hline M9 & 19.12 .2012 & 23:09 & $23: 30$ & 0.36 & 1.33 & Original \\
\hline M9 & 20.12 .2012 & $22: 53$ & $23: 22$ & 0.65 & 0.07 & Original \\
\hline M9 & 16.01 .2013 & 00:02 & $00: 23$ & 1.54 & 0.90 & Original \\
\hline M9 & 12.02 .2013 & $23: 18$ & $23: 48$ & 0.75 & 0.03 & Original \\
\hline M9 & 13.02 .2013 & $23: 07$ & $23: 30$ & 1.29 & 0.03 & Original \\
\hline M9 & 11.03 .2013 & $21: 50$ & $22: 16$ & 1.17 & 0.04 & Original \\
\hline M9 & 08.04 .2013 & $20: 57$ & $21: 17$ & 2.09 & 0.08 & Original \\
\hline M9 & 12.04 .2013 & $19: 43$ & $20: 11$ & 2.72 & 0.03 & Original \\
\hline M9 & 06.05 .2013 & $19: 20$ & $19: 58$ & 1.30 & 0.74 & Original \\
\hline M10 & 14.03 .2013 & $22: 40$ & $22: 59$ & 0.52 & 0.03 & Original \\
\hline M10 & 08.04 .2013 & $20: 57$ & $21: 17$ & 0.04 & 0.04 & Original \\
\hline M12 & 16.01 .2013 & 00:02 & $00: 23$ & 1.71 & 0.04 & Original \\
\hline M12 & 13.02 .2013 & $23: 07$ & $23: 30$ & 1.35 & 0.75 & Original \\
\hline M12 & 10.04 .2013 & 20:03 & $20: 15$ & 1.58 & 1.03 & Original \\
\hline M12 & 02.08 .2013 & $19: 14$ & $19: 35$ & 1.16 & 1.16 & Original \\
\hline M19 & 14.01 .2013 & 00:00 & 00:30 & 1.53 & 0.28 & Original \\
\hline M19 & 15.01 .2013 & $23: 53$ & $00: 13$ & 1.58 & 0.78 & Original \\
\hline M19 & 18.01 .2013 & $23: 10$ & $23: 25$ & 1.54 & 0.03 & Original \\
\hline M19 & 11.02 .2013 & $23: 21$ & $23: 47$ & 1.52 & 0.04 & Original \\
\hline M19 & 12.02 .2013 & $23: 18$ & $23: 48$ & 0.37 & 0.21 & Original \\
\hline M19 & 15.03 .2013 & $21: 48$ & $22: 12$ & 0.23 & 0.30 & Original \\
\hline M19 & 08.04 .2013 & $20: 57$ & $21: 17$ & 0.95 & 0.08 & Original \\
\hline M19 & 04.06 .2013 & $20: 19$ & $20: 41$ & 2.23 & 0.68 & Original \\
\hline M19 & 04.07 .2013 & $18: 53$ & $19: 13$ & 2.92 & 1.47 & Original \\
\hline M21 & 20.12 .2013 & $22: 53$ & $23: 22$ & 1.31 & 0.19 & Original \\
\hline M21 & 15.01 .2013 & $23: 53$ & $00: 13$ & 2.05 & 0.08 & Original \\
\hline M21 & 16.01 .2013 & 00:02 & $00: 23$ & 2.15 & 0.03 & Original \\
\hline M21 & 11.02 .2013 & $23: 21$ & $23: 47$ & 2.30 & 0.31 & Original \\
\hline M21 & 14.02 .2013 & $22: 43$ & $23: 06$ & 1.11 & 0.20 & Original \\
\hline M21 & 11.03 .2013 & $21: 50$ & $22: 16$ & 1.32 & 0.03 & Original \\
\hline M21 & 14.03 .2013 & $22: 40$ & $22: 59$ & 2.83 & 0.03 & Original \\
\hline M21 & 09.04 .2013 & $20: 21$ & $20: 45$ & 0.64 & 0.06 & Original \\
\hline M21 & 06.05 .2013 & $19: 20$ & $19: 58$ & 2.32 & 0.57 & Original \\
\hline M21 & 07.05 .2013 & $19: 28$ & $19: 43$ & 1.29 & 0.04 & Original \\
\hline M21 & 04.06 .2013 & $20: 19$ & $20: 41$ & 1.58 & 0.03 & Original \\
\hline M21 & 01.07 .2013 & $19: 10$ & $19: 35$ & 1.58 & 0.08 & Original \\
\hline M23 & 18.11 .2012 & $21: 53$ & $22: 37$ & 2.40 & 0.04 & Original \\
\hline M23 & 22.11 .2012 & $21: 54$ & $22: 25$ & 1.74 & 0.05 & Original \\
\hline M23 & 13.02 .2013 & $23: 07$ & $23: 30$ & 0.81 & 0.30 & Original \\
\hline M23 & 15.02 .2013 & $23: 11$ & $23: 29$ & 2.70 & 1.22 & Original \\
\hline M23 & 15.03 .2013 & $21: 48$ & $22: 12$ & 2.83 & 0.59 & Original \\
\hline M23 & 08.04 .2013 & $20: 57$ & $21: 17$ & 2.74 & 1.26 & Original \\
\hline M23 & 12.04 .2013 & $19: 43$ & $20: 11$ & 3.07 & 0.54 & Original \\
\hline M23 & 06.05 .2013 & $19: 20$ & $19: 58$ & 1.76 & 0.17 & Original \\
\hline M23 & 08.05 .2013 & $19: 24$ & $19: 47$ & 1.53 & 0.47 & Original \\
\hline M23 & 01.07 .2013 & $19: 10$ & $19: 35$ & 2.15 & 0.03 & Original \\
\hline M23 & 02.07.2013 & $19: 23$ & $19: 45$ & 3.07 & 0.03 & Original \\
\hline
\end{tabular}




\begin{tabular}{|c|c|c|c|c|c|c|}
\hline M28 & 21.12.2012 & 00:11 & $00: 26$ & 0.47 & 1.31 & Original \\
\hline M28 & 15.01 .2013 & $23: 53$ & $00: 13$ & 0.40 & 0.71 & Original \\
\hline M28 & 11.02 .2013 & $23: 21$ & $23: 47$ & 1.38 & 0.02 & Original \\
\hline M28 & 12.02.2013 & $23: 18$ & $23: 48$ & 0.03 & 0.90 & Original \\
\hline M28 & 13.02 .2013 & $23: 07$ & $23: 30$ & 0.04 & 0.37 & Original \\
\hline M28 & 14.02 .2013 & $22: 43$ & $23: 06$ & 0.02 & 0.03 & Original \\
\hline M28 & 15.02 .2013 & $23: 11$ & $23: 29$ & 0.03 & 0.10 & Original \\
\hline M28 & 11.03 .2013 & $21: 50$ & $22: 16$ & 0.02 & 1.15 & Original \\
\hline M28 & 15.03 .2013 & $21: 48$ & $22: 12$ & 0.23 & 0.03 & Original \\
\hline M28 & 08.05 .2013 & $19: 24$ & $19: 47$ & 0.19 & 0.04 & Original \\
\hline M28 & 03.06.2013 & $18: 57$ & $19: 20$ & 0.12 & 0.10 & Original \\
\hline 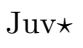 & 24.10 .2012 & $21: 16$ & $21: 53$ & 0.12 & 0.11 & Original \\
\hline Juv & 24.10 .2012 & $21: 16$ & $21: 53$ & 1.91 & 0.05 & Original \\
\hline 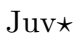 & 24.10 .2012 & $21: 16$ & $21: 53$ & 3.07 & 0.85 & Original \\
\hline Juv* & 24.10 .2012 & $21: 16$ & $21: 53$ & 3.06 & 0.94 & Original \\
\hline Juv & 24.10 .2012 & $21: 16$ & $21: 53$ & 2.70 & 1.13 & Original \\
\hline 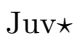 & 25.10 .2012 & $21: 53$ & $22: 22$ & 2.71 & 1.46 & Original \\
\hline Juv* & 18.11.2012 & $21: 53$ & $22: 37$ & 3.05 & 0.82 & Original \\
\hline 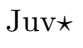 & 20.11 .2012 & $21: 43$ & $22: 02$ & 1.93 & 0.43 & Original \\
\hline 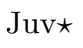 & 22.11.2012 & $21: 54$ & $22: 25$ & 2.71 & 0.98 & Original \\
\hline 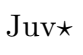 & 18.12 .2012 & 00:13 & $00: 35$ & 0.13 & 0.03 & Original \\
\hline 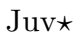 & 18.12 .2012 & $00: 13$ & $00: 35$ & 0.03 & 0.27 & Original \\
\hline Juv* & 18.12.2012 & 00:13 & $00: 35$ & 1.52 & 0.39 & Original \\
\hline Juv & 18.12 .2012 & $00: 13$ & $00: 35$ & 2.99 & 0.03 & Original \\
\hline 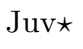 & 18.12 .2012 & $00: 13$ & $00: 35$ & 3.07 & 0.37 & Original \\
\hline Juv* & 18.12 .2012 & $00: 13$ & $00: 35$ & 3.07 & 0.66 & Original \\
\hline Juv & 18.12 .2012 & $00: 13$ & $00: 35$ & 3.06 & 1.45 & Original \\
\hline 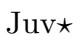 & 19.12.2012 & 23:09 & $23: 30$ & 0.66 & 0.54 & Original \\
\hline 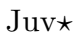 & 19.12 .2012 & 23:09 & $23: 30$ & 1.53 & 0.36 & Original \\
\hline 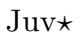 & 19.12 .2012 & $23: 09$ & $23: 30$ & 3.03 & 0.17 & Original \\
\hline 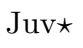 & 20.12.2012 & $22: 53$ & $23: 22$ & 3.07 & 0.43 & Original \\
\hline 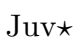 & 20.12 .2012 & $22: 53$ & $23: 22$ & 3.06 & 0.40 & Original \\
\hline 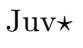 & 21.12 .2012 & $00: 11$ & $00: 26$ & 0.75 & 0.24 & Original \\
\hline Juv* & 14.01 .2013 & 00:00 & $00: 30$ & 0.02 & 0.08 & Original \\
\hline Juv & 14.01 .2013 & 00:00 & $00: 30$ & 0.03 & 0.14 & Original \\
\hline 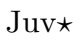 & 14.01 .2013 & 00:00 & $00: 30$ & 0.40 & 0.02 & Original \\
\hline Juv* & 14.01 .2013 & 00:00 & $00: 30$ & 1.62 & 0.27 & Original \\
\hline 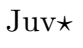 & 14.01 .2013 & 00:00 & $00: 30$ & 1.87 & 0.03 & Original \\
\hline 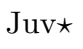 & 14.01 .2013 & 00:00 & 00:30 & 3.06 & 0.36 & Original \\
\hline Juv & 14.01 .2013 & 00:00 & $00: 30$ & 3.06 & 0.55 & Original \\
\hline Juv & 14.01 .2013 & 00:00 & $00: 30$ & 2.95 & 1.39 & Original \\
\hline 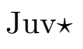 & 14.01 .2013 & 00:00 & $00: 30$ & 3.04 & 1.33 & Original \\
\hline Juv & 14.01 .2013 & 00:00 & $00: 30$ & 2.93 & 1.30 & Original \\
\hline 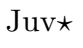 & 15.01 .2013 & $23: 53$ & $00: 13$ & 0.03 & 0.28 & Original \\
\hline 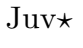 & 15.01 .2013 & $23: 53$ & $00: 13$ & 2.63 & 0.50 & Original \\
\hline Juv & 15.01 .2013 & $23: 53$ & $00: 13$ & 3.08 & 1.26 & Original \\
\hline 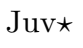 & 15.01 .2013 & $23: 53$ & $00: 13$ & 2.80 & 1.47 & Original \\
\hline Juv* & 16.01 .2013 & 00:02 & $00: 23$ & 2.73 & 0.03 & Original \\
\hline
\end{tabular}




\begin{tabular}{|c|c|c|c|c|c|c|}
\hline 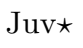 & 16.01 .2013 & 00:02 & $00: 23$ & 3.07 & 1.17 & Original \\
\hline Juv & 16.01 .2013 & 00:02 & $00: 23$ & 2.88 & 1.46 & Original \\
\hline 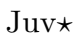 & 16.01 .2013 & 00:02 & $00: 23$ & 3.07 & 1.00 & Original \\
\hline Juv* & 18.01.2013 & $23: 10$ & $23: 25$ & 2.36 & 1.22 & Original \\
\hline Juv & 11.02 .2013 & $23: 21$ & $23: 47$ & 1.56 & 0.05 & Original \\
\hline 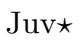 & 11.02 .2013 & $23: 21$ & $23: 47$ & 3.07 & 0.40 & Original \\
\hline Juv* & 11.02 .2013 & $23: 21$ & $23: 47$ & 2.55 & 0.39 & Original \\
\hline 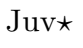 & 11.02 .2013 & $23: 21$ & $23: 47$ & 3.06 & 1.30 & Original \\
\hline 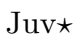 & 11.02 .2013 & $23: 21$ & $23: 47$ & 0.03 & 1.24 & Original \\
\hline Juv夫 & 11.02 .2013 & $23: 21$ & $23: 47$ & 0.03 & 1.24 & Original \\
\hline 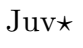 & 11.02 .2013 & $23: 21$ & $23: 47$ & 0.36 & 1.01 & Original \\
\hline 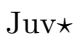 & 11.02 .2013 & $23: 21$ & $23: 47$ & 0.75 & 1.24 & Original \\
\hline Juv* & 12.02 .2013 & $23: 18$ & $23: 48$ & 0.32 & 0.03 & Original \\
\hline 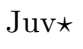 & 12.02 .2013 & $23: 18$ & $23: 48$ & 3.07 & 0.35 & Original \\
\hline Juv* & 12.02 .2013 & $23: 18$ & $23: 48$ & 3.06 & 1.20 & Original \\
\hline Juv & 12.02 .2013 & $23: 18$ & $23: 48$ & 2.80 & 1.35 & Original \\
\hline 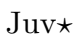 & 12.02 .2013 & $23: 18$ & $23: 48$ & 2.70 & 0.79 & Original \\
\hline Juv* & 12.02 .2013 & $23: 18$ & $23: 48$ & 0.29 & 1.22 & Original \\
\hline 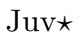 & 12.02 .2013 & $23: 18$ & $23: 48$ & 0.05 & 1.34 & Original \\
\hline 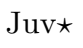 & 12.02 .2013 & $23: 18$ & $23: 48$ & 0.37 & 0.80 & Original \\
\hline Juv & 13.02 .2013 & $23: 07$ & $23: 30$ & 3.00 & 0.13 & Original \\
\hline 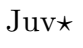 & 13.02 .2013 & $23: 07$ & $23: 30$ & 3.06 & 0.52 & Original \\
\hline Juv* & 13.02 .2013 & $23: 07$ & $23: 30$ & 2.52 & 1.24 & Original \\
\hline Juv & 13.02 .2013 & $23: 07$ & $23: 30$ & 0.17 & 1.15 & Original \\
\hline 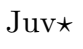 & 14.02 .2013 & $22: 43$ & $23: 06$ & 3.01 & 0.31 & Original \\
\hline Juv* & 15.02 .2013 & $23: 11$ & $23: 29$ & 2.34 & 1.29 & Original \\
\hline 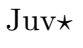 & 15.02 .2013 & $23: 11$ & $23: 29$ & 2.68 & 1.18 & Original \\
\hline 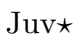 & 15.02 .2013 & $23: 11$ & $23: 29$ & 0.39 & 1.30 & Original \\
\hline 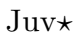 & 15.02 .2013 & $23: 11$ & $23: 29$ & 0.04 & 1.35 & Original \\
\hline 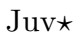 & 15.02 .2013 & $23: 11$ & $23: 29$ & 0.02 & 1.12 & Original \\
\hline 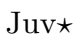 & 13.03 .2013 & $21: 37$ & $21: 58$ & 2.77 & 1.32 & Original \\
\hline 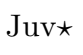 & 13.03 .2013 & $21: 37$ & $21: 58$ & 2.72 & 1.33 & Original \\
\hline 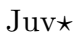 & 13.03 .2013 & $21: 37$ & $21: 58$ & 2.74 & 1.36 & Original \\
\hline Juv* & 13.03 .2013 & $21: 37$ & $21: 58$ & 0.32 & 1.41 & Original \\
\hline 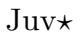 & 13.03 .2013 & $21: 37$ & $21: 58$ & 0.60 & 1.46 & Original \\
\hline 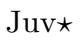 & 13.03 .2013 & $21: 37$ & $21: 58$ & 0.49 & 1.35 & Original \\
\hline Juv* & 08.04 .2013 & $20: 57$ & $21: 17$ & 0.04 & 0.46 & Original \\
\hline 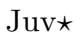 & 08.04 .2013 & $20: 57$ & $21: 17$ & 0.13 & 0.75 & Original \\
\hline 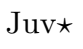 & 08.04 .2013 & $20: 57$ & $21: 17$ & 0.42 & 0.36 & Original \\
\hline 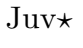 & 08.04 .2013 & $20: 57$ & $21: 17$ & 2.14 & 0.20 & Original \\
\hline 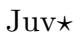 & 08.04 .2013 & $20: 57$ & $21: 17$ & 2.22 & 0.14 & Original \\
\hline 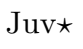 & 08.04 .2013 & $20: 57$ & $21: 17$ & 2.89 & 0.75 & Original \\
\hline Juv & 08.04 .2013 & $20: 57$ & $21: 17$ & 3.00 & 0.63 & Original \\
\hline 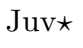 & 08.04 .2013 & $20: 57$ & $21: 17$ & 2.94 & 0.37 & Original \\
\hline 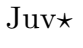 & 08.04 .2013 & $20: 57$ & $21: 17$ & 3.03 & 0.47 & Original \\
\hline Juv & 08.04 .2013 & $20: 57$ & $21: 17$ & 2.82 & 1.15 & Original \\
\hline 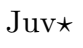 & 08.04 .2013 & $20: 57$ & $21: 17$ & 0.18 & 1.22 & Original \\
\hline Juv* & 09.04.2013 & $20: 21$ & $20: 45$ & 0.68 & 0.36 & Original \\
\hline
\end{tabular}




\begin{tabular}{|c|c|c|c|c|c|c|}
\hline Juv* & 09.04 .2013 & $20: 21$ & $20: 45$ & 0.18 & 0.70 & Original \\
\hline Juv & 09.04 .2013 & $20: 21$ & $20: 45$ & 1.58 & 0.38 & Original \\
\hline 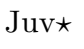 & 09.04 .2013 & $20: 21$ & $20: 45$ & 2.92 & 0.75 & Original \\
\hline 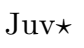 & 09.04 .2013 & $20: 21$ & $20: 45$ & 2.92 & 0.64 & Original \\
\hline Juv $\star$ & 09.04 .2013 & $20: 21$ & $20: 45$ & 3.06 & 1.31 & Original \\
\hline Juv $\star$ & 09.04 .2013 & $20: 21$ & $20: 45$ & 2.98 & 1.47 & Original \\
\hline 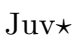 & 09.04.2013 & $20: 21$ & $20: 45$ & 2.95 & 1.42 & Original \\
\hline 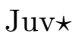 & 10.04 .2013 & $20: 03$ & $20: 15$ & 1.58 & 0.05 & Original \\
\hline 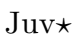 & 10.04 .2013 & $20: 03$ & $20: 15$ & 2.55 & 0.04 & Original \\
\hline 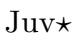 & 10.04 .2013 & $20: 03$ & $20: 15$ & 3.07 & 0.12 & Original \\
\hline 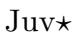 & 10.04 .2013 & $20: 03$ & $20: 15$ & 3.06 & 0.57 & Original \\
\hline Juv* & 10.04 .2013 & 20:03 & $20: 15$ & 0.16 & 1.30 & Original \\
\hline 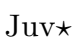 & 11.04 .2013 & $20: 42$ & $20: 56$ & 0.66 & 0.57 & Original \\
\hline 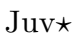 & 11.04 .2013 & $20: 42$ & $20: 56$ & 0.04 & 1.16 & Original \\
\hline 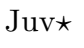 & 06.05 .2013 & $19: 20$ & $19: 58$ & 0.16 & 0.02 & Original \\
\hline Juv $\star$ & 06.05 .2013 & $19: 20$ & $19: 58$ & 0.02 & 0.05 & Original \\
\hline Juv $\star$ & 06.05 .2013 & $19: 20$ & $19: 58$ & 2.04 & 0.04 & Original \\
\hline 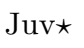 & 06.05 .2013 & $19: 20$ & $19: 58$ & 2.20 & 0.06 & Original \\
\hline 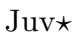 & 06.05 .2013 & $19: 20$ & $19: 58$ & 2.97 & 0.05 & Original \\
\hline 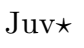 & 06.05 .2013 & $19: 20$ & $19: 58$ & 2.77 & 0.02 & Original \\
\hline Juv $\star$ & 06.05 .2013 & $19: 20$ & $19: 58$ & 3.08 & 0.46 & Original \\
\hline 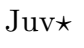 & 06.05 .2013 & $19: 20$ & $19: 58$ & 3.06 & 0.78 & Original \\
\hline 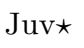 & 06.05 .2013 & $19: 20$ & $19: 58$ & 3.06 & 1.43 & Original \\
\hline Juv $\star$ & 06.05 .2013 & $19: 20$ & $19: 58$ & 2.89 & 1.07 & Original \\
\hline 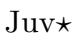 & 06.05 .2013 & $19: 20$ & $19: 58$ & 0.78 & 1.23 & Original \\
\hline 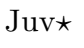 & 06.05 .2013 & $19: 20$ & $19: 58$ & 0.21 & 1.47 & Original \\
\hline Juv $\star$ & 06.05 .2013 & $19: 20$ & $19: 58$ & 0.10 & 1.30 & Original \\
\hline Juv $\star$ & 06.05 .2013 & $19: 20$ & $19: 58$ & 0.02 & 1.15 & Original \\
\hline Juv* & 06.05 .2013 & $19: 20$ & $19: 58$ & 0.33 & 0.77 & Original \\
\hline 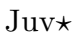 & 07.05 .2013 & $19: 28$ & $19: 43$ & 0.19 & 0.03 & Original \\
\hline 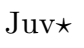 & 07.05 .2013 & $19: 28$ & $19: 43$ & 3.07 & 1.30 & Original \\
\hline Juv $\star$ & 07.05 .2013 & $19: 28$ & $19: 43$ & 0.57 & 1.47 & Original \\
\hline 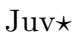 & 08.05 .2013 & $19: 24$ & $19: 47$ & 3.05 & 0.69 & Original \\
\hline 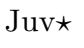 & 08.05 .2013 & $19: 24$ & $19: 47$ & 3.07 & 0.73 & Original \\
\hline 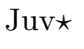 & 08.05 .2013 & $19: 24$ & $19: 47$ & 3.07 & 1.15 & Original \\
\hline Juv & 08.05 .2013 & $19: 24$ & $19: 47$ & 0.03 & 1.15 & Original \\
\hline 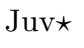 & 08.05 .2013 & $19: 24$ & $19: 47$ & 0.03 & 1.23 & Original \\
\hline 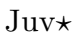 & 09.05 .2013 & $20: 13$ & $20: 35$ & 0.41 & 0.90 & Original \\
\hline Juv $\star$ & 09.05 .2013 & $20: 13$ & $20: 35$ & 0.14 & 0.03 & Original \\
\hline 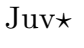 & 09.05 .2013 & $20: 13$ & $20: 35$ & 0.16 & 0.08 & Original \\
\hline 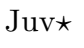 & 09.05 .2013 & $20: 13$ & $20: 35$ & 1.72 & 0.07 & Original \\
\hline Juv & 09.05 .2013 & $20: 13$ & $20: 35$ & 3.07 & 0.23 & Original \\
\hline Juv $\star$ & 09.05 .2013 & $20: 13$ & $20: 35$ & 2.63 & 0.03 & Original \\
\hline 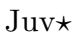 & 09.05 .2013 & $20: 13$ & $20: 35$ & 3.06 & 0.62 & Original \\
\hline 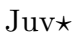 & 09.05 .2013 & $20: 13$ & $20: 35$ & 3.06 & 1.34 & Original \\
\hline 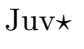 & 09.05 .2013 & $20: 13$ & $20: 35$ & 0.76 & 1.17 & Original \\
\hline Juv & 09.05 .2013 & $20: 13$ & $20: 35$ & 0.02 & 1.30 & Original \\
\hline 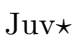 & 09.05 .2013 & $20: 13$ & $20: 35$ & 0.07 & 1.23 & Original \\
\hline
\end{tabular}




\begin{tabular}{|c|c|c|c|c|c|c|}
\hline Juv & 09.05 .2013 & $20: 13$ & $20: 35$ & 0.35 & 0.95 & Original \\
\hline Juv $\star$ & 10.05 .2013 & $19: 24$ & $19: 44$ & 0.02 & 0.38 & Original \\
\hline Juv* & 10.05 .2013 & $19: 24$ & $19: 44$ & 3.07 & 0.61 & Original \\
\hline 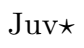 & 10.05 .2013 & $19: 24$ & $19: 44$ & 3.03 & 1.38 & Original \\
\hline Juv & 03.06 .2013 & $18: 57$ & $19: 20$ & 3.04 & 0.66 & Original \\
\hline Juv & 03.06.2013 & $18: 57$ & $19: 20$ & 3.06 & 1.46 & Original \\
\hline Juv & 03.06.2013 & $18: 57$ & $19: 20$ & 0.06 & 1.43 & Original \\
\hline 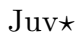 & 03.06 .2013 & $18: 57$ & $19: 20$ & 0.03 & 1.46 & Original \\
\hline 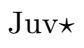 & 04.06 .2013 & $20: 19$ & $20: 41$ & 0.78 & 0.03 & Original \\
\hline 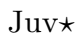 & 04.06 .2013 & $20: 19$ & $20: 41$ & 0.24 & 0.05 & Original \\
\hline 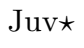 & 04.06 .2013 & $20: 19$ & $20: 41$ & 0.04 & 0.37 & Original \\
\hline 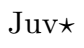 & 04.06 .2013 & 20:19 & $20: 41$ & 2.15 & 0.05 & Original \\
\hline Juv $\star$ & 04.06 .2013 & $20: 19$ & $20: 41$ & 1.71 & 0.05 & Original \\
\hline 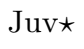 & 04.06 .2013 & $20: 19$ & $20: 41$ & 3.06 & 0.03 & Original \\
\hline 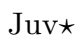 & 04.06 .2013 & 20:19 & $20: 41$ & 2.51 & 0.03 & Original \\
\hline Juv & 04.06 .2013 & $20: 19$ & $20: 41$ & 2.59 & 1.18 & Original \\
\hline Juv & 04.06 .2013 & 20:19 & $20: 41$ & 3.06 & 1.37 & Original \\
\hline Juv & 04.06.2013 & 20:19 & $20: 41$ & 0.20 & 1.23 & Original \\
\hline 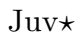 & 04.06 .2013 & $20: 19$ & $20: 41$ & 0.36 & 1.12 & Original \\
\hline 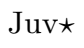 & 04.06 .2013 & $20: 19$ & $20: 41$ & 0.65 & 1.38 & Original \\
\hline Juv & 05.06 .2013 & $18: 48$ & 19:02 & 3.07 & 0.80 & Original \\
\hline 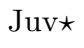 & 05.06 .2013 & $18: 48$ & 19:02 & 0.15 & 1.47 & Original \\
\hline Juv & 06.06.2013 & $18: 45$ & $19: 06$ & 0.18 & 0.25 & Original \\
\hline 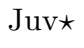 & 06.06 .2013 & $18: 45$ & $19: 06$ & 1.77 & 0.06 & Original \\
\hline 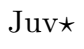 & 06.06 .2013 & $18: 45$ & $19: 06$ & 3.05 & 0.76 & Original \\
\hline Juv* & 06.06 .2013 & $18: 45$ & $19: 06$ & 0.65 & 1.47 & Original \\
\hline Juv & 06.06 .2013 & $18: 45$ & $19: 06$ & 0.03 & 1.28 & Original \\
\hline Juv & 07.06 .2013 & 19:00 & $19: 23$ & 0.30 & 0.20 & Original \\
\hline Juv & 07.06 .2013 & 19:00 & $19: 23$ & 3.02 & 0.64 & Original \\
\hline 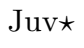 & 07.06 .2013 & $19: 00$ & $19: 23$ & 3.06 & 0.75 & Original \\
\hline 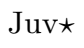 & 07.06.2013 & $19: 00$ & $19: 23$ & 3.08 & 0.90 & Original \\
\hline Juv & 07.06 .2013 & 19:00 & $19: 23$ & 3.07 & 1.13 & Original \\
\hline 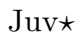 & 07.06 .2013 & $19: 00$ & $19: 23$ & 3.07 & 1.43 & Original \\
\hline Juv* & 07.06 .2013 & 19:00 & $19: 23$ & 0.02 & 1.22 & Original \\
\hline Juv & 07.06 .2013 & 19:00 & $19: 23$ & 0.47 & 1.48 & Original \\
\hline 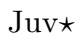 & 01.07 .2013 & $19: 10$ & $19: 35$ & 0.17 & 0.03 & Original \\
\hline 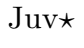 & 01.07 .2013 & $19: 10$ & $19: 35$ & 3.07 & 0.38 & Original \\
\hline 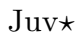 & 01.07 .2013 & $19: 10$ & $19: 35$ & 3.01 & 0.76 & Original \\
\hline Juv & 01.07 .2013 & $19: 10$ & $19: 35$ & 3.07 & 1.43 & Original \\
\hline Juv & 01.07 .2013 & $19: 10$ & $19: 35$ & 0.05 & 1.34 & Original \\
\hline 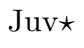 & 02.07 .2013 & $19: 23$ & $19: 45$ & 0.64 & 0.40 & Original \\
\hline 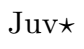 & 02.07 .2013 & $19: 23$ & $19: 45$ & 0.75 & 0.03 & Original \\
\hline Juv & 02.07 .2013 & $19: 23$ & $19: 45$ & 0.46 & 0.11 & Original \\
\hline 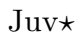 & 02.07 .2013 & $19: 23$ & $19: 45$ & 0.17 & 0.21 & Original \\
\hline Juv & 02.07 .2013 & $19: 23$ & $19: 45$ & 1.99 & 0.05 & Original \\
\hline Juv & 02.07 .2013 & $19: 23$ & $19: 45$ & 2.75 & 0.05 & Original \\
\hline 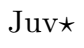 & 02.07 .2013 & $19: 23$ & $19: 45$ & 3.06 & 1.46 & Original \\
\hline 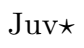 & 02.07.2013 & $19: 23$ & $19: 45$ & 0.11 & 1.43 & Original \\
\hline
\end{tabular}




\begin{tabular}{|c|c|c|c|c|c|c|}
\hline Juv» & 02.07 .2013 & $19: 23$ & $19: 45$ & 0.90 & 1.33 & Original \\
\hline 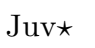 & 02.07 .2013 & $19: 23$ & $19: 45$ & 0.15 & 1.21 & Original \\
\hline 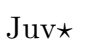 & 03.07 .2013 & 19:02 & $19: 25$ & 0.17 & 0.05 & Original \\
\hline 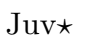 & 03.07.2013 & 19:02 & $19: 25$ & 0.36 & 0.04 & Original \\
\hline Juv & 03.07 .2013 & 19:02 & $19: 25$ & 0.29 & 0.17 & Original \\
\hline Juv $\star$ & 03.07 .2013 & 19:02 & $19: 25$ & 2.40 & 0.10 & Original \\
\hline 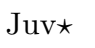 & 03.07.2013 & 19:02 & $19: 25$ & 3.07 & 0.66 & Original \\
\hline Juv $\star$ & 03.07.2013 & 19:02 & $19: 25$ & 3.05 & 1.36 & Original \\
\hline 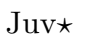 & 03.07 .2013 & 19:02 & $19: 25$ & 3.07 & 1.19 & Original \\
\hline 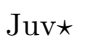 & 03.07.2013 & 19:02 & $19: 25$ & 0.03 & 1.30 & Original \\
\hline 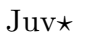 & 03.07 .2013 & 19:02 & $19: 25$ & 0.98 & 0.73 & Original \\
\hline 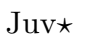 & 04.07 .2013 & $18: 53$ & $19: 13$ & 1.56 & 0.12 & Original \\
\hline 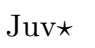 & 04.07 .2013 & $18: 53$ & $19: 13$ & 3.02 & 0.72 & Original \\
\hline 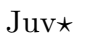 & 04.07 .2013 & $18: 53$ & $19: 13$ & 0.03 & 1.25 & Original \\
\hline 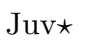 & 04.07 .2013 & $18: 53$ & $19: 13$ & 0.13 & 1.48 & Original \\
\hline Juv & 05.07 .2013 & $18: 47$ & $19: 06$ & 0.08 & 0.03 & Original \\
\hline Juv & 05.07 .2013 & $18: 47$ & $19: 06$ & 0.27 & 0.12 & Original \\
\hline 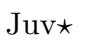 & 05.07 .2013 & $18: 47$ & $19: 06$ & 0.02 & 0.39 & Original \\
\hline Juv $\star$ & 05.07 .2013 & $18: 47$ & 19:06 & 1.90 & 0.07 & Original \\
\hline 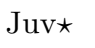 & 05.07 .2013 & $18: 47$ & $19: 06$ & 3.08 & 0.75 & Original \\
\hline 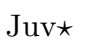 & 05.07 .2013 & $18: 47$ & $19: 06$ & 0.02 & 1.29 & Original \\
\hline 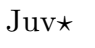 & 29.07 .2013 & $19: 51$ & $20: 22$ & 1.67 & 0.06 & Original \\
\hline 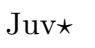 & 30.07 .2013 & $19: 37$ & $19: 57$ & 1.56 & 0.17 & Original \\
\hline Juv $\star$ & 30.07 .2013 & $19: 37$ & $19: 57$ & 2.62 & 0.90 & Original \\
\hline 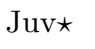 & 30.07 .2013 & $19: 37$ & $19: 57$ & 3.07 & 0.59 & Original \\
\hline 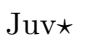 & 31.07 .2013 & $19: 50$ & $20: 17$ & 0.19 & 0.11 & Original \\
\hline Juv & 31.07 .2013 & $19: 50$ & $20: 17$ & 0.26 & 0.21 & Original \\
\hline Juv & 31.07 .2013 & $19: 50$ & $20: 17$ & 0.52 & 0.05 & Original \\
\hline 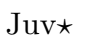 & 31.07 .2013 & $19: 50$ & $20: 17$ & 1.60 & 0.13 & Original \\
\hline 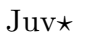 & 31.07 .2013 & $19: 50$ & $20: 17$ & 0.03 & 1.26 & Original \\
\hline 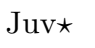 & 02.08 .2013 & $19: 14$ & $19: 35$ & 0.50 & 0.06 & Original \\
\hline Juv & 02.08 .2013 & $19: 14$ & $19: 35$ & 1.56 & 0.15 & Original \\
\hline 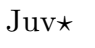 & 02.08 .2013 & $19: 14$ & $19: 35$ & 2.58 & 1.32 & Original \\
\hline 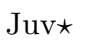 & 02.08 .2013 & $19: 14$ & $19: 35$ & 0.03 & 1.47 & Original \\
\hline N1 & 05.12 .2012 & $23: 20$ & $23: 42$ & 0.22 & 1.48 & Second \\
\hline N1 & 14.01 .2013 & $00: 42$ & $00: 53$ & 1.22 & 0.03 & Second \\
\hline $\mathrm{N} 2$ & 17.12 .2012 & 03:04 & $03: 25$ & 0.47 & 0.04 & Second \\
\hline N2 & 14.01 .2013 & $00: 42$ & $00: 53$ & 1.42 & 0.49 & Second \\
\hline N3॰ & 17.12 .2012 & 03:04 & $03: 25$ & 0.96 & 0.04 & Second \\
\hline N3 & 12.04 .2013 & $20: 58$ & $21: 07$ & 1.51 & 1.47 & Second \\
\hline N4 & 17.12 .2012 & 03:04 & $03: 25$ & 2.69 & 0.03 & Second \\
\hline N5॰ & 16.01 .2013 & $00: 33$ & $00: 48$ & 0.04 & 0.12 & Second \\
\hline $\mathrm{N} 6 \diamond *$ & & & & & & Second \\
\hline $\mathrm{N} 7 *$ & & & & & & Second \\
\hline N8* & & & & & & Second \\
\hline N9 & 04.06 .2013 & $20: 50$ & $21: 02$ & 2.49 & 1.48 & Second \\
\hline N10 & 09.05 .2013 & $20: 50$ & $20: 57$ & 2.53 & 1.47 & Second \\
\hline N10 & 04.06 .2013 & $20: 50$ & 21:02 & 2.53 & 1.46 & Second \\
\hline
\end{tabular}




\begin{tabular}{|c|c|c|c|c|c|c|}
\hline N11* & & & & & & Second \\
\hline N12 & 04.06 .2013 & $20: 50$ & $21: 02$ & 1.15 & 0.39 & Second \\
\hline A3 & 20.12 .2012 & $00: 52$ & 01:00 & 2.47 & 0.06 & Te Mahanga \\
\hline A3 & 21.12 .2012 & $00: 56$ & 01:00 & 2.45 & 0.04 & Te Mahanga \\
\hline A3 & 11.02 .2013 & $00: 14$ & $00: 26$ & 2.48 & 0.02 & Te Mahanga \\
\hline A 3 & 15.02 .2013 & $23: 44$ & $23: 59$ & 2.47 & 0.04 & Te Mahanga \\
\hline A3 & 15.03 .2013 & $22: 55$ & $23: 00$ & 2.47 & 0.05 & Te Mahanga \\
\hline A3 & 11.04 .2013 & $21: 12$ & $21: 18$ & 1.85 & 0.03 & Te Mahanga \\
\hline A3 & 04.06 .2013 & $21: 08$ & $21: 18$ & 1.86 & 0.77 & Te Mahanga \\
\hline A4 & 22.11 .2012 & $22: 47$ & $23: 00$ & 0.76 & 0.23 & Te Mahanga \\
\hline A4 & 19.12.2012 & $00: 25$ & $00: 30$ & 0.36 & 0.05 & Te Mahanga \\
\hline $\mathrm{A} 4$ & 21.12 .2012 & $00: 56$ & 01:00 & 1.88 & 0.16 & Te Mahanga \\
\hline A4 & 16.01 .2013 & $00: 53$ & 01:00 & 1.88 & 0.03 & Te Mahanga \\
\hline A4 & 11.02 .2013 & $00: 14$ & $00: 26$ & 1.96 & 0.13 & Te Mahanga \\
\hline A4 & 13.02 .2013 & $23: 51$ & $23: 54$ & 2.47 & 0.02 & Te Mahanga \\
\hline A4 & 14.02 .2013 & $23: 48$ & $23: 59$ & 1.31 & 0.20 & Te Mahanga \\
\hline A4 & 15.02 .2013 & $23: 44$ & $23: 59$ & 2.06 & 0.03 & Te Mahanga \\
\hline $\mathrm{A} 4$ & 11.03 .2013 & 23:09 & $23: 15$ & 2.47 & 0.03 & Te Mahanga \\
\hline A4 & 12.03 .2013 & $22: 23$ & $22: 27$ & 1.66 & 0.04 & Te Mahanga \\
\hline A4 & 14.03 .2013 & $23: 21$ & $23: 28$ & 2.39 & 0.06 & Te Mahanga \\
\hline A4 & 08.04 .2013 & $21: 47$ & $21: 54$ & 0.99 & 0.04 & Te Mahanga \\
\hline A4 & 09.04 .2013 & 21:01 & $21: 11$ & 2.31 & 0.62 & Te Mahanga \\
\hline A4 & 11.04 .2013 & $21: 12$ & $21: 18$ & 1.18 & 0.05 & Te Mahanga \\
\hline A4 & 12.04 .2013 & 21:09 & $21: 17$ & 0.64 & 0.78 & Te Mahanga \\
\hline A4 & 06.05 .2013 & $20: 58$ & $21: 04$ & 0.68 & 0.14 & Te Mahanga \\
\hline A4 & 09.05 .2013 & $21: 01$ & 21:09 & 0.46 & 0.29 & Te Mahanga \\
\hline A4 & 03.06 .2013 & $20: 14$ & $20: 22$ & 2.46 & 0.03 & Te Mahanga \\
\hline $\mathrm{A} 4$ & 04.06 .2013 & $21: 08$ & $21: 18$ & 0.16 & 0.74 & Te Mahanga \\
\hline A4 & 06.06 .2013 & $20: 12$ & $20: 17$ & 2.47 & 0.02 & Te Mahanga \\
\hline A4 & 01.07 .2013 & $20: 42$ & $20: 39$ & 2.45 & 0.04 & Te Mahanga \\
\hline $\mathrm{A} 4$ & 02.07 .2013 & $20: 51$ & $21: 02$ & 2.47 & 0.03 & Te Mahanga \\
\hline $\mathrm{A} 4$ & 29.07 .2013 & $21: 23$ & $21: 28$ & 2.48 & 0.19 & Te Mahanga \\
\hline A4 & 01.08 .2013 & $21: 17$ & $21: 22$ & 2.47 & 0.04 & Te Mahanga \\
\hline B3 & 17.12 .2012 & $03: 28$ & $03: 36$ & 2.47 & 0.05 & Te Mahanga \\
\hline B3 & 20.12 .2012 & $00: 52$ & 01:00 & 2.45 & 0.04 & Te Mahanga \\
\hline B3 & 14.01 .2013 & 01:02 & 01:10 & 2.47 & 0.03 & Te Mahanga \\
\hline B3 & 11.02 .2013 & $00: 14$ & $00: 26$ & 0.02 & 0.33 & Te Mahanga \\
\hline B3 & 12.02 .2013 & $00: 22$ & $00: 30$ & 1.31 & 0.40 & Te Mahanga \\
\hline B3 & 14.02 .2013 & $23: 48$ & $23: 59$ & 2.47 & 0.03 & Te Mahanga \\
\hline B3 & 15.02 .2013 & $23: 44$ & $23: 59$ & 2.44 & 0.03 & Te Mahanga \\
\hline B3 & 13.03 .2013 & $21: 15$ & $21: 18$ & 2.40 & 0.03 & Te Mahanga \\
\hline B3 & 14.03 .2013 & $23: 21$ & $23: 28$ & 0.61 & 0.05 & Te Mahanga \\
\hline B3 & 09.04 .2013 & $21: 01$ & $21: 11$ & 1.17 & 0.40 & Te Mahanga \\
\hline B3 & 11.04 .2013 & $21: 12$ & $21: 18$ & 2.04 & 0.04 & Te Mahanga \\
\hline B3 & 06.05 .2013 & $20: 58$ & $21: 04$ & 0.69 & 0.77 & Te Mahanga \\
\hline B3 & 08.05 .2013 & $20: 29$ & $20: 35$ & 0.11 & 0.78 & Te Mahanga \\
\hline B3 & 04.06 .2013 & $21: 08$ & $21: 18$ & 1.58 & 0.04 & Te Mahanga \\
\hline B3 & 07.06 .2013 & $20: 48$ & $20: 55$ & 1.58 & 0.78 & Te Mahanga \\
\hline
\end{tabular}




\begin{tabular}{|c|c|c|c|c|c|c|}
\hline B3 & 01.07 .2013 & $20: 42$ & $20: 39$ & 2.48 & 0.02 & Te Mahanga \\
\hline B3 & 02.07 .2013 & $20: 51$ & 21:02 & 1.58 & 0.77 & Te Mahanga \\
\hline B3 & 01.08 .2013 & $21: 17$ & $21: 22$ & 1.96 & 0.78 & Te Mahanga \\
\hline B3 & 02.08 .2013 & $20: 55$ & $20: 58$ & 2.01 & 0.13 & Te Mahanga \\
\hline M17 & 14.03 .2013 & $23: 21$ & $23: 28$ & 1.57 & 0.38 & Te Mahanga \\
\hline M17 & 09.04 .2013 & 21:01 & $21: 11$ & 1.34 & 0.77 & Te Mahanga \\
\hline M17 & 06.05 .2013 & $20: 58$ & 21:04 & 1.07 & 0.77 & Te Mahanga \\
\hline M17 & 09.05 .2013 & 21:01 & 21:09 & 1.63 & 0.24 & Te Mahanga \\
\hline M17 & 03.06.2013 & $20: 14$ & $20: 22$ & 1.12 & 0.60 & Te Mahanga \\
\hline M17 & 04.06.2013 & $21: 08$ & $21: 18$ & 0.74 & 0.42 & Te Mahanga \\
\hline M17 & 03.07 .2013 & $20: 20$ & $20: 25$ & 1.49 & 0.77 & Te Mahanga \\
\hline M17 & 30.07 .2013 & 21:01 & 21:06 & 2.25 & 0.27 & Te Mahanga \\
\hline M17 & 31.07 .2013 & $21: 07$ & $21: 11$ & 0.04 & 0.77 & Te Mahanga \\
\hline M22 & 08.04 .2013 & $21: 47$ & $21: 54$ & 0.60 & 0.05 & Te Mahanga \\
\hline M22 & 09.04 .2013 & 21:01 & $21: 11$ & 1.93 & 0.65 & Te Mahanga \\
\hline M22 & 09.05 .2013 & 21:01 & 21:09 & 0.79 & 0.27 & Te Mahanga \\
\hline M22 & 10.05 .2013 & $20: 22$ & $20: 28$ & 1.51 & 0.11 & Te Mahanga \\
\hline M22 & 03.06.2013 & $20: 14$ & $20: 22$ & 1.87 & 0.77 & Te Mahanga \\
\hline M22 & 04.06 .2013 & $21: 08$ & $21: 18$ & 0.44 & 0.31 & Te Mahanga \\
\hline M27 & 18.11.2012 & $23: 07$ & $23: 18$ & 0.61 & 0.02 & Te Mahanga \\
\hline M27 & 19.12.2012 & $23: 12$ & $23: 20$ & 0.08 & 0.05 & Te Mahanga \\
\hline M27 & 18.01 .2013 & $00: 14$ & $00: 22$ & 0.98 & 0.04 & Te Mahanga \\
\hline M27 & 11.02 .2013 & $00: 14$ & $00: 26$ & 0.02 & 0.26 & Te Mahanga \\
\hline M27 & 12.02 .2013 & 00:22 & $00: 30$ & 0.03 & 0.02 & Te Mahanga \\
\hline M27 & 13.02 .2013 & $23: 51$ & $23: 54$ & 0.48 & 0.27 & Te Mahanga \\
\hline M27 & 14.02 .2013 & $23: 48$ & $23: 59$ & 0.92 & 0.04 & Te Mahanga \\
\hline M27 & 11.03 .2013 & 23:09 & $23: 15$ & 0.93 & 0.03 & Te Mahanga \\
\hline M27 & 15.03 .2013 & $22: 55$ & $23: 00$ & 0.11 & 0.90 & Te Mahanga \\
\hline M27 & 09.04 .2013 & 21:01 & $21: 11$ & 0.60 & 0.78 & Te Mahanga \\
\hline M27 & 12.04 .2013 & 21:09 & $21: 17$ & 0.23 & 0.03 & Te Mahanga \\
\hline M27 & 03.06.2013 & $20: 14$ & $20: 22$ & 0.17 & 0.65 & Te Mahanga \\
\hline M27 & 07.06 .2013 & $20: 48$ & $20: 55$ & 0.58 & 0.02 & Te Mahanga \\
\hline $\mathrm{N} 3 \diamond *$ & & & & & & Te Mahanga \\
\hline N5॰ & 04.06.2013 & 21:08 & $21: 18$ & 0.60 & 0.73 & Te Mahanga \\
\hline N6॰ & 04.06 .2013 & 21:08 & $21: 18$ & 1.26 & 0.71 & Te Mahanga \\
\hline Juv $\star$ & 18.11.2012 & $23: 07$ & $23: 18$ & 2.30 & 0.66 & Te Mahanga \\
\hline Juv $\star$ & 17.12.2012 & $03: 28$ & $03: 36$ & 0.05 & 0.04 & Te Mahanga \\
\hline Juv $\star$ & 14.01 .2013 & 01:02 & 01:10 & 0.03 & 0.42 & Te Mahanga \\
\hline Juv $\star$ & 14.01 .2013 & 01:02 & 01:10 & 1.57 & 0.77 & Te Mahanga \\
\hline Juv $\star$ & 08.04 .2013 & $21: 47$ & $21: 54$ & 0.32 & 0.20 & Te Mahanga \\
\hline Juv & 08.04 .2013 & $21: 47$ & $21: 54$ & 1.84 & 0.77 & Te Mahanga \\
\hline Juv $\star$ & 12.04 .2013 & 21:09 & $21: 17$ & 1.24 & 0.23 & Te Mahanga \\
\hline Juv & 06.05 .2013 & $20: 58$ & $21: 04$ & 0.24 & 0.23 & Te Mahanga \\
\hline Juv $\star$ & 06.06.2013 & $20: 12$ & $20: 17$ & 2.02 & 0.04 & Te Mahanga \\
\hline
\end{tabular}

1. Coordinates: Original \& second enclosure boundaries $x=0.0,3.10 \& y=0.0,1.50 ;$ Te Mahanga enclosure boundary $\mathrm{x}=0.0,2.50 \& \mathrm{y}=0.0,0.08$ 
$\diamond$ frogs relocated from second enclosure to Te Mahanga enclosure

* frogs not recaptured

$\star$ juvenile (count only), ranging from newly metamorphosed froglets to sub-adult recruits 


\section{Appendix $\mathrm{C}$}

\section{Kiwi-frog encounter (raw data)}

\begin{tabular}{|c|c|c|c|c|c|c|c|c|}
\hline Site $^{1}$ & Date set & Time set & Time Coll. ${ }^{2}$ & Camera & $\begin{array}{l}\text { Total } \\
\text { Videos }\end{array}$ & $\begin{array}{l}\text { Time } \\
\text { triggered }^{3}\end{array}$ & Activity $^{4}$ & $\begin{array}{l}\text { Vid. } \\
\text { no. }^{5}\end{array}$ \\
\hline 1 & 23.06 .2013 & $16: 36$ & 09:09 & $\mathrm{V} 2$ & 0 & & & \\
\hline 1 & 23.06 .2013 & $16: 36$ & 09:09 & $\mathrm{Z} 2$ & 0 & & & \\
\hline 1 & 24.06 .2013 & $15: 38$ & $08: 55$ & $\mathrm{~V} 2$ & 2 & $06: 32$ & kiwi & 0007 \\
\hline 1 & 24.06 .2013 & & & $\mathrm{Z} 2$ & 1 & $06: 31$ & kiwi & 0003 \\
\hline 1 & 25.06 .2013 & $15: 35$ & 09:36 & $\mathrm{V} 2$ & & $16: 23$ & diurnal bird & 0011 \\
\hline 1 & & & & $\mathrm{~V} 2$ & & $16: 24$ & diurnal bird & 0012 \\
\hline 1 & & & & $\mathrm{~V} 2$ & 5 & $16: 26$ & diurnal bird & 0013 \\
\hline 1 & 25.06 .2013 & $15: 35$ & 09:36 & $\mathrm{Z} 2$ & 0 & & & \\
\hline 1 & 26.06 .2013 & $15: 30$ & 09:40 & $\mathrm{V} 2$ & & 01:12 & kiwi & 0007 \\
\hline 1 & & & & $\mathrm{~V} 2$ & & 08:20 & diurnal bird & 0008 \\
\hline 1 & & & & $\mathrm{~V} 2$ & 6 & $08: 39$ & diurnal bird & 0009 \\
\hline 1 & 26.06 .2013 & $15: 30$ & 09:40 & $\mathrm{Z} 2$ & 3 & 01:12 & kiwi & 0003 \\
\hline 1 & 27.06 .2013 & $15: 37$ & $09: 45$ & $\mathrm{~V} 2$ & 0 & & & \\
\hline 1 & 27.06 .2013 & $15: 37$ & 09:45 & $\mathrm{Z} 2$ & 1 & 09:10 & diurnal bird & 0004 \\
\hline 2 & 23.06 .2013 & $17: 35$ & $08: 42$ & $\mathrm{~V} 4$ & & $20: 14$ & frog & 0009 \\
\hline 2 & & & & V4 & 48 & $06: 31$ & frog & 0045 \\
\hline 2 & 23.06 .2013 & $17: 35$ & $8: 42$ & $\mathrm{Z} 1$ & 0 & & & \\
\hline 2 & 24.06 .2013 & $16: 12$ & $9: 20$ & $\mathrm{~V} 4$ & & $17: 53$ & kiwi & 0057 \\
\hline 2 & & & & $\mathrm{~V} 4$ & & $17: 54$ & kiwi & 0058 \\
\hline 2 & & & & $\mathrm{~V} 4$ & 31 & $03: 50$ & rodent & 0073 \\
\hline 2 & 24.06 .2013 & $16: 12$ & 09:20 & $\mathrm{Z} 1$ & 0 & & & \\
\hline 2 & 25.06 .2013 & $16: 20$ & $09: 14$ & $\mathrm{~V} 4$ & 54 & & & \\
\hline 2 & 25.06 .2013 & $16: 20$ & $09: 14$ & $\mathrm{Z} 1$ & 0 & & & \\
\hline 2 & 26.06.2013 & 16:06 & 09:24 & V4 & 7 & & & \\
\hline 2 & 26.06 .2013 & 16:06 & $09: 24$ & $\mathrm{Z} 1$ & 0 & & & \\
\hline 2 & 27.06 .2013 & $16: 14$ & 09:30 & $\mathrm{V} 4$ & 2 & & & \\
\hline 2 & 27.06 .2013 & $16: 14$ & 09:30 & $\mathrm{Z} 1$ & 0 & & & \\
\hline 3 & 23.06 .2013 & $17: 17$ & $08: 35$ & V1 & 2 & & & \\
\hline
\end{tabular}




\begin{tabular}{|c|c|c|c|c|c|c|c|}
\hline \multirow[t]{5}{*}{23.06 .2013} & $17: 17$ & $08: 35$ & V3 & & $18: 35$ & frog & 0009 \\
\hline & & & $\mathrm{V} 3$ & & $21: 12$ & kiwi & 0029 \\
\hline & & & $\mathrm{V} 3$ & & $07: 40$ & frog & 0117 \\
\hline & & & V3 & & $07: 43$ & diurnal bird & 0118 \\
\hline & & & V3 & 122 & $08: 35$ & diurnal bird & 0128 \\
\hline \multirow[t]{7}{*}{24.06 .2013} & $15: 55$ & 09:05 & V1 & & $07: 42$ & diurnal bird & 0008 \\
\hline & & & V1 & & $07: 46$ & diurnal bird & 0009 \\
\hline & & & V1 & & $08: 27$ & diurnal bird & 00010 \\
\hline & & & V1 & & $08: 32$ & diurnal bird & 00011 \\
\hline & & & V1 & & $08: 43$ & diurnal bird & 0012 \\
\hline & & & V1 & & 08:44 & diurnal bird & 0013 \\
\hline & & & V1 & 8 & $08: 45$ & diurnal bird & 0014 \\
\hline \multirow[t]{7}{*}{24.06 .2013} & $15: 55$ & 09:05 & V3 & & $15: 55$ & human & 0131 \\
\hline & & & V3 & & $18: 21$ & kiwi & 0139 \\
\hline & & & V3 & & $18: 26$ & kiwi & 0140 \\
\hline & & & V3 & & $18: 37$ & kiwi & 0141 \\
\hline & & & V3 & & $18: 48$ & kiwi & 0142 \\
\hline & & & V3 & & $00: 34$ & frog & 0176 \\
\hline & & & V3 & 96 & $07: 23$ & frog & 0225 \\
\hline \multirow[t]{3}{*}{25.06 .2013} & $16: 01$ & 09:01 & V1 & & $00: 13$ & kiwi & 0014 \\
\hline & & & V1 & & 08:06 & diurnal bird & 0015 \\
\hline & & & V1 & 3 & 08:44 & diurnal bird & 0016 \\
\hline \multirow[t]{4}{*}{25.06 .2013} & 16:01 & 09:01 & V3 & & $16: 52$ & frog & 0003 \\
\hline & & & V3 & & $07: 40$ & frog & 0124 \\
\hline & & & V3 & & $07: 45$ & diurnal bird & 0125 \\
\hline & & & V3 & 134 & 08:06 & diurnal bird & 0128 \\
\hline \multirow[t]{4}{*}{26.06 .2013} & $15: 51$ & 09:10 & V1 & & $18: 12$ & kiwi & 0008 \\
\hline & & & V1 & & 08:09 & diurnal bird & 0009 \\
\hline & & & V1 & & $08: 13$ & diurnal bird & 0010 \\
\hline & & & V1 & 6 & $08: 30$ & diurnal bird & 0011 \\
\hline \multirow[t]{4}{*}{ 26.06.2013 } & $15: 51$ & $09: 10$ & V3 & & $18: 12$ & frog & 0009 \\
\hline & & & V3 & & 08:06 & diurnal bird & 0050 \\
\hline & & & V3 & & 08:09 & diurnal bird & 0051 \\
\hline & & & V3 & 57 & $08: 12$ & diurnal bird & 0054 \\
\hline \multirow[t]{10}{*}{27.06 .2013} & $15: 58$ & $09: 20$ & V1 & & $16: 05$ & diurnal bird & 0003 \\
\hline & & & V1 & & $16: 07$ & diurnal bird & 0004 \\
\hline & & & V1 & & $16: 24$ & diurnal bird & 0005 \\
\hline & & & V1 & & $16: 26$ & diurnal bird & 0006 \\
\hline & & & V1 & & $16: 42$ & diurnal bird & 0007 \\
\hline & & & V1 & & $16: 43$ & diurnal bird & 0008 \\
\hline & & & V1 & & $16: 44$ & diurnal bird & 0009 \\
\hline & & & V1 & & $17: 40$ & kiwi & 0010 \\
\hline & & & V1 & & $22: 50$ & kiwi & 0011 \\
\hline & & & V1 & 10 & $05: 16$ & kiwi & 0012 \\
\hline \multirow[t]{4}{*}{27.06 .2013} & $15: 58$ & $09: 20$ & V3 & & $16: 05$ & diurnal bird & 0006 \\
\hline & & & V3 & & $16: 11$ & diurnal bird, frog & 0008 \\
\hline & & & V3 & & $16: 22$ & diurnal bird & 0010 \\
\hline & & & V3 & & $16: 24$ & diurnal bird & 0011 \\
\hline
\end{tabular}




\begin{tabular}{|c|c|c|c|c|c|}
\hline 3 & V3 & & $16: 26$ & diurnal bird & 0012 \\
\hline 3 & V3 & & $16: 31$ & diurnal bird & 0013 \\
\hline 3 & V3 & & $16: 33$ & diurnal bird & 0014 \\
\hline 3 & V3 & & $16: 42$ & diurnal bird & 0015 \\
\hline 3 & V3 & & $16: 43$ & diurnal bird & 0016 \\
\hline 3 & V3 & & $16: 44$ & diurnal bird & 0017 \\
\hline 3 & V3 & & $16: 46$ & diurnal bird & 0018 \\
\hline 3 & V3 & & $17: 42$ & kiwi & 0019 \\
\hline 3 & $\mathrm{~V} 3$ & & 18:02 & frog & 0020 \\
\hline 3 & V3 & & $22: 51$ & kiwi & 0035 \\
\hline 3 & $\mathrm{~V} 3$ & & $02: 52$ & kiwi & 0048 \\
\hline 3 & V3 & & $05: 15$ & kiwi & 0057 \\
\hline 3 & V3 & & $07: 28$ & frog & 0064 \\
\hline 3 & V3 & & $07: 45$ & diurnal bird & 0065 \\
\hline 3 & $\mathrm{~V} 3$ & 70 & $08: 59$ & diurnal bird & 0071 \\
\hline
\end{tabular}

Note: Empty videos have been omitted. If no activity is noted, the video did not contain any apparent fauna.

Frog Weight Data

\begin{tabular}{ccccc} 
Date & Site $^{1}$ & Time (h) & Frog ID & Wgt $^{6}(\mathrm{~g})$ \\
\hline 22.06 .2013 & 1 & $20: 30$ & B14 & 9.2 \\
24.06 .2013 & 1 & $09: 12$ & B14 & 8.6 \\
24.06 .2013 & 1 & $15: 24$ & B14 & 8.5 \\
25.06 .2013 & 1 & $09: 20$ & B14 & 8.6 \\
25.06 .2013 & 1 & $15: 17$ & B14 & 8.5 \\
26.06 .2013 & 1 & $09: 41$ & B14 & 8.6 \\
26.06 .2013 & 1 & $15: 15$ & B14 & 8.7 \\
27.06 .2013 & 1 & $09: 25$ & B14 & 8.4 \\
27.06 .2013 & 1 & $15: 30$ & B14 & 8.5 \\
28.06 .2013 & 1 & $09: 35$ & B14 & 8.6 \\
22.06 .2013 & 2 & $20: 30$ & B12 & 11.2 \\
24.06 .2013 & 2 & $09: 12$ & B12 & 10.9 \\
24.06 .2013 & 2 & $15: 24$ & B12 & 10.6 \\
25.06 .2013 & 2 & $09: 20$ & B12 & 10.3 \\
25.06 .2013 & 2 & $15: 17$ & B12 & 10.6 \\
26.06 .2013 & 2 & $09: 41$ & B12 & 10.3 \\
26.06 .2013 & 2 & $15: 15$ & B12 & 10.5 \\
27.06 .2013 & 2 & $09: 25$ & B12 & 10.3 \\
27.06 .2013 & 2 & $15: 30$ & B12 & 10.4
\end{tabular}




$\begin{array}{llllc}28.06 .2013 & 2 & 09: 35 & \text { B12 } & 10.1 \\ 22.06 .2013 & 3 & 20: 30 & \text { M28 } & 7.0 \\ 24.06 .2013 & 3 & 09: 12 & \text { M28 } & 6.7 \\ 24.06 .2013 & 3 & 15: 24 & \text { M28 } & 6.5 \\ 25.06 .2013 & 3 & 09: 20 & \text { M28 } & 6.5 \\ 25.06 .2013 & 3 & 15: 17 & \text { M28 } & 6.6 \\ 26.06 .2013 & 3 & 09: 41 & \text { M28 } & 6.5 \\ 26.06 .2013 & 3 & 15: 15 & \text { M28 } & 6.5 \\ 27.06 .2013 & 3 & 09: 25 & \text { M28 } & 6.6 \\ 27.06 .2013 & 3 & 15: 30 & \text { M28 } & 6.8 \\ 28.06 .2013 & 3 & 09: 35 & \text { M28 } & 6.7\end{array}$

1. 1- Te Mahanga track (frog B14); 2- Swamp track (frog M28); 3- Lake Road track (frog B12)

2. Time collected occurred on the following day.

3. Time the camera was triggered to record. Only videos with apparent fauna activity were noted.

4. Fauna activity seen in video

5. Video number

6. Weight 


\section{Appendix D}

\section{Translocated frog recaptures (raw data)}

\begin{tabular}{|c|c|c|c|c|c|c|}
\hline Frog ID & Date & $\begin{array}{l}\text { Start time } \\
\text { (h) }\end{array}$ & $\begin{array}{l}\text { End time } \\
\text { (h) }\end{array}$ & $\mathrm{Wgt}^{1}(\mathrm{~g})$ & $\mathrm{X}^{2}$ & $\mathrm{Y}^{2}$ \\
\hline $\mathrm{T} 1$ & 14.01 .2013 & $22: 21$ & $23: 55$ & 9.2 & 3.76 & 14.87 \\
\hline $\mathrm{T} 2$ & 17.12.2013 & $22: 15$ & 01:50 & 8.1 & 0.09 & 10.63 \\
\hline $\mathrm{T} 2$ & 15.01 .2013 & $22: 10$ & $23: 52$ & 8.8 & 4.05 & 9.79 \\
\hline $\mathrm{T} 2$ & 16.01 .2013 & $22: 03$ & $23: 59$ & 8.7 & 5.10 & 9.45 \\
\hline $\mathrm{T} 2$ & 12.02 .2013 & $22: 02$ & $23: 15$ & 9.3 & 3.03 & 9.47 \\
\hline $\mathrm{T} 2$ & 15.02 .2013 & $21: 58$ & 23:09 & 9.2 & 2.73 & 9.79 \\
\hline $\mathrm{T} 2$ & 08.04 .2013 & $19: 30$ & $20: 54$ & 10.1 & 4.01 & 9.79 \\
\hline $\mathrm{T} 2$ & 10.04 .2013 & $19: 21$ & $20: 11$ & 9.9 & 3.09 & 9.39 \\
\hline $\mathrm{T} 2$ & 08.05 .2013 & $18: 35$ & $20: 14$ & 10.2 & 4.13 & 9.98 \\
\hline $\mathrm{T} 2$ & 09.05 .2013 & $18: 37$ & $20: 10$ & 9.9 & 2.71 & 8.43 \\
\hline $\mathrm{T} 2$ & 03.06 .2013 & $18: 22$ & $20: 00$ & 9.6 & 8.88 & -0.25 \\
\hline T3 & 17.12 .2012 & $22: 15$ & $01: 50$ & 7.2 & 5.25 & 11.42 \\
\hline T3 & 02.07.2013 & $10: 30$ & 20:19 & 9.0 & 8.41 & 10.73 \\
\hline T3 & 01.08 .2013 & $18: 55$ & $20: 57$ & 8.4 & 7.5 & 10.85 \\
\hline $\mathrm{T} 4$ & 21.12.2012 & $22: 08$ & 00:05 & 8.0 & 5.81 & 10.59 \\
\hline $\mathrm{T} 4$ & 15.01 .2013 & $22: 10$ & $23: 52$ & 7.7 & 5.79 & 10.06 \\
\hline $\mathrm{T} 4$ & 11.04 .2013 & $19: 25$ & $20: 40$ & 9.5 & 6.16 & 11.24 \\
\hline $\mathrm{T} 4$ & 04.06 .2013 & $18: 34$ & $20: 16$ & 9.3 & 5.12 & 9.83 \\
\hline $\mathrm{T} 5$ & 13.02 .2013 & $21: 51$ & $23: 05$ & 8.1 & 8.47 & 10.46 \\
\hline $\mathrm{T} 5$ & 15.03 .2013 & $21: 20$ & $22: 39$ & 8.6 & 7.19 & 10.65 \\
\hline $\mathrm{T} 5$ & 08.04 .2013 & $19: 30$ & $20: 54$ & 8.6 & 8.39 & 10.08 \\
\hline $\mathrm{T} 5$ & 30.07 .2013 & 19:00 & $20: 38$ & 8.8 & 9.00 & 11.90 \\
\hline \multicolumn{7}{|l|}{$\mathrm{T} 6 *$} \\
\hline $\mathrm{T} 7$ & 17.12.2012 & $22: 15$ & 01:50 & 7.3 & 7.52 & 14.87 \\
\hline $\mathrm{T} 7$ & 15.02 .2013 & $21: 58$ & 23:09 & 9.1 & 8.82 & 10.38 \\
\hline $\mathrm{T} 7$ & 07.06 .2013 & $18: 32$ & $20: 22$ & 9.8 & 8.53 & 10.2 \\
\hline $\mathrm{T} 7$ & 01.08 .2013 & $18: 55$ & $20: 57$ & 9.4 & 7.70 & 10.71 \\
\hline
\end{tabular}




\begin{tabular}{|c|c|c|c|c|c|c|}
\hline $\mathrm{T} 8$ & 13.03 .2013 & 21:08 & $22: 00$ & 8.6 & 8.88 & -0.17 \\
\hline $\mathrm{T} 8$ & 01.07.2013 & $18: 35$ & $20: 20$ & 9.4 & 8.23 & 0.46 \\
\hline $\mathrm{T} 8$ & 29.07 .2013 & $19: 10$ & $20: 56$ & 9.1 & 8.80 & 0.11 \\
\hline \multicolumn{7}{|l|}{$\mathrm{T} 9 *$} \\
\hline $\mathrm{T} 10$ & 20.12 .2012 & $22: 03$ & $23: 26$ & 10.7 & 8.29 & 13.89 \\
\hline T10 & 14.01 .2013 & $22: 21$ & $23: 55$ & 10.5 & 8.59 & 14.69 \\
\hline $\mathrm{T} 10$ & 16.01 .2013 & 22:03 & $23: 59$ & 10.5 & 8.90 & 14.67 \\
\hline $\mathrm{T} 10$ & 18.01 .2013 & $22: 11$ & $23: 40$ & 10.5 & 7.72 & 13.35 \\
\hline T10 & 12.02 .2013 & 22:02 & $23: 15$ & 10.7 & 7.23 & 14.91 \\
\hline T10 & 13.02 .2013 & $21: 51$ & 23:05 & 10.7 & 9.12 & 14.83 \\
\hline T10 & 09.04 .2013 & $19: 20$ & $20: 18$ & 11.6 & 7.86 & 14.85 \\
\hline $\mathrm{T} 10$ & 10.05 .2013 & $18: 38$ & $19: 52$ & 11.8 & 2.99 & 9.35 \\
\hline $\mathrm{T} 11$ & 17.12 .2012 & $22: 15$ & $01: 50$ & 6.5 & 2.24 & 13.59 \\
\hline T11 & 18.01 .2013 & $22: 11$ & $23: 40$ & 6.6 & 2.79 & 9.81 \\
\hline $\mathrm{T} 11$ & 12.02 .2013 & 22:02 & $23: 15$ & 7.0 & 2.32 & 14.08 \\
\hline T11 & 13.02 .2013 & $21: 51$ & 23:05 & 7.1 & 2.22 & 13.73 \\
\hline T11 & 15.02 .2013 & $21: 58$ & 23:09 & 7.2 & 3.34 & 13.79 \\
\hline $\mathrm{T} 11$ & 11.03 .2013 & $21: 20$ & $22: 46$ & 7.0 & 2.89 & 14.77 \\
\hline T11 & 11.04 .2013 & $19: 25$ & $20: 40$ & 7.5 & 0.70 & 13.51 \\
\hline T11 & 02.08.2013 & $18: 45$ & $20: 40$ & 8.4 & 2.75 & 11.44 \\
\hline \multicolumn{7}{|c|}{$\mathrm{T} 12 *$} \\
\hline $\mathrm{T} 13$ & 17.12 .2012 & $22: 15$ & 01:50 & 8.7 & 6.97 & 8.01 \\
\hline $\mathrm{T} 13$ & 15.01 .2013 & $22: 10$ & $23: 52$ & 9.4 & 8.35 & 6.51 \\
\hline $\mathrm{T} 13$ & 16.01 .2013 & $22: 03$ & $23: 59$ & 9.9 & 8.25 & 6.49 \\
\hline $\mathrm{T} 13$ & 14.02 .2013 & $21: 54$ & $23: 13$ & 9.8 & 7.88 & 9.08 \\
\hline $\mathrm{T} 13$ & 10.04 .2013 & $19: 21$ & $20: 11$ & 10.2 & 8.31 & 8.82 \\
\hline $\mathrm{T} 13$ & 06.05 .2013 & $18: 42$ & $20: 32$ & 10.2 & 7.21 & 8.76 \\
\hline T13 & 08.05.2013 & $18: 35$ & $20: 14$ & 9.2 & 2.12 & 4.05 \\
\hline T13 & 03.06 .2013 & $18: 22$ & $20: 00$ & 10.0 & 8.23 & 9.02 \\
\hline T14 & 17.12 .2012 & $22: 15$ & 01:50 & 7.4 & 8.23 & 14.89 \\
\hline T14 & 12.04 .2013 & $19: 21$ & $20: 42$ & 8.5 & 9.47 & 14.14 \\
\hline T15 & 17.12 .2012 & $22: 15$ & $1: 50$ & 6.6 & 4.68 & 12.66 \\
\hline $\mathrm{T} 15$ & 19.12 .2012 & $22: 20$ & $23: 55$ & 6.6 & 4.19 & 12.86 \\
\hline $\mathrm{T} 15$ & 16.01 .2013 & $22: 03$ & $23: 59$ & 6.9 & 8.11 & 0.96 \\
\hline T16 & 17.12 .2012 & $22: 15$ & $01: 50$ & 7.4 & 2.65 & 9.73 \\
\hline T16 & 14.01 .2013 & $22: 21$ & $23: 55$ & 7.7 & 0.07 & 13.45 \\
\hline T16 & 16.01 .2013 & $22: 03$ & $23: 59$ & 8.0 & 3.22 & 11.80 \\
\hline T16 & 11.02 .2013 & $21: 52$ & $23: 18$ & 8.5 & 2.79 & 11.52 \\
\hline T16 & 12.02 .2013 & 22:02 & $23: 15$ & 8.0 & 2.77 & 12.05 \\
\hline T16 & 14.02 .2013 & $21: 54$ & $23: 13$ & 8.4 & 2.44 & 11.84 \\
\hline T16 & 11.04 .2013 & $19: 25$ & $20: 40$ & 8.6 & 2.73 & 12.07 \\
\hline $\mathrm{T} 17$ & 18.12 .2012 & $22: 18$ & $00: 10$ & 8.3 & 3.70 & 5.75 \\
\hline T17 & 14.02 .2013 & $21: 54$ & $23: 13$ & 9.1 & 2.81 & 3.93 \\
\hline $\mathrm{T} 17$ & 09.04 .2013 & $19: 20$ & $20: 18$ & 9.9 & 1.77 & 3.70 \\
\hline T17 & 06.05 .2013 & $18: 42$ & $20: 32$ & 9.4 & 2.26 & 3.85 \\
\hline T17 & 03.06 .2013 & $18: 22$ & $20: 00$ & 9.1 & 1.84 & 4.54 \\
\hline \multicolumn{7}{|c|}{$\mathrm{T} 18 *$} \\
\hline T19 & 21.12 .2012 & $22: 08$ & 00:05 & 8.5 & 3.76 & 9.90 \\
\hline
\end{tabular}




\begin{tabular}{|c|c|c|c|c|c|c|}
\hline T19 & 12.02 .2013 & $22: 02$ & $23: 15$ & 10.2 & 3.13 & 3.97 \\
\hline $\mathrm{T} 19$ & 31.07 .2013 & 19:01 & $20: 48$ & 9.3 & 3.54 & 9.59 \\
\hline $\mathrm{T} 20$ & 17.12 .2012 & $22: 15$ & 01:50 & 7.0 & 0.11 & 4.31 \\
\hline $\mathrm{T} 21$ & 18.12 .2012 & $22: 18$ & 00:10 & 8.8 & 9.67 & 2.26 \\
\hline $\mathrm{T} 21$ & 15.01 .2013 & $22: 10$ & $23: 52$ & 9.1 & 0.15 & 12.88 \\
\hline $\mathrm{T} 21$ & 16.01 .2013 & $22: 03$ & $23: 59$ & 9.2 & 4.23 & 13.79 \\
\hline $\mathrm{T} 21$ & 12.02 .2013 & $22: 02$ & $23: 15$ & 9.3 & 5.75 & 10.26 \\
\hline $\mathrm{T} 21$ & 09.04 .2013 & $19: 20$ & $20: 18$ & 9.8 & 8.29 & 11.44 \\
\hline $\mathrm{T} 21$ & 03.06.2013 & $18: 22$ & 20:00 & 10.0 & 7.78 & 12.47 \\
\hline $\mathrm{T} 22$ & 18.01 .2013 & $22: 11$ & $23: 40$ & 9.5 & 12.41 & 12.01 \\
\hline $\mathrm{T} 22$ & 11.02 .2013 & $21: 52$ & $23: 18$ & 9.5 & 11.84 & 11.68 \\
\hline $\mathrm{T} 22$ & 15.03 .2013 & $21: 20$ & $22: 39$ & 8.8 & 11.88 & 11.58 \\
\hline $\mathrm{T} 22$ & 07.06 .2013 & $18: 32$ & $20: 22$ & 9.8 & 11.13 & 3.07 \\
\hline \multicolumn{7}{|c|}{$\mathrm{T} 23 *$} \\
\hline $\mathrm{T} 24$ & 12.02 .2013 & $22: 02$ & $23: 15$ & 6.7 & 6.18 & 14.91 \\
\hline $\mathrm{T} 24$ & 09.05.2013 & $18: 37$ & $20: 10$ & 7.6 & 5.87 & 13.98 \\
\hline $\mathrm{T} 24$ & 10.05 .2013 & $18: 38$ & $19: 52$ & 7.5 & 5.00 & 14.44 \\
\hline $\mathrm{T} 25$ & 18.12 .2012 & $22: 18$ & 00:10 & 9.1 & 11.48 & 13.37 \\
\hline $\mathrm{T} 25$ & 19.12.2012 & $22: 20$ & $23: 55$ & 9.5 & 11.39 & 13.69 \\
\hline $\mathrm{T} 25$ & 16.01 .2013 & $22: 03$ & 00:00 & 10.5 & 12.17 & 13.61 \\
\hline $\mathrm{T} 25$ & 18.01 .2013 & $22: 11$ & $23: 40$ & 10.4 & 11.13 & 14.20 \\
\hline $\mathrm{T} 25$ & 12.02 .2013 & $22: 02$ & $23: 15$ & 10.4 & 11.94 & 12.09 \\
\hline $\mathrm{T} 25$ & 13.02 .2013 & $21: 51$ & $23: 05$ & 10.5 & 11.23 & 13.43 \\
\hline $\mathrm{T} 25$ & 15.02 .2013 & $21: 58$ & 23:09 & 10.3 & 12.00 & 12.41 \\
\hline $\mathrm{T} 25$ & 08.04.2013 & $19: 30$ & $20: 54$ & 11.3 & 10.83 & 12.78 \\
\hline $\mathrm{T} 25$ & 12.04 .2013 & $19: 21$ & $20: 42$ & 10.6 & 11.58 & 13.37 \\
\hline $\mathrm{T} 25$ & 09.05.2013 & $18: 37$ & $20: 10$ & 10.6 & 9.79 & 14.34 \\
\hline $\mathrm{T} 25$ & 04.06 .2013 & $18: 34$ & $20: 16$ & 11.0 & 6.02 & 14.46 \\
\hline $\mathrm{T} 25$ & 01.07 .2013 & $18: 35$ & $20: 20$ & 10.9 & 7.58 & 13.35 \\
\hline $\mathrm{T} 25$ & 02.07.2013 & $10: 30$ & 20:19 & 10.7 & 8.70 & 13.39 \\
\hline $\mathrm{T} 26$ & 17.12 .2012 & $22: 15$ & 01:50 & 8.6 & 1.71 & 11.84 \\
\hline $\mathrm{T} 27$ & 20.12 .2012 & $22: 03$ & $23: 26$ & 9.8 & 8.92 & 1.59 \\
\hline $\mathrm{T} 27$ & 15.01 .2013 & $22: 10$ & $23: 52$ & 10.6 & 11.31 & 0.66 \\
\hline $\mathrm{T} 28$ & 17.12 .2012 & $22: 15$ & $01: 50$ & 7.1 & 1.84 & 14.81 \\
\hline $\mathrm{T} 28$ & 19.12 .2012 & $22: 20$ & $23: 55$ & 7.3 & 4.45 & 13.16 \\
\hline $\mathrm{T} 28$ & 21.12 .2012 & $22: 08$ & 00:05 & 7.7 & 3.28 & 11.8 \\
\hline $\mathrm{T} 28$ & 14.01 .2013 & $22: 21$ & $23: 55$ & 8.4 & 7.99 & 14.89 \\
\hline $\mathrm{T} 28$ & 16.01 .2013 & $22: 03$ & $23: 59$ & 8.5 & 5.49 & 13.20 \\
\hline $\mathrm{T} 28$ & 11.02 .2013 & $21: 52$ & $23: 18$ & 8.6 & 5.39 & 0.27 \\
\hline $\mathrm{T} 28$ & 14.03 .2013 & $21: 17$ & $22: 38$ & 8.6 & 0.33 & 9.79 \\
\hline $\mathrm{T} 28$ & 11.04 .2013 & $19: 25$ & $20: 40$ & 9.8 & 3.46 & 0.07 \\
\hline $\mathrm{T} 28$ & 06.05 .2013 & $18: 42$ & $20: 32$ & 9.7 & 0.29 & 4.39 \\
\hline $\mathrm{T} 29$ & 18.01 .2013 & $22: 11$ & $23: 40$ & 9.1 & 8.68 & 1.71 \\
\hline $\mathrm{T} 29$ & 14.02 .2013 & $21: 54$ & $23: 13$ & 10.6 & 9.77 & 0.13 \\
\hline T30 & 17.12 .2012 & $22: 15$ & $01: 50$ & 8.7 & 9.99 & 11.01 \\
\hline T30 & 11.02 .2013 & $21: 52$ & $23: 18$ & 9.9 & 8.19 & 10.79 \\
\hline T30 & 04.06 .2013 & $18: 34$ & $20: 16$ & 8.8 & 6.99 & 14.83 \\
\hline T31 & 11.02 .2013 & $21: 52$ & $23: 18$ & 8.7 & 5.04 & 7.80 \\
\hline
\end{tabular}




\begin{tabular}{|c|c|c|c|c|c|c|}
\hline $\mathrm{T} 31$ & 09.04 .2013 & $19: 20$ & $20: 18$ & 9.6 & 4.33 & 6.91 \\
\hline T31 & 11.04 .2013 & $19: 25$ & $20: 40$ & 9.3 & 2.59 & 8.43 \\
\hline T31 & 04.06.2013 & $18: 34$ & $20: 16$ & 9.4 & 5.81 & 4.98 \\
\hline T32 & 17.12 .2012 & $22: 15$ & 01:50 & 8.0 & 8.35 & 10.67 \\
\hline T32 & 15.01 .2013 & $22: 10$ & $23: 52$ & 8.9 & 9.20 & 9.71 \\
\hline T32 & 16.01 .2013 & 22:03 & $23: 59$ & 8.8 & 8.23 & 8.62 \\
\hline T32 & 11.04 .2013 & $19: 25$ & $20: 40$ & 9.3 & 8.35 & 10.63 \\
\hline T32 & 06.05 .2013 & $18: 42$ & $20: 32$ & 9.0 & 8.55 & 10.50 \\
\hline T32 & 09.05.2013 & $18: 37$ & $20: 10$ & 9.0 & 9.79 & 9.53 \\
\hline T32 & 04.06.2013 & $18: 34$ & $20: 16$ & 8.7 & 8.01 & 10.48 \\
\hline T32 & 01.07 .2013 & $18: 35$ & $20: 20$ & 9.0 & 5.89 & 10.52 \\
\hline $\mathrm{T} 33$ & 17.12 .2012 & $22: 15$ & $01: 50$ & 7.9 & 11.66 & 13.47 \\
\hline T33 & 18.12 .2012 & $22: 18$ & $00: 10$ & 8.0 & 5.47 & 14.77 \\
\hline T33 & 21.12 .2012 & 22:08 & 00:05 & 7.8 & 11.15 & 12.78 \\
\hline T33 & 14.01 .2013 & $22: 21$ & $23: 55$ & 8.8 & 11.17 & 14.89 \\
\hline T33 & 15.01 .2013 & $22: 10$ & $23: 52$ & 8.7 & 7.99 & 14.60 \\
\hline T33 & 16.01 .2013 & 22:03 & $23: 59$ & 8.5 & 4.82 & 13.83 \\
\hline T33 & 15.02 .2013 & $21: 58$ & 23:09 & 8.8 & 10.87 & 14.56 \\
\hline T33 & 09.04 .2013 & $19: 20$ & $20: 18$ & 9.4 & 8.23 & 12.19 \\
\hline $\mathrm{T} 33$ & 04.06 .2013 & $18: 34$ & $20: 16$ & 9.0 & 9.99 & 14.85 \\
\hline \multicolumn{7}{|c|}{$\mathrm{T} 34 *$} \\
\hline T35 & 15.02 .2013 & $21: 58$ & 23:09 & 7.6 & 10.06 & 8.15 \\
\hline T36 & 17.12 .2012 & $22: 15$ & $01: 50$ & 2.8 & 6.73 & 9.81 \\
\hline T36 & 03.07 .2013 & $18: 25$ & 20:00 & 4.1 & 8.53 & 9.88 \\
\hline T37 & 21.12 .2012 & 22:08 & 0:05 & 6.4 & 8.19 & 12.19 \\
\hline T37 & 16.01 .2013 & $22: 03$ & $23: 59$ & 6.6 & 8.19 & 8.47 \\
\hline T37 & 14.03 .2013 & $21: 17$ & $22: 38$ & 6.3 & 9.47 & 10.77 \\
\hline $\mathrm{T} 37$ & 03.06.2013 & $18: 22$ & 20:00 & 7.4 & 8.39 & 10.36 \\
\hline T38 & 17.12 .2012 & $22: 15$ & $01: 50$ & 6.6 & 1.49 & 7.89 \\
\hline T38 & 18.12 .2012 & $22: 18$ & $00: 10$ & 6.8 & 5.18 & 13.81 \\
\hline T38 & 14.01 .2013 & $22: 21$ & $23: 55$ & 6.9 & 0.09 & 7.40 \\
\hline T38 & 15.01 .2013 & $22: 10$ & $23: 52$ & 7.2 & 4.51 & 8.13 \\
\hline T38 & 16.01 .2013 & 22:03 & $23: 59$ & 6.9 & 5.27 & 9.39 \\
\hline T38 & 11.02 .2013 & $21: 52$ & $23: 18$ & 7.3 & 4.45 & 9.35 \\
\hline T38 & 15.02 .2013 & $21: 58$ & 23:09 & 7.4 & 2.22 & 7.20 \\
\hline T38 & 14.03 .2013 & $21: 17$ & $22: 38$ & 6.9 & 2.85 & 9.81 \\
\hline T38 & 11.04 .2013 & $19: 25$ & $20: 40$ & 7.6 & 0.70 & 2.40 \\
\hline T38 & 07.05.2013 & $18: 38$ & $20: 15$ & 7.9 & 2.32 & 6.53 \\
\hline T38 & 01.08 .2013 & $18: 55$ & $20: 57$ & 7.8 & 1.00 & 4.52 \\
\hline T39 & 08.04 .2013 & $19: 30$ & $20: 54$ & 9.2 & 0.13 & 11.52 \\
\hline T39 & 04.06 .2013 & $18: 34$ & $20: 16$ & 9.4 & 2.42 & 11.50 \\
\hline T39 & 07.06 .2013 & $18: 32$ & $20: 22$ & 9.4 & 2.14 & 11.15 \\
\hline $\mathrm{T} 40$ & 14.02 .2013 & $21: 54$ & $23: 13$ & 8.9 & 10.14 & 4.15 \\
\hline $\mathrm{T} 41$ & 21.12.2012 & 22:08 & 00:05 & 8.6 & 9.26 & 7.97 \\
\hline $\mathrm{T} 41$ & 14.02 .2013 & $21: 54$ & $23: 13$ & 9.4 & 8.98 & 8.54 \\
\hline $\mathrm{T} 41$ & 15.02 .2013 & $21: 58$ & 23:09 & 9.5 & 10.22 & 8.76 \\
\hline $\mathrm{T} 41$ & 14.03 .2013 & $21: 17$ & $22: 38$ & 9.0 & 10.01 & 10.34 \\
\hline $\mathrm{T} 41$ & 11.04 .2013 & $19: 25$ & $20: 40$ & 10.0 & 7.13 & 8.78 \\
\hline
\end{tabular}




\begin{tabular}{|c|c|c|c|c|c|c|}
\hline $\mathrm{T} 42$ & 17.12 .2012 & $22: 15$ & $01: 50$ & 7.9 & 5.18 & 4.68 \\
\hline $\mathrm{T} 42$ & 18.12 .2012 & $22: 18$ & 00:10 & 7.6 & 8.65 & 3.32 \\
\hline $\mathrm{T} 42$ & 20.12 .2012 & $22: 03$ & $23: 26$ & 7.9 & 8.43 & 1.80 \\
\hline $\mathrm{T} 42$ & 16.01 .2013 & $22: 03$ & $23: 59$ & 8.1 & 6.46 & 3.74 \\
\hline $\mathrm{T} 42$ & 18.01 .2013 & $22: 11$ & $23: 40$ & 8.1 & 8.37 & 1.71 \\
\hline $\mathrm{T} 42$ & 12.02 .2013 & $22: 02$ & $23: 15$ & 7.8 & 5.51 & 3.74 \\
\hline $\mathrm{T} 42$ & 13.02 .2013 & $21: 51$ & $23: 05$ & 8.3 & 8.37 & 1.47 \\
\hline $\mathrm{T} 42$ & 07.05 .2013 & $18: 38$ & $20: 15$ & 9.0 & 5.77 & 1.86 \\
\hline $\mathrm{T} 42$ & 09.05 .2013 & $18: 37$ & $20: 10$ & 9.0 & 6.89 & 3.70 \\
\hline $\mathrm{T} 42$ & 04.06 .2013 & $18: 34$ & $20: 16$ & 8.6 & 6.65 & 4.31 \\
\hline $\mathrm{T} 43$ & 18.12.2012 & $22: 18$ & 00:10 & 6.8 & 7.68 & 5.27 \\
\hline $\mathrm{T} 43$ & 19.12 .2012 & $22: 20$ & $23: 55$ & 7.0 & 7.99 & 5.73 \\
\hline $\mathrm{T} 43$ & 21.12 .2012 & $22: 08$ & 00:05 & 7.3 & 9.00 & 6.00 \\
\hline $\mathrm{T} 43$ & 15.01 .2013 & $22: 10$ & $23: 52$ & 8.2 & 9.14 & 5.19 \\
\hline $\mathrm{T} 43$ & 12.02 .2013 & $22: 02$ & $23: 15$ & 8.2 & 8.61 & 5.29 \\
\hline $\mathrm{T} 43$ & 14.03 .2013 & $21: 17$ & $22: 38$ & 7.8 & 9.99 & 4.94 \\
\hline $\mathrm{T} 43$ & 11.04 .2013 & $19: 25$ & $20: 40$ & 9.0 & 6.77 & 5.06 \\
\hline $\mathrm{T} 43$ & 09.05 .2013 & $18: 37$ & $20: 10$ & 8.6 & 10.12 & 7.99 \\
\hline $\mathrm{T} 43$ & 29.07.2013 & $19: 10$ & $20: 56$ & 8.5 & 7.92 & 6.00 \\
\hline $\mathrm{T} 44$ & 17.12 .2012 & $22: 15$ & 01:50 & 2.8 & 8.49 & 1.80 \\
\hline $\mathrm{T} 44$ & 11.04 .2013 & $19: 25$ & $20: 40$ & 4.4 & 8.63 & 4.15 \\
\hline $\mathrm{T} 44$ & 09.05.2013 & $18: 37$ & $20: 10$ & 4.6 & 9.73 & 3.16 \\
\hline $\mathrm{T} 44$ & 04.06 .2013 & $18: 34$ & $20: 16$ & 4.2 & 7.86 & 0.82 \\
\hline $\mathrm{T} 44$ & 01.07 .2013 & $18: 35$ & $20: 20$ & 4.9 & 8.39 & 1.98 \\
\hline $\mathrm{T} 45$ & 17.12 .2012 & $22: 15$ & 01:50 & 7.7 & 9.93 & 4.50 \\
\hline $\mathrm{T} 45$ & 18.12 .2012 & $22: 18$ & 00:10 & 8.0 & 9.79 & 2.57 \\
\hline $\mathrm{T} 45$ & 15.01 .2013 & $22: 10$ & $23: 52$ & 9.3 & 8.03 & 0.52 \\
\hline $\mathrm{T} 45$ & 16.01 .2013 & $22: 03$ & $23: 59$ & 8.9 & 7.62 & 3.50 \\
\hline $\mathrm{T} 45$ & 13.02 .2013 & $21: 51$ & $23: 05$ & 9.2 & 8.98 & 0.88 \\
\hline $\mathrm{T} 45$ & 11.04 .2013 & $19: 25$ & $20: 40$ & 10.2 & 11.09 & 0.46 \\
\hline $\mathrm{T} 46$ & 18.01 .2013 & $22: 11$ & $23: 40$ & 8.0 & 7.82 & 12.68 \\
\hline $\mathrm{T} 46$ & 14.02 .2013 & $21: 54$ & $23: 13$ & 8.6 & 8.88 & 12.09 \\
\hline $\mathrm{T} 46$ & 15.02 .2013 & $21: 58$ & 23:09 & 8.8 & 7.86 & 12.62 \\
\hline \multicolumn{7}{|c|}{$\mathrm{T} 47 *$} \\
\hline \multicolumn{7}{|c|}{$\mathrm{T} 48 *$} \\
\hline $\mathrm{T} 49$ & 14.01 .2013 & $22: 21$ & $23: 55$ & 5.6 & 11.48 & 0.07 \\
\hline $\mathrm{T} 49$ & 08.04 .2013 & $19: 30$ & $20: 54$ & 6.4 & 11.84 & 4.52 \\
\hline $\mathrm{T} 49$ & 09.05.2013 & $18: 37$ & $20: 10$ & 6.3 & 9.69 & 4.11 \\
\hline T50 & 17.12 .2012 & $22: 15$ & $01: 50$ & 7.6 & 0.78 & 14.89 \\
\hline $\mathrm{T} 50$ & 21.12 .2012 & $22: 08$ & 00:05 & 7.7 & 0.09 & 6.24 \\
\hline T51 & 20.12 .2012 & $22: 03$ & $23: 26$ & 5.8 & 2.46 & 6.49 \\
\hline $\mathrm{T} 52$ & 18.12 .2012 & $22: 18$ & 00:10 & 4.7 & 6.46 & 14.69 \\
\hline T52 & 16.01 .2013 & $22: 03$ & $23: 59$ & 5.5 & 2.59 & 7.54 \\
\hline $\mathrm{T} 53$ & 17.12 .2012 & $22: 15$ & $01: 50$ & 7.7 & 1.98 & 7.68 \\
\hline $\mathrm{T} 53$ & 11.02 .2013 & $21: 52$ & $23: 18$ & 8.4 & 2.73 & 6.08 \\
\hline T53 & 14.03 .2013 & $21: 17$ & $22: 38$ & 7.4 & 0.86 & 9.16 \\
\hline T53 & 03.06.2013 & $18: 22$ & $20: 00$ & 9.4 & 0.09 & 8.29 \\
\hline $\mathrm{T} 53$ & 29.07 .2013 & $19: 10$ & $20: 56$ & 8.8 & 1.86 & 7.68 \\
\hline
\end{tabular}




\begin{tabular}{|c|c|c|c|c|c|c|}
\hline $\mathrm{T} 54$ & 09.05.2013 & $18: 37$ & $20: 10$ & 7.1 & 7.82 & 9.33 \\
\hline $\mathrm{T} 55$ & 17.12 .2012 & $22: 15$ & 01:50 & 7.1 & 4.13 & 14.85 \\
\hline $\mathrm{T} 55$ & 18.12 .2012 & $22: 18$ & 00:10 & 6.8 & & \\
\hline \multicolumn{7}{|c|}{ T56* } \\
\hline $\mathrm{T} 57$ & 17.12 .2012 & $22: 15$ & $01: 50$ & 7.2 & 0.09 & 8.49 \\
\hline $\mathrm{T} 57$ & 18.12 .2012 & $22: 18$ & 00:10 & 7.2 & 0.19 & 14.40 \\
\hline $\mathrm{T} 57$ & 21.12 .2012 & $22: 08$ & 00:05 & 7.2 & 0.19 & 12.15 \\
\hline $\mathrm{T} 57$ & 14.01 .2013 & $22: 21$ & $23: 55$ & 7.2 & 0.03 & 2.00 \\
\hline $\mathrm{T} 57$ & 16.01 .2013 & $22: 03$ & $23: 59$ & 8.2 & 2.22 & 6.79 \\
\hline $\mathrm{T} 58$ & 17.12 .2012 & $22: 15$ & 01:50 & 8.1 & 10.93 & 7.82 \\
\hline \multicolumn{7}{|c|}{$\mathrm{T} 59 *$} \\
\hline T60 & 18.12.2012 & $22: 18$ & 00:10 & 6.7 & 5.16 & 9.43 \\
\hline T60 & 08.04 .2013 & $19: 30$ & $20: 54$ & 8.2 & 0.09 & 10.16 \\
\hline T60 & 11.04 .2013 & $19: 25$ & $20: 40$ & 8.3 & 0.17 & 12.47 \\
\hline \multicolumn{7}{|c|}{ T61* } \\
\hline T62 & 21.12 .2012 & $22: 08$ & 00:05 & 8.5 & 6.34 & 5.79 \\
\hline T62 & 15.01 .2013 & $22: 10$ & $23: 52$ & 9.4 & 5.77 & 5.31 \\
\hline T62 & 12.02 .2013 & $22: 02$ & $23: 15$ & 9.3 & 6.22 & 7.42 \\
\hline T63 & 17.12 .2012 & $22: 15$ & $01: 50$ & 7.9 & & \\
\hline T63 & 18.12 .2012 & $22: 18$ & 00:10 & 7.7 & 8.39 & 10.42 \\
\hline T63 & 21.12 .2012 & $22: 08$ & 00:05 & 8.5 & 8.17 & 10.71 \\
\hline T63 & 14.01 .2013 & $22: 21$ & $23: 55$ & 8.4 & 4.84 & 5.75 \\
\hline T63 & 15.01 .2013 & $22: 10$ & $23: 52$ & 8.6 & 8.11 & 10.46 \\
\hline T63 & 16.01 .2013 & $22: 03$ & $23: 59$ & 8.3 & 10.16 & 9.83 \\
\hline T63 & 15.02 .2013 & $21: 58$ & 23:09 & 8.6 & 8.19 & 9.21 \\
\hline T63 & 11.04 .2013 & $19: 25$ & $20: 40$ & 8.9 & 6.73 & 9.21 \\
\hline T64 & 21.12 .2012 & $22: 08$ & 00:05 & 5.9 & 0.66 & 6.71 \\
\hline T64 & 08.04.2013 & $19: 30$ & $20: 54$ & 6.3 & 2.97 & 9.65 \\
\hline \multicolumn{7}{|c|}{ Т65* } \\
\hline T66 & 13.02 .2013 & $21: 51$ & $23: 05$ & 1.0 & 7.25 & 6.02 \\
\hline T67 & 17.12 .2012 & $22: 15$ & $01: 50$ & 5.9 & 5.94 & 5.13 \\
\hline T67 & 19.12 .2012 & $22: 20$ & $23: 55$ & & 4.35 & 4.58 \\
\hline T67 & 13.02 .2013 & $21: 51$ & $23: 05$ & 7.1 & 5.77 & 4.78 \\
\hline T67 & 08.04 .2013 & $19: 30$ & $20: 54$ & 7.6 & 7.48 & 4.96 \\
\hline T67 & 03.06.2013 & $18: 22$ & $20: 00$ & 7.8 & 5.79 & 5.06 \\
\hline T68 & 17.12 .2012 & $22: 15$ & $01: 50$ & 7.7 & 0.13 & 14.85 \\
\hline T68 & 15.01 .2013 & $22: 10$ & $23: 52$ & 8.8 & 0.64 & 13.41 \\
\hline T68 & 12.02 .2013 & $22: 02$ & $23: 15$ & 8.5 & 0.13 & 8.54 \\
\hline T69 & 17.12 .2012 & $22: 15$ & $01: 50$ & 4.8 & 2.42 & 11.97 \\
\hline T69 & 16.01 .2013 & $22: 03$ & $23: 59$ & 5.3 & 2.20 & 10.79 \\
\hline T69 & 02.07.2013 & $10: 30$ & 20:19 & 6.5 & 1.25 & 10.30 \\
\hline T70 & 17.12 .2012 & $22: 15$ & $01: 50$ & 5.1 & 0.09 & 11.93 \\
\hline $\mathrm{T} 71$ & 17.12 .2012 & $22: 15$ & $01: 50$ & 5.2 & 8.37 & 10.44 \\
\hline $\mathrm{T} 71$ & 14.01 .2013 & $22: 21$ & $23: 55$ & 5.1 & 6.87 & 10.69 \\
\hline $\mathrm{T} 71$ & 11.02 .2013 & $21: 52$ & $23: 18$ & 5.5 & 8.82 & 10.75 \\
\hline $\mathrm{T} 71$ & 12.02 .2013 & $22: 02$ & $23: 15$ & 5.2 & 9.20 & 11.34 \\
\hline $\mathrm{T} 71$ & 11.04 .2013 & $19: 25$ & $20: 40$ & 5.7 & 8.49 & 10.65 \\
\hline $\mathrm{T} 71$ & 30.07 .2013 & 19:00 & $20: 38$ & 5.1 & 2.85 & 11.95 \\
\hline
\end{tabular}




\begin{tabular}{|c|c|c|c|c|c|c|}
\hline $\mathrm{T} 72$ & 11.02 .2013 & $21: 52$ & $23: 18$ & 4.9 & 4.62 & 8.29 \\
\hline $\mathrm{T} 72$ & 14.03 .2013 & $21: 17$ & $22: 38$ & 5.4 & 5.53 & 11.38 \\
\hline $\mathrm{T} 72$ & 08.05 .2013 & $18: 35$ & $20: 14$ & 5.9 & 6.24 & 9.90 \\
\hline $\mathrm{T} 72$ & 09.05.2013 & $18: 37$ & $20: 10$ & 5.6 & 7.72 & 9.65 \\
\hline $\mathrm{T} 73$ & 21.12 .2012 & $22: 08$ & 00:05 & 7.6 & 2.87 & 9.81 \\
\hline $\mathrm{T} 73$ & 15.01 .2013 & $22: 10$ & $23: 52$ & 9.6 & 5.37 & 9.47 \\
\hline $\mathrm{T} 73$ & 12.02 .2013 & $22: 02$ & $23: 15$ & 9.0 & 5.67 & 9.79 \\
\hline $\mathrm{T} 73$ & 15.02 .2013 & $21: 58$ & 23:09 & 9.1 & 4.98 & 9.77 \\
\hline $\mathrm{T} 73$ & 14.03 .2013 & $21: 17$ & $22: 38$ & 9.2 & 3.95 & 9.79 \\
\hline $\mathrm{T} 73$ & 09.05 .2013 & $18: 37$ & $20: 10$ & 9.2 & 5.20 & 9.85 \\
\hline $\mathrm{T} 73$ & 03.06 .2013 & $18: 22$ & $20: 00$ & 9.2 & 5.51 & 9.65 \\
\hline $\mathrm{T} 73$ & 03.07.2013 & $18: 25$ & 20:00 & 8.7 & 4.27 & 10.32 \\
\hline $\mathrm{T} 74$ & 14.01 .2013 & $22: 21$ & $23: 55$ & 8.1 & 0.90 & 6.32 \\
\hline $\mathrm{T} 74$ & 12.02 .2013 & $22: 02$ & $23: 15$ & 7.6 & 0.17 & 6.63 \\
\hline $\mathrm{T} 74$ & 14.03 .2013 & $21: 17$ & $22: 38$ & 6.5 & 0.48 & 7.07 \\
\hline $\mathrm{T} 74$ & 08.04 .2013 & $19: 30$ & $20: 54$ & 7.7 & 0.13 & 7.22 \\
\hline $\mathrm{T} 74$ & 11.04 .2013 & $19: 25$ & $20: 40$ & 7.3 & 0.19 & 3.50 \\
\hline $\mathrm{T} 74$ & 04.06 .2013 & $18: 34$ & $20: 16$ & 8.1 & 0.07 & 7.48 \\
\hline $\mathrm{T} 74$ & 05.07 .2013 & $18: 17$ & $19: 38$ & 7.7 & 1.33 & 6.99 \\
\hline $\mathrm{T} 75$ & 14.01 .2013 & $22: 21$ & $23: 55$ & 8.8 & 0.09 & 4.78 \\
\hline $\mathrm{T} 75$ & 15.02 .2013 & $21: 58$ & 23:09 & 9.2 & 0.13 & 3.34 \\
\hline T75 & 04.06 .2013 & $18: 34$ & $20: 16$ & 9.8 & 0.09 & 9.83 \\
\hline $\mathrm{T} 76$ & 11.02 .2013 & $21: 52$ & $23: 18$ & 1.0 & 8.21 & 9.90 \\
\hline \multicolumn{7}{|c|}{$\mathrm{T} 77 *$} \\
\hline T78 & 14.01 .2013 & $22: 21$ & $23: 55$ & 10.2 & 6.02 & 3.28 \\
\hline $\mathrm{T} 78$ & 15.02 .2013 & $21: 58$ & 23:09 & 10.6 & 10.3 & 2.75 \\
\hline $\mathrm{T} 78$ & 14.03 .2013 & $21: 17$ & $22: 38$ & 11.4 & 10.06 & 3.93 \\
\hline T79 & 21.12 .2012 & $22: 08$ & 00:05 & 7.8 & 10.48 & 2.81 \\
\hline T79 & 15.01 .2013 & $22: 10$ & $23: 52$ & 8.5 & 11.96 & 0.64 \\
\hline T79 & 16.01 .2013 & $22: 03$ & $23: 59$ & 8.4 & 11.64 & 1.61 \\
\hline T79 & 13.02 .2013 & $21: 51$ & 23:05 & 9.2 & 10.89 & 2.51 \\
\hline $\mathrm{T} 79$ & 15.02 .2013 & $21: 58$ & 23:09 & 8.6 & 11.60 & 2.00 \\
\hline T79 & 14.03 .2013 & $21: 17$ & $22: 38$ & 9.0 & 11.72 & 0.92 \\
\hline T79 & 12.04 .2013 & $19: 21$ & $20: 42$ & 9.2 & 11.48 & 1.13 \\
\hline T79 & 06.05 .2013 & $18: 42$ & $20: 32$ & 8.6 & 12.04 & 1.94 \\
\hline T79 & 09.05 .2013 & $18: 37$ & $20: 10$ & 8.5 & 10.44 & 1.19 \\
\hline $\mathrm{T} 80$ & 17.12 .2012 & $22: 15$ & 01:50 & 7.3 & 8.11 & 10.79 \\
\hline T80 & 19.12 .2012 & $22: 20$ & $23: 55$ & 7.3 & 8.23 & 9.83 \\
\hline $\mathrm{T} 80$ & 14.02 .2013 & $21: 54$ & $23: 13$ & 8.0 & 9.49 & 7.91 \\
\hline $\mathrm{T} 81$ & 17.12 .2012 & $22: 15$ & 01:50 & 6.3 & 5.73 & 10.42 \\
\hline T81 & 16.01 .2013 & $22: 03$ & $23: 59$ & 7.4 & 6.18 & 6.18 \\
\hline T81 & 18.01 .2013 & $22: 11$ & $23: 40$ & 7.2 & 6.71 & 6.57 \\
\hline $\mathrm{T} 81$ & 11.02 .2013 & $21: 52$ & $23: 18$ & 7.1 & 5.83 & 10.26 \\
\hline T81 & 12.02 .2013 & $22: 02$ & $23: 15$ & 7.3 & 5.77 & 9.47 \\
\hline $\mathrm{T} 81$ & 09.04 .2013 & $19: 20$ & $20: 18$ & 9.0 & 5.87 & 10.12 \\
\hline $\mathrm{T} 81$ & 02.07 .2013 & $10: 30$ & $20: 19$ & 8.4 & 7.11 & 11.24 \\
\hline T81 & 31.07 .2013 & 19:01 & $20: 48$ & 8.9 & 3.01 & 11.60 \\
\hline $\mathrm{T} 82$ & 15.01 .2013 & $22: 10$ & $23: 52$ & 6.4 & 11.52 & 0.70 \\
\hline
\end{tabular}




\begin{tabular}{|c|c|c|c|c|c|c|}
\hline $\mathrm{T} 82$ & 11.02 .2013 & $21: 52$ & $23: 18$ & 6.1 & 9.06 & 0.54 \\
\hline T82 & 15.02 .2013 & $21: 58$ & 23:09 & 6.2 & 11.01 & 0.46 \\
\hline T82 & 14.03 .2013 & $21: 17$ & $22: 38$ & 6.2 & 11.62 & 0.11 \\
\hline $\mathrm{T} 83$ & 17.12 .2012 & $22: 15$ & $01: 50$ & 5.8 & 12.63 & 12.25 \\
\hline T83 & 21.12.2012 & $22: 08$ & 00:05 & 5.5 & 8.25 & 11.38 \\
\hline $\mathrm{T} 84$ & 17.12 .2012 & $22: 15$ & $01: 50$ & 6.0 & 6.52 & 0.56 \\
\hline T84 & 15.03 .2013 & $21: 20$ & $22: 39$ & 7.1 & 11.88 & 0.74 \\
\hline T84 & 08.04 .2013 & $19: 30$ & $20: 54$ & 7.8 & 11.70 & 1.80 \\
\hline $\mathrm{T} 85$ & 14.02 .2013 & $21: 54$ & $23: 13$ & 7.1 & 8.92 & 3.48 \\
\hline T85 & 14.03 .2013 & $21: 17$ & $22: 38$ & 7.3 & 8.96 & 3.74 \\
\hline T86 & 18.12.2012 & $22: 18$ & $00: 10$ & 6.0 & 7.19 & 0.80 \\
\hline $\mathrm{T} 86$ & 21.12.2012 & 22:08 & 00:05 & 6.2 & 9.32 & 3.05 \\
\hline $\mathrm{T} 86$ & 15.01 .2013 & $22: 10$ & $23: 52$ & 7.3 & 8.70 & 1.45 \\
\hline T86 & 08.05 .2013 & $18: 35$ & $20: 14$ & 8.2 & 8.35 & 1.98 \\
\hline $\mathrm{T} 87$ & 20.12 .2012 & $22: 03$ & $23: 26$ & 6.8 & 10.26 & 1.67 \\
\hline T87 & 21.12.2012 & $22: 08$ & 00:05 & 6.7 & 10.16 & 1.63 \\
\hline $\mathrm{T} 87$ & 16.01 .2013 & 22:03 & $23: 59$ & 7.5 & 8.21 & 1.96 \\
\hline $\mathrm{T} 87$ & 14.03 .2013 & $21: 17$ & $22: 38$ & 7.9 & 11.44 & 0.07 \\
\hline T87 & 11.04 .2013 & $19: 25$ & $20: 40$ & 8.8 & 9.75 & -0.23 \\
\hline $\mathrm{T} 87$ & 03.06.2013 & $18: 22$ & 20:00 & 8.5 & 11.27 & 1.61 \\
\hline $\mathrm{T} 87$ & 02.07 .02013 & $10: 30$ & $20: 19$ & 8.8 & 10.87 & 2.28 \\
\hline \multicolumn{7}{|l|}{$\mathrm{T} 88 *$} \\
\hline T89 & 01.08 .2013 & $18: 55$ & $20: 57$ & 5.3 & 6.28 & 11.42 \\
\hline Т90 & 18.12 .2012 & $22: 18$ & $00: 10$ & 4.9 & 1.41 & 14.52 \\
\hline T91 & 18.12.2012 & $22: 18$ & $00: 10$ & 5.1 & 5.12 & 12.07 \\
\hline Т91 & 13.02 .2013 & $21: 51$ & $23: 05$ & 6.0 & 3.13 & 11.93 \\
\hline T92 & 21.12 .2012 & $22: 08$ & 00:05 & 4.8 & 6.32 & 14.75 \\
\hline T92 & 14.01 .2013 & $22: 21$ & $23: 55$ & 4.9 & 6.30 & 12.70 \\
\hline T93 & 15.01 .2013 & $22: 10$ & $23: 52$ & 4.9 & 6.04 & 12.98 \\
\hline T93 & 16.01 .2013 & 22:03 & $23: 59$ & 4.8 & 6.81 & 14.34 \\
\hline T93 & 11.02 .2013 & $21: 52$ & $23: 18$ & 4.9 & 1.41 & 12.72 \\
\hline T93 & 13.02 .2013 & $21: 51$ & $23: 05$ & 4.9 & 5.89 & 12.60 \\
\hline T93 & 11.04 .2013 & $19: 25$ & $20: 40$ & 5.5 & 0.76 & 13.02 \\
\hline T93 & 09.05 .2013 & $18: 37$ & $20: 10$ & 5.8 & 3.89 & 12.17 \\
\hline Т94 & 17.12 .2012 & $22: 15$ & 01:50 & 5.5 & 4.35 & 12.39 \\
\hline T94 & 21.12.2012 & $22: 08$ & 0:05 & 5.8 & 4.60 & 5.23 \\
\hline T94 & 13.02 .2013 & $21: 51$ & $23: 05$ & 6.0 & 2.77 & 12.03 \\
\hline T94 & 02.07 .2013 & $10: 30$ & $20: 19$ & 5.9 & 2.73 & 12.03 \\
\hline T95 & 17.12 .2012 & $22: 15$ & $01: 50$ & 6.7 & 2.55 & 7.99 \\
\hline T95 & 21.12 .2012 & $22: 08$ & 00:05 & 6.3 & 1.86 & 6.14 \\
\hline \multicolumn{7}{|l|}{ Т96* } \\
\hline Т97 & 16.01 .2013 & 22:03 & $23: 59$ & 8.2 & 10.32 & 2.22 \\
\hline T97 & 15.02 .2013 & $21: 58$ & 23:09 & 8.1 & 11.90 & 3.93 \\
\hline T98 & 17.12 .2012 & $22: 15$ & $01: 50$ & 6.7 & 12.33 & 11.88 \\
\hline T98 & 15.02 .2013 & $21: 58$ & 23:09 & 7.6 & 5.81 & 11.70 \\
\hline T98 & 09.04 .2013 & $19: 20$ & $20: 18$ & 7.6 & 5.47 & 13.83 \\
\hline T99 & 17.12 .2012 & $22: 15$ & $01: 50$ & 8.6 & 0.11 & 10.12 \\
\hline T100 & 17.12 .2012 & $22: 15$ & $01: 50$ & 8.0 & 7.15 & 14.87 \\
\hline
\end{tabular}




$\begin{array}{lllllll}\text { T100 } & 16.01 .2013 & 22: 03 & 23: 59 & 8.2 & 7.17 & 14.22 \\ \text { T100 } & 14.03 .2013 & 21: 17 & 22: 38 & 8.5 & 9.51 & 14.85 \\ \text { T100 } & 12.04 .2013 & 19: 21 & 20: 42 & 9.2 & 10.91 & 14.63 \\ \text { T100 } & 02.08 .2013 & 18: 45 & 20: 40 & 9.4 & 8.33 & 14.95 \\ \text { T101 } & 17.12 .2012 & 22: 15 & 01: 50 & 3.7 & 3.66 & 13.67 \\ \text { T101 } & 18.12 .2012 & 22: 18 & 00: 10 & 3.8 & 3.09 & 12.15 \\ \text { T101 } & 08.05 .2013 & 18: 35 & 20: 14 & 4.6 & 2.73 & 12.35 \\ \text { T101 } & 04.07 .2013 & 18: 23 & 19: 53 & 4.8 & 2.57 & 12.11\end{array}$

1. Weight

2. Coordinates: Fence boundaries $\mathrm{x}=0.00,12.50 \mathrm{y}=0.00,15.00$; Search boundaries $\mathrm{x}=-2.00,14.50$ $\& \mathrm{y}=-2.00,17.00$

* frogs not recaptured 


\section{Appendix E}

\section{Original translocation survivors and progeny re-captures (raw data)}

\begin{tabular}{|c|c|c|c|c|c|c|}
\hline Frog ID & Date & Start time $(\mathrm{h})$ & End time $(\mathrm{h})$ & $\begin{array}{l}\mathrm{Wgt}^{1} \\
(\mathrm{~g})\end{array}$ & $\mathrm{X}$ & $\mathrm{Y}$ \\
\hline B1 & 17.12 .2012 & $22: 15$ & $01: 50$ & 7.3 & 0.11 & 14.63 \\
\hline B1 & 18.12 .2012 & $22: 18$ & $00: 10$ & 7.5 & 0.11 & 12.31 \\
\hline B1 & 21.12.2012 & $22: 08$ & 00:05 & 7.5 & 2.79 & 11.58 \\
\hline B8 & 17.12.2012 & $22: 15$ & $01: 50$ & 10.0 & 10.75 & 14.87 \\
\hline B8 & 18.12 .2012 & $22: 18$ & $00: 10$ & 9.9 & 4.47 & 14.73 \\
\hline B8 & 19.12 .2012 & $22: 20$ & $23: 55$ & 9.7 & 5.12 & 14.50 \\
\hline B8 & 20.12 .2012 & $22: 03$ & $23: 26$ & 9.9 & 6.65 & 13.79 \\
\hline B8 & 14.01 .2013 & $22: 21$ & $23: 55$ & 9.9 & 2.51 & 14.87 \\
\hline B8 & 15.01 .2013 & $22: 10$ & $23: 52$ & 10.4 & 11.19 & 14.38 \\
\hline B8 & 16.01 .2013 & $22: 03$ & $23: 59$ & 10.3 & 9.63 & 14.44 \\
\hline B8 & 13.02 .2013 & $21: 51$ & $23: 05$ & 10.5 & 7.88 & 12.82 \\
\hline B8 & 14.02 .2013 & $21: 54$ & $23: 13$ & 10.2 & 9.20 & 14.06 \\
\hline B8 & 09.04 .2013 & $19: 20$ & $20: 18$ & 11.4 & 7.09 & 14.00 \\
\hline B8 & 09.05 .2013 & $18: 37$ & $20: 10$ & 11.1 & 10.01 & 14.54 \\
\hline B15 & 15.01 .2013 & $22: 10$ & $23: 52$ & 10.7 & 0.15 & 9.41 \\
\hline B15 & 11.02 .2013 & $21: 52$ & $23: 18$ & 10.8 & 2.75 & 5.82 \\
\hline B15 & 11.04 .2013 & $19: 25$ & $20: 40$ & 10.9 & 2.46 & 8.51 \\
\hline B15 & 07.06 .2013 & $18: 32$ & $20: 22$ & 10.6 & 3.87 & 4.58 \\
\hline M15 & 04.06 .2013 & $18: 34$ & $20: 16$ & 7.3 & 0.03 & 5.55 \\
\hline UNK1 & 17.12 .2013 & $22: 15$ & $01: 50$ & 8.7 & 7.13 & 5.02 \\
\hline UNK1 & 18.12 .2013 & $22: 18$ & $00: 10$ & 8.9 & 5.55 & 5.17 \\
\hline UNK1 & 13.02 .2013 & $21: 51$ & $23: 05$ & 10.6 & 8.96 & 7.05 \\
\hline UNK1 & 14.03 .2013 & $21: 17$ & $22: 38$ & 9.9 & 3.93 & 7.74 \\
\hline
\end{tabular}




$\begin{array}{lllllll}\text { UNK2 } & 17.12 .2012 & 22: 15 & 01: 50 & 2.7 & 1.19 & 7.20 \\ \text { UNK2 } & 11.04 .2013 & 19: 25 & 20: 40 & 3.5 & 2.75 & 9.53 \\ \text { UNK2 } & 04.06 .2013 & 18: 34 & 20: 16 & 3.7 & 1.45 & 10.97 \\ \text { UNK2 } & 01.07 .2013 & 18: 35 & 20: 20 & 4.2 & 2.69 & 9.53 \\ \text { UNK3 } & 17.12 .2012 & 22: 15 & 01: 50 & 0.5 & 3.74 & 14.32 \\ \text { UNK3 } & 06.06 .2013 & 18: 22 & 19: 44 & 1.5 & 4.47 & 13.81 \\ \text { UNK3 } & 04.07 .2013 & 18: 23 & 19: 53 & 1.8 & 4.88 & 14.04 \\ \text { UNK4 } & 18.12 .2012 & 22: 18 & 00: 10 & 4.5 & 8.23 & 10.71 \\ \text { UNK5 } & 18.12 .2012 & 22: 18 & 00: 10 & 0.7 & 5.79 & 9.94 \\ \text { UNK5 } & 21.12 .2012 & 22: 08 & 00: 05 & 0.6 & 5.77 & 10.20 \\ \text { UNK6 } & 21.12 .2012 & 22: 08 & 00: 05 & 0.9 & -0.68 & 11.13 \\ \text { UNK6 } & 14.01 .2013 & 22: 21 & 23: 55 & 1.1 & 3.85 & 5.15 \\ \text { UNK6 } & 04.06 .2013 & 18: 34 & 20: 16 & 1.9 & 2.93 & 6.18 \\ \text { UNK7 } & 16.01 .2013 & 22: 03 & 00: 00 & 1.1 & 9.16 & 1.63 \\ \text { UNK8 } & 11.02 .2013 & 21: 52 & 23: 18 & 1.9 & 14.4 & 11.70\end{array}$

1. Weight 
Appendix F

Trajectories and areas utilized by the 16 most frequently captured frogs

$\triangle$ Liberation point

$\triangle$ Recapture location

Final recapture location

Centre of activity 


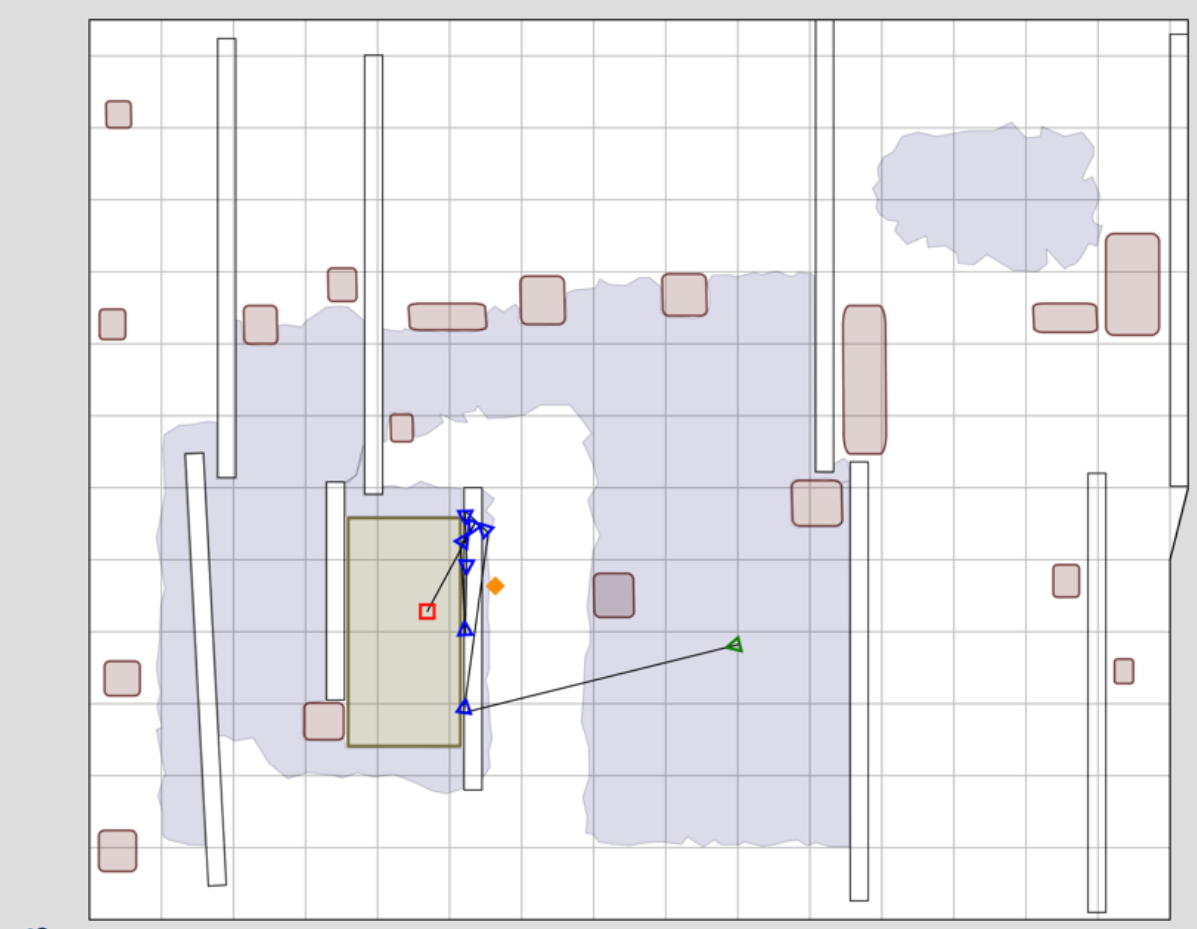

$\stackrel{m}{F}$

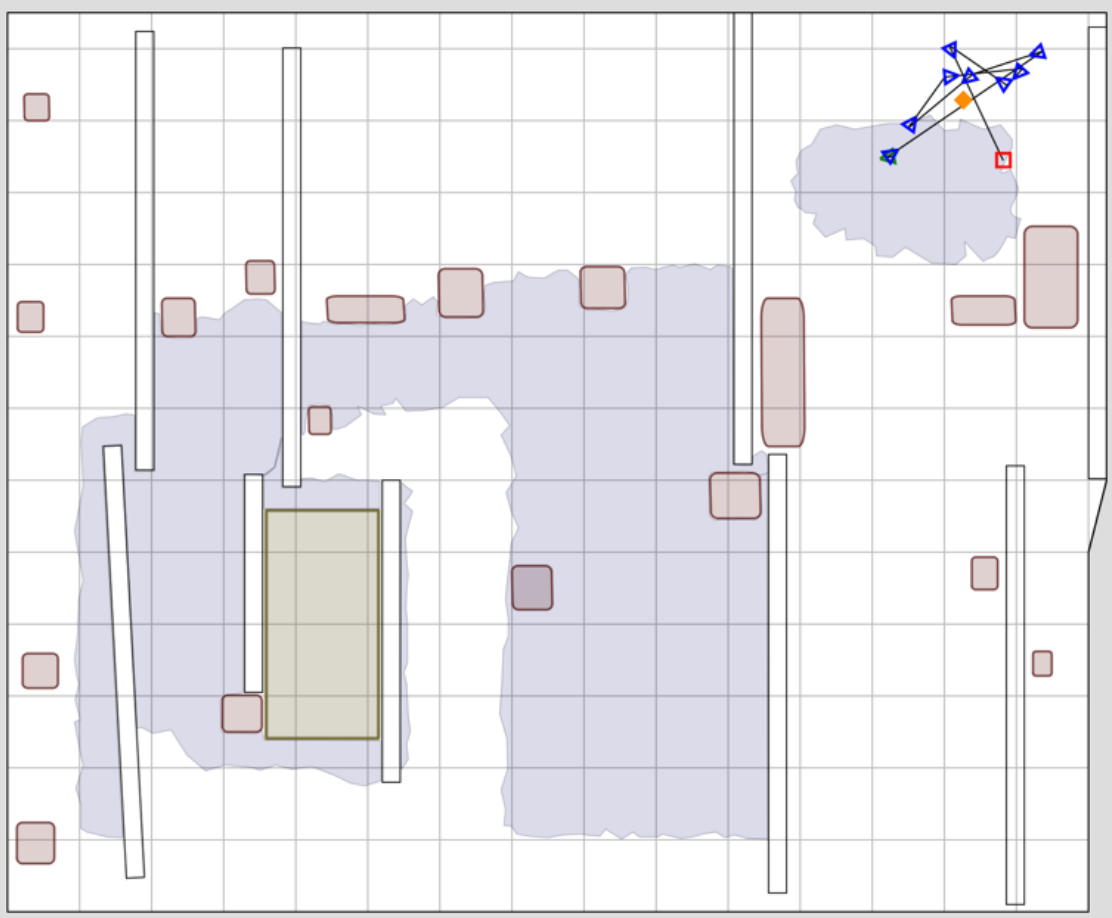

$\stackrel{9}{F}$ 


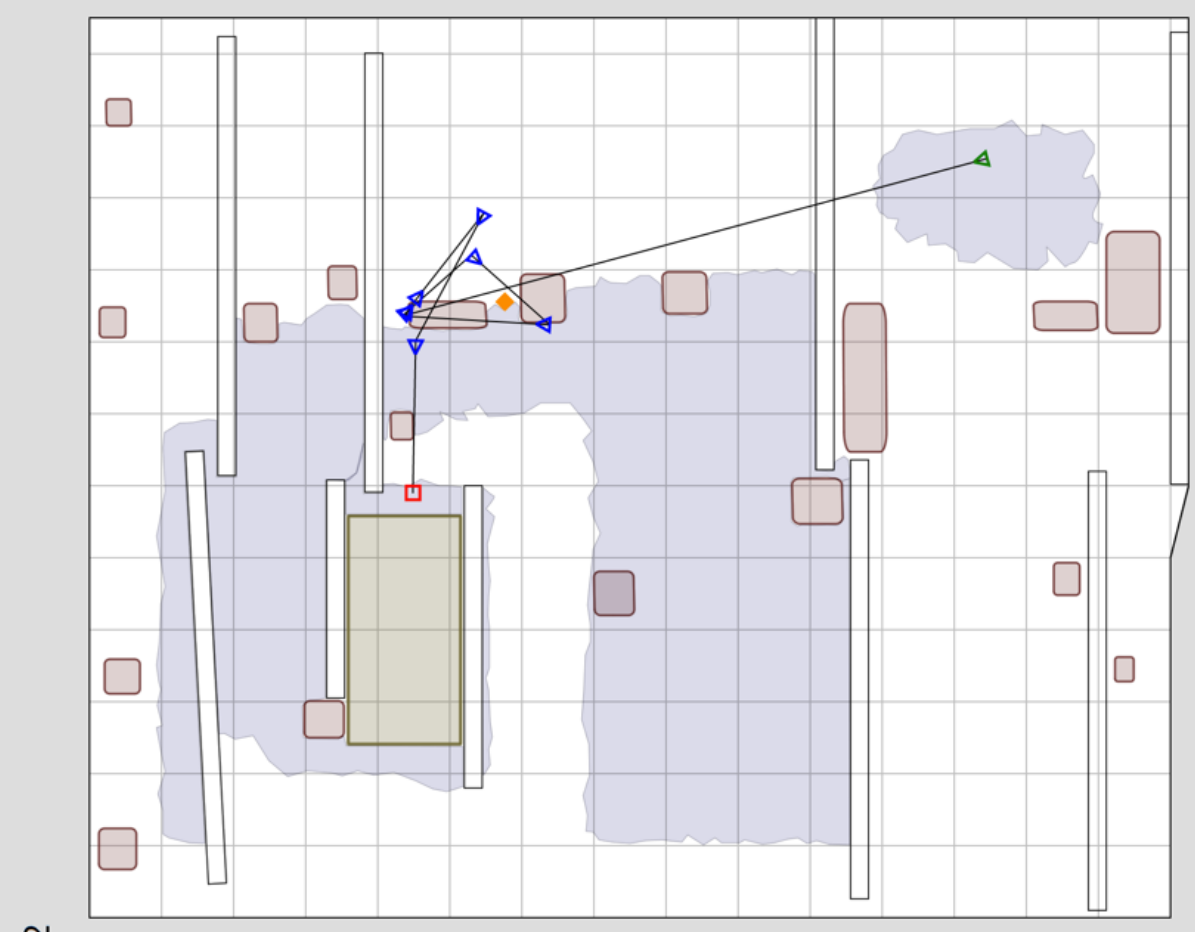

$\stackrel{\sim}{\llcorner}$

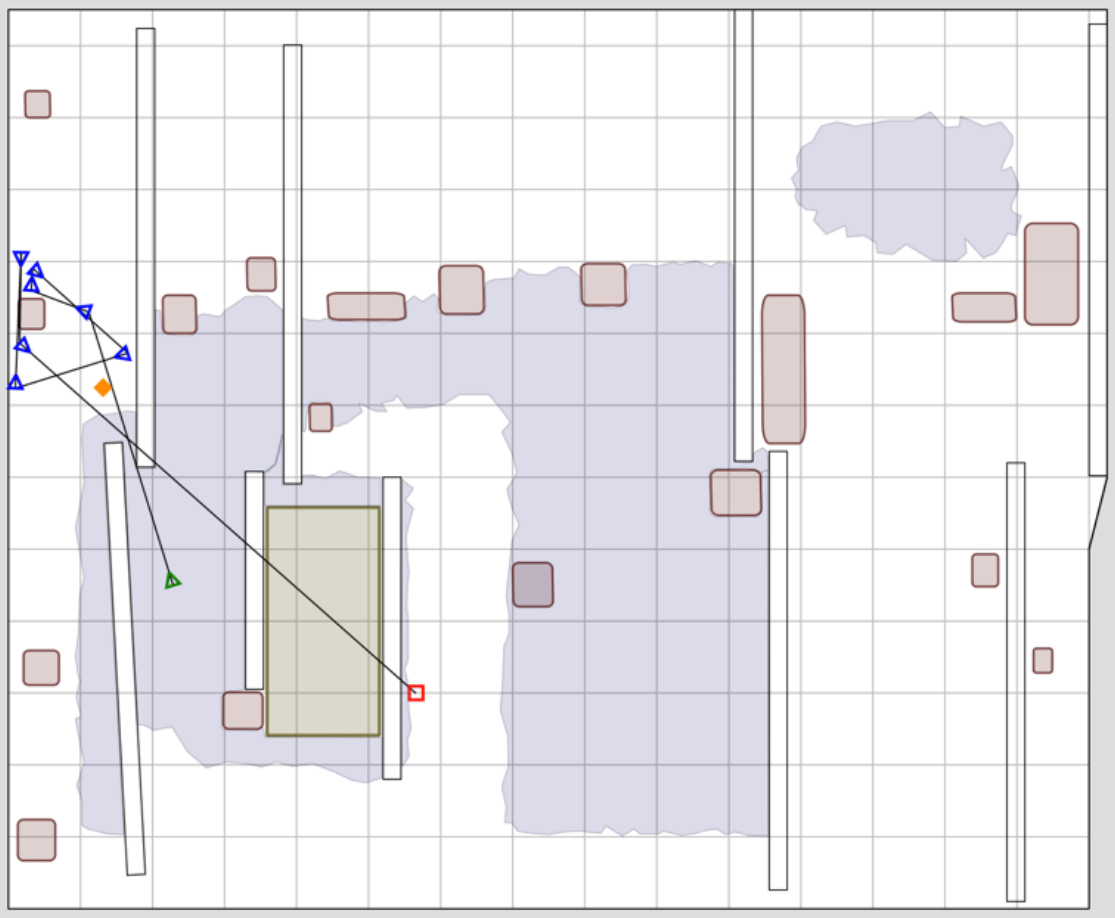

욷 


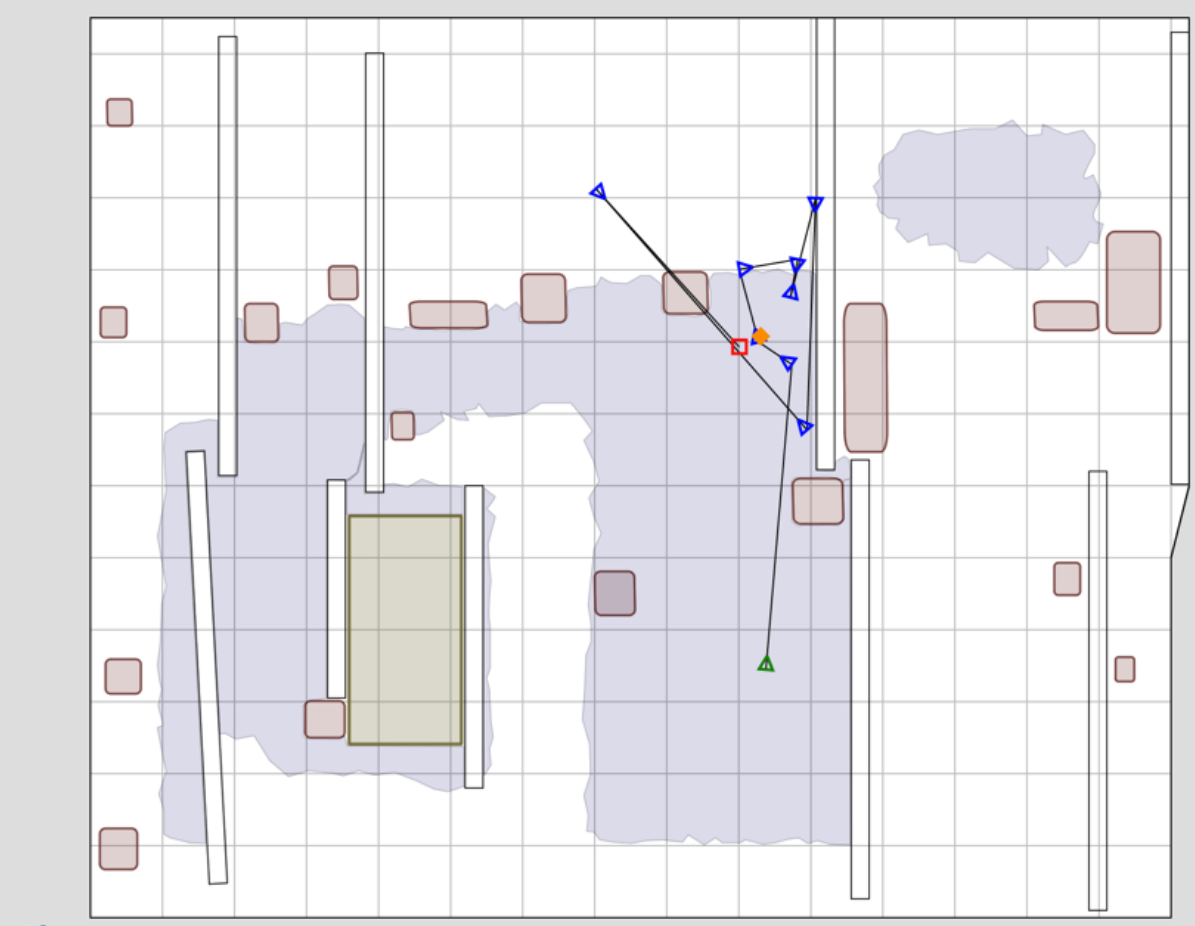

$\stackrel{m}{\vdash}$

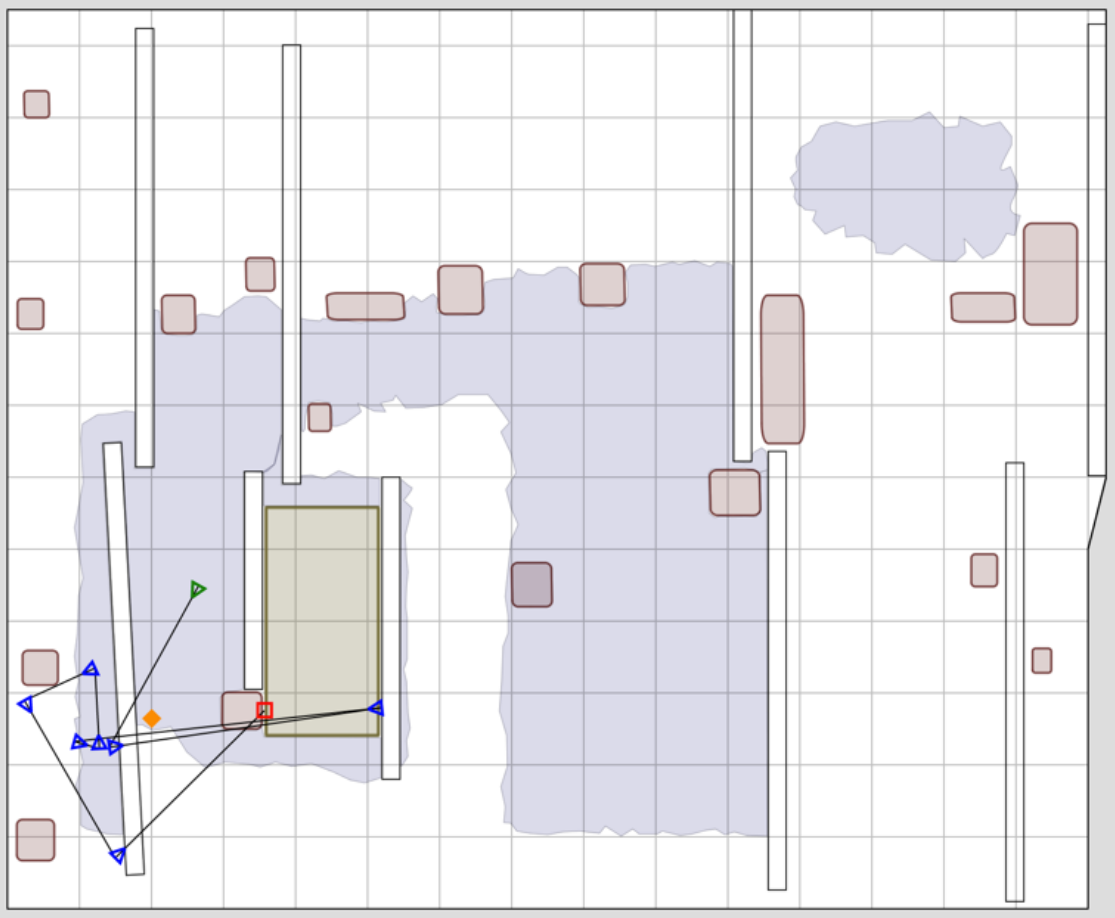

F 


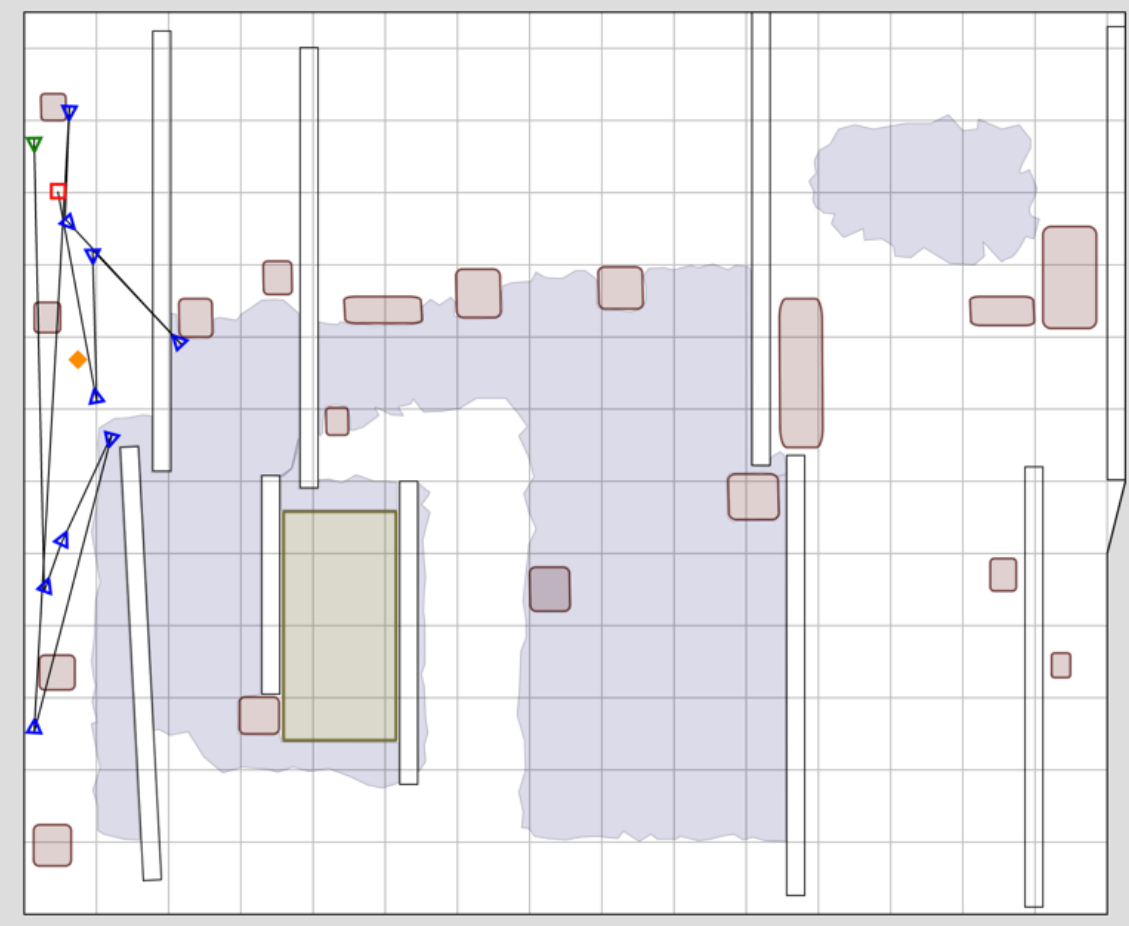

$\stackrel{\infty}{\infty}$

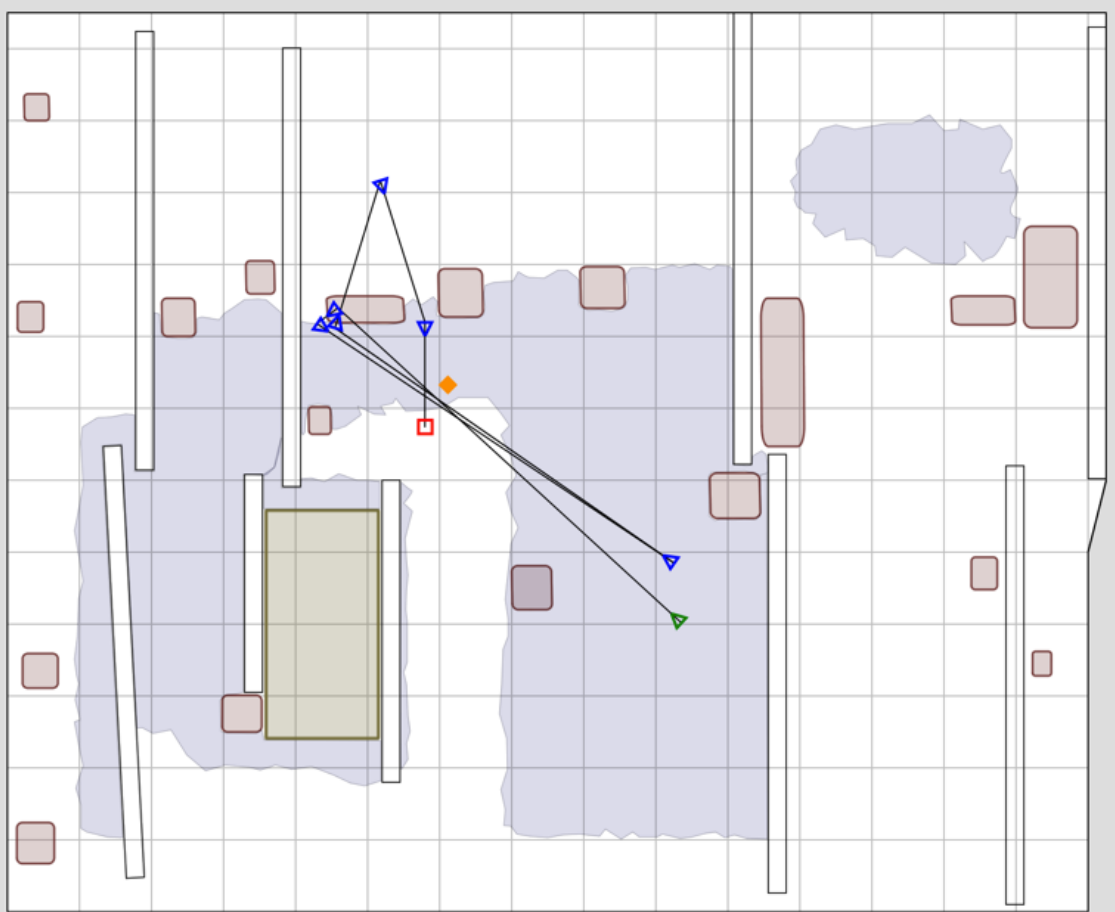

$\stackrel{\wp}{\vdash}$ 


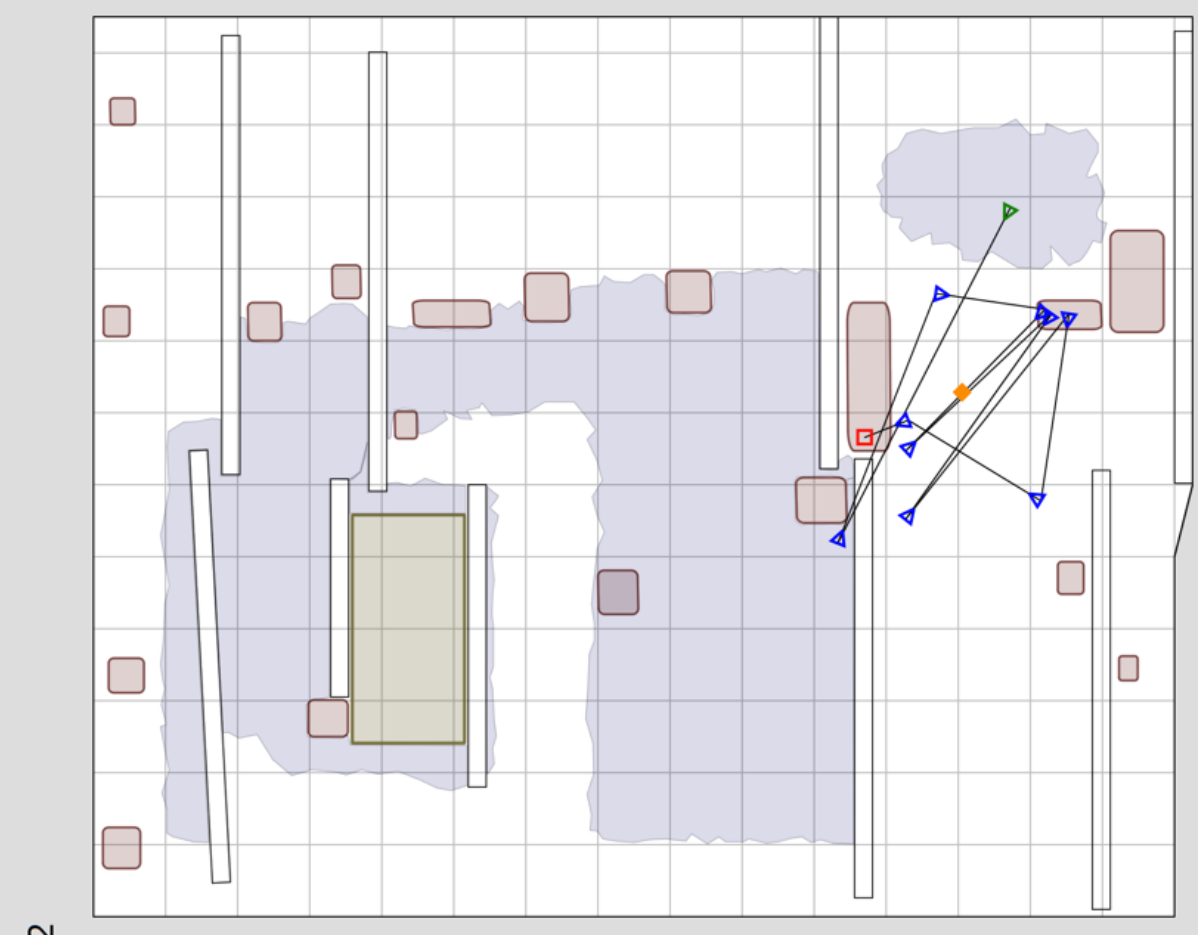

$\stackrel{\stackrel{\sim}{\vdash}}{\leftarrow}$

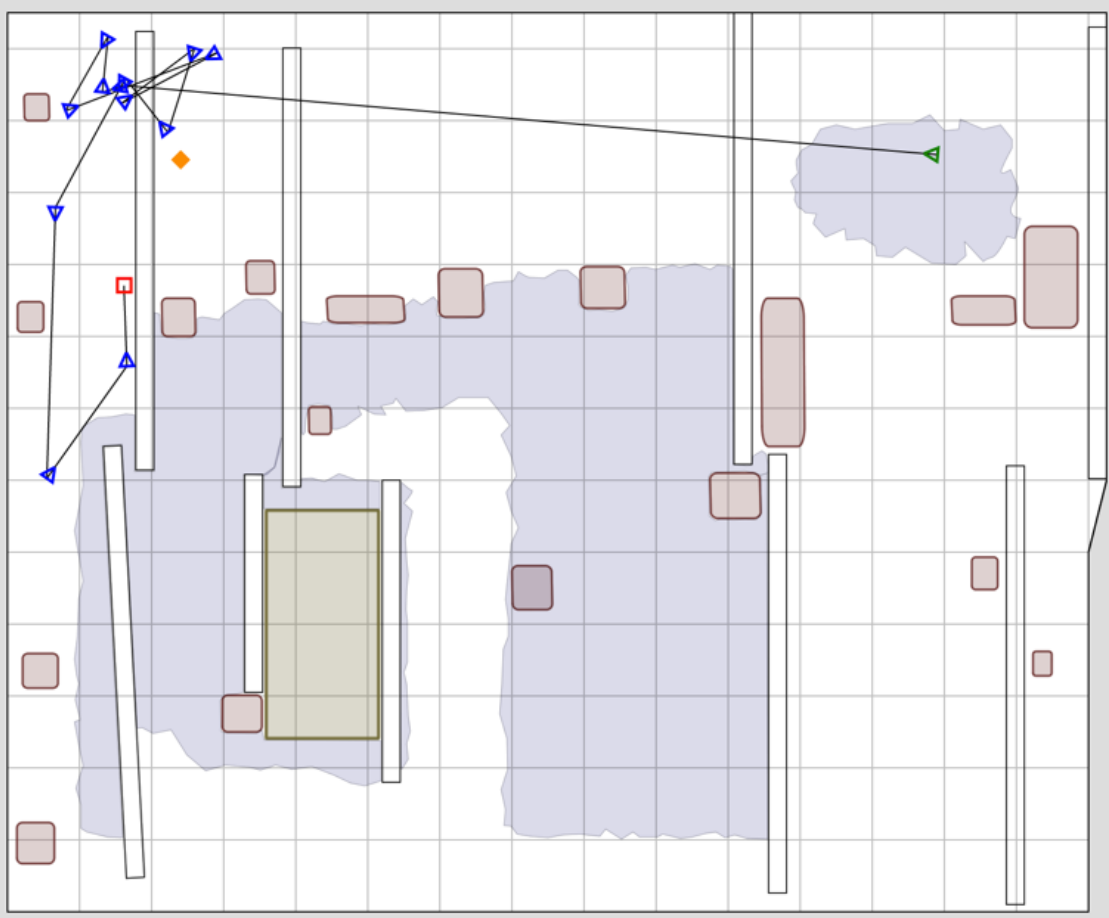

$\stackrel{\llcorner}{\stackrel{\sim}{\vdash}}$ 


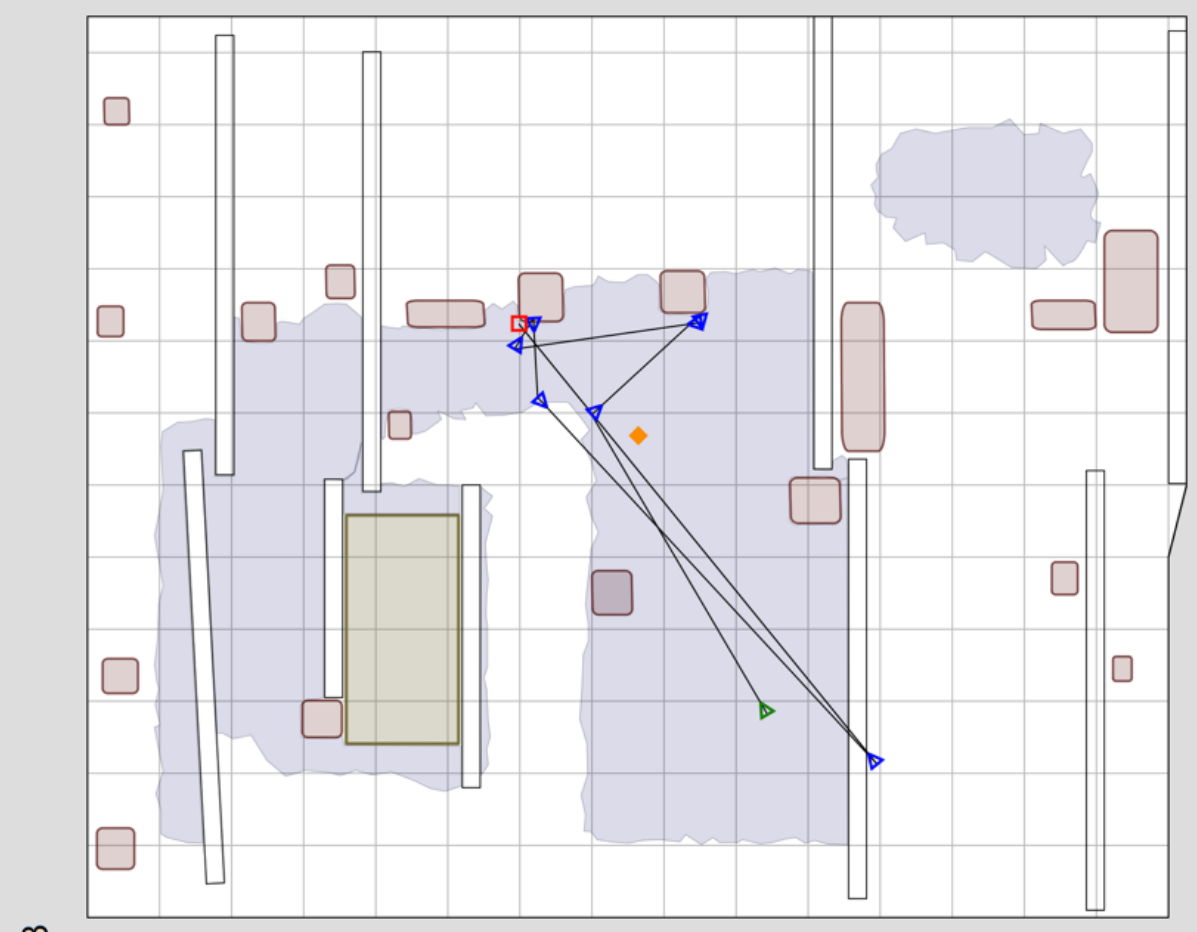

$\stackrel{m}{F}$

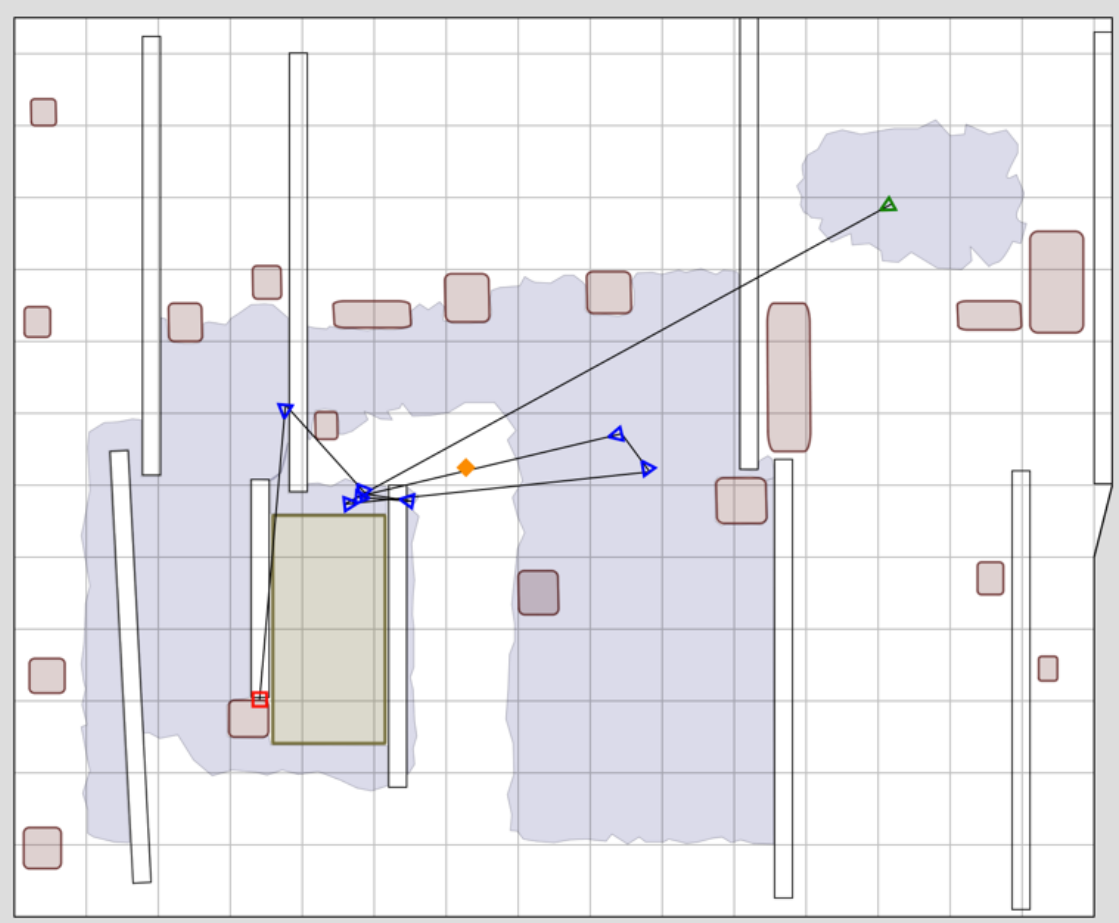

$\stackrel{\infty}{\vdash}$ 


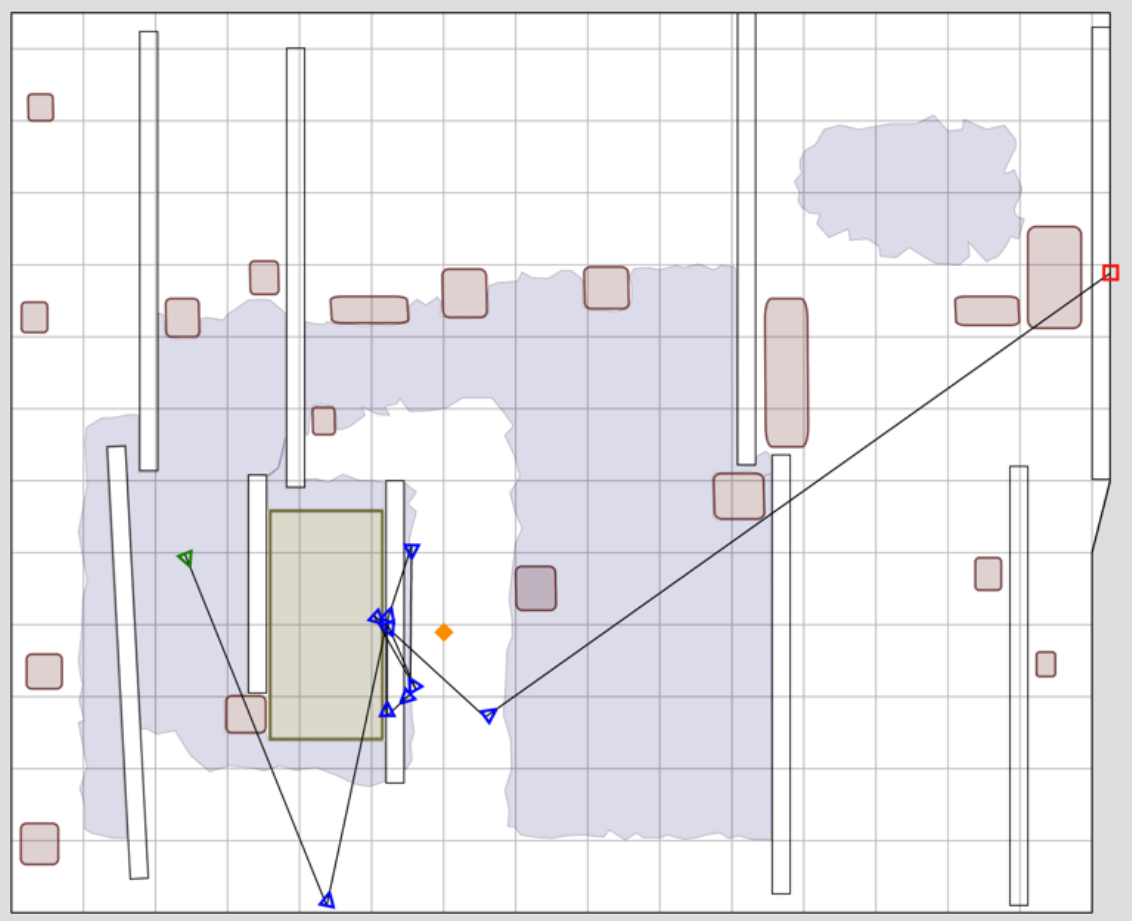

$\stackrel{\sim}{\vdash}$

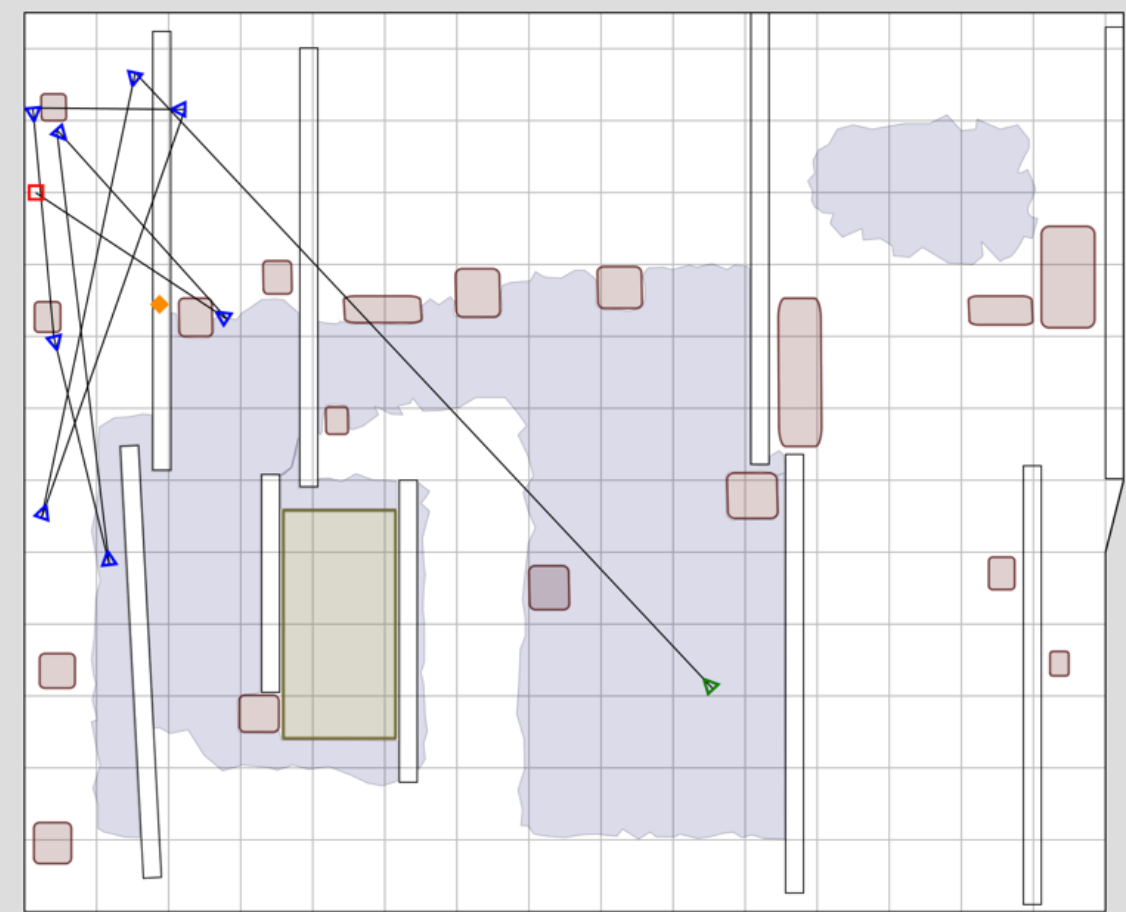

$\stackrel{m}{\vdash}$ 


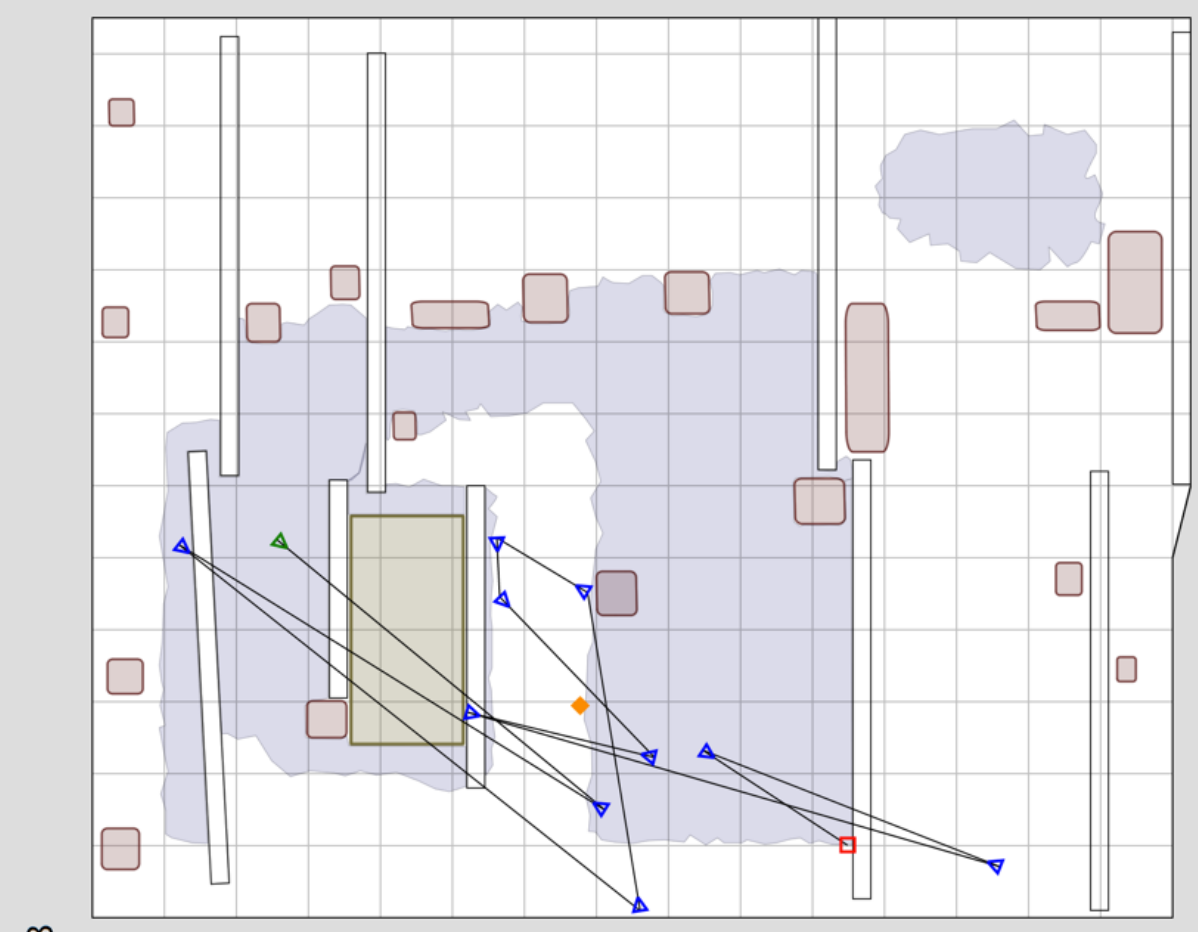

$\stackrel{\infty}{\sim}$

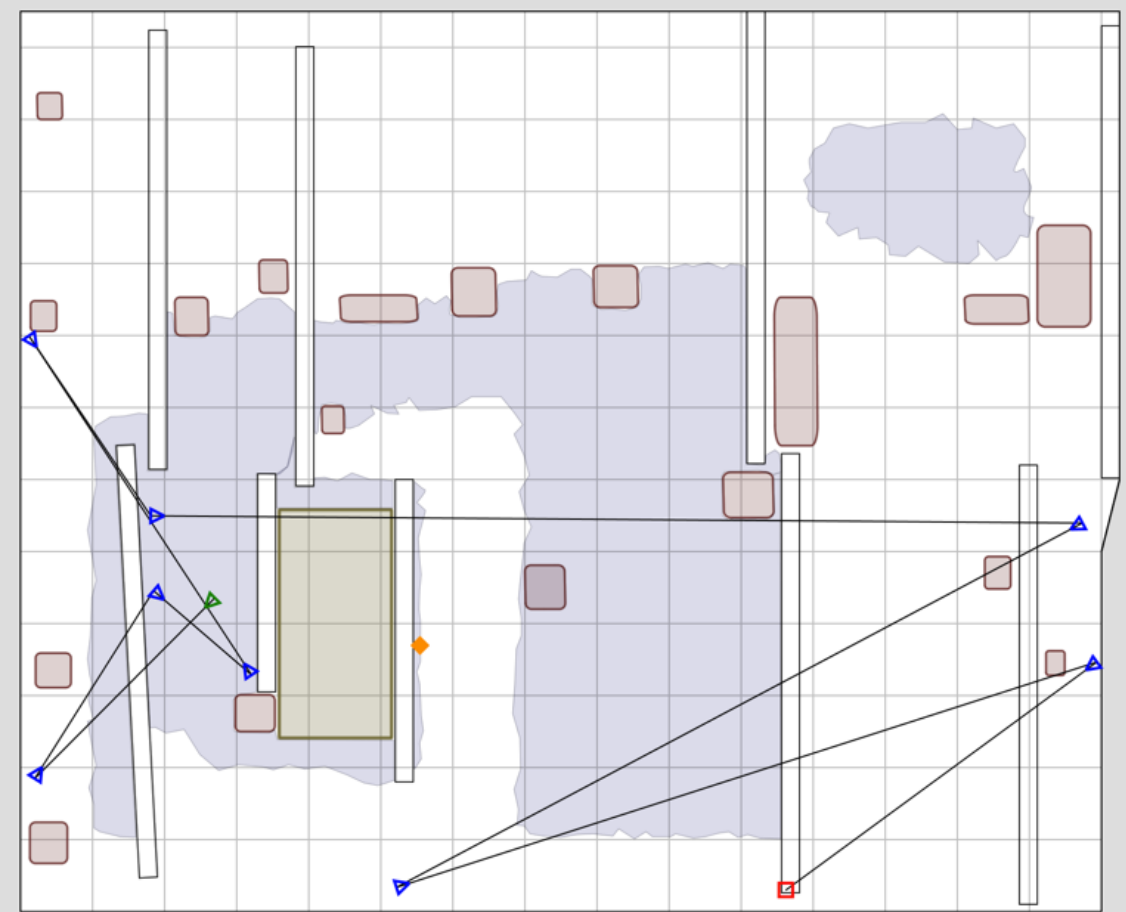

$\stackrel{\infty}{\sim}$ 


\section{References}

Baker, C. F. (2006). Predation of inanga (Galaxias maculatus) eggs by field mice (Mus musculus). Journal Of The Royal Society Of New Zealand, 36(4):143-147.

Beausoleil, N. J., Mellor, D. J., and Stafford, K. J. (2004). Methods for marking New Zealand wildlife: Amphibians, reptiles and marine mammals. Technical report, Department of Conservation, Wellington, New Zealand.

Beebee, T. J. and Griffiths, R. A. (2005). The amphibian decline crisis: A watershed for conservation biology? Biological Conservation, 125(3):271-285.

Bell, B. D. (1978). Observations on the Ecology and Reproduction of the New Zealand Leiopelmid Frogs. Herpetologica, 34(4):340-354.

Bell, B. D. (1982). The amphibian fauna of New Zealand. In Newman, D. G., editor, New Zealand Herpetology, pages 27-89, Wellington. New Zealand Wildlife Service.

Bell, B. D. (1985a). Conservation status of the endemic New Zealand frogs. In Grigg, G., Shine, R., and Ehmann, H., editors, The Biology of Australasian frogs and reptiles, pages 449-458. Chipping Norton.

Bell, B. D. (1985b). Development and parental-care in the endemic New Zealand frogs. In Grigg, G., Shine, R., and Ehmann, H., editors, The Biology of Australasian frogs and reptiles, pages 269-278. Surrey Beatty \& Sons Pty Limited, Chopping Norton.

Bell, B. D. (1994). A review of the status of New Zealand Leiopelma species (Anura: Leiopelmatidae), including a summary of demographic studies in Coromandel and on Maud Island. New Zealand Journal of Zoology, 21:341-349.

Bell, B. D. (2008a). The discovery of Maud Island frogs Leiopelma pakeka breeding in Karori Wildlife Sanctuary and the rearing of their young. Restoration Ecology, 1:1-21.

Bell, B. D. (2008b). The threatened Leiopelmatid frogs of New Zealand: Natural history integrates with conservation. Herpetological Conservation and Biology, 5(3):515-528.

Bell, B. D. (2011a). Breeding phenology of Leiopelma pakeka: A threatened frog never found breeding in the wild. Journal of Herpetology, 42(1):29-32.

Bell, B. D. (2011b). Longterm population monitoring of the Maud Island frog and Archey's frog, Victoria University of Wellington. FROGLOG, Newsletter of the Amphibian Specialist Group, 99(November 2011):40-41.

Bell, B. D., Bishop, P. J., and Germano, J. M. (2010). Lessons learned from a series of translocations of the archaic Hamilton's frog and Maud Island frog in central New Zealand. IUCN Global Reintroduction Perspectives: Additional case-studies from around the globe, pages 81-87. 
Bell, B. D., Carver, S., Mitchell, N. J., and Pledger, S. (2004a). The recent decline of a New Zealand endemic: How and why did populations of Archey's frog Leiopelma archeyi crash over 1996-2001? Biological Conservation, 120(2):189-199.

Bell, B. D., Daugherty, C. H., and Hay, J. M. (1998). Leiopelma pakeka, n. sp. (Anura: Leiopelmatidae), a cryptic species of frog from Maud Island, New Zealand, and a reassessment of the conservation status of $L$. hamiltoni from Stephens Island. Journal Of The Royal Society Of New Zealand, 28(1):39-54.

Bell, B. D. and Moore, J. (2012). Staying in place: extreme site fidelity in a threatened New Zealand frog. In Abstracts, 7th World Congress of Herpetology, 8-14 August 2012, page 51, Vancouver, Canada.

Bell, B. D., Newman, D. G., and Daugherty, C. H. (1985). The ecological biogeography of the archaic New Zealand herpetofauna (Leiopelmatidea, Sphenodontiadea). In Grigg, G., Shine, R., and Ehmann, H., editors, The Biology of Australasian Frogs and Reptiles, pages 99-106. Surrey Beatty \& Sons Pty Limited, Chipping Norton.

Bell, B. D. and Pledger, S. (2005). Does toe clipping affect the return rates of the terrestrial frog Leiopelma pakeka on Maud Island, New Zealand. New Zealand Journal of Zoology, 32:219-220.

Bell, B. D. and Pledger, S. (2010). How has the remnant population of the threatened frog Leiopelma pakeka (Anura: Leiopelmatidae) fared on Maud Island, New Zealand, over the past 25 years? Austral Ecology, 35(3):241-256.

Bell, B. D., Pledger, S., and Dewhurst, P. L. (2004b). The fate of a population of the endemic frog Leiopelma pakeka (Anura: Leiopelmatidae) translocated to restored habitat on Maud Island, New Zealand. New Zealand Journal of Zoology, 31:123-131.

Berkes, F., Colding, J., and Folke, C. (2000). Rediscovery of traditional ecological knowledge as adaptive management. Ecological Applications, 10(5):1251-1262.

Beukema, W. (2011). Ontogenetic pattern change in amphibians: the case of Salamandra corsica. Acta Herpetologica, 6(2):169-174.

Bishop, P. J. (2008). Bell frog populations in New Zealand - good news or bad news? Australian Zoologist, 34(3):408-414.

Bishop, P. J., Speare, R., Poulter, R., Butler, M., Speare, B. J., Hyatt, A., Olsen, V., and Haigh, A. (2009). Elimination of the amphibian chytrid fungus Batrachochytrium dendrobatidis by Archey's frog Leiopelma archeyi. Diseases of Aquatic Organisms, 84:9-15.

Booth, L., Eason, C., Spurr, E (2001). Literature review of the acute toxicity and persistence of brodifacoum to invertebrates and studies of residue risks to wildlife. Technical report, Department of Conservation, Wellington, New Zealand.

Bradfield, K. S. (2004). Photographic identification of individual Archey's frogs, Leiopelma archeyi, from natural markings. Technical report, Department of Conservation, Wellington, New Zealand.

Bradley, G. (2006). UK Safari Longworth Humane Mammal Trap. http://www.uksafari.com/shop/longworth.pdf. accessed: 1 March 2013.

Butler, D. and McLennan, J. A. (1991). Kiwi Recovery Plan. Technical Report 2, Department of Conservation, Wellington. 
Calenge, C. (2006). The package adehabitat for the R software: a tool for the analysis of space and habitat use by animals. Ecological Modelling, 197:516-519.

Campbell-Hunt, D. (2002). Developing a Sanctuary: The Karori Experience. Victoria Link Ltd, Wellington.

Carafa, M. and Biondi, M. (2004). Application of a method for individual photographic identification during a study on Salamandra salamandra gigliolii in central Italy. Italian Journal of Zoology, 2:181184.

Castro, I., Cunningham, S. J., Gsell, A. C., Jaffe, K., Cabrera, A., and Liendo, C. (2010). Olfaction in birds: a closer look at the kiwi (Apterygidae). Journal of Avian Biology, 41(3):213-218.

Colbourne, R. M., Baird, K., and Jolly, J. N. (1990). Relationship between invertebrates eaten by little spotted kiwi, Apteryx owenii, and their availability on Kapiti Island, New Zealand. New Zealand Journal of Zoology, 17(4):533-542.

Craig, J., Anderson, S., Clout, M., Creese, B., Mitchell, N., Ogden, J., Roberts, M., and Ussher, G. (2000). Conservation issues in New Zealand. Annual Review of Ecology and Systematics, 31(2000):6178.

Cree, A. (1985). Water balance of New Zealand's native frogs (Anura: Leiopelmatidae). In Grigg, G., Shine, R., and Ehmann, H., editors, The Biology of Australasian frogs and reptiles, pages 361-371. Surrey Beatty \& Sons Pty Limited, Chipping Norton.

Cree, A. (1989). Relationship between environmental conditions and nocturnal activity of the terrestrial frog, Leiopelma archeyi. Journal of Herpetology, 23(1):61-68.

Cunningham, S. J. and Castro, I. (2011). The secret life of wild brown kiwi: studying behaviour of a cryptic species by direct observation. New Zealand Journal of Ecology, 35(3):209-220.

Cunningham, S. J., Castro, I., and Alley, M. (2007). A new prey-detection mechanism for kiwi (Apteryx spp.) suggests convergent evolution between paleognathous and neognathous birds. Journal of Anatomy, 211(4):493-502.

Cunningham, S. J., Castro, I., and Potter, M. A. (2009). The relative importance of olfaction and remote touch in prey detection by North Island brown kiwis. Animal Behaviour, 78(4):899-905.

Deng, L., Bertinshaw, D. J., Klette, R., Klette, G., and Jeffries, D. (2004). Footprint identification of weta and other insects. Technical report, CITR, The University of Auckland, New Zealand, Auckland.

Department of Conservation (2013a). Department of Conservation. http://www.doc.govt.nz. accessed: 8 July 2013.

Department of Conservation (2013b). Mice found on predator-free Maud Island. Department of Conservation Media Release, 07 November 2013, (November):1 pp.

Digby, A., Bell, B. D., and Teal, P. D. (2013). Vocal cooperation between the sexes in little spotted kiwi Apteryx owenii. Ibis, 155:229-245.

Eason, C., Spurr, E. (1995). Review of the toxicity and impacts of brodifacoum on non-target wildlife in New Zealand. New Zealand Journal of Zoology, 22:371-379. 
Egeter, B., Bishop, P. J., and Robertson, B. C. (2011). DNA detects frog predation, University of Otago. FROGLOG, Newsletter of the Amphibian Specialist Group, 99(November 2011):36-37.

Essner, R. L. J., Suffian, D. J., Bishop, P. J., and Reilly, S. M. (2010). Landing in basal frogs: evidence of saltational patterns in the evolution of anuran locomotion. Naturwissenschaften, 97(10):935-939.

Germano, J. M. (2006). Responses of the Maud Island frog, Leiopelma pakeka, to artificial displacement. MSc thesis, University of Otago.

Germano, J. M. and Bishop, P. J. (2007a). Leiopelma pakeka (Maud Island frog) reproduction. Herpetological Review, 38(2):187-188.

Germano, J. M. and Bishop, P. J. (2007b). The responses of Leiopelma pakeka to artificial displacement. New Zealand Journal of Zoology, 34(3):263 pp.

Germano, J. M. and Bishop, P. J. (2009). Suitability of amphibians and reptiles for translocation. Conservation Biology, 23(1):7-15.

Germano, J. M., Molinia, F. C., Bishop, P. J., Bell, B. D., and Cree, A. (2012). Urinary hormone metabolites identify sex and imply unexpected winter breeding in an endangered, subterranean-nesting frog. General and Comparative Endocrinology, 175(3):464-472.

Gibson, R. and Fraser, I. (2011). Auckland Zoo - Captive Breeding. FROGLOG, Newsletter of the Amphibian Specialist Group, 99(November 2011):32-33.

Green, D. M. (1988). Antipredator behaviour and skin glands in the New Zealand native frogs, genus Leiopelma. New Zealand Journal of Zoology, 15(1):39-45.

Green, D. M. and Cannatella, D. (1993). Phylogenetic significance of the amphicoelous frogs, Ascaphidae and Leiopelmatidae. Ethology Ecology $\&$ Evolution, 5(2):233-245.

Harris-Ching, R. (1990). Kiwis: A monograph of the family Apterydidae. SeTo Publishing, Auckland, New Zealand.

Hasler, N., Klette, R., and Agnew, W. (2004). Footprint recognition of rodents and insects. Technical report, CITR, The University of Auckland, New Zealand.

Hoare, J. and Hare, K. (2006). The impact of brodifacoum on non-target wildlife: gaps in knowledge. New Zealand Journal of Ecology, 30(2):157-167.

Holyoake, A., Waldman, B., and Gemmell, N. J. (2001). Determining the species status of one of the world's rarest frogs: a conservation dilemma. Animal Conservation, 4:29-35.

Holzapfel, A., Robertson, H. A., McLennan, J. A., Sporle, W., Hackwell, K., and Impey, M. (2008). Kiwi (Apteryx spp.) recovery plan: 2008-2018. Technical report, Department of Conservation, Wellington, New Zealand.

Hoque, S., Azhar, M., and Deravi, F. (2011). ZOOMETRICS-Biometric identification of wildlife using natural body marks. International Journal of Bio-Science and Bio-Technology, 3(3):45-54.

IUCN Red List (2012). IUCN Red List of Threatened Species. www.iucnredlist.org. accessed: 7 March 2012.

Jolly, J. N. and Colbourne, R. M. (1991). Translocations of the little spotted kiwi (Apteryx owenii) between offshore islands of New Zealand. Journal of the Royal Society of New Zealand, 21(2):143-149. 
Karori Sanctuary Trust (2000). The Ecological Restoration of the Karori Wildlife Sanctuary Strategy. Technical report, Zealandia: The Karori Sanctuary Experience, Wellington, New Zealand.

Kenyon, N., Phillott, A. D., and Alford, R. A. (2010). Temporal variation in dorsal patterns of juvenile Green-Eyed frogs, Litoria genimaculata (Anura: Hylidae). Herpetological Conservation and Biology, $5(1): 126-131$.

King, C. M. (1990). The handbook of New Zealand mammals. Oxford University Press, Melbourne.

King, C. M., Roberts, C. D., Bell, B. D., Fordyce, R. E., Nicoll, R. S., Worthy, T. H., Paulin, C. D., Hitchmough, R. A., Keyes, I. W., Baker, A. N., Stewart, A. L., Hiller, N., Mcdowall, R. M., Holdaway, R. N., Mcphee, R. P., Schwarzhans, W. W., Tennyson, A. J., Rust, S., and Macadie, I. (2009). Phylum Chordata: Lancelets, Fishes, Amphibians, Reptiles, Birds, Mammals. In The New Zealand Inventory of Biodiveristy: A Species 2000 Symposium Review, chapter 24, pages 433-554. Canterbury University Press.

Kleinpaste, R. (1990). Kiwis in a pine forest habitat. Kiwis, a monograph of the family Apterygidae, pages 97-138. SeTo Publishing, Auckland, New Zealand.

Krebs, C. J. (1966). Demographic changes in fluctuating populations of Microtus californicus. Ecological Monographs, 36(3):239-273.

Laver, P. N. and Kelly, M. J. (2008). A critical review of home range studies. Journal of Wildlife Management, 72(1):290-298.

Le Roux, J. and Bell, B. D. (2007). A re-estimation of the population size of Leiopelma pakeka (Anura: Leiopelmatidae) in its remnant forest habitat on Maud Island. New Zealand Journal of Zoology, $34: 265$.

Lee, J. S. and Waldman, B. (2002). Communication by fecal chemosignals in an archaic frog, Leiopelma hamiltoni. Copeia, 3:679-686.

Lukis, K. (2009). Returning an endemic frog to the New Zealand mainland: Transfer and adaptive management of Leiopelma pakeka at Karori Sanctuary, Wellington. MSc thesis, Victoria University of Wellington, New Zealand.

Martin, G. R., Wilson, K.-J., Wild, J. M., Parsons, S., Kubke. M. F., and Corfield, J. (2007). Kiwi forego vision in the guidance of their nocturnal activities. PloS one, 2(2):e198.

McCulloch, A. (1919). A new discoglossid frog from New Zealand. Transactions of the New Zealand Institute, 51:447-449.

McLennan, J. A., Potter, M. A., Robertson, H. A., Wake, G., Colbourne, R. M., Dew, L., Joyce, L., McCann, A., Miles, J., Miller, P., and Reid, J. (1996). Role of predation in the decline of kiwi, Apteryx spp., in New Zealand. New Zealand Journal of Ecology, 20(1):27-35.

Mellor, D. J., Beausoleil, N. J., and Stafford, K. J. (2004). Marking amphibians, reptiles and marine mammals: animal welfare, practicalities and public perceptions in New Zealand. Technical report, Department of Conservation, Wellington, New Zealand.

Melzer, S. and Bishop, P. J. (2010). Skin peptide defences of New Zealand frogs against chytridiomycosis. Animal Conservation, 13:44-52. 
Melzer, S. and Bishop, P. J. (2011). Just juice? Attempting to unravel the secrets of skin secretions in New Zealand's endemic frogs. FROGLOG, Newsletter of the Amphibian Specialist Group, 99(November 2011):37-38.

Melzer, S., Clerens, S., and Bishop, P. J. (2011). Differential polymorphism in cutaneous glands of archaic Leiopelma species. Journal of Morphology, 272(9):1116-1130.

Miller, A. P. and Webb, P. I. (2001). Diet of house mice (Mus musculus L.) on coastal sand dunes, Otago, New Zealand. New Zealand Journal of Zoology, 28(1):49-55.

Ministry for the Environment, M. M. T. T. (2007). Distribution of kiwi (all species) in New Zealand. http://www.mfe.govt.nz/environmental-reporting/biodiversity/indicator-species/kiwi/. accessed: 27 February 2013.

Miskelly, C. M., Elliott, G. P., Powlesland, R. G., Robertson, H. A., Sagar, P. M., Scofield, R. P., and Taylor, G. A. (2008). Conservation status of New Zealand birds, 2008. Notornis, 55:117-135.

Moeed, A. and Meads, M. (1987). Invertebrate survey of offshore islands in relation to potential food sources for the little spotted kiwi, Apteryx owenii (Aves: Apterygidae ). New Zealand Entomologist, 10(1):50-64.

Narayan, E. J., Molinia, F. C., Kindermann, C., Cockrem, J. F., and Hero, J.-M. (2011). Urinary corticosterone responses to capture and toe-clipping in the cane toad (Rhinella marina) indicate that toe-clipping is a stressor for amphibians. General and Comparative Endocrinology, 174(2):238-45.

Newman, D. G. (1990). Activity, dispersion, and population densities of Hamilton's frog (Leiopelma hamiltoni) on Maud and Stephen's Islands, New Zealand. Herpetologica, 46(3):319-330.

Newman, D. G. (1994). Effects of a mouse, Mus musculus, eradication programme and habitat change on lizard populations of Mana Island, New Zealand, with special reference to McGregor's skink, Cyclodina macgregori. New Zealand Journal of Zoology, 21(4):443-456.

Newman, D. G. (1996). Native Frog (Leiopelma spp.) Recovery Plan. Technical Report 18, Department of Conservation, Wellington, New Zealand.

Newman, D. G., Bell, B. D., Bishop, P. J., and Burns, R. (2013). Conservation status of New Zealand frogs, 2013. Technical report, Department of Conservation, Wellington, New Zealand.

Newman, D. G., Bell, B. D., Bishop, P. J., Burns, R., Haigh, A., Hitchmough, R. A., and Tocher, M. (2010). Conservation status of New Zealand frogs, 2009. New Zealand Journal of Zoology, 37(2):121130.

Newman, D. G., Crook, I., and Imboden, C. (1978). Comparisons of the climates of the two habitats of Hamilton's frog (Leiopelma hamiltoni (McCulloch)). New Zealand Journal of Ecology, 1:84-90.

Newman, J. and Moller, H. (2005). Use of matauranga (Maōri traditional knowledge) and science to guide a seabird harvest- getting the best of both worlds? Senri Ethnological Studies, 67:303-321.

NIWA (2013). Dust Bowled. Water \& Atmosphere, (September):12-20.

Nosi, D., Terreni, A., Alvarez, B., and Delfino, G. (2002). Serous gland polymorphism in the skin of Phyllomedusa hypochondrialis azurea (Anura, Hylidae): response by different gland types to norepinephrine stimulation. Zoomorphology, 121(3):139-148. 
NZFrog (2006). NZFrog. http://www.nzfrogs.org. accessed: 9 July 2013.

Ohmer, M., Herbert, S. M., Speare, R., Bishop, P. J. (2013). Experimental exposure indicated the amphibian chytrid pathogen poses low risk to New Zealand's threatened endemic frogs. Animal Conservation, 16(4):422-429.

Pledger, S., Pollock, K. H., and Norris, J. L. (2010). Open capture-recapture models with heterogeneity: II. Jolly-Seber model. Biometrics, 66(3):883-90.

R Core Team (2013). R: A Language and Environment for Statistical Computing. http://www.rproject.org/.

Robb, J. (1986). New Zealand amphibians and reptiles. William Collins Publishers Ltd., Auckland, 2nd edition.

Roberts, M., Norman, I. W., Minhinnick, N., Wihongi, D., and Kirkwood, C. (1995). Kaitiakitanga: Maōri perspectives on conservation. Pacific Conservation Biology, 2:7-20.

Roelants, K. and Bossuyt, F. (2005). Archaeobatrachian paraphyly and pangaean diversification of crown-group frogs. Systematic Biology, 54(1):111-26.

Row, J. R. and Blouin-Demers, G. (2006). Kernels are not accurate estimators of home-range size for herpetofauna. Copeia, December 2(4):797-802.

Russell, J. and Clout, M. (2005). Rodent incursions on New Zealand islands. Technical Report Atkinson 1986, University of Auckland, Auckland, New Zealand.

Sacchi, R., Scali, S., Pellitteri-Rosa, D., Pupin, F., Gentilli, A., Tettamanti, S., Cavigioli, L., Racina, L., Maiocchi, V., Galeotti, P., and Fasola, M. (2010). Photographic identification in reptiles: a matter of scales. Amphibia-Reptilia, 31(4):489-502.

Sales, J. (2005). The endangered kiwi: A review. Folia Zoologica, 54(1/2):1-20.

Sales, J. (2006). Feeding of the captive kiwi. Zoos' Print Journal, 21(11):2454-2458.

Seaman, D. E., Millspaugh, J. J., Kernohan, B. J., and Brundige, G. C. (1999). Effects of sample size on kernel home range estimates. The Journal of Wildlife Management, 63(2):739-747.

Sharell, R. (1966). The tuatara, lizards and frogs of New Zealand. Collins, London.

Shaw, S. D., Bishop, P. J., Berger, L., Skerratt, L. F., Garland, S., Gleeson, D. M., Haigh, A., Herbert, S., and Speare, R. (2010). Experimental infection of self-cured Leiopelma archeyi with the amphibian chytrid Batrachochytrium dendrobatidis. Diseases of Aquatic Organisms, 92(2-3):159-63.

Shaw, S. D., Skerratt, L. F., Haigh, A., Bell, B. D., Daglish, L., Bishop, P. J., Summers, R., Moreno, V., Melzer, S., Ohmer, M., Herbert, S., Gleeson, D. M., Rowe, L., and Speare, R. (2013). The distribution and host range of Batrachochytrium dendrobatidis in New Zealand, 1930-2010. Ecology, 94(9):2108.

Stephenson, E. M. (1961). New Zealand Native Frogs. Tuatara, 8(3):99-106.

Taiepa, T., Lyver, P., Horsley, P., Davis, J., Bragg, M., and Moller, H. (1997). Co-management of New Zealand's conservation estate by Maōri and Pakeha: a review. Environmental Conservation, $24(3): 236-250$. 
The Zoological Society of London (2012). Evolutionarily Distinct and Globally Endangered. http://www.edgeofexistence.org/amphibians/top ${ }_{1}$ 00.php. accessed : 12August2012.

Thurley, T. and Bell, B. D. (1994). A review of the status of New Zealand Leiopelma species (Anura: Leiopelmatidae), including a summary of demographic studies in Coromandel and on Maud Island. New Zealand Journal of Zoology, 21(4):341-349.

Tocher, M., Fletcher, D., and Bishop, P. J. (2006). A modelling approach to determine a translocation scenario for the endangered New Zealand frog Leiopelma hamiltoni. Herpetological Journal, 16:97-106.

Tocher, M. and Pledger, S. (2005). The inter-island translocation of the New Zealand frog Leiopelma hamiltoni. Applied Herpetology, 2:401-413.

Toledo, L., Ribeiro, R., and Haddad, C. (2007). Anurans as prey: An exploratory analysis and size relationships between predators and their prey. Journal of Zoology, 271(2):170-177.

Towns, D. R. and Daugherty, C. H. (1994). Patterns of range contractions and extinctions in the New Zealand herptofauna following human colonisation. New Zealand Journal of Zoology, 21:325-339.

Towns, D. R., Daugherty, C. H., and Cree, A. (2001). Raising the prospects for a forgotten fauna: a review of 10 years of conservation effort for New Zealand reptiles. Biological Conservation, 99:3-16.

Towns, D. R. and Ferreira, S. M. (2001). Conservation of New Zealand lizards (Lacertilia: Scincidae) by translocation of small populations. Biological Conservation, 98(2):211-222.

Wakelin, M., Smuts-Kennedy, C., Thurley, T., and Webster, N. (2003). Artificial cover objects for Leiopelmatid frogs. Technical report, Department of Conservation, Wellington, New Zealand.

Waldman, B. (2004). ARC Conference: Captivity, reintroduction and disease control technologies for Amphibians, Victoria, Australia.

Waldman, B. and Bishop, P. J. (2004). Chemical communication in an archaic anuran amphibian. Behavioral Ecology, 15(1):88-93.

Waldman, B., Van De Wolfshaar, K., Klena, J., Andjic, V., Bishop, P. J., and Norman, R. (2001). Chytridiomycosis in New Zealand frogs. Surveillance, 28(3):9-11.

Ward, S. (2000). Mouse report, Comalco Lodge, Maud Island, June/July/August internal report. Technical report, Department of Conservation, Picton, New Zealand.

Webster, J. (2004). Individual identification, disease monitoring and home range of Leiopelma hamiltoni. MSc thesis, University of Canterbury.

Wickham, H. (2009). ggplot2: elegant graphics for data analysis. Springer New York. http://had.co.nz/ggplot2/book.

Worthy, T. H. (1987). Osteology of Leiopelma (Amphibia: Leiopelmatidae) and descriptions of three new sub-fossil Leiopelma species. Journal Of The Royal Society Of New Zealand, 17:201-251.

Worthy, T., Tennyson, A., Scofield, R., and Hand, S. (2013). Early Miocene fossil frogs (Anura: Leiopelmatidae) from New Zealand. Journal of the Royal Society of New Zealand, 43(4):211-230.

Zaffaroni Caorsi, V., Rocha Santos, R., and Grant, T. (2012). Clip or Snap? An evaluation of toeclipping and photo-identification methods for identifying individual Southern Red-Bellied Toads, Melanophryniscus cambaraensis. South American Journal of Herpetology, 7(2):79-84. 
Zealandia (2012). Zealandia: The Karori Sanctuary Experience. http://www.visitzealandia.com. accessed: 8 July 2013. 